Florida International University FIU Digital Commons

$11-6-2013$

\title{
A Decision Support Framework for Infrastructure Maintenance Investment Decision-Making
}

Farrukh Arif

Florida International University, farif001@fiu.edu

DOI: $10.25148 /$ etd.FI13120901

Follow this and additional works at: https:// digitalcommons.fiu.edu/etd

Part of the Civil Engineering Commons, and the Construction Engineering and Management Commons

\section{Recommended Citation}

Arif, Farrukh, "A Decision Support Framework for Infrastructure Maintenance Investment Decision-Making" (2013). FIU Electronic Theses and Dissertations. 1002.

https://digitalcommons.fiu.edu/etd/1002

This work is brought to you for free and open access by the University Graduate School at FIU Digital Commons. It has been accepted for inclusion in FIU Electronic Theses and Dissertations by an authorized administrator of FIU Digital Commons. For more information, please contact dcc@fiu.edu. 


\section{FLORIDA INTERNATIONAL UNIVERSITY \\ Miami, Florida}

\section{A DECISION SUPPORT FRAMEWORK FOR INFRASTRUCTURE MAINTENANCE INVESTMENT DECISION-MAKING}

A dissertation submitted in partial fulfillment of

the requirements for the degree of

DOCTOR OF PHILOSOPHY

in

CIVIL ENGINEERING

by

Farrukh Arif

2013 
To: Dean Amir Mirmiran

College of Engineering and Computing

This dissertation, written by Farrukh Arif, and entitled A Decision Support Framework for Infrastructure Maintenance Investment Decision-Making, having been approved in respect to style and intellectual content, is referred to you for judgment.

We have read this dissertation and recommend that it be approved.

Omar I. Abdul-Aziz

Berrin Tansel

Arindam G. Chowdhury, Co-Major Professor

M. Emre Bayraktar, Co-Major Professor

Date of Defense: November 06, 2013

The dissertation of Farrukh Arif is approved.

Dean Amir Mirmiran

College of Engineering and Computing

Dean Lakshmi N. Reddi

University Graduate School

Florida International University, 2013 


\section{ACKNOWLEDGMENTS}

First, I would like to thank the Almighty Allah for providing me with courage, strength and determination to complete this dissertation. I would have not been able to achieve anything in my life without His countless blessings bestowed upon me.

I would like to thank the members of my dissertation advisory committee, Dr. Omar I. Abdul Aziz and Dr. Berrin Tansel for their understanding, support and guidance during my research. I would also like to thank Dr. Caesar Abi Shdid and Dr. Nakin Suksawang, who served previously as members of the dissertation advisory committee before leaving Florida International University (FIU). I would like to specially thank Dr. Arindam G. Chowdhury for serving as a committee member as well as my Co-Major Advisor. His guidance, efforts and understanding have been valuable throughout my research.

I would like to express my heartiest respect and gratitude to Dr. M. Emre Bayraktar, Co-Major Advisor, for his invaluable efforts, mentorship and encouragement throughout my studies at Florida International University. Without his support and understanding, I would have not been able to complete this dissertation or my Ph.D. studies. He has been extraordinarily helpful during my difficult times as well as in shaping my professional and personal growth.

I would also like to indicate my appreciation of both, the Department of Civil and Environmental Engineering and the OHL School Construction, for providing me with the opportunity to pursue my Ph.D at Florida International University. Specially, I would like to thank Dr. Irtishad U. Ahmad, Director OHL School of Construction, for his continuous 
understanding, support and encouragement. I would also like to thank all the faculty, staff members, and fellow students at the OHL School of Construction.

A special note of appreciation is due to Pima County Department of Transportation who helped in case study implementation of the developed framework. In this regard, I would like to thank all members of the decision-making group and specially Mr. Dean Papajohn, for his continuous participation in the research. I would also like to thank Pima Association of Governments (PAG) for their help during case study implementation.

My appreciation also goes to Prof. S.F.A. Rafeeqi and Prof. Sarosh H. Lodi from NED University of Engineering \& Technology, Karachi, for their continuous motivation and support.

Special thanks to University Graduate School of Florida International University for providing me with the financial support in the form of Dissertation Year Fellowship. I would also like to express gratitude to the OHL School of Construction, FIU, and Association for the Advancement of Cost Engineering (AACE), Graduate and Professional Student Committee, FIU, which provided the financial support in terms of assistantship, scholarships, and travel grants to continue my Ph.D. studies.

Lots of appreciation goes to my parents, my father (K.M. Arif Rasheed), my mother (Najma Arif) and to my sister (Mehwish Arif). Without their patience, sacrifice and moral support, it would have been extremely difficult to complete this research. I owe a lot to my wife, Nida Azhar, for her consistent patience, understanding and reassurance throughout good or bad times during my studies. Finally, I dedicate this achievement to the best thing that has ever happened to me, my daughter, Manha. 


\title{
ABSTRACT OF THE DISSERTATION \\ A DECISION SUPPORT FRAMEWORK FOR INFRASTRUCTURE MAINTENANCE INVESTMENT DECISION-MAKING
}

\author{
by \\ Farrukh Arif \\ Florida International University, 2013 \\ Miami, Florida \\ Professor M. Emre Bayraktar, Co-Major Professor \\ Professor Arindam G. Chowdhury, Co-Major Professor \\ Infrastructure management agencies are facing multiple challenges, including \\ aging infrastructure, reduction in capacity of existing infrastructure, and availability of \\ limited funds. Therefore, decision makers are required to think innovatively and develop \\ inventive ways of using available funds. Maintenance investment decisions are generally \\ made based on physical condition only. It is important to understand that spending money \\ on public infrastructure is synonymous with spending money on people themselves. This \\ also requires consideration of decision parameters, in addition to physical condition, such \\ as strategic importance, socioeconomic contribution and infrastructure utilization. \\ Consideration of multiple decision parameters for infrastructure maintenance investments \\ can be beneficial in case of limited funding. Given this motivation, this dissertation \\ presents a prototype decision support framework to evaluate trade-off, among competing \\ infrastructures, that are candidates for infrastructure maintenance, repair and
} rehabilitation investments. 
Decision parameters' performances measured through various factors are combined to determine the integrated state of an infrastructure using Multi-Attribute Utility Theory (MAUT). The integrated state, cost and benefit estimates of probable maintenance actions are utilized alongside expert opinion to develop transition probability and reward matrices for each probable maintenance action for a particular candidate infrastructure. These matrices are then used as an input to the Markov Decision Process (MDP) for the finite-stage dynamic programming model to perform project (candidate)-level analysis to determine optimized maintenance strategies based on reward maximization. The outcomes of project (candidate)-level analysis are then utilized to perform network-level analysis taking the portfolio management approach to determine a suitable portfolio under budgetary constraints. The major decision support outcomes of the prototype framework include performance trend curves, decision logic maps, and a network-level maintenance investment plan for the upcoming years. The framework has been implemented with a set of bridges considered as a network with the assistance of the Pima County DOT, AZ. It is expected that the concept of this prototype framework can help infrastructure management agencies better manage their available funds for maintenance. 


\section{TABLE OF CONTENTS}

CHAPTER

PAGE

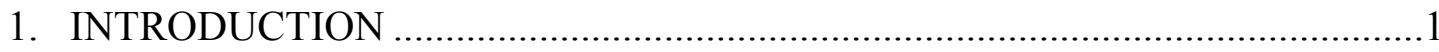

1.1 Context and Motivation ..............................................................................

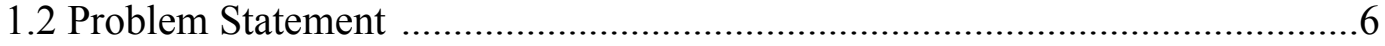

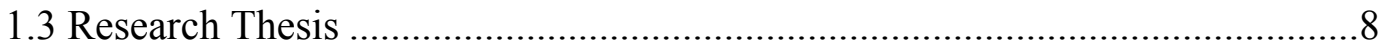

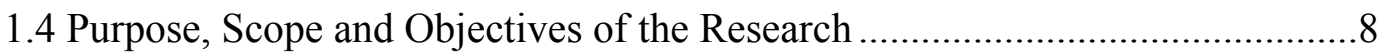

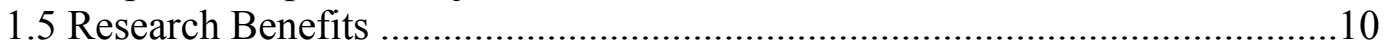

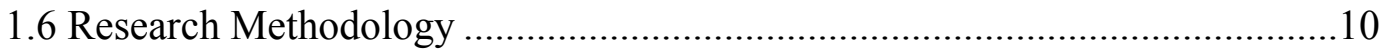

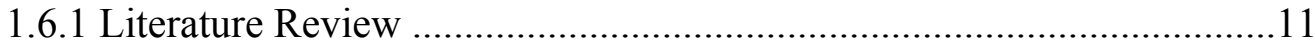

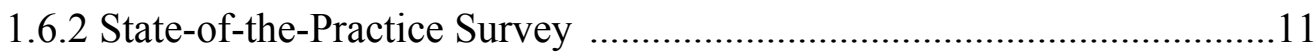

1.6.3 Conceptual Framework Development .................................................12

1.6.4 Final Framework Development ........................................................12

1.6.5 Implementation by Case Study …………........................................12

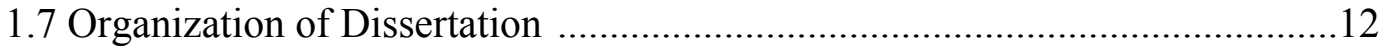

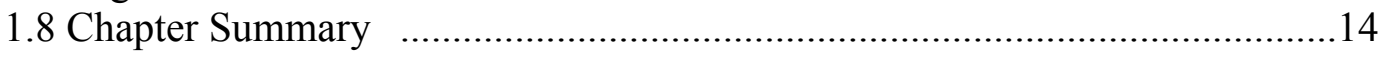

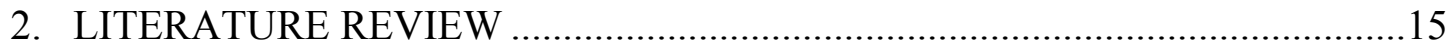

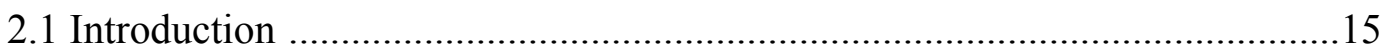

2.2 Infrastructure Management and Maintenance Decision Making .....................15

2.2.1 Functions of Infrastructure Management ...............................................16

2.2.2 Infrastructure Maintenance Investment Decision-Making ...................17

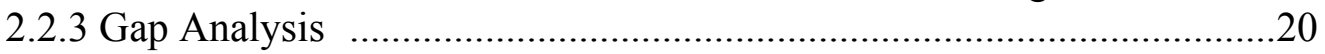

2.3 Decision Support Frameworks/Systems .......................................................22

2.3.1 Decision Support Frameworks/Systems in Infrastructure Management

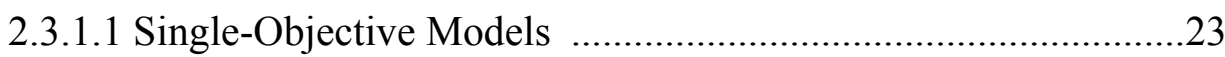

2.3.1.2 Multi-Objective Models ..........................................................24

2.3.1.3 Cost/Finance-Based Models ..................................................25

2.3.2 Decision Support Frameworks/Systems for Infrastructure Investment 26

2.3.3 Gaps in Existing Approaches .............................................................28

2.4 Decision Parameters Influencing Infrastructure Maintenance Investment

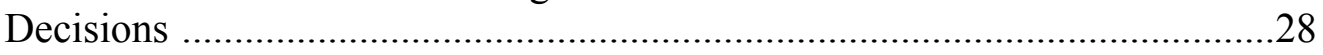

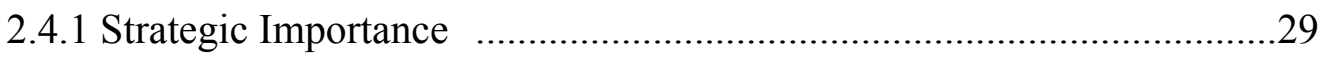

2.4.2 Socioeconomic Contribution ………………….............................29

2.4.3 Infrastructure Utilization ..................................................................

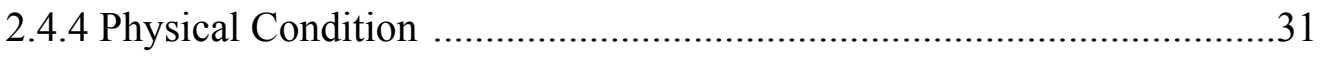

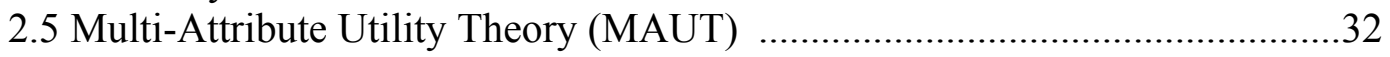

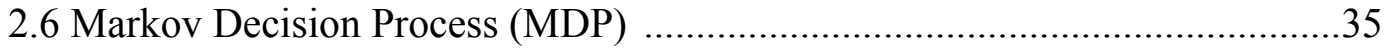

2.7 Chapter Summary ................................................................................ 


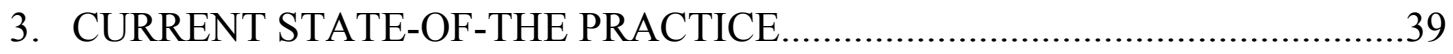

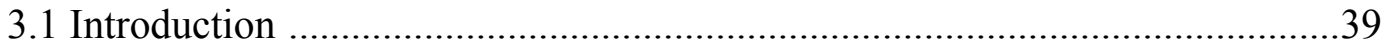

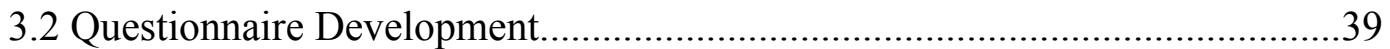

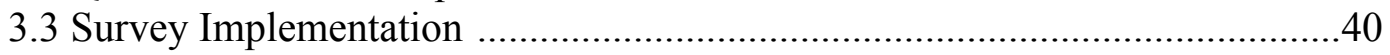

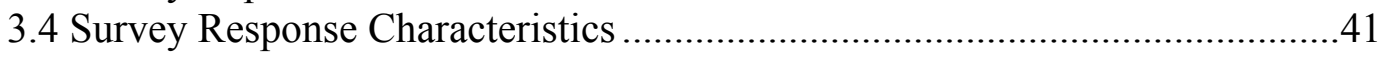

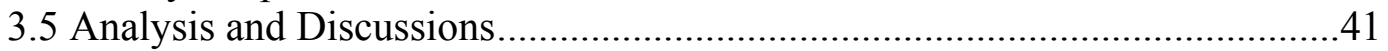

3.5.1 Research Thesis Justification.............................................................42

3.5.1.1 Decision Parameters Considerations.............................................42

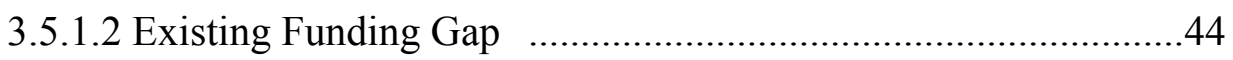

3.5.2 Current Investment Practices ..................................................................45

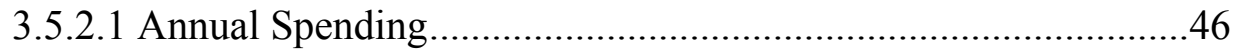

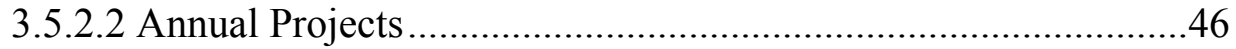

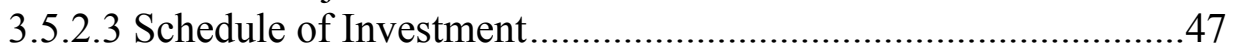

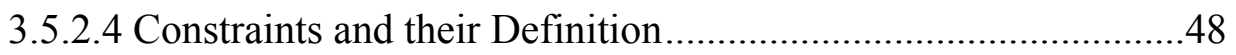

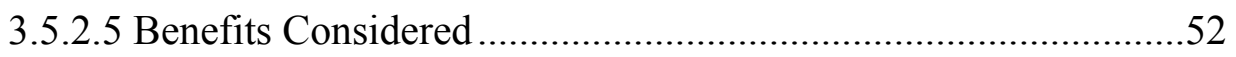

3.5.3 Performance Assessment Practices.........................................................53

3.5.3.1 Performance Measurement .....................................................54

3.5.3.2 Performance Analysis …………………………......................5

3.5.3.3 Performance Reporting ...........................................................57

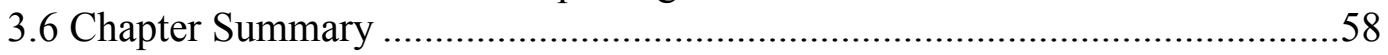

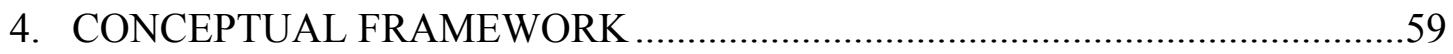

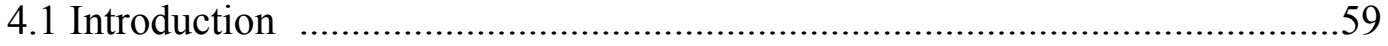

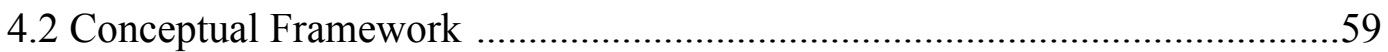

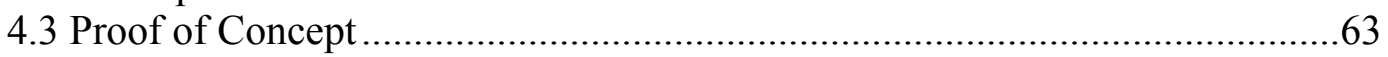

4.3.1 Agreement by DOT Professionals .........................................................63

4.3.2 Agreement by Infrastructure Management Experts ...............................66

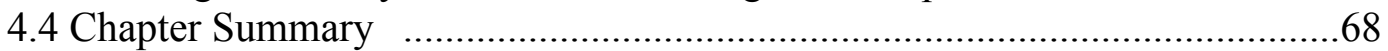

5. INFRASTRUCTURE MAINTENANCE INVESTMENT DECISION SUPPORT

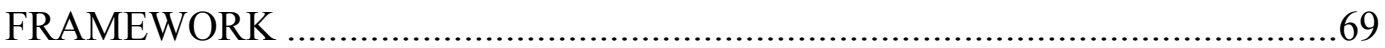

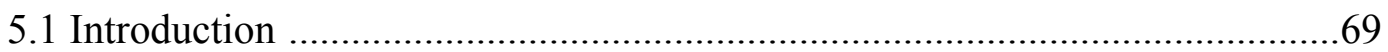

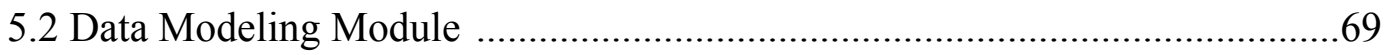

5.2.1 Performance Measurement ……………………................................69

5.2.2 Determination of Integrated State Rating (ISR) ……………................77

5.2.2.1 Developing Single Attribute Utility (SAU) Function .................78

5.2.2.2 Determining the Scaling Factor ……………...........................8

5.2.2.3 Development of Multi Attribute Utility Function (MAUF) .......81

5.2.2.4 Conversion of Multi Attribute Utility (MAU) to Integrated State

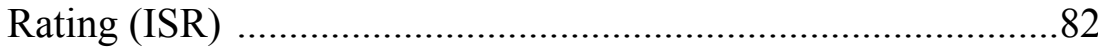

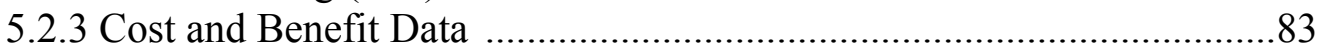

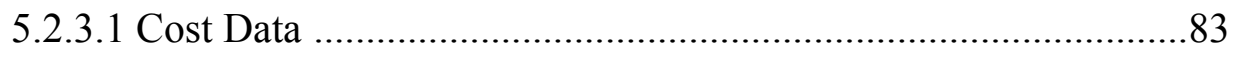

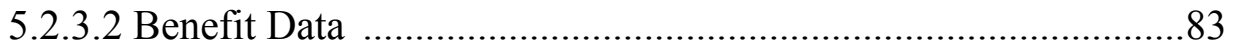

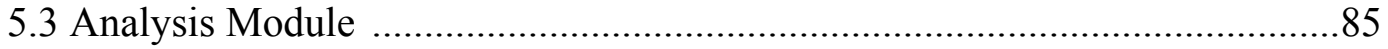

5.3.1 Level 1: Project Level Analysis ............................................................. 


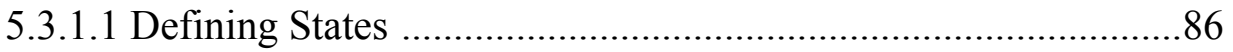

5.3.1.2 Defining Set of Probable Actions (A) ........................................86

5.3.1.3 Calculating Transition Probabilities (T) ...................................8

5.3.1.3.1 Transition Probability Matrix for "Maintenance" (MAIN) Action ……................................................ 88

5.3.1.3.2 Transition Probability Matrix for "Repair" (RPR) Action .................................................................90

5.3.1.3.3 Transition Probability Matrix for "Rehabilitation" (REH) Action ..........................................................92

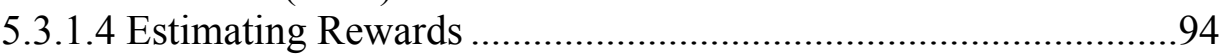

5.3.1.5 Markov Decision Process (MDP) ..............................................95

5.3.1.6 Development of Decision Logic Map (DLM) ............................96

5.3.2 Level 2: Network Level Analysis .......................................................98

5.3.2.1 Assigning the Cost and Benefits to Decision Logic Maps .........99

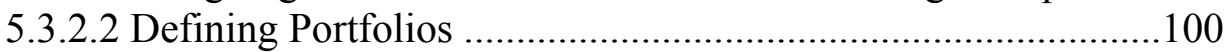

5.3.2.3 Screening for Portfolios to Define Feasible Portfolios ...............102

5.3.2.4 Funding Allocation to Candidate Infrastructure ........................102

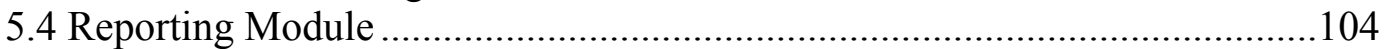

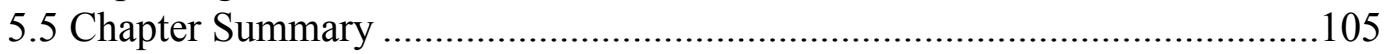

6. FRAMEWORK IMPLEMENTATION THROUGH CASE STUDY..................106

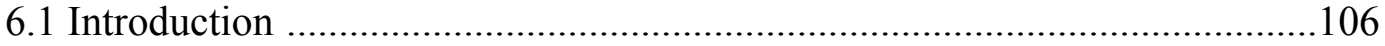

6.2 Characteristics of Geographical Area for Case Study (Pima County) ...........106

6.3 Decision-Making Group for Case Study ....................................................108

6.4 Characteristics of Candidate Infrastructure for Case Study ...........................109

6.5 Development of Multi-Attribute Utility Function ........................................112

6.6 Performance Measurement and Integrated State Rating (ISR) ......................117

6.7 Decision Support Outcomes from Performance Measurement ......................122

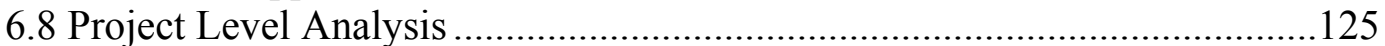

6.9 Decision Support Outcome from Project Level Analysis ................................137

6.10 Network Level Analysis …………………….......................................140

6.11 Decision Support Outcome from Network Level Analysis ...........................140

6.12 Feedback from the Decision-Making Group ..............................................142

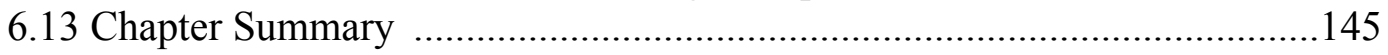

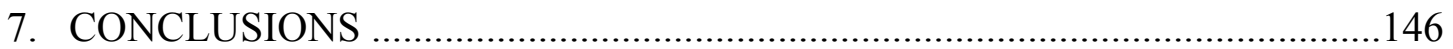

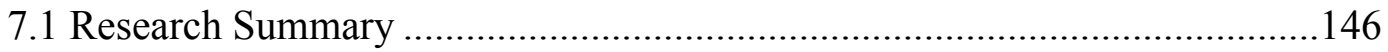

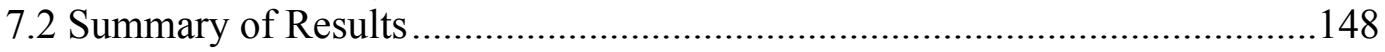

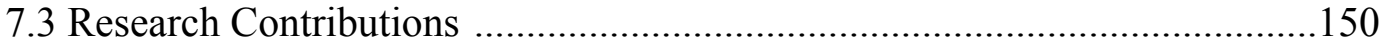

7.4 Limitations and Future Research Potential ...................................................151

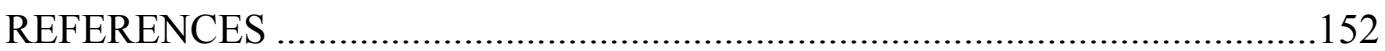

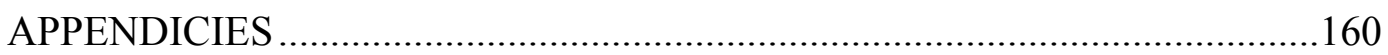

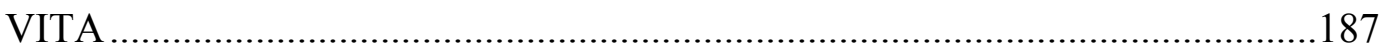




\section{LIST OF TABLES}

TABLE

PAGE

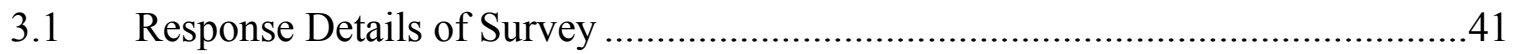

3.2 Decision Parameters Performance Measurement Factors........................................56

4.1 Infrastructure Management Experts' Characteristics ........................................67

5.1 Strategic Importance Measurement Matrix …………......................................73

5.2 Socioeconomic Performance Measurement Matrix..............................................74

5.3 Infrastructure Utilization Performance Measurement Matrix..................................75

5.4 Physical Condition Performance Measurement Matrix ............................................76

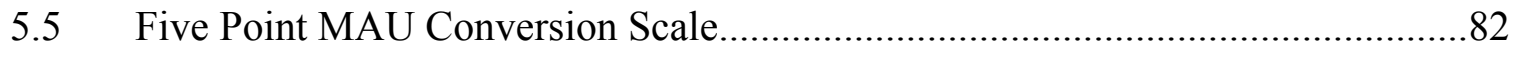

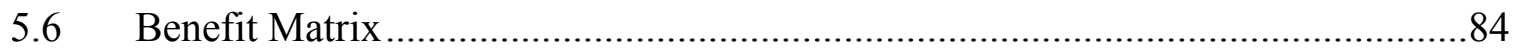

5.7 Typical Transition Probability Matrix for Maintenance Action.............................90

5.8 Typical Transition Probability Matrix for Repair Action .....................................92

5.9 Typical Transition Probability Matrix for Rehabilitation Action..........................93

5.10 Typical Reward Matrix for Maintenance Action...................................................94

5.11 Typical Reward Matrix for Repair Action ……….............................................94

5.12 Typical Reward Matrix for Rehabilitation Action................................................94

5.13 Decision Support Outcomes and their Usefulness............................................105

6.1 PCDOT Decision-Making Group for Case Study ……….................................108

6.2 General Characteristics of Candidate Bridges ...................................................110

6.3 Scaling Factors for Decision Parameters ………................................................116

6.4 Data Availability Period for Candidate Bridges ................................................118

6.5 Data Sources Details for Performance Measurement ............................................119 
6.6 Performance Measurement Results for Bridge 7760 ...................................120

6.7 Performance Measurement Results for Bridge 8318 .......................................120

6.8 Performance Measurement Results for Bridge 8724 .....................................121

6.9 Performance Measurement Results for Bridge 9552 ....................................121

6.10 Transition Probability Matrices for "MAIN" Action .......................................125

6.11 Transition Probability Matrix for "RPR" Action ............................................126

6.12 Transition Probability Matrix for "REH" Action............................................126

6.13 Cost Estimates for Maintenance Actions ..................................................127

6.14 Benefits Estimates for Maintenance Actions ...............................................127

6.15 State wise Costs and Benefits for Candidate Bridges ....................................129

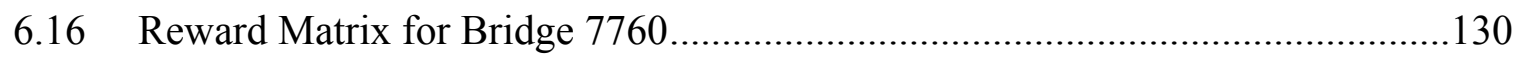

6.17 Reward Matrices for Bridge 8318............................................................131

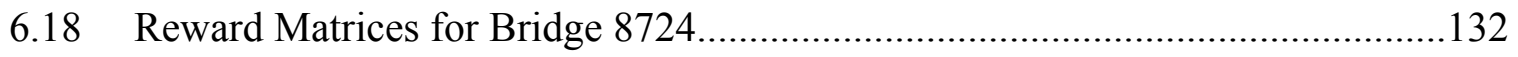

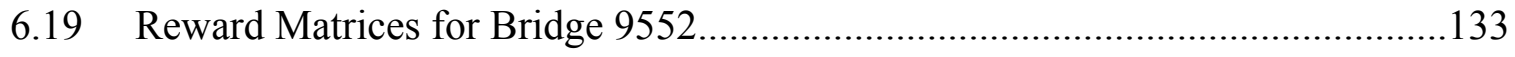

6.20 Markov Decision Process Results for Bridge 7760 .......................................134

6.21 Markov Decision Process Results for Bridge 8318 .....................................135

6.22 Markov Decision Process Results for Bridge 8724 ......................................136

6.23 Markov Decision Process Results for Bridge 9552 ......................................137

6.24: Network Level Maintenance Investment Plan for Five Years ...........................142

6.25: Feedback on Data Modeling and its Outcomes ..........................................143

6.26: Feedback on Project (Candidate) Level Analysis and its Outcomes .................144

6.27: Feedback on Network Level Analysis and its Outcomes ...............................145 


\section{LIST OF FIGURES}

FIGURE

PAGE

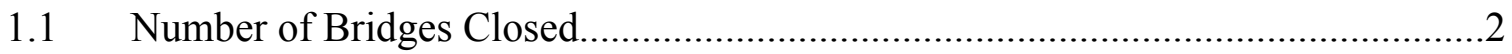

1.2 Global Competitiveness of Overall U.S. Infrastructure .....................................

1.3 Global Competitiveness of U.S. Quality of Roads ..........................................5

1.4 Multiple Decision Parameters in Infrastructure Maintenance Investment Decisions

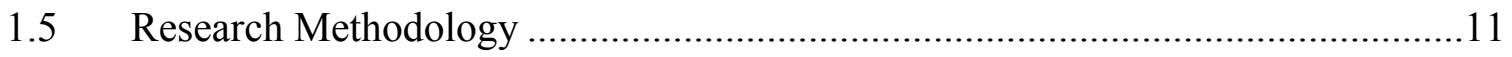

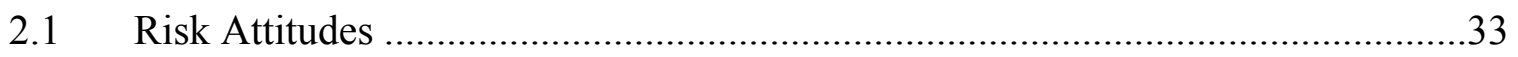

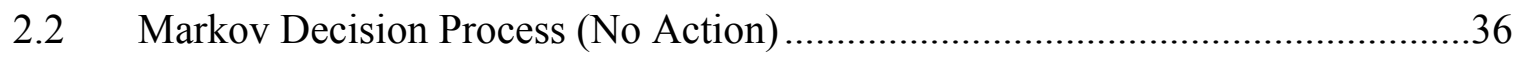

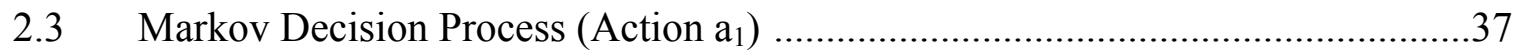

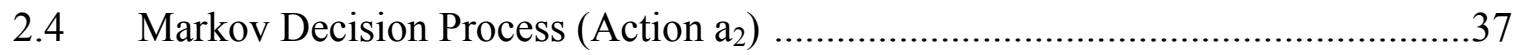

3.1 Geographical Coverage of Survey Reponses...............................................42

3.2 Decision Parameters' Consideration for Different Maintenance Strategies..........43

3.3 Finding Gap for Infrastructure Management ...............................................45

3.4 Typical Number of Bridge Maintenance and Rehabilitation Projects per Year ....47

3.5 Infrastructure Maintenance Investment Decision Making Constraints ................48

3.6 Responsibility for Defining Budget Constraints...........................................49

3.7 Responsibility for Defining Threshold Condition Constraints ..........................51

3.8 Benefits Considered for Infrastructure Maintenance Investment Decision-Making

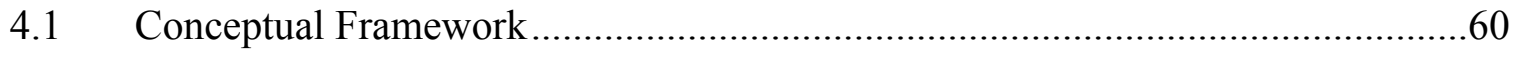

4.2 Agreement to Conceptual Framework by DOT Professionals ............................64

5.1 Bridge Management Action Categories (Ahmad 2011) ....................................86

5.2 Transition Scenario for Maintenance Action.................................................90 
5.3 Transition Scenario for Repair Action.............................................................

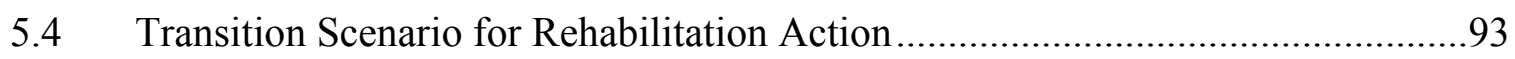

5.5 Typical Decision Logic Map Example ………………..........................................98

5.6 Example DLM with Assigned Cost and Benefits .................................................101

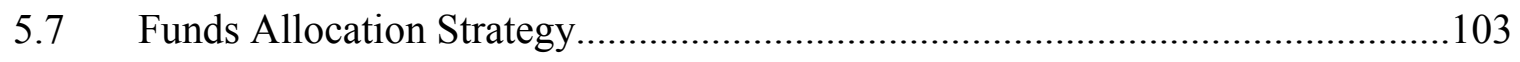

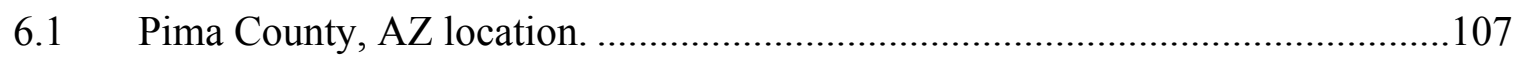

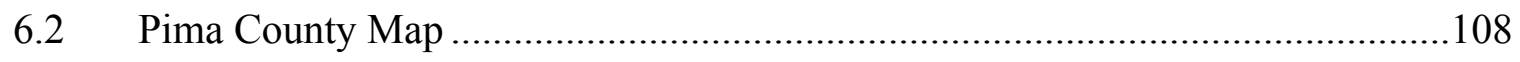

6.3 Location Map of Candidate Bridges …………………....................................111

6.4 SAU Curve for Strategic Importance............................................................114

6.5 SAU Curve for Socioeconomic Contribution ....................................................114

6.6 SAU Curve for Infrastructure Utilization .....................................................115

6.7 SAU Curve for Physical Condition.................................................................115

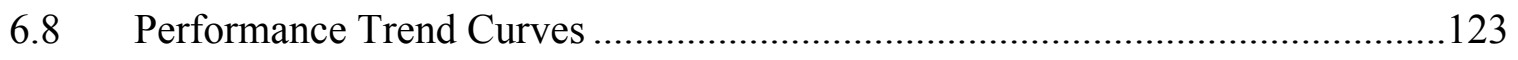

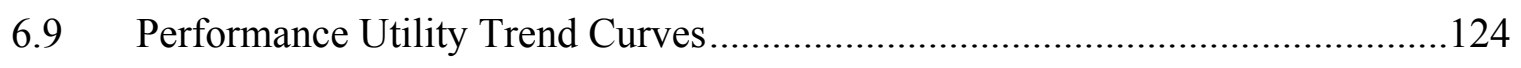

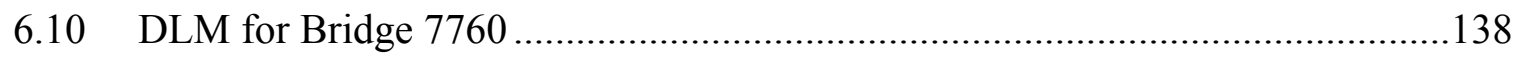

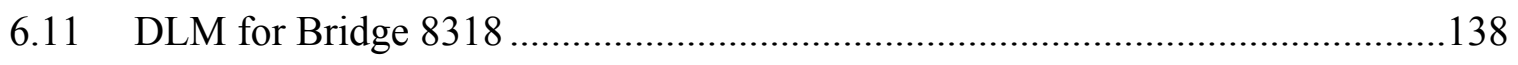

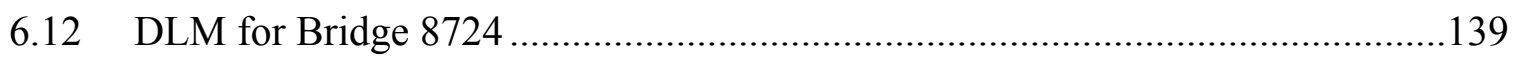

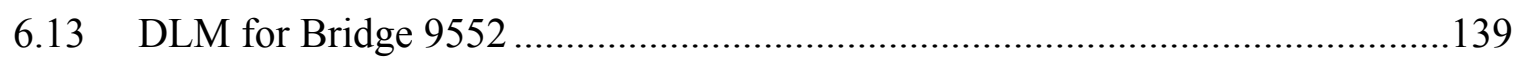

6.14 Cost and Benefits Assignment on DLMs..........................................................141 


\section{LIST OF ACRONYMS}

\begin{tabular}{|c|c|}
\hline ASCE & American Society of Civil Engineers \\
\hline AADT & Average Annual Daily Traffic \\
\hline AASHTO & American Association of State Highway and Transportation Officials \\
\hline DOT & Department of Transportation \\
\hline DLM & Decision Logic Map \\
\hline FHWA & Federal Highway Administration \\
\hline ISR & Integrated State Rating \\
\hline MAIN & Maintenance \\
\hline MDP & Markov Decision Process \\
\hline MAUT & Multi-Attribute Utility Theory \\
\hline MAU & Multi-Attribute Utility \\
\hline NBI & National Bridge Inventory \\
\hline NCHRP & National Cooperative Highway Research Program \\
\hline PAG & Pima Association of Governments \\
\hline $\mathrm{PC}$ & Physical condition \\
\hline PCDOT & Pima County Department of Transportation \\
\hline PL & Performance Level \\
\hline RPR & Repair \\
\hline $\mathrm{REH}$ & Rehabilitation \\
\hline SAU & Single-Attribute Utility \\
\hline ST & Strategic Importance \\
\hline $\mathrm{SE}$ & Socioeconomic Contribution \\
\hline UT & Infrastructure Utilization \\
\hline
\end{tabular}




\section{CHAPTER-1: INTRODUCTION}

\subsection{CONTEXT AND MOTIVATION}

The U.S. infrastructure is facing many challenges prominently due to its aging, resulting in capacity reduction capped with funding limitations. The outcome of these challenges is decreasing global competitiveness of the U.S. infrastructure (Graves 2013). In the next several decades, a significant percentage of the transportation, communications, environmental, and power system infrastructure, as well as public buildings and facilities, will have to be renewed or replaced due to aging. For example, if we consider the highway bridges, the average age of bridges in the U.S. is 42 years in 2013; more than $30 \%$ of existing bridges have exceeded their 50 -year design life as per FHWA. Most public sewer mains in the U.S. were installed after World War II. The average age of the 84,000 dams in the country is 52 years old (design of dams is typically based on a 50-year economic life as per USSD 2013). All of this means that significant funding will be required in order to preserve the aging infrastructure, while replacement will also be a huge challenge considering the budget constraints (ASCE 2013). Another challenge is the capacity and capability of existing infrastructure to be at its optimum utilization to cope up with the increasing demands. Over the years, social factors, increasing population and greater development have resulted in limitations to the utility of existing infrastructure from an overall perspective. For example, if we consider bridges, Figure 1.1 shows a trend analysis of the number of bridges closed due to load restrictions or other capacity issues using National Bridge Inventory Data (NBI 2013a). 


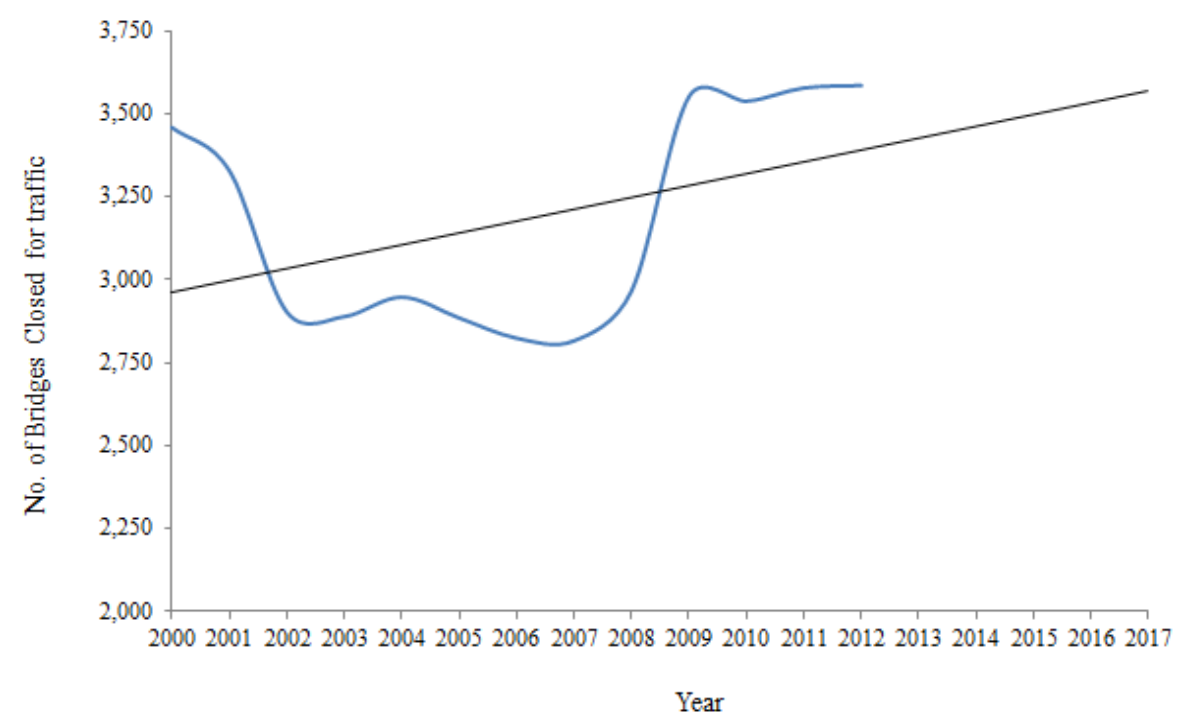

Figure 1.1: Number of Bridges Closed (Data Source: NBI 2013a)

There was a declining trend from 2001 until 2002, a relatively stable trend from 2002 to 2008 , and an increasing trend from 2008 until now as far as the number of bridge closures in concerned. Overall, prediction does not reveal a promising future if the current level of efforts is sustained. Thus, it will result in a further reduction in capacity of the highway network that may specifically affect freight movement. The most prominent of the key challenges, however, has been the budget and investment constraints. The allocated infrastructure-related funding is spent on a mixture of system expansion and preservation projects. Although these allocations have often been sufficient to avoid the imminent failure of key facilities, the continued deterioration leaves a significant and mounting burden on the U.S. economy (ASCE 2011). Since the 1970s, there has been a drastic decline in funding that supports the infrastructure of the U.S. In 1960, the U.S. federal public spending on infrastructure was $5 \%$ of its gross 
domestic product (GDP); by the mid-1990s, this figure was down to $2.5 \%$ (Snavely 2011). Today, the U.S. spends roughly $2 \%$ of GDP on infrastructure-about half what it did 50 years ago, according to a U.S. government report from October. Europe spends around 5\% and China 9\% (Lange 2011). It is understandable that the other aforementioned countries may have comparatively lesser GDP in terms of dollars than that of U.S. However, a higher percentage of spending (i.e. \% of GDP) shows the available room and desire in the budget of those countries as compared to the U.S. If capital investment levels for infrastructure maintenance needs are kept at the current level, it is predicted that there will be a funding gap of $13 \%$ by year 2020 , which will increase to $27 \%$ by year 2040 (ASCE 2011). The overall estimated investment needed by 2020 to maintain a "state of good repair" is around $\$ 3.6$ trillion, with surface transportation having an estimated funding gap of almost 50\% from the total need (ASCE 2013). This is a dire situation as far as limitations of funding are concerned.

The impact of the aforementioned challenges is evident through weakening of the global competitiveness of the U.S. infrastructure. Moreover, future predictions considering the current trends are not reassuring. Figure 1.2 shows a trend analysis of global competitiveness of the U.S. infrastructure using data published by the World Economic Forum (WEF 2013). The graph shows a plot of the U.S. infrastructure score against the top 20 countries' average score for last seven periods since 2006-2007. The score is on a scale of 1 to 7 , where 1 is extremely underdeveloped and 7 is a top score. The U.S. infrastructure competitiveness score has decreased from 6.14 in 2006-2007 to 5.8 in 2012-2013. Comparatively, the top 20 countries' average has increased from 5.8 in 2006-2007 to 6 in 2012-2013. Currently, the U.S. ranks at number 14 out of the top 20 
countries as compared to the rank of 7 in 2006-2007. Countries such as the United Arab Emirates, Spain and Luxembourg have made rapid progress to overtake the U.S. The dotted lines show trends for the U.S. and the top 20 countries based on the linear regression curve fitting. The analysis clearly shows that the U.S. has a swiftly declining global competitiveness while the rest of the competitors have an increasing trend for the last 7 years. If the current level of effort is maintained in preserving U.S. infrastructure, the gap will increase further and will become difficult to sustain the U.S. infrastructure.

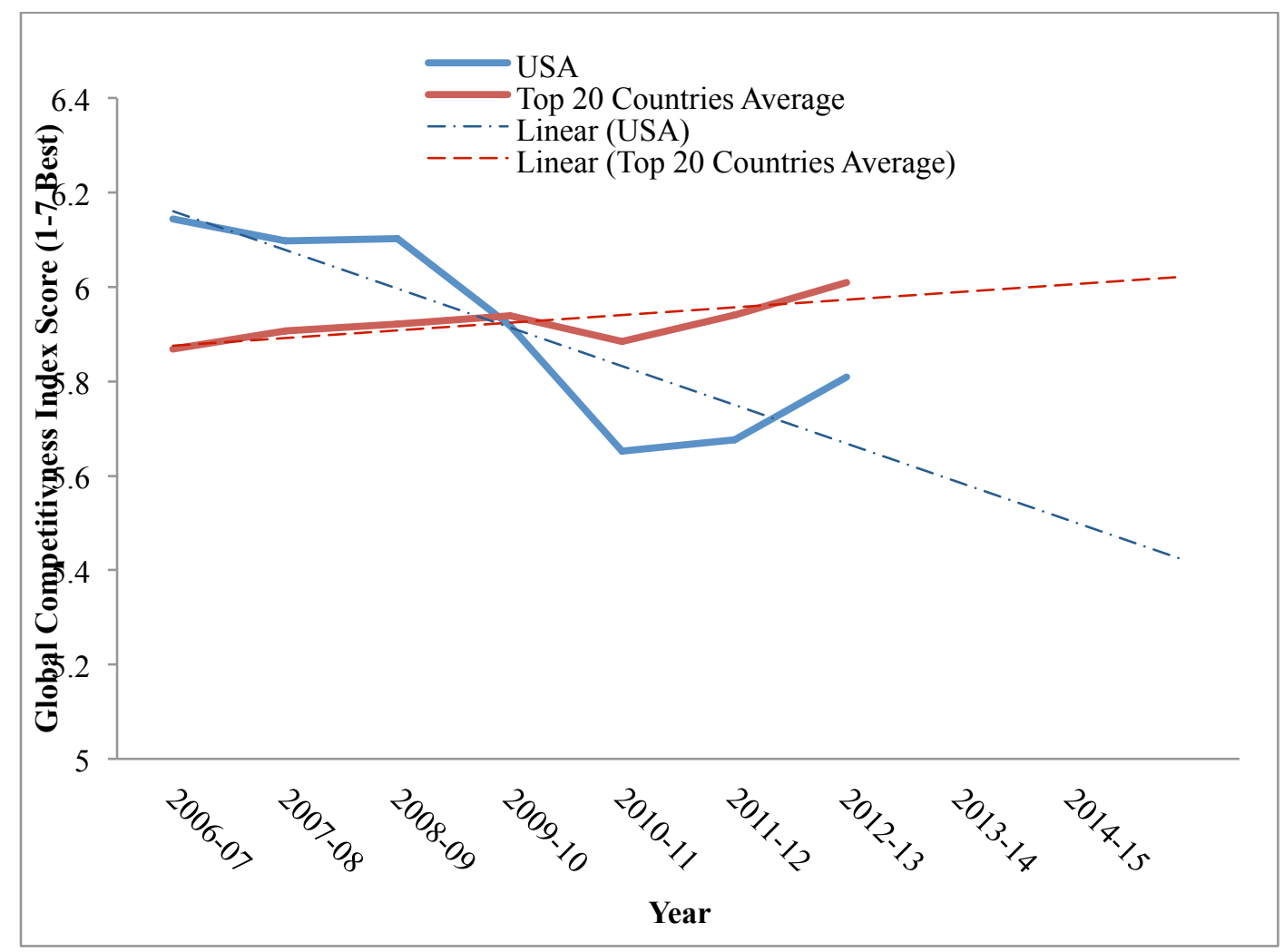

Figure 1.2: Global Competitiveness of Overall U.S. Infrastructure (WEF 2013)

As far as surface transportation quality is concerned, Figure 1.3 provides an insight into the global competitiveness through assessing the quality of roads using a similar trend analysis approach to that of the overall infrastructure. The trend analysis 
shows the plot of the U.S. infrastructure score against the top 20 countries' average score for the last seven periods since 2006-2007. The U.S. infrastructure competitiveness score has decreased from 6.1 in $2006-2007$ to 5.6 in $2012-2013$. Comparatively, the top 20 countries' average has been relatively stable, hovering around 6. Currently, the U.S. ranks at number 20 with regard to quality of roads out of the top 20 countries, as compared to rank 7 in 2006-2007. The analysis clearly shows that the road transportation infrastructure has been on the worse side of the things when compared to the overall infrastructure competitiveness.

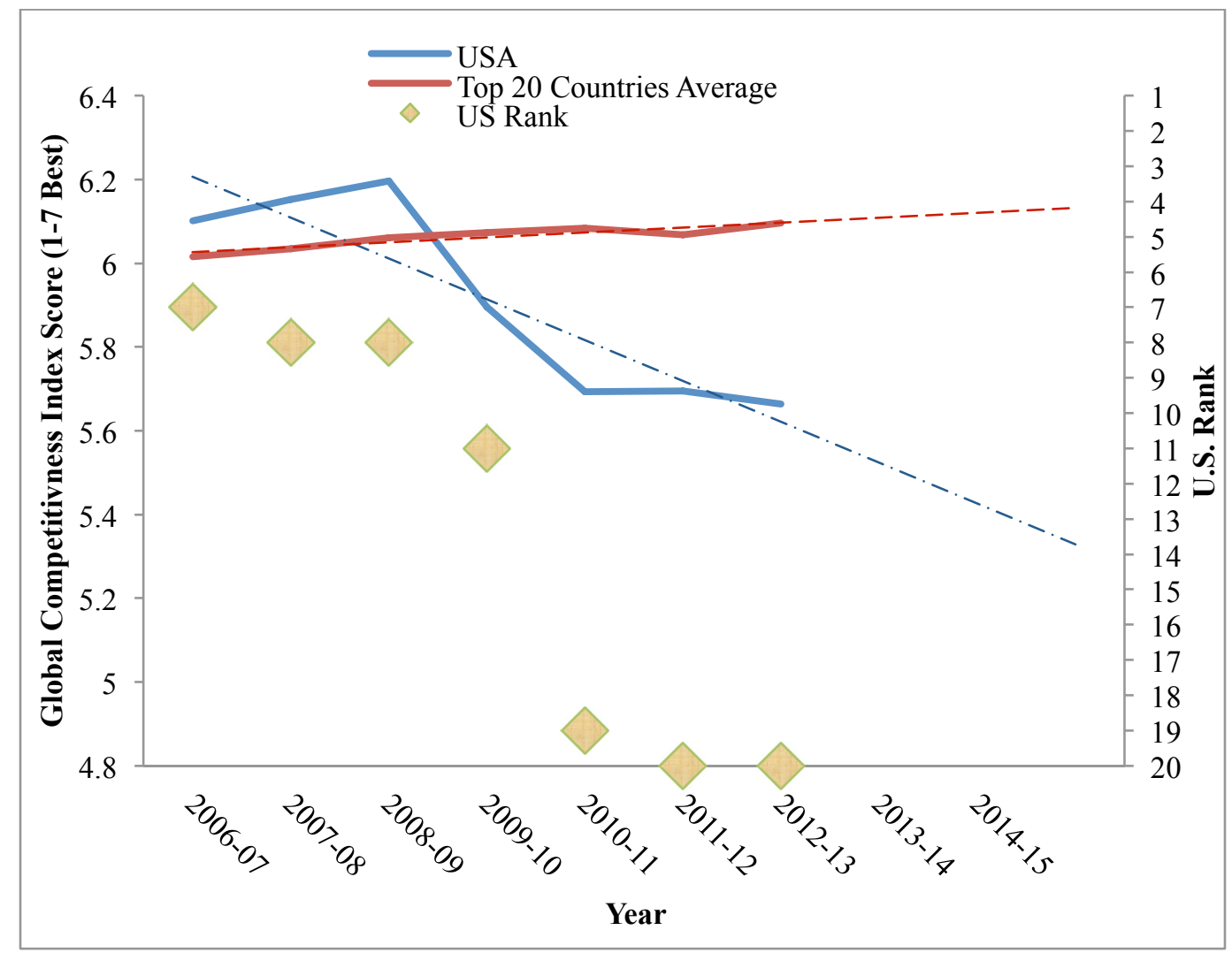

Figure 1.3: Global Competitiveness of U.S. Quality of Roads (WEF 2013)

The aforementioned challenges and their outcomes have convinced public agencies to develop better mechanisms for infrastructure maintenance investment 
decision-making. Traditionally, such decision making has been based on the "worst first" criterion. That is, maintenance investment decisions are generally made based on physical condition only. However, it may not often result in a beneficial utilization of the available funds. It is important to understand that spending money on public infrastructure is synonymous with spending money on people themselves. Therefore, decision makers are required to think innovatively and develop inventive ways of using available funds. This creates a need for having systematic processes, decision support frameworks, and procedures in place that would enable better decision making based (Mihai et. al. 2000).

\subsection{PROBLEM STATEMENT}

Infrastructure maintenance investment decision-making is a challenging task. Generally, focus has been on physical condition only while making such decisions. This approach ignores the importance of certain other aspects, consideration of which can be further beneficial in case of limited funding. This means that infrastructure maintenance investment decision making involves various objective and subjective decision parameters (Figure 1.4). Failure to consider such parameters can undermine strategic thinking regarding infrastructure management. Another major challenge for decision makers is to allocate available funds across the group of infrastructures that are candidate for maintenance i.e., treating the candidate projects as a portfolio, rather than selecting some and ignoring the others. 


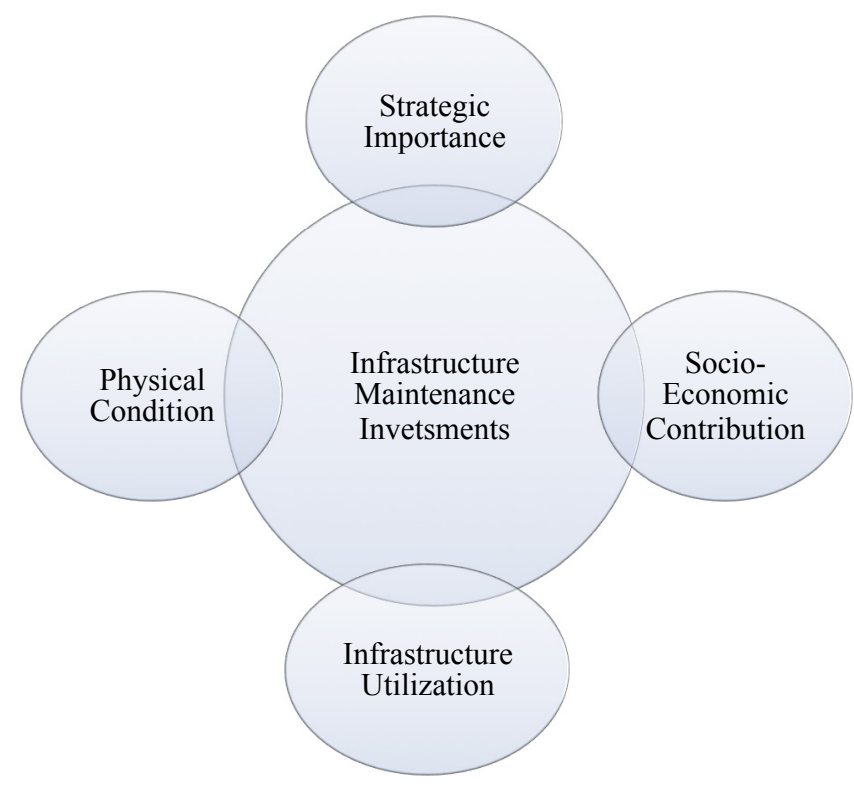

Figure 1.4: Multiple Decision Parameters in Infrastructure Maintenance Investment Decisions

Thus, there is a need for "integrating multiple decision parameters in maintenance investment decision-making in order to deal with budgetary constraints and better utilize available funding by taking a portfolio management approach.” Such an approach can also help in addressing the wide spectrum of requirements and constraints of the diverse perspectives of different stakeholders.

This research is an effort to address the aforementioned need by developing a prototype decision support framework that integrates multiple decision parameters, and guides decision makers for allocating infrastructure maintenance funds with consideration of budget constraints across the group of candidate infrastructures through adapting portfolio management approach. 


\subsection{RESEARCH THESIS}

Investment decisions related to infrastructure maintenance projects are difficult to make due to budget constraints. Maintenance investment decisions are generally made based on physical condition only. Spending money on public infrastructure is synonymous with spending money on people themselves. This requires consideration of other decision parameters, in addition to physical condition, such as strategic importance, socioeconomic contribution and infrastructure utilization. Consideration of multiple decision parameters for infrastructure maintenance investments can be beneficial in case of limited funding. The aforementioned considerations present a challenge to the decision makers. Therefore, a decision support framework that would allow evaluating multiple decision parameters with consideration of budget constraints, by adopting a portfolio management approach can help decision makers to use available maintenance funds in a beneficial manner.

\subsection{PURPOSE, SCOPE AND OBJECTIVES OF THE RESEARCH}

The purpose of this research is to develop a prototype framework to provide decision support tools, and maintenance investment plan for budget-constrained infrastructure maintenance investment decisions by considering multiple decision parameters.

The scope of this research includes bridge maintenance investments. However, the framework has been kept flexible enough to customize it for use in other similar infrastructures such as airports, rest areas on highways, etc. The focus of the framework is to provide a decision support framework whose output can be utilized for: 
1. Disbursement of maintenance budget available to an infrastructure management entity,

a. Based on project-wise evaluation

b. On a network of infrastructure.

2. Procuring more funds from state or federal level funds based on solid rationale from the decision support framework's outputs.

The main research questions to be answered by this research are:

1. What are the appropriate decision parameters for infrastructure maintenance investments?

2. What are the critical tangible and intangible factors that could influence these decision parameters?

3. What criteria and techniques should be used, to assess the collective effect of the decision parameters, using parameters' assessment to define optimal maintenance strategies, and for adopting portfolio management approach for allocation of available funds to candidate infrastructure?

4. What type of outcomes can be helpful for decision makers as a decision support tool?

The main objectives of this research include:

1. Review existing literature.

2. Assess the current state-of-the-practice of infrastructure management entities in order to understand decision-making processes and identify their potential needs to be addressed by the decision support framework.

3. Identify decision parameters. 
4. Identify factors within each decision parameter.

5. Establish mechanism for measurement and integration of decision parameters.

6. Perform Project (Candidate) level analysis to determine optimal maintenance action.

7. Determine most feasible portfolio at network level.

8. Apply the framework using a case study.

\subsection{RESEARCH BENEFITS}

The outcome of this research is a prototype decision support framework. The methodology and decision support framework developed through this study can be used by infrastructure management agencies to make the maintenance investment decisionmaking procedure more strategic, innovative, and holistic. The research can serve as an innovation in traditional infrastructure maintenance investment planning and decisionmaking. Addressing various subjective parameters, such as strategic, socioeconomic contribution, and infrastructure utilization factors, that can help to achieve higher levels of service for its user by spending public money in a more beneficial manner.

\subsection{RESEARCH METHODOLOGY}

The first step was to establish the research objectives. This was necessary in order to determine the need for the research, its potential objectives, and the desired outcomes. To achieve the study objectives, the entire research approach has been divided into five tasks (Figure 1.5). These research tasks are described below. 


\subsubsection{LITERATURE REVIEW}

The identification of the research objectives follows a comprehensive literature review of journal and academic publications to establish the knowledge base of infrastructure maintenance investment decisions, and existing decision support systems in infrastructure management.

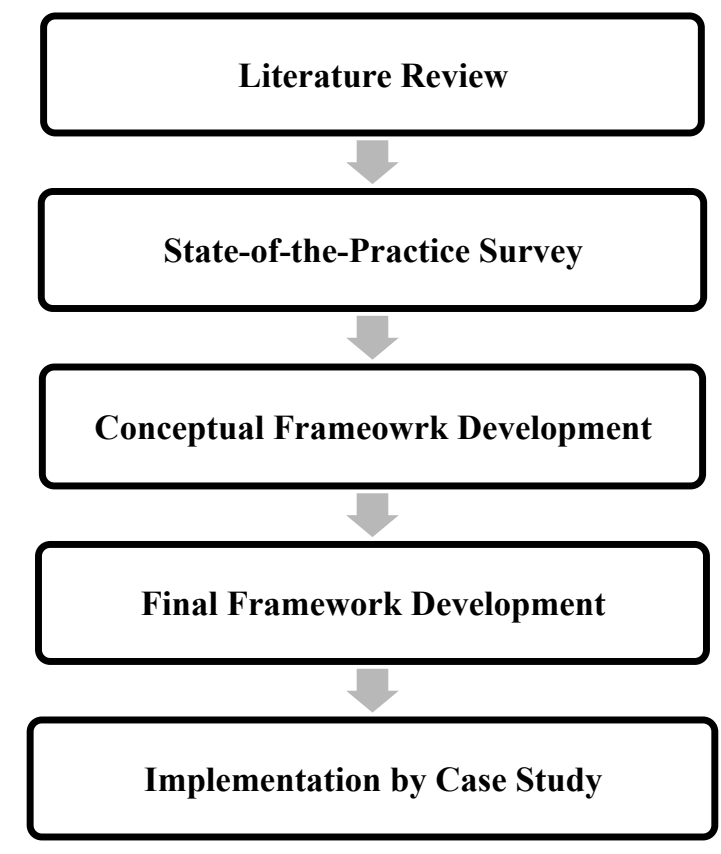

Figure 1.5: Research Methodology

\subsubsection{STATE-OF-THE-PRACTICE SURVEY}

An online survey has been conducted to assess the existing state-of-the-practice of the decision makers or the decision-making entities involved in infrastructure maintenance investment decision-making. The survey was conducted from maintenance offices of the state departments of transportation (DOT) at district-level. This was necessary to incorporate the points of view of actual decision makers and define the requirements of the conceptual framework. 


\subsubsection{CONCEPTUAL FRAMEWORK DEVELOPMENT}

The purpose of defining the conceptual framework was to develop a skeleton of the proposed framework. The conceptual framework was also utilized in achieving proof of concept of the decision support framework.

\subsubsection{FINAL FRAMEWORK DEVELOPMENT}

The literature review, state-of-the-practice survey results and conceptual framework was succeeded by development of the final working framework that includes detailed description of mathematics involved in data modeling process, analysis and provides details on the decision support outcomes of the framework.

\subsubsection{IMPLEMENTATION BY CASE STUDY}

Finally, the framework has been implemented through case study by using actual data for bridge maintenance.

\subsection{ORGANIZATION OF DISSERTATION}

Chapter 1 (Introduction) provided an overall context and motivation that derives the concept of this research in terms of key challenges faced by the U.S. infrastructure. In the light of the context, it described the problem, research thesis, purpose, scope and objectives of the research and research methodology adopted to achieve the objectives.

Chapter 2 (Literature Review) provides a comprehensive review of fundamental concepts and contemporary issues involved in the infrastructure maintenance investment decision-making. It also reviews prior studies and existing frameworks to provide gap 
analysis in order to highlight the importance of the major objectives of the proposed research.

Chapter 3 (Current State-of-the-Practice) provides findings and analysis of an online survey conducted at district level of various department of transportations throughout the U.S. The purpose was to elicit information regarding current state-of-thepractice and to validate the identified challenges.

Chapter 4 (Conceptual Framework) presents conceptual framework for the development of final working framework by utilizing the outcomes of the literature review and state-of-the-practice survey. Furthermore, it presents assessment of the framework by infrastructure management experts' and DOT professionals to provide proof of concept.

Chapter 5 (Infrastructure Maintenance Investment Decision Support Framework) presents a maintenance investment decision framework developed in this research. It provides extensive step-by-step details of the entire phases including data modeling, project (candidate) level analysis and network-level analysis. It also discusses the expected outcomes of the decision support framework.

Chapter 6 (Framework Implementation through Case Study) presents implementation of the developed framework through a case study. It provides detailed account and step-by-step processes of implementation, and reports the results of the case study as well as feedback on the outcomes.

Chapter 7 (Conclusions) provides an overall summary and conclusions of the research presented in the dissertation. It also discusses research contributions, limitations and presents recommendations for future research. 


\subsection{CHAPTER SUMMARY}

The text presented in this chapter provided an overall background and motivation for the research. The specific goal of the discussion presented was to introduce the problem, purpose, scope, and objectives of the investigation. It also highlighted the specific benefits of the research. The next chapter will present the literature review. 


\section{CHAPTER-2: LITERATURE REVIEW}

\subsection{INTRODUCTION}

The main idea of this research is to develop a decision support framework. The framework is intended to facilitate optimal fund allocation and prioritize investment decisions for similar infrastructure maintenance projects, considering various investment decision parameters, critical factors, and budgetary constraints. The first chapter introduced the need for the research while defining the scope, purpose, objectives, and research methodology and dissertation arrangement. This chapter presents the findings of a comprehensive literature survey and review of fundamental concepts and contemporary issues involved in the infrastructure maintenance investment decision making. In addition, it provides an account of the previously conducted studies and existing decision support tools and frameworks. It also presents gap analysis to further highlight the importance of the major objectives of the proposed research. Finally, the chapter offers a brief review of the tools and techniques that have been utilized for the modeling of the problem and the development of the decision framework.

\subsection{INFRASTRUCTURE MANAGEMENT AND MAINTENANCE DECISION-} MAKING

This section provides a literature review to discuss different aspects of infrastructure management and its functions, with the main focus on the maintenance investment decision making. 


\subsubsection{FUNCTIONS OF INFRASTRUCTURE MANAGEMENT}

Infrastructure management generally has five functions, which consist of planning, programming, construction program delivery, maintenance and operation, and system monitoring. Planning encompasses procedures to identify future needs and recommend solutions in the long- to mid-term time frames; develop strategies at a statewide, network, or corridor level across modes; undertake studies of particular needs that require major transportation investments (as for capacity or service expansion); and address strategic issues such as environmental protection and energy conservation. Programming and budgeting involve allocations of finances, staff, equipment, and other resources to the different investment areas. Construction program delivery implements the programs involving construction projects, whether for new facilities (or additional capacity for existing facilities), capital preservation, or installation of operations infrastructure. Maintenance and operations include delivery of routine maintenance and system management and operations services to existing facilities. System monitoring tracks system conditions and service levels to determine the extent to which established performance objectives are being addressed (NCHRP 2006). Chin et al. (2009) have suggested that there are now six main drivers of the infrastructure asset management process. These are as follows: (1) advances in the maintenance, repair, and rehabilitation market; (2) changes in account reporting regarding infrastructure asset values; (3) the need for performance-based maintenance; (4) limitations of government funds and increasing opportunities for private-public partnerships; (5) implementation of life cycle cost analysis for maintenance; and (6) information technology use for massive and complicated asset inventory management. 


\subsubsection{INFRASTRUCTURE MAINTENANCE INVESTMENT DECISION-MAKING}

As public funding shifts from construction to maintenance, maintenance organizations become more accountable to administrators, politicians, and the public for safe, convenient, and accessible systems. The infrastructure investment levels have also decreased due to budgetary constraints. This shift in emphasis brings new governance and institutional issues. The nation's aging infrastructure is challenging maintenance managers to respond with more effective business practices (TRB 2006). Budget constraints and increasing demands have required agencies to be more accountable and provide cost justification before allocating money to maintenance and rehabilitation. As a result, the emphasis of decision making has also shifted to asset registers, valuation, information collection, and data systems. However, information by itself is not sufficient. Agencies have begun to recognize the need to have systematic processes, decision support systems, and procedures in place that would enable business decisions based on the information available (Mihai et. al. 2000). Given the changing dynamics of investment decision making as described in the above paragraph, several researchers have proposed decision making frameworks to align with the contemporary investment constraints in infrastructure management. The following text provides a review of some of the frameworks.

In 2001, the federal government, through its Infrastructure Canada Program (IC) and the National Research Council (NRC), joined forces with the Federation of Canadian Municipalities (FCM) to create the National Guide to Sustainable Municipal Infrastructure (InfraGuide). This program publishes reports on a regular basis titled "Decision Making and Investment Planning" to help decision makers plan infrastructure 
and fund it on a life cycle basis. They include best practices for alternative funding, for coordinating infrastructure projects, and for applying useful reference points for investment policies and planning decisions (Infraguide 2011). Piyatrapoomi et al. (2003a) developed a strategy for the development of an investment decision-making framework for road asset management for the Queensland department of main roads. The aim of the research was to develop a systematic investment decision-making framework for infrastructure asset management by incorporating economic, social, and environmental considerations in the decision-making process. The framework focused on providing the most favorable option for the investment. Piyatrapoomi et al. (2003b) conducted another study in which they provided a summary of the broad nature of decision-making tools used by governments and other organizations in Australia, New Zealand, Europe, and North America, showing their overall approach to risk assessment in assessing public infrastructure proposals. The same authors also proposed a framework for investment decision making under risk and uncertainty for Infrastructure Asset Management (Piyatrapoomi et al. 2004). Rahman and Vanier (2004), based on the response of infrastructure management professionals, concluded that Life Cycle Cost assessment (LCCA) can be used as a potential decision tool for municipal infrastructure investment planning. They provided an overview of the fundamentals of LCC calculations and analysis, and identified many of the costs that must be taken into consideration. The study was part of a larger project on Municipal Infrastructure Investment Planning (MIIP) conducted by Canada's Institute for Research in Construction (IRC) to provide managers of municipal infrastructure with decision support tools to optimize their investments and maximize the value of assets over their life cycles (MIIP 2011). NCHRP (2005) presents 
two tools developed to support trade-off analysis for transportation asset management. It also provides a gap analysis in the existing tools and identified the need for improvement. Rogers and Grigg (2006) proposed a methodology to prioritize pipe replacement in water utility asset management based on "what-if" scenario analysis. Furthermore, Cohen and Tadepalli (2006) provided a statistical framework to address the problem of developing optimal maintenance and rehabilitation investment policies for transportation infrastructure facilities. The framework addresses two sub-problems: a state estimation problem that involves processing condition data and using them to develop condition forecasts, and an optimization problem whose solution yields maintenance and rehabilitation policies. The major use of the framework is to quantify the effect of uncertainties both in the deterioration process and in the data collection process for the optimal life cycle costs of managing infrastructure facilities. In ASME (2009), a framework was suggested to create an environment for developing short- and long-term solutions to complex issues involving a multitude of stakeholder support. This framework supports an infrastructure portfolio of existing, renewed, and new assets that optimize the economic, environmental, and societal function of the given area (metropolitan, state, regional, or national) relative to whatever budgetary or other constraints apply. Sobanjo and Tompson (2011) recently conducted a project for the Florida Department of Transportation (FDOT) to enhance the FDOT's project- and network-level bridge management analysis tool. They developed a spreadsheet-based project level analysis tool (PLAT) to process and present Pontis analytical results in a useful form for bridgelevel analysis decision making. In conjunction with this, a network-level programming 
and budgeting decision support tool was also developed to use the project-level analysis results.

The above discussion reviewed the research efforts conducted in infrastructure management and maintenance investment decision making. The scope of the review was the last decade, wherein the maintenance investment decision making has been thrust into the limelight due to the deteriorating economy having budget constraints, thus making such decisions a critical issue. The following section provides a gap analysis of the reviewed and some other research efforts to highlight the importance and need for the proposed research.

\subsubsection{GAP ANALYSIS}

The increasing complexity and sophistication of infrastructure management processes have also resulted in creating diverse areas of knowledge, expertise, and responsibilities. Infrastructure asset management decision making is inherently an integrated process that requires the assimilation of a multitude of data, processes, and software systems. However, fragmentation of work processes and asset data, a typical characteristic of today's practices, is a major obstacle toward adopting more efficient, integrated, and proactive management strategies. Throughout the last two decades,

municipalities have made significant investments in implementing software tools to address the increasing complexity of infrastructure management processes (Vanier 2001; Halfawy et al. 2006). Although the use of these tools has undoubtedly improved the efficiency of managing infrastructure assets, it has also, ironically, exacerbated the negative impact of process fragmentation by creating information gaps between different 
processes and variables. It is understandable that every framework or tool proposed has its limitations, but due to rapidly changing needs, some of the limitations have created gaps that are necessary to fill. For example, Piyatrapoomi et al. (2003b) concluded that while there are established techniques to quantify financial and economic risks, quantification is far less developed for political, social, and environmental risks and impacts. For risks that cannot be readily quantified, assessment techniques commonly include classification or rating systems for likelihood and consequence. NCHRP (2005) provided a key finding that many existing analytical tools were not being used to their full potential regarding their ability to influence investment decision making. This underutilization is related to the capabilities of the tools themselves, the credibility of input data and models, and organizational factors. Among many gaps identified in the existing tools, the report highlighted the improved ability to calculate the economic benefit for a program of projects. The report further stressed that investment decision tools should be focused on the impacts to customers/users as opposed to facility conditions only. The ASME (2009) framework attempted to take into account the important subjective investment variables related to infrastructure maintenance. It also advocated the portfolio investment analysis approach; however, the analysis did not fully take into account the condition of the infrastructure. The framework seems to support the policymaker's perspective for trade-off among the macro investment alternatives such as power plants, dams, bridges, etc. While the study conducted by Sobanjo and Tompson (2011) was based on in-depth analysis of the overall bridge infrastructure management, it acknowledged that none of the work presented regarding investment decision rules can be considered as a recommendation, primarily because the benefits of the investments were 
not evaluated based on multi-objective analysis. They concluded that such a method with a multi-objective risk-based approach would be an important enhancement.

The discussion presented above highlighted some of the macro-level gaps in the existing frameworks for infrastructure maintenance investment decision making. The following section will focus on the review of the role and use of decision support systems in general, as well as the existing decision support systems in infrastructure management as a whole and, in particular, for infrastructure maintenance investment decision making. Finally, it will provide a general account of the flaws in the existing decision support systems.

\subsection{DECISION SUPPORT FRAMEWORKS/SYSTEMS}

Decision support systems are tools that help users in a problem-solving environment to improve their productivity and decision-making ability (Hastak 1994; Bhargava et al. 1995; Molenaar and Songer 2001). Decision support systems include a diverse set of techniques and applications such as artificial intelligence and expert systems, database queries, and group conference decision support systems (Loughlin et al. 1995; McIntyre and Parfitt 1998). The traditional description of a decision support system is "a computational or computerized environment for assisting human decision making" (Kroenke and Hatch 1993; Molenaar and Songer 2001). Decision support systems do not provide the decision maker with a direct solution, but help the user add value to the system output in order to reach a decision (Molenaar and Songer 2001; Loughlin et al. 1995). McIntyre and Parfitt (1998) indicate that a decision support system involves four basic interrelated elements: (i) human input, (ii) data describing the 
problem, (iii) procedures for operating the system, and (iv) computerized system.

\subsubsection{DECISION SUPPORT FRAMEWORKS/SYSTEMS IN INFRASTRUCTURE MANAGEMENT}

The construction industry provides an excellent opportunity for the utilization of decision support systems due to the highly unstable environment of construction projects and the need for increased effectiveness in such a situation (Hastak and Vanegas 1993). Several researchers have attempted to build mathematical models to optimize maintenance. These models can be classified into single-objective models, multiobjective models, and cost/finance-based models. The following text lists some notable examples of decision support systems in the field of infrastructure management according to the aforementioned classification.

\subsubsection{SINGLE-OBJECTIVE MODELS}

Sadek et al. (2003) developed an integrated infrastructure management system that maximizes the overall condition of the transportation system as subject to budget constraints. The budget allocation module has two levels: transportation system and individual component. Wang and Liu (1997) presented a network optimization system for pavements which maximizes pavement network performances given a known budget in future years. Fuzzy sets are used to model coefficients of the pavement condition factors. Worm and van Harten (1996) constructed a model that minimizes the net present value of future maintenance costs while accounting for the economies of scale in road maintenance. Another approach is to model the highway network with respect to traffic loads to determine the optimal maintenance priorities (Donaghy and Schintler 1998). 
These are single-objective models that are limited in their real-world utility and practicality; unfortunately, this seems to be the trend in highway infrastructure maintenance management.

\subsubsection{MULTI-OBJECTIVE MODELS}

The multi-objective nature of the situation in a decision-making framework has been addressed in several works. Fwa et al. (2000) developed a genetic algorithm-based approach to determine the Pareto optimal frontier for pavement maintenance options. Chan et al. (2003) employed a two-stage genetic algorithm procedure for a central authority to allocate resources to regional or district agencies. In the first stage, only the needs and requirements of regional or district agencies are considered. In the second stage, the constraints and requirements of the central authority are imposed to arrive at a solution. For investment decisions, Hsieh and Liu (1997) presented a 0-1, nonlinear, multi-objective knapsack problem that is solved using heuristics. A goal-programming methodology was developed by Ravirala and Grivas (1995) for integrating pavement and bridge programs. Gharaibeh et al. (1999) presented a geographic information systembased methodology for managing highway assets. Multiple performance measures were used in project selection. Hastak et al. (2005) developed a decision support software program to help governing agencies plan, select, and make decisions for infrastructure maintenance based on socioeconomic factors, cost and funding constraints, and management considerations. Hastak and Abu-Mallouh (2000) developed a decision support system for selecting subway stations for rehabilitation. Gokhale and Hastak (2000) developed decision aids for sewer pipeline installation and rehabilitation. 


\subsubsection{COST/FINANCE-BASED MODELS}

Some researchers have focused on accurate cost estimation and financing as opposed to the overall optimization model. Sobanjo (2000) uses fuzzy probabilities to assess bridge costs and employs a utility-based economic analysis technique to select among maintenance alternatives. Meanwhile, Dornan (2000) discusses the long-term implications of maintenance deferral for roads and bridges, and suggests methods for financing the operation and maintenance of these assets in order to have the resources available to properly maintain them. He further suggests that avoiding the costs associated with deferred maintenance will lead to significant savings in the long run. Some researchers have applied risk analysis to maintenance decision making. According to Paté-Cornell (2002b), the important inputs to the optimal allocation of resources are the magnitude of the risk and its uncertainty. Probabilistic risk analysis was used by PatéCornell (2002a, 2002b) to assess risk and its uncertainty, and to prioritize the mitigating options. Bayesian probability is used to perform analysis with the evidence obtained from past experiences of failure, surrogate data, test data, engineering models, and expert opinion (Paté-Cornell 2002a). Matthews et al. (2002) acknowledge that risk analysis contributes significantly to life cycle assessment and improves the life cycle results and implications. Chang and Shinozuka (1996) have presented a life cycle cost analysis

which considers the risk of natural hazards, particularly earthquakes. Amekudzi and McNeil (2000) state that data and model uncertainties are present in highway performance estimates. They have developed an approach that captures data- and modelinduced changes in the expected value and variability of estimates. Easa et al. (1996) 
offer a reliability-based model which predicts thermal cracking of pavements and relates it to cold winters, spring thaws, and daily cyclic thermal loading.

\subsubsection{DECISION SUPPORT FRAMEWORKS/SYSTEMS FOR INFRASTRUCTURE INVESTMENT}

The literature review resulted in many examples of tools and support systems for infrastructure investment decisions. Salem et al. (2003) derived an approach for estimating life cycle costs and evaluating infrastructure rehabilitation and construction alternatives from probability theory and simulation application. This model mainly took into account uncertainties related to the condition of the infrastructure alternative (pavement condition, etc.)

The World Road Association (PIARC) offers HDM-4 for the analysis of roadway management and investment alternatives. The system has been used internationally to evaluate road projects, budget scenarios, and roadway policy options. HDM-4 has functionality similar to HERS-ST, with a more detailed set of pavement models. However, the system does not use HPMS data as an input, and has not been implemented in the U.S. (NCHRP 2009).

FHWA's HERS-ST, the state version of the federal HERS program, uses HPMS data to predict highway investment needs and measures. The system simulates both pavement preservation and highway capacity expansion needs. FHWA itself uses a federal version of HERS for developing its biennial report on the conditions and performance of U.S. highways, bridges, and transit (FHWA 2011; NCHRP 2009). 
FHWA's National Bridge Investment Analysis System (NBIAS) is designed for modeling bridge investment needs at the national level. FHWA uses NBIAS in conjunction with HERS when preparing the C\&P Report, and has recently made a number of enhancements to the system to facilitate state use. The system uses a modeling approach originally adapted from the Pontis BMS to predict bridge preservation and functional improvement investment needs (NCHRP 2009).

The Multi-Objective Optimization System (MOOS) network-level model is a spreadsheet tool for bridge investment analysis. The system uses data on work candidates generated separately to project future conditions and performance, given performance and/or budget constraints and objectives. The tool supports use of a multi-objective approach, but requires extensive data to run, to be specified for each individual bridge using the MOOS bridge-level model (NCHRP 2007).

AssetManager NT, developed by the NCHRP Project (NCHRP 2005) and now released through AASHTO, is an investment analysis tool designed to integrate data from other investment analysis and management systems. It takes analysis results generated by systems such as HERS-ST, NBIAS, and agency management systems as inputs, and uses this information to show performance measure results over time for different funding scenarios.

In addition to the systems described, a number of agencies have developed their own investment analysis approaches, frequently using spreadsheets, to support the process. The Alaska Department of Transportation and Public Facilities and Michigan DOT are two examples of agencies that have developed spreadsheet approaches. Other agencies have developed their own cross-asset analysis systems. The New Brunswick 
Department of Transportation has recently adapted the Remsoft Spatial Planning System (RSPS) to perform strategic analysis of its pavement and bridge investment needs. The RSPS, however, is a suite of tools originally designed for developing long-term forest management plans (NCHRP 2009).

\subsubsection{GAPS IN EXISTING APPROACHES}

The underlying problem with the single-objective cost benefit models is that they attempt to assign weights to concepts, such as lives lost, economic benefit to the state, and accessibility, in order to translate them into monetary units. As a result, the solutions to these types of models tend to be unstable and lacking in credibility. Small changes in the values of input parameters often lead to significant changes in the optimal maintenance program. On the other hand, multi-objective risk-based approaches (including operational, economic, social, and environmental risks) connected to urban drainage failures are available in the literature and have sometimes been tested in real cases; however, they are quite often limited by insufficient system knowledge which is needed to evaluate the possible consequences of failure, the transition from reliable systems to failure-prone systems, or failure evolution paths and criticality of the system.

\subsection{DECISION PARAMETERS INFLUENCING INFRASTRUCTURE}

\section{MAINTENANCE INVESTMENT DECISIONS}

As discussed earlier, there are some important decision parameters attached to the

investment. These include strategic importance of the infrastructure, socioeconomic contribution, infrastructure utilization, and physical condition. The following text 
presents an account of the importance of considering these infrastructure maintenance investment decision parameters, as is argued in the current literature and publications.

\subsubsection{STRATEGIC IMPORTANCE}

A strategic approach to infrastructure asset management provides a better understanding of how to align the asset portfolio so that it best meets the service delivery needs of customers, both now and in the future (LGV 2004). The need for a strategic and integrated approach has slowly gained attention. For example, Too et al. (2006) reviewed some of the current asset management practices by government agencies in Australia and found that despite the different frameworks adopted in the practice, each advocates a strategic approach. The American Association of State Highway and Transportation Officials (AASHTO 2002) similarly echoed that asset management represents a strategic approach to managing infrastructure. Humphrey (2003) has also stressed that the role of asset managers (infrastructure managers) should be to focus on asset strategic importance in decision making. An infrastructure's strategic importance is one of the key factors in corporate strategy and should thus be considered when determining the outcomes of maintenance investment decisions.

\subsubsection{SOCIOECONOMIC CONTRIBUTION}

From the standpoint of the human environment, infrastructure projects, as "public works" projects, assist in maintaining, improving, or otherwise changing the economic condition, social well-being, and health and safety, as well as the lifestyles of humans. In modern infrastructure planning, social impacts should be considered throughout the entire process by which projects are identified, planned, analyzed, reviewed, authorized, and 
implemented (Goodman and Hastak 2006). Kaganova and Nayyar-Stone (2000) indicate that public property was commonly treated as a public good until the 1980 s. There was no systematic consideration of the optimization of use or financial performance of public property (infrastructure) in order to maximize the profitability of the assets; only the capital costs of new public projects, rather than the ongoing performance of the assets, were of concern. In addition, local government does not usually acknowledge any such income generated from infrastructure assets through socioeconomic factors (Lemer, 1999). This is because the type of social "revenue" generated by infrastructure assets is typically indirect. Such income might be identified, for example, from a road improvement or water-and-sewer extension that enhances property values, which in turn leads to higher property tax revenues. Higher sales tax receipts might result from infrastructure investments that enable the development or expansion of retail and entertainment activities in a downtown or suburban area. Higher income tax revenues can be achieved when infrastructure improvements facilitate the efforts of local industry to expand its workforce, increase its productivity, and compete more effectively by controlling its costs (Hanis et al. 2011). However, in the early 1980s, a new vision in managing public infrastructure assets developed, which involved treating public assets as productive and potentially capable of showing financial return. Thus, socioeconomic factors play a vital role not only in terms of providing a qualitative improvement to the life of the infrastructure user, but also in generating monetary benefits out of the infrastructure asset. Maintenance investment decisions, therefore, also have the impact of such socioeconomic factors at the macro level of decision making. 


\subsubsection{INFRASTRUCTURE UTILIZATION}

Infrastructure use is directly related to its operational performance. Performance measures of operational effectiveness are used in a planning and systems engineering context to prioritize projects, provide feedback on the effectiveness of long-term strategies, refine goals and objectives, and improve processes for the delivery of transportation services. Performance measures in planning are principally used in reporting trends, conditions, and outcomes resulting from transportation improvements (NCHRP 2003). Performance measures should describe not only the physical assets' condition, but also how assets are serving their intended functions with respect to comfort, convenience, safety, and service (NCHRP 2006). One of the basic uses of performance measures is to help evaluate different options in the resource allocation process, such as for determining how to prioritize different investments and/or comparing the impact of different funding levels (NCHRP 2009). Therefore, measurement of the usage improvement is an important aspect of evaluating alternatives, resource allocation, and infrastructure investment in decision making.

\subsubsection{PHYSICAL CONDITION}

Data collection and processing for condition assessment is required to determine the need for the cost-effective leveraging of the technology used to provide information on the condition of maintained features necessary for effective maintenance management. The departments responsible for infrastructure management regularly assess the current condition of the infrastructure asset. The New York State Department of Transportation (DOT) tracks multiple technical measures related to bridge condition, such as the bridge 
condition index and maintenance condition index. Furthermore, the Michigan DOT and local transportation agencies are members of an Asset Management Council; one of the responsibilities of this council is to report infrastructure conditions in a consistent way (NCHRP 2006). Although the use of current condition data is a regular feature of investment decision making, limited aspects of condition data are usually covered, especially at macro-level investment decision making, as depicted in the New York State DOT example. The Florida Department of Transportation believes that the asset management concepts of data-supported decision making, management systems, strong relationships between condition and performance, and an emphasis on trade-off and investment analysis are integral components of daily business (NCHRP 2006). The Ohio DOT's districts' budgets are driven by the condition of the assets for which they are responsible (Cambridge Systematics 2007). This is how quality condition data should support the decision-making process. Thus, if resources are not allocated according to condition data, the decision-making process is not performance-based (Cooksey 2011).

The following section will provide a brief review of the analytical tools, techniques, and financial concepts that will be used in modeling the proposed framework of this research. This includes an account of Multi-Attribute Utility Theory (MAUT) and the Markov Decision Process (MDP).

\subsection{MULTI-ATTRIBUTE UTILITY THEORY (MAUT)}

A utility function is basically a mathematical model or representation of the preferences. It can represent preference of a decision maker called utility function. This representation can then be included into an overall decision analysis framework to 
analyze the decision based on the set preferences. Developing a utility function helps in judging subjective matters involved in an overall decision analysis. Every decision maker can have his or her own preference for the decision under consideration. The preference signifies its attitude towards the decision under consideration, termed as risk attitude. If the utility function is represented in a graphical form, it will provide clear insight into the risk attitude of the decision maker. Figure 2.1 shows three possible risk attitudes. A convex (opening upward) utility curve indicates a risk-seeking behavior. Concavity in the utility curve implies that decision maker is risk-averse, while linearity will symbolize the risk-neutral behavior of a decision maker (Clemen 1996).

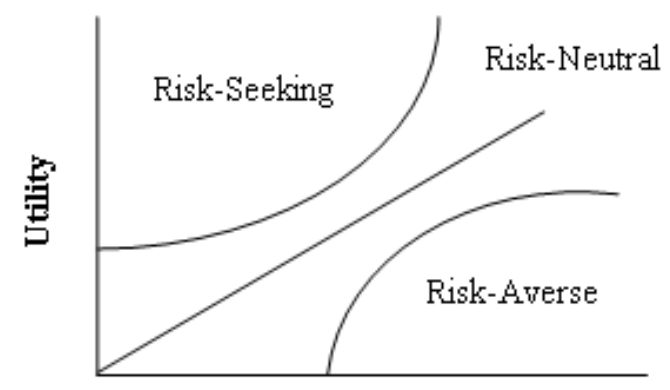

Attribute Value

Figure 2.1: Risk Attitudes

A utility function based on a single attribute or a decision parameter is termed as single-attribute utility (SAU) function. However, when there is more than one parameter or attribute that defines a decision under consideration, it becomes necessary to incorporate all of the parameters together in to a multi-attribute function (MAUF) to make a better decision. Multi-attribute utility theory can be used in this regard. MAUT is a mathematical framework that analyzes and quantifies choices for decision problems 
that involve multiple competitive outcomes (Wu et. al 2012). MAUT is an extensively used decision tool utilized for ranking of alternatives for probable consequences according to the decision maker's preferences (Gharaibeh et al. 2006). It is based on the hypothesis that every decision maker tries to optimize a function which aggregates all of their points of view. The advantage of using MAUT is that it quantifies decision maker's preferences for a decision and has enough flexibility to be combined with other optimization methods to generate optimal solution(s) (Wu et. al 2012). There are basically two approaches for defining the models to develop a multi-attribute function, i.e., the additive model and the multiplicative model as defined by Keeney and Raiffa (1976). Describing the details of both of the models is beyond the scope of this dissertation. However, Keeney and Raiffa (1976) provide extensive details on it. Furthermore, the procedure defined for the development of Integrated State Rating (ISR) in section 5.2.2.3 will provide some of the mathematical details on developing MAUF.

Various researchers have utilized MAUT either as the whole or part of decisionmaking models for asset maintenance and rehabilitation and budget allocation. Mohan and Bushnak (1985) discussed the procedure for using multi-attribute utility theory to optimize the decision maker's utility or satisfaction for social factors or attributes, such as safety and quality in pavement rehabilitation decisions. Park (2004) applied MAUT with uncertainty to assess the seismic rehabilitation of structural systems. Rahman and Zayed (2009) used value-additive multi-attribute theory for determining the condition index of a water treatment plants component, considering combining technical, physical, environmental, and operational aspects. Gharaibeh et al. (2006) defined a decision methodology for allocating funds across transportation infrastructure assets. 


\subsection{MARKOV DECISION PROCESS (MDP)}

The Markov decision process is based upon the Markov property that states that "the effects of an action taken in a state depend only on that state and not on the prior history." (Thodore J. Sheskin). An example of such a scenario could be that of the probability that it will rain tomorrow. We might consider that such a probability only depends on whether it is raining today but not on the weather yesterday. The idea of a Markov process, as described by Jordaan (2005), is sometimes also summarized in the statement "Knowledge of the present makes the future independent of the past."

Mathematically, the Markov decision process results in the generation of a sequence of states (s) and a sequence of rewards (r) under a set of probable actions (a). The transition of state from one to the other caused by an action is governed by the transition probabilities $(t)$. The criterion that defines a set of actions for all of the states is called policy. The policy is assumed independent of time (stationary) when the planning horizon is infinite; the main objective of the decision process is to maximize the gain, or expected reward per period (Thodore J. Sheskin). The following analytical example explains the working of a Markov Decision Process (MDP).

Let us assume that a decision scenario is one involving an infrastructure that can have three states: $S_{0}, S_{1}$ and $S_{2}$. The relationship between the states is such that $S_{2}>S_{1}>$ $\mathrm{S}_{0}$. If no action is applied to the system, there exists a chance that the state of the infrastructure may attain a lower-level state from a higher state. It means that the infrastructure may change its state to $S_{1}$ from $S_{2}$ or $S_{0}$ from $S_{1}$. The state change would be

governed by transition probabilities (t) and there still would be some rewards (r) out of each state change possibility, but those rewards will be negative reward, or in other 
words, penalty. The explained scenario is depicted in figure 2.2 .

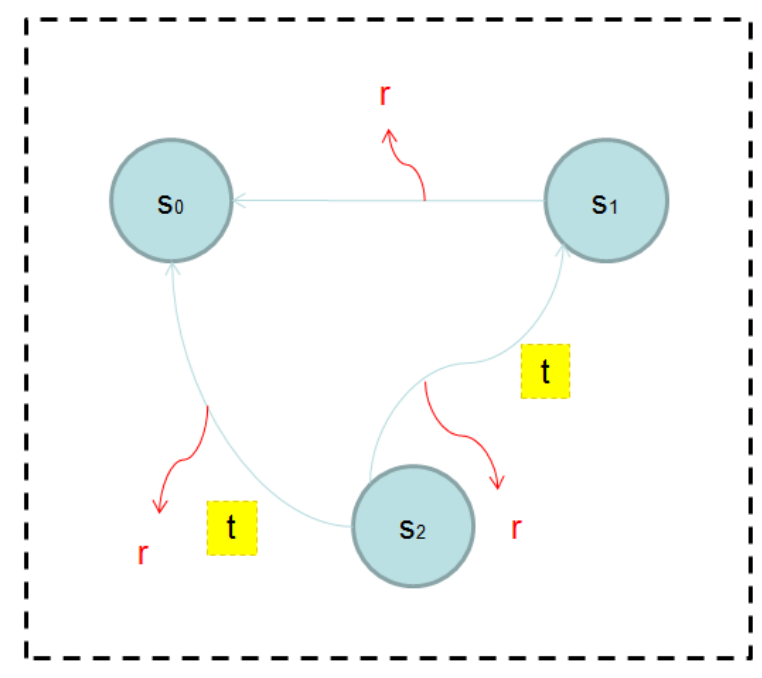

$\mathrm{S}_{2}>\mathrm{S}_{1}>\mathrm{S}_{0}$

Figure 2 2: Markov Decision Process (no action)

Let us assume the same scenario, except that this time, there is an action $\mathrm{a}_{1}$ applied to the system from the set of possible actions. In this case, the infrastructure may improve its state due to action from $S_{0}$ to $S_{1}$ or from $S_{1}$ to $S_{2}$. There is also a possibility that the infrastructure changes state from $S_{0}$ to directly $S_{2}$ depending upon the characteristics of the action applied. The state change would be governed by transition probabilities ( $\mathrm{t}$ ), and there would be positive rewards (r) out of each state change possibility. The explained scenario is depicted in Figure 2.3. 


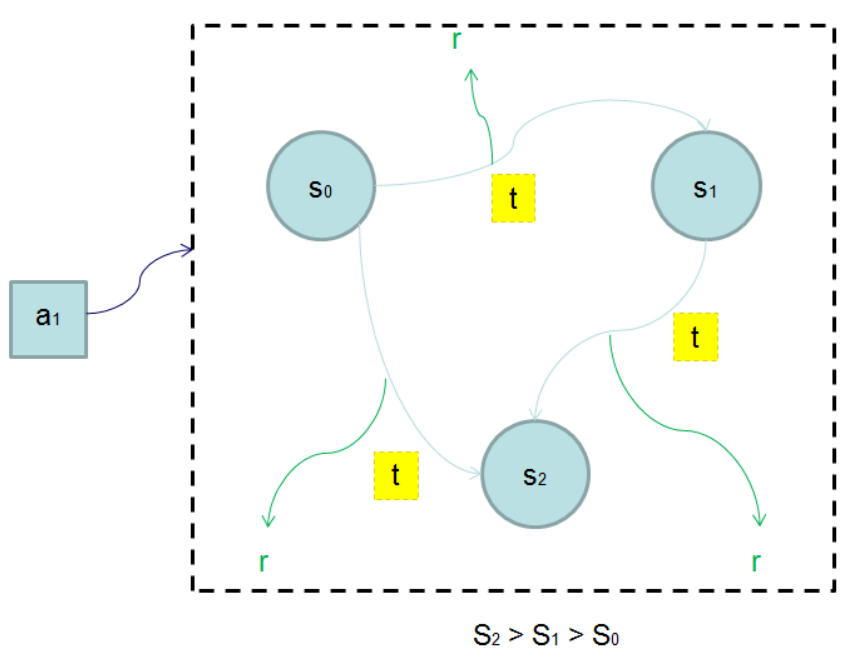

Figure 2.3: Markov Decision Process (Action $\mathrm{a}_{1}$ )

Once the infrastructure has changed its state from the current state (say, $\mathrm{S}_{0}$ ) to a higher (better) state, the current state $\left(\mathrm{S}_{0}\right)$ will no longer be considered in the next step of MDP. Therefore, the system would consist of two states, $\mathrm{S}_{1}$ and $\mathrm{S}_{2}$, and transition between them would only be considered both in case there is no action or another action $\mathrm{a}_{2}$ from the set of actions, as shown in Figure 2.4.

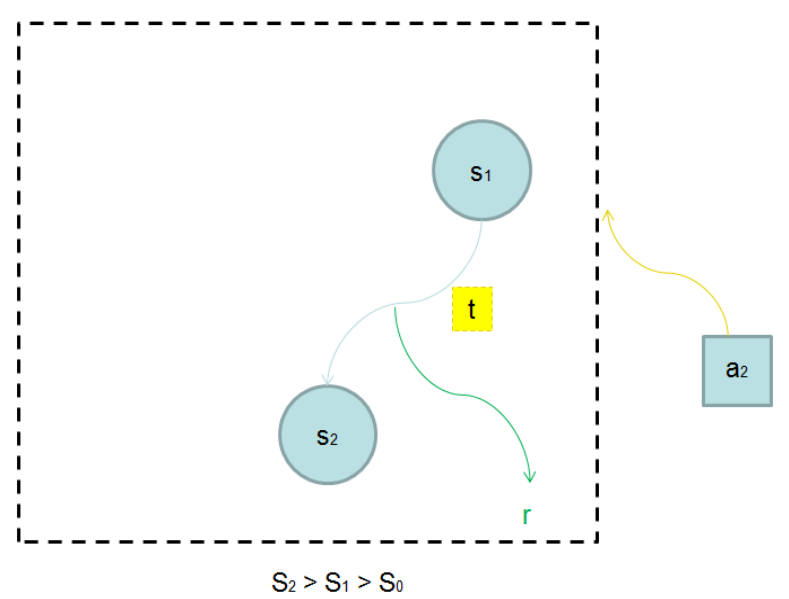

Figure 2.4: Markov Decision Process (Action $\mathrm{a}_{2}$ ) 
The Markov Decision Process (MDP) is derived from Markov-Chain models. The Markov-Chain models are suitable as a predicting mechanism for performance deterioration of infrastructure. They have the ability to account for time dependence and uncertainty of deterioration, maintenance and operations and initial condition, making them perfect for network-level analysis (Morcous and Lounis, 2005). Markovian chains have been used successfully in many state highway agencies to predict the pavement and bridge condition and estimate the cost of such maintenance requirements during the life cycle of the asset. Two nationwide projects in the United States, PONTIS and BRIDGIT, have implemented the Markovian approach to model the impact in the condition of bridge elements as a result of implementing different maintenance policies (Kalmlesh 2009).

\subsection{CHAPTER SUMMARY}

This chapter provided an extensive literature review of the infrastructure maintenance investment decision making concepts, existing decision support systems, and gap analysis in the existing approaches. It also provided detailed account of the factors influencing maintenance investment decision making. It further reviewed the fundamental concepts of the analysis tools, techniques, and theories that will be utilized for developing framework in the proposed research. The following chapter will describe in detail the current state-of-the-practice of the maintenance investment decision-making based on the findings and analysis of a questionnaire survey conducted at DOT's districts levels throughout the U.S. 


\section{CHAPTER-3: CURRENT STATE-OF-THE-PRACTICE}

\subsection{INTRODUCTION}

Previous chapters provided the basis of the research - mainly the research thesis, conceptual basis and the research methodology and literature review related to various aspects of this dissertation. However, it was thought necessary to assess the existing state-of-the-practice of the decision makers or the decision-making entities involved in the infrastructure investment decision making. This was necessary so that the study could be broad enough to incorporate the points of view of concerned parties - in this case, the DOT maintenance offices for the development of decision support framework. This chapter provides valuable information on the current state-of-the-practice of infrastructure maintenance and rehabilitation investment decision-making and presents the results of the survey conducted to address the aforementioned idea. The analysis is based on responses from surveyed DOT districts throughout the United States. The findings of the survey have been utilized to provide research thesis justification, current investment practices, and performance assessment practices.

\subsection{QUESTIONNAIRE DEVELOPMENT}

An online questionnaire targeting district maintenance offices of state departments of transportation was prepared. The questionnaire consists of several questions covering issues related to infrastructure maintenance, repair and rehabilitation investments. The questions focused on the issues of current investment practices such as: investment decisions parameters, current situation and practices of infrastructure 
maintenance funding, constraints and benefits considered in the process of investment decision-making. Furthermore, questions were also asked related to the performance assessment practice. Once the questionnaire was developed, expert opinion was taken into account in order to finalize the questionnaire's content so that the most appropriate information to the research scope and objectives could be elicited. The questionnaire was designed in a user-friendly online format using Qualtrics ${ }^{\mathrm{TM}}$. Prior to sending the online survey to the participants, the response time and other technical features of the survey were tested through pilot surveys.

\subsection{SURVEY IMPLEMENTATION}

The survey was conducted with the professionals involved in the decision-making process in the maintenance divisions/departments/sections at the district level of state departments of transportation throughout the U.S. The professionals were invited to participate in the survey through e-mail. The invitation e-mail comprised the brief introduction of the researcher along with the short abstract of the research in order to create a better understanding of the research among the survey participants. Furthermore, the e-mail also provided the web link to the survey. After 15 days from the initial survey invitation, follow-up e-mails were sent to the respondents who did not attempt the survey in order to encourage them and increase the response rate. The online conduct of the survey allowed reducing the survey responding time and better maintenance of the responses. A general draft of the invitation e-mail and the online questionnaire are attached in Appendix A. 


\subsection{SURVEY RESPONSE CHARACTERISTICS}

Researchers suggest that questionnaire surveys are the most frequently used research method, specifically for psychological, management and marketing research (Woodside 2010). The questionnaire method is based on the logic that the responding individual represents not only his/her own thinking process but also that of others who are involved in the decision process over the span of the respondents' experience. The usual reported response rate to such studies is typically in the range of $8 \%$ to $30 \%$ (Woodside 2010). Table 3.1 provides details of the responses for the survey. Figure 3.1 shows a map of the U.S. that provides an idea of the responses' geographical coverage.

Table 3.1: Response Details of Survey

\begin{tabular}{|l|c|}
\hline Total Survey Requests & 244 \\
\hline Total Number of Valid and Complete Reponses & 63 \\
\hline Response Rate (\%) & $26 \%$ \\
\hline Number of States that Submitted at Least One Response & 26 \\
\hline
\end{tabular}

\subsection{ANALYSIS AND DISCUSSIONS}

The following sections and subsections present analysis and discussion based on survey responses to elicit information about the state-of-the-practice. 


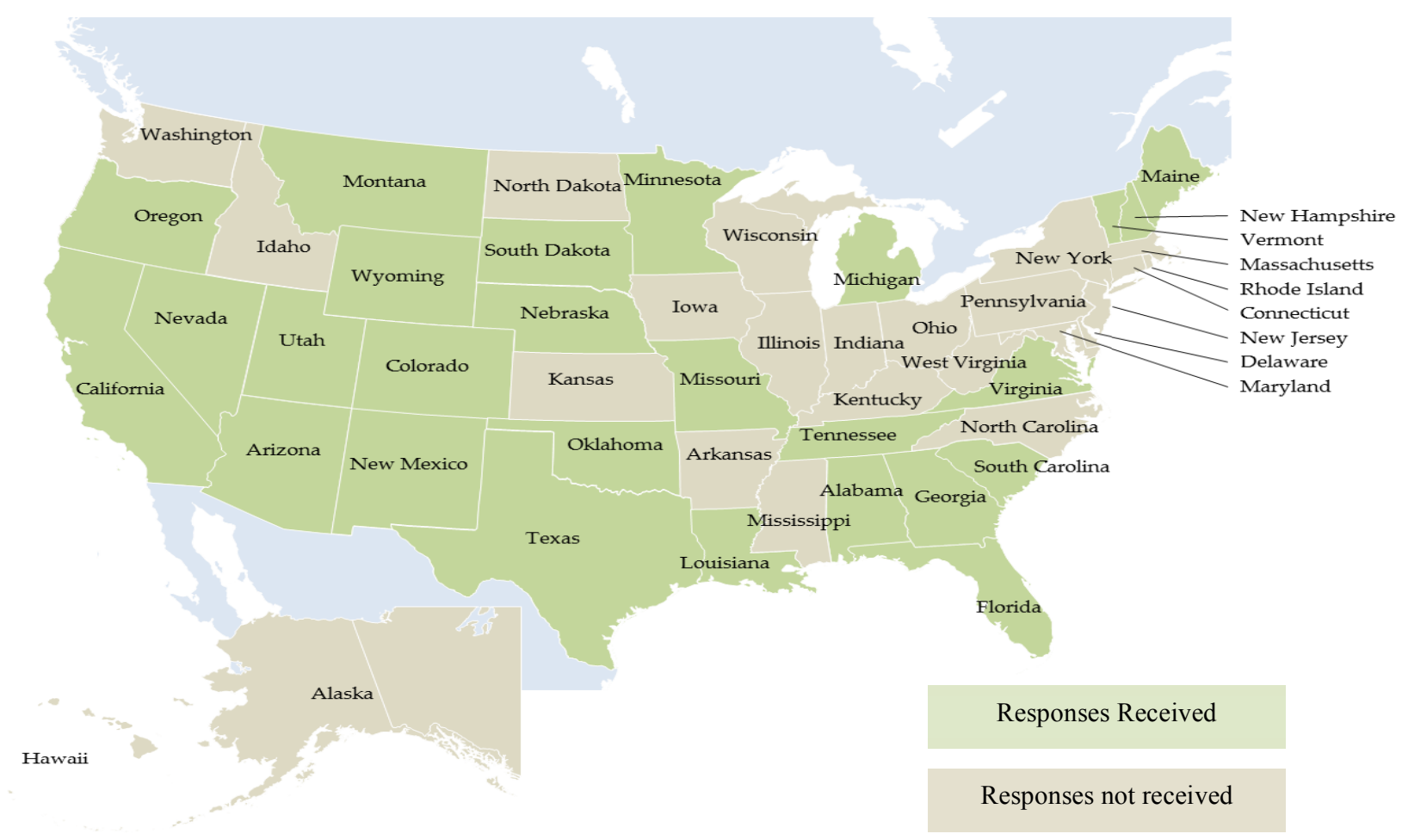

Figure 3.1: Geographical Coverage of Survey Reponses

\subsubsection{RESEARCH THESIS JUSTIFICATION}

The research thesis is based on the two major aspects that should be considered for infrastructure maintenance investment decision making. These include multiple decision parameters and budgetary constraints. The districts were asked regarding their current consideration of multiple decision parameters, constraints considerations and existing funding gap. The following subsections provide discussions and inferences drawn based on responses to provide research thesis justification.

\subsubsection{DECISION PARAMETERS' CONSIDERATION}

The respondents were asked whether they consider multiple decision parameters (condition, socioeconomic contribution, infrastructure utilization and strategic 
importance) while implementing particular infrastructure management strategy, i.e., preventive/corrective maintenance, rehabilitation and replacement. Figure 3.2 shows a bar chart depicting the percentages of districts that consider particular decision parameters for each of the aforementioned strategies.

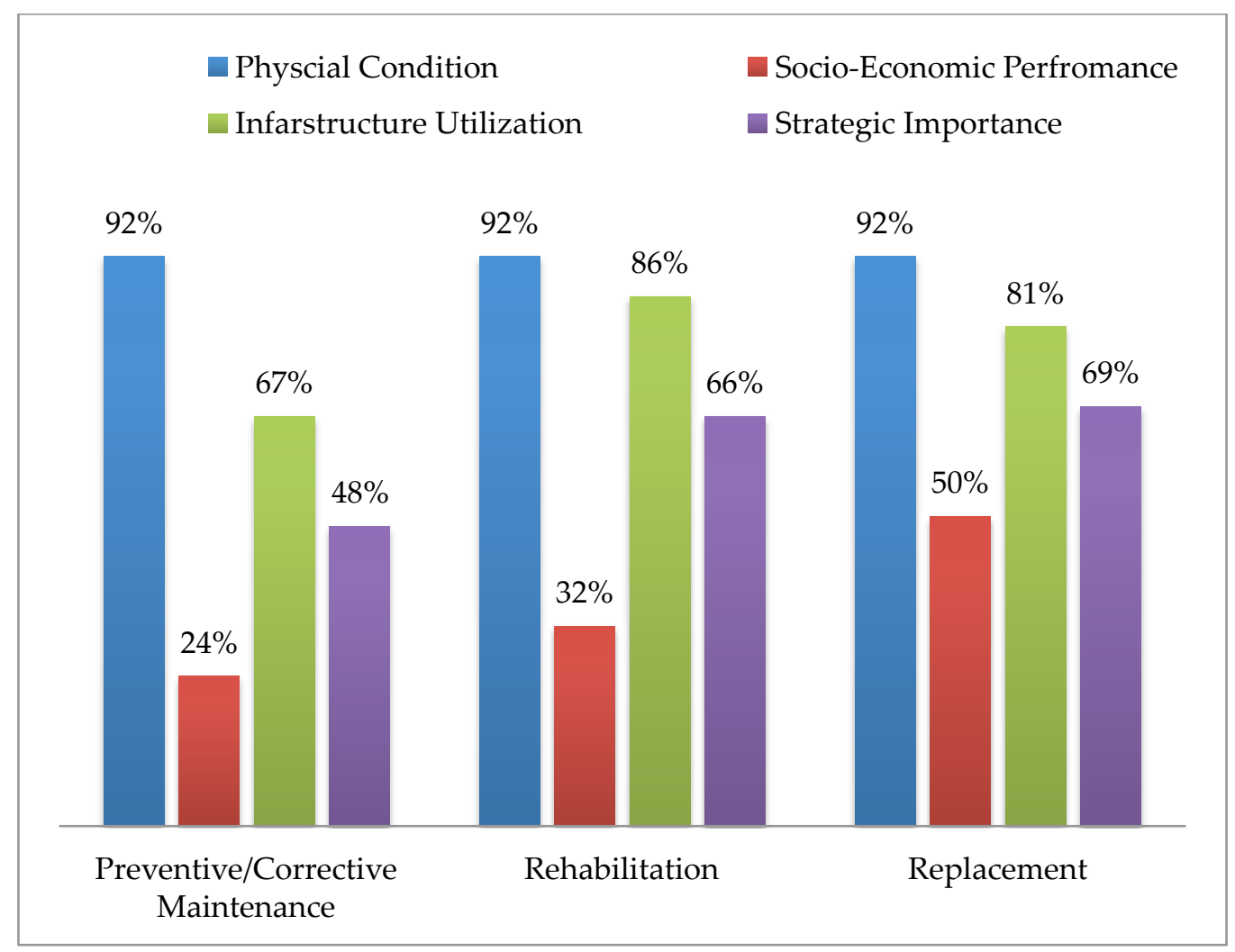

Figure 3.2: Decision Parameters' Consideration for Different Maintenance Strategies

The results show that majority of the districts-i.e., $92 \%$ - consider the physical condition of the infrastructure as the major decision parameter. The infrastructure utilization is the other significant decision parameter that is being considered for preventive/corrective maintenance by $67 \%$ of the districts, for rehabilitation by $86 \%$ of the districts and for replacement by $81 \%$ of the districts. The consideration of the other parameters-i.e., strategic importance and socioeconomic performance-is not that 
significant. However, it is pertinent to mention here that districts take into account strategic importance to certain extent for each of the maintenance strategies, i.e., preventive/corrective maintenance (48\%), rehabilitation (66\%) and replacement $(69 \%)$. However, based on the experts' (decision makers') opinion, so far there is no clear agreement regarding the definition or scope of strategic importance for the districts.

It is evident from the above analysis that most of the districts consider physical condition of the infrastructure and infrastructure utilization as the major decision parameters for all three maintenance strategies. For utilization, generally average daily traffic and level of service are the only considerations. Both of these parameters are objective in nature from mathematical and measurement perspectives. Therefore, it confirms the assumption that drives the basis of the problem statement and research thesis that there is lack of integrated consideration of decision parameters that are defined for this research.

\subsubsection{EXISTING FUNDING GAP}

The districts were asked regarding the average funding deficit (gap) that exists for infrastructure maintenance projects in their districts, annually, as a percentage (\%) of the amount required for such projects. The pie chart in Figure 3.3 shows the percentage of the districts lying in a particular funding deficit (\%) interval. The results show that $40 \%$ of the respondent districts currently have a funding gap of $30 \%$ or more annually as a percentage of the amount required for infrastructure maintenance/repair/rehabilitation projects. This shows that currently the maintenance decision makers have to make investment decisions under significant financial constraints. 


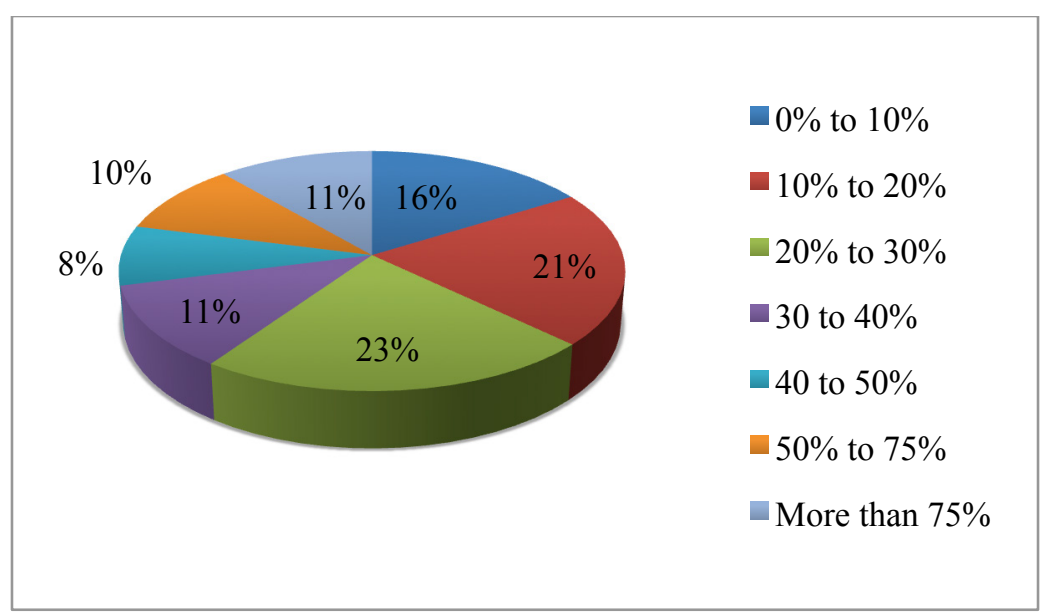

Figure 3.3: Finding Gap for Infrastructure Management

The above analysis and discussion show that it is necessary to make infrastructure maintenance/repair/rehabilitation decisions under an informed decision support system. Such a system should have integrated consideration of the decision parameters as defined for this research. In addition, it should also be able to consider budgetary constraints due to existing funding gap. This will ensure that the value and benefit of such investments are maximized. Hence, the analysis presented above confirms and justifies the research thesis.

\subsubsection{CURRENT INVESTMENT PRACTICES}

The decision makers were asked several questions in order to assess the current state of practice regarding investment decision making for maintenance projects. 


\subsubsection{ANNUAL SPENDING}

The DOT districts were asked various questions regarding the infrastructure maintenance spending. The survey results show that the majority of the districts-i.e., $51 \%$ - have an annual infrastructure maintenance/rehabilitation spending between $\$ 10$ million and $\$ 50$ million annually. $20 \%$ of the districts spend between $\$ 1$ million and $\$ 10$ million. Another $18 \%$ of the districts spend between $\$ 50$ million and $\$ 100$ million on infrastructure maintenance/rehabilitation programs. Only $8 \%$ of the districts have a spending of $\$ 100$ million or greater, while just 3\% spend less than $\$ 1$ million. The bridge maintenance and rehabilitation projects survey results revealed that, on average, a majority of the districts (82\%) use less than $25 \%$ of their annual infrastructure maintenance/rehabilitation spending on bridge projects.

\subsubsection{ANNUAL PROJECTS}

The districts were asked about the typical number of bridge maintenance/rehabilitation projects undertaken annually. The pie chart in Figure 3.4 represents the distribution of the responses. $37 \%$ of the districts undertake 1 to 5 projects, $29 \%$ of the districts undertake 6 to 10 projects, and $24 \%$ of the districts undertake 11 to 25 projects on annual basis. The remaining $10 \%$ of the districts undertake 26 or more projects annually. The analysis of the responses shows that more than one-third i.e. majority of the districts $(37 \%)$ undertake 1 to 5 projects annually. This leads to an important inference that a decision support system that is capable of analyzing five maintenance and rehabilitation projects both at the project (candidate) and network levels would address the need. 


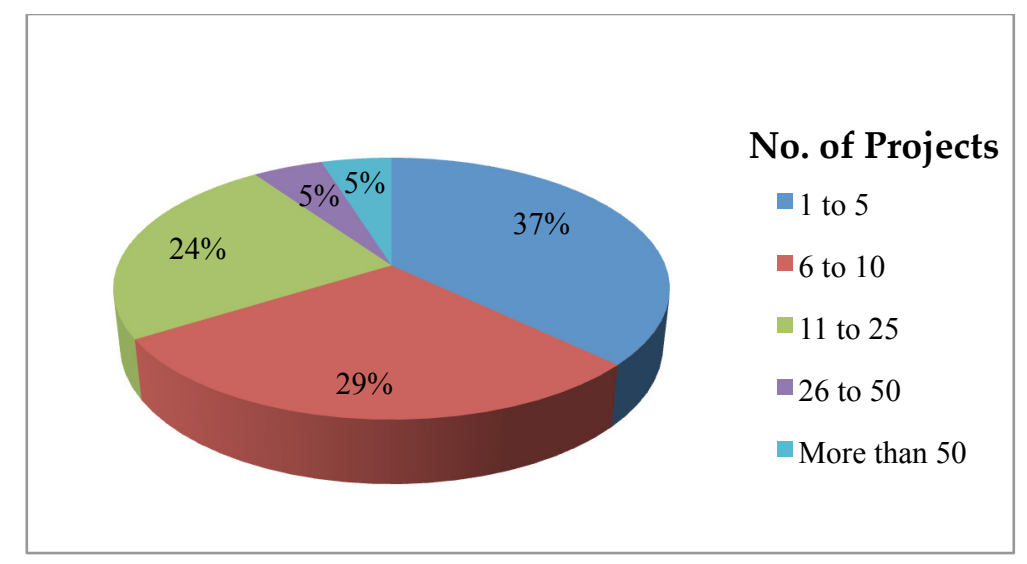

Figure 3.4: Typical Number of Bridge Maintenance and Rehabilitation Projects per Year

\subsubsection{SCHEDULE OF INVESTMENT}

The districts were asked about the frequency of the investment decision-making exercise. A majority of the districts (63\%) take maintenance/repair/rehabilitation investment decisions on annual basis. The districts were also asked about the number of years for which the investment decisions are made or the investments are allocated. The results show that the majority of the districts make allocations for 1 to 3 years $(45 \%)$ and 3 to 5 years $(40 \%)$. The respondents have also mentioned that roadway investments are done for a 1-to-3-year period while structural investments (e.g., bridges) are done for 3to-5-year period. One of the respondents also related this to the size of the program. In that case, for example, a $\$ 30$ million program is scheduled for 3 years ahead on bridges, and $\$ 2-\$ 2.5$ million are spent annually on an as-needed basis. Therefore, it can be concluded based on the response analysis that typically, districts allocate investments each year for a 1-to-5-year period in case of bridge maintenance.

Hence, a decision support framework that can make allocations for a period of up to 5 years can address need. 


\subsubsection{CONSTRAINTS AND THEIR DEFINITION}

The districts were asked about the constraints currently considered for infrastructure maintenance investment decision making. The Venn diagram in Figure 3.5 represents the distribution of the responses.

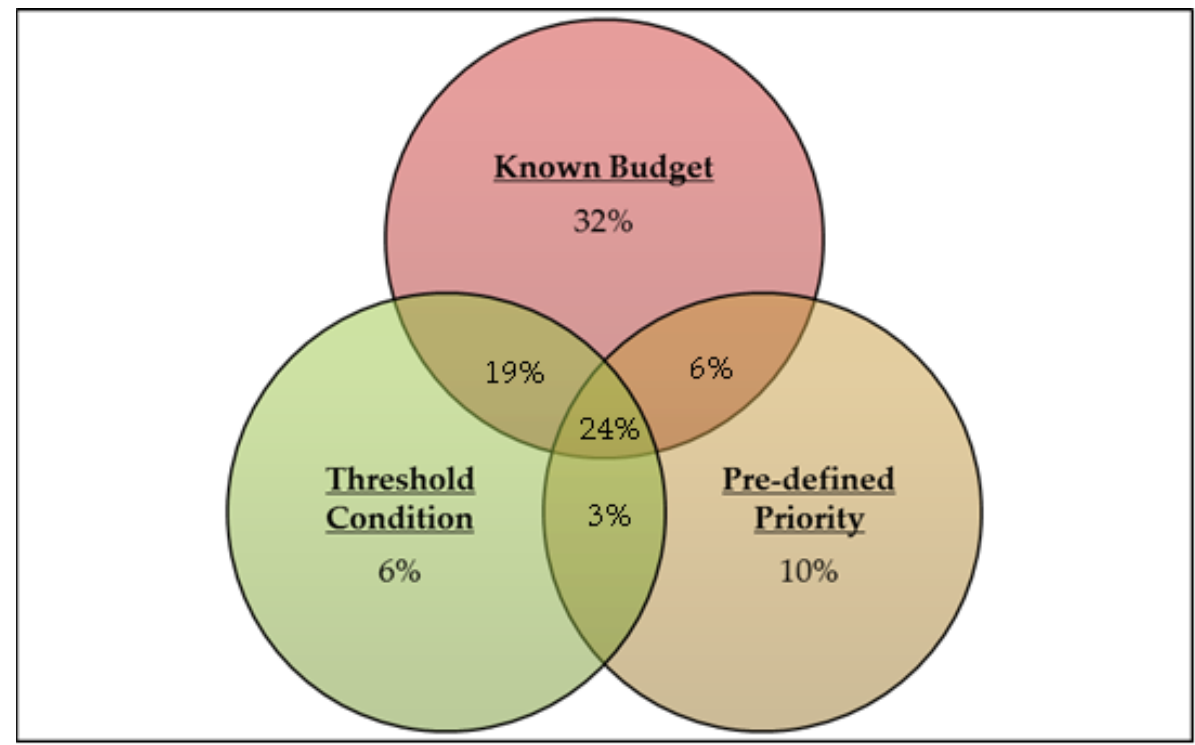

Figure 3.5: Infrastructure Maintenance Investment Decision-Making Constraints

The response analysis shows that $32 \%$ of the districts perform investment decisions under a known budget constraint only. On the other hand, $6 \%$ of the districts have pre-defined threshold conditions as the only constraint, while $10 \%$ have a predefined project priority. There are $24 \%$ of districts that have all three types of constraints for investment decision making. There are $43 \%$ districts that have budget and threshold conditions as the constraints, $30 \%$ of the districts having both budget and predefined project priority as the constraints, and $27 \%$ of the districts having both threshold condition and pre-defined priority as the constraints. 
In overall terms, response analysis shows that $81 \%$ of the districts make maintenance investment decisions for a known budget, $52 \%$ of the districts make such decisions for a known threshold condition, while $43 \%$ of the districts have a pre-defined priority of the infrastructure for investment decision making. These results show that a majority of the districts are currently under budgetary constraints.

DOT districts were further asked about the responsibility of defining the budget constraints. The bar chart in Figure 3.6 represents the distribution of the responses in terms of percentage of agreement with each option.

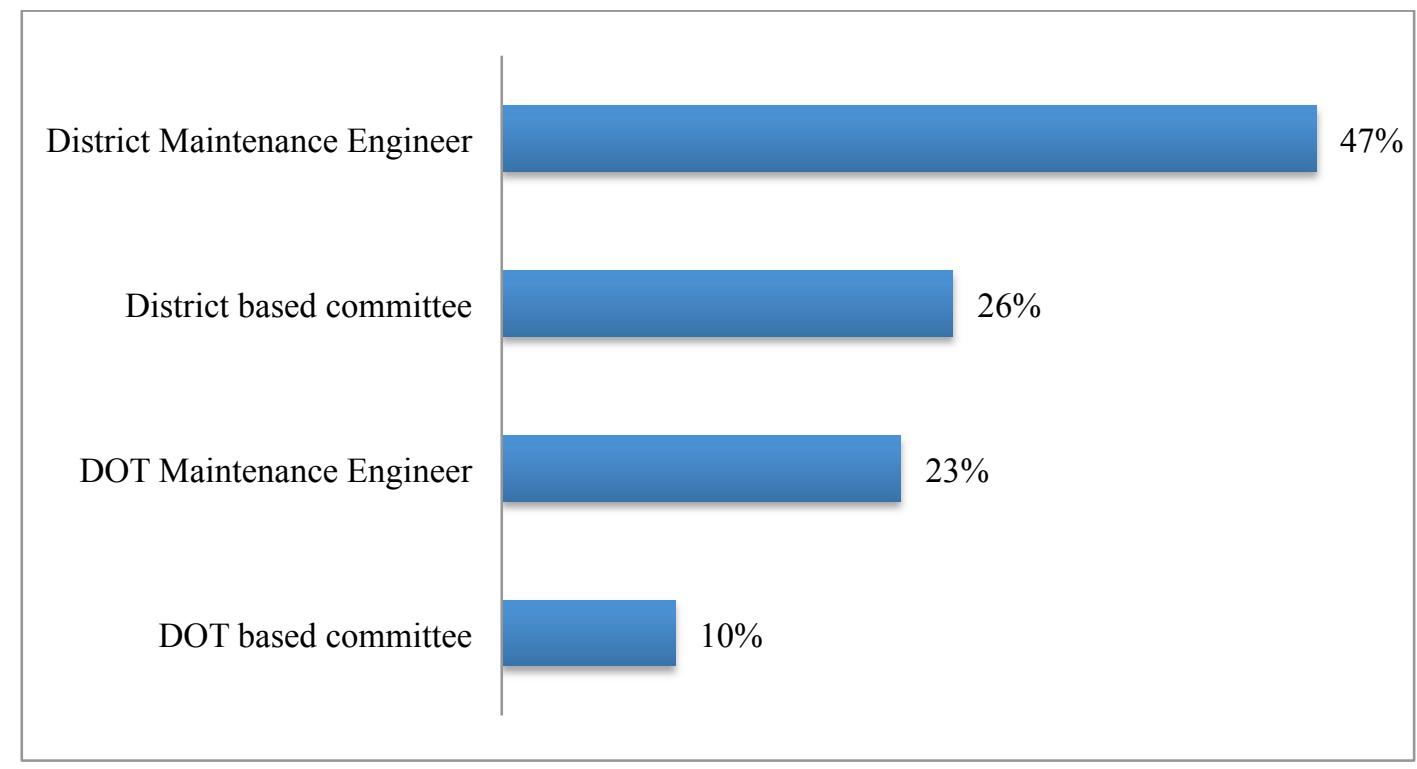

Figure 3.6: Responsibility for Defining Budget Constraints

The response analysis shows that in $47 \%$ of the districts, the district maintenance engineer defines the budget constraints, while in $26 \%$ of the districts; the district-based committee is responsible for defining the budget constraints. On the other hand, $23 \%$ of the districts replied that the DOT maintenance engineer defines their districts' budget limit, while $10 \%$ of the districts have their budget limits defined by a DOT-based 
committee. However, responses indicated fewer occurrences of any combined mechanism between district- and DOT-level personnel and/or committees to define budget constraints.

It is also pertinent to mention that, as per respondents' comments, money coming from different sources has different limits. Projects utilizing district maintenance funds are based on priority and available district funds by the district administrator. On the other hand, statewide funds are budgeted through the statewide design/engineering division. In some districts, limits are set through coordination between the district and central structures divisions. Also, in some districts asset management system drives recommendations, which are than approved by a commission.

DOT districts were also asked about the responsibility of defining the infrastructure threshold conditions. The bar chart in Figure 3.7 represents the distribution of the responses in terms of percentage of agreement with each option.

The response analysis shows that in $46 \%$ of the districts, the district maintenance engineer defines the threshold conditions, while in $36 \%$ of the districts; the district-based committee is responsible for defining the threshold conditions. On the other hand, only $9 \%$ of the districts replied that the DOT maintenance engineer defines their infrastructure threshold conditions, while only $4 \%$ of the districts have their infrastructure threshold conditions defined by a DOT-based committee. However, responses indicated fewer occurrences of any combined mechanism between district- and DOT-level personnel and/or committees to define the infrastructure threshold conditions. 


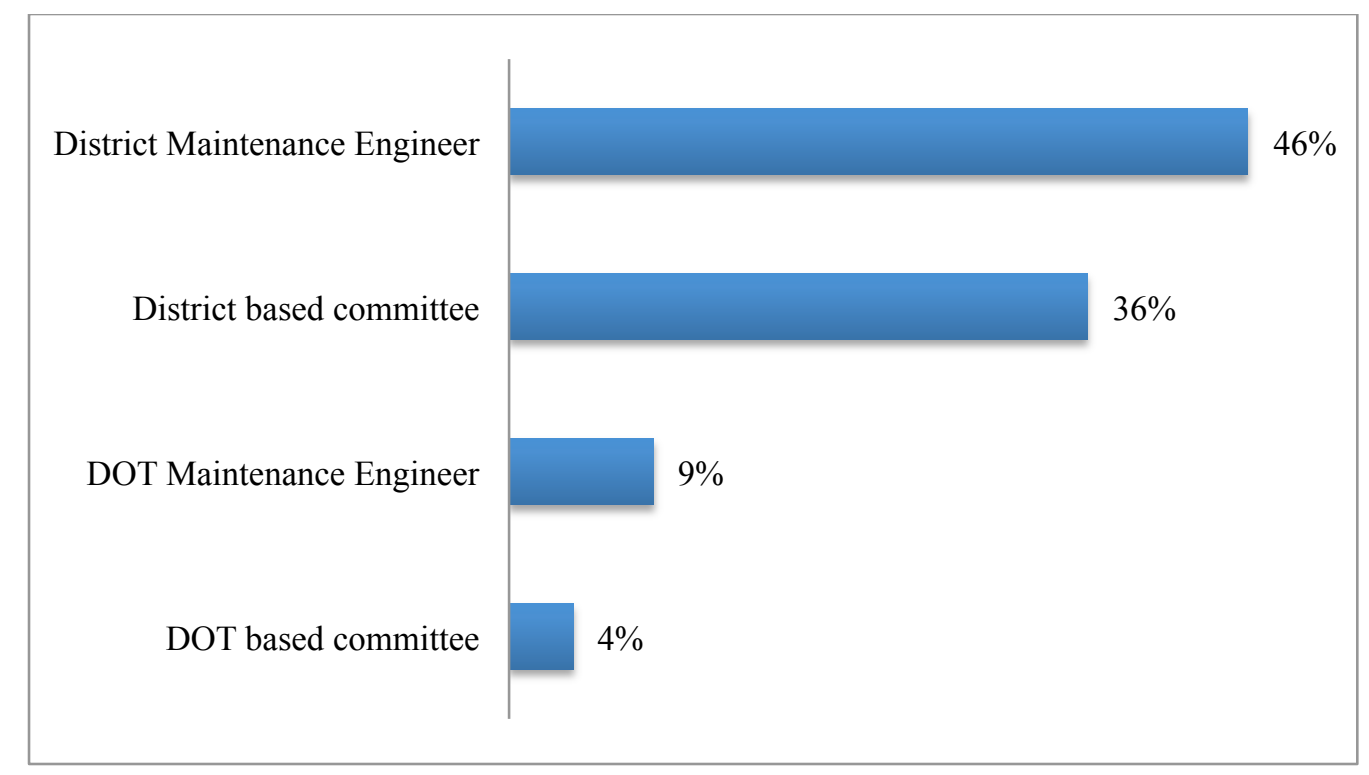

Figure 3.7: Responsibility for Defining Threshold Condition Constraints

Therefore, it can be concluded based on the analysis of the results that budget limits are to be the major common ( $81 \%$ of the districts agreed in overall perspective) and stand-alone constraint (32\%—-see Figure 3.5) while undertaking investment decisions for maintenance of infrastructure. This conclusion also supports the research thesis from the constraint's perspective. Hence, it is worthy to consider the budget constraint in mathematical terms in the proposed framework.

However, the researcher also understands that there has to be certain predefined threshold condition levels while undertaking such decisions. These threshold conditions are mainly set by the district-level decision makers themselves - mainly the maintenance engineer (as mentioned in the discussion above, and see Figure 3.7). Therefore, an assumption can be made that while dealing with the projects' physical condition parameter, the decision makers will also have threshold condition levels under consideration as set by the districts. 
Another indirect conclusion that can be drawn from this assessment is that the investment decision-making group is generally a district maintenance engineer in coordination with a district-based committee; thus, the probable users of the proposed framework can be a decision-making group or committee.

\subsubsection{BENEFITS CONSIDERED}

The DOT districts were asked about the benefits that are considered during investment decision making for infrastructure maintenance. This assessment was necessary in order to understand the current benefit performance factors that are accounted for in investment decision making. It was also necessary to identify potential benefit factors that can be included in the proposed framework. The bar chart in Figure 3.8 represents the distribution of the responses in terms of percentage of agreement with each option.

On a general note, almost all of the benefits are accounted for by the districts for investment decision making. However, the prominent benefits considered are reduced accident risk ( $89 \%$ of districts), benefit of replacement ( $80 \%$ of districts) and benefit of widening (75\% of districts). Less formal mechanisms exists for quantification of such benefits.

In addition, the DOT districts have also identified some other benefits that are or needed to be considered for the investment decision making. These are listed as follows:

- Reduction in the risk of failure

- Benefit to rehabilitee

- Reduced future maintenance cost 
- Benefit of improved rideability

- Delaying deterioration of structural components

- $\quad$ Reduced distressed miles

- Benefit of increased life cycle

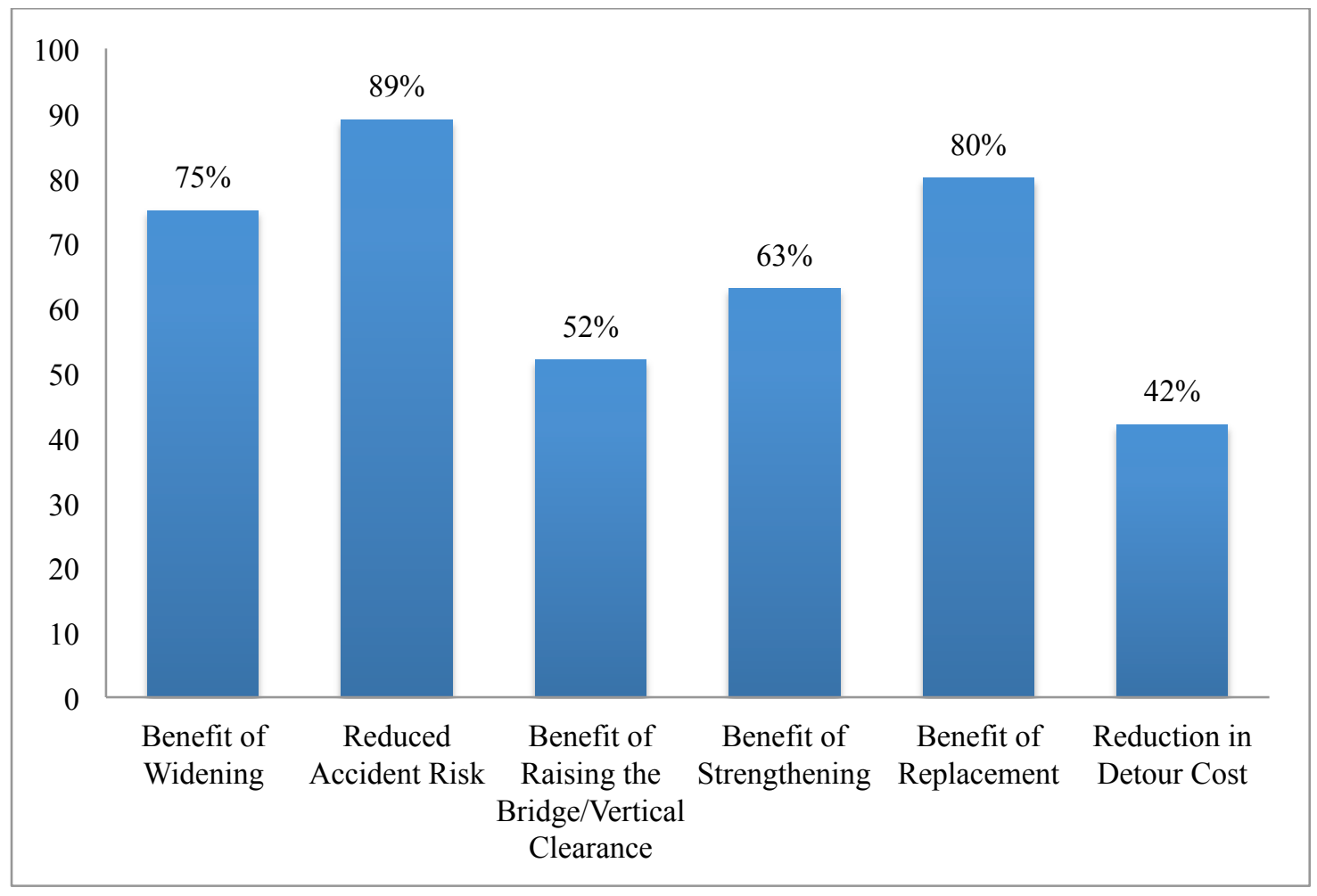

Figure 3.8: Benefits Considered for Infrastructure Maintenance Investment-Decision Making

\subsubsection{PERFORMANCE ASSESSMENT PRACTICES}

The DOT districts were asked about the performance assessment practices. The main purpose of the query was to elicit information regarding the current means of measurement, analysis and reporting of the decision parameters defined for the scope of this research. Those, as stated in earlier chapters as well, include condition, infrastructure utilization, socioeconomic contribution and strategic importance of the infrastructure. 
The question was kept as an open-ended descriptive response question. This was important to procure maximum information. The conclusions drawn are discussed in the following subsections.

\subsubsection{PERFORMANCE MEASUREMENT}

The responses to the question indicated that many of the DOT districts use Pavement Management Information System (PMIS) to measure the needs for rehabilitation and to measure performance of program as far as the road infrastructure is concerned. This system mainly focuses on the condition performance of the roadways. The decision-making process is generally supported by pavement condition ratings such as ride index that is referred to as Ride Comfort Index (RCI), lane miles of distressed miles in terms of Surface distress index (SDI), Adequacy Index (SAI), and a composite of the previous indices, the Pavement Quality Index (PQI). Rutting, skid resistance and cracking are also some of the parameters used to define the condition performance of the roadways. Some of the districts also mentioned that they perform an annual random generated review/assessment of a one-mile segment on each road to assess the performance.

The districts also mentioned various ratings and systems that are utilized to depict performance of the bridge infrastructure. These include bridge condition states and condition ratings. Three types of ratings are mainly used. These include Bridge Health Index (BHI), Sufficiency Rating (SR) and National Bridge Inventory Rating (NBI). Structural deficiency is another way of showing the bridge's performance. The DOT districts also identify the bridges that have become functionally obsolete. 
As far as the decision parameters other than condition ratings/indices are concerned, it was found that, in general, average daily traffic (ADT) or annual average daily traffic (AADT) and the level of service (LOS) are the common decision parameters. These parameters are specially utilized while conducting performance analysis and priority assignment to the infrastructure.

Some other factors that were mentioned are listed in the following Table 3.2, categorized under related decision parameters defined for the scope of this research.

The respondents were additionally asked about how DOT districts account for the strategic importance of an infrastructure. Their response indicates that districts typically get political and public input for projects. They work with local cities and governmental entities to meet their goals and plans, and also work with a planning section to make sure that they are not spending maintenance money on roads that will require rehabilitation and/or reconstruction in near future. However, strategic importance does not receive high importance in the decision-making process for a project. They usually consider that strategic importance only plays a role in replacement funds.

\subsubsection{PERFORMANCE ANALYSIS}

The DOT districts use economic analysis as performance measurement and priority assignment mechanism for making decisions while evaluating potential investments. One of the districts replied that "(since) our focus at the district level is on preventative maintenance - with major rehabilitation and replacement projects coming out of our Structures Division. So our performance measures are focused on cost/benefit 
of maintenance versus structures that are too far deteriorated for 'preventative' measures (those that are on a replacement schedule). Of the remaining structures traffic volumes, length of detour, and return on investment in terms of extending structure life are key factors. Also anything that is causing other sorts of maintenance problems such as spalling concrete, potholes, rough joints are prioritized."

Table 3.2: Decision Parameters Performance Measurement Factors

\begin{tabular}{|c|c|}
\hline Decision Parameter & Factors Used for Performance Measurement \\
\hline Strategic Importance & $\begin{array}{l}\text { - Importance of schools } \\
\text { - Importance of businesses, or other } \\
\text { - } \text { Eublic buildings } \\
\text { - Dergency or evacuation routes } \\
\text { - } \text { routes } \\
\text { - Defense considerations } \\
\text { - Life of infrastructure }\end{array}$ \\
\hline Socioeconomic Contribution & 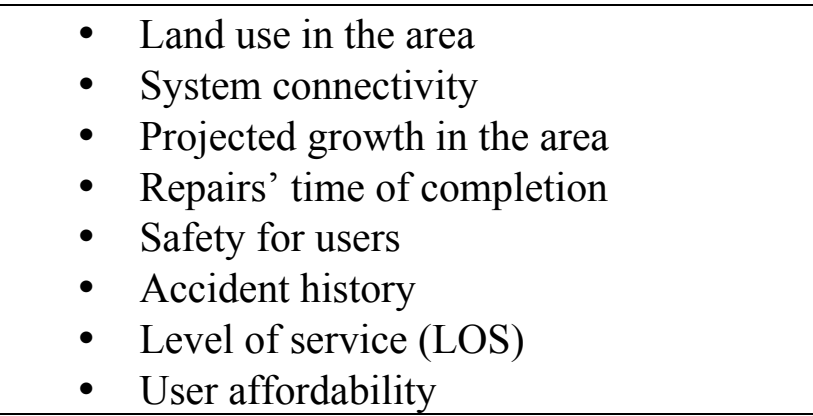 \\
\hline Infrastructure Utilization & $\begin{array}{l}\text { Functional classification of roadway } \\
\text { (Interstate highway, U.S. highway, } \\
\text { state highway, farm to market road, } \\
\text { others) } \\
\text { - System capacity } \\
\text { - Average daily traffic (ADT) or annual } \\
\text { average daily traffic (AADT) } \\
\text { - Percentage of commercial (truck) } \\
\text { traffic } \\
\text { - Percent of lane miles improved }\end{array}$ \\
\hline
\end{tabular}

Certain DOT districts also utilize construction management risk analysis techniques for maintenance investment decision-making. One of the district replied that 
"Pavement Management System Engineering Analysis Process is to assign the most effective treatment to each management section. Decision trees are used to facilitate this process. Decision variables may include; age, AADT (average annual daily traffic), system (functional designation, depth (thickness of all pavements and base layers), type (asphalt cement or Portland cement concrete surface layer), CI (all condition indices, ESAL (18 kip equivalent single axel loads). Pavement Management System pavement treatments are meant as a 'general' remedy for pavement deterioration or failure based on 'network'-level analysis."

\subsubsection{PERFORMANCE REPORTING}

It was also discussed in the text above that DOT districts generally utilize many ratings and indices for the purpose of performance measurement with special reference to condition assessment. Those ratings and indices are reported in various modes for the purpose of decision making and performance reporting. The DOT districts mentioned that they utilize the PONTIS program reports as the decision support system. Some of the district also mentioned that they utilize the Structure Replacement and Improvement Needs (STRAIN) Report for bridge related investment decision making.

Some of the districts also use state tracker reports as decision support tool. One of the respondents mentioned that "These are like CEO budget reports, only instead of reporting finances they report results on pre-defined measures. Some areas emphasized for improvement track items like SF deck repair, SF pavement repair, and some other reports track amount of time spent in each activity. I'm an advocate that you must focus your tracking on results." 
Some states also have a web-based reporting mechanism known as a "dashboard." Dashboards are available online as public Web sites that are based on a scorecard reporting mechanism on improvements to certain metrics. The DOT districts use those dashboards (as well as district-level dashboards) as the decision support system.

\subsection{CHAPTER SUMMARY}

This chapter presented findings and discussions on the survey conducted for eliciting information regarding current state-of-the-practice in infrastructure maintenance investment decision-making. The literature review and information from the survey analysis have then been utilized to develop conceptual framework. The next chapter provides details of the conceptual framework. 


\section{CHAPTER-4: CONCEPTUAL FRAMEWORK}

\subsection{INTRODUCTION}

As discussed earlier, the purpose of this research is to develop a prototype decision support framework. The objective of framework is to assist decision makers in defining appropriate maintenance investment plan for candidate infrastructure by considering multiple decision parameters and budgetary constraints. Previous chapters described the importance of multiple decision parameters in maintenance investment decision-making, introduced certain mathematical techniques related to decision-making, and identified requirements to be addressed by the proposed framework based on current state-of-the-practice. The information elicited has been utilized to develop conceptual framework. This chapter describes the developed conceptual framework. Furthermore, the chapter also discusses the proof of concept based on the DOT professionals and infrastructure management experts' opinions.

\subsection{CONCEPTUAL FRAMEWORK}

The conceptual framework developed is shown in Figure 4.1. The framework has three modules, i.e., the Data Modeling Module, the Analysis Module (having two levels named "Project Level Analysis" and "Network Level Analysis") and the Reporting Module. 


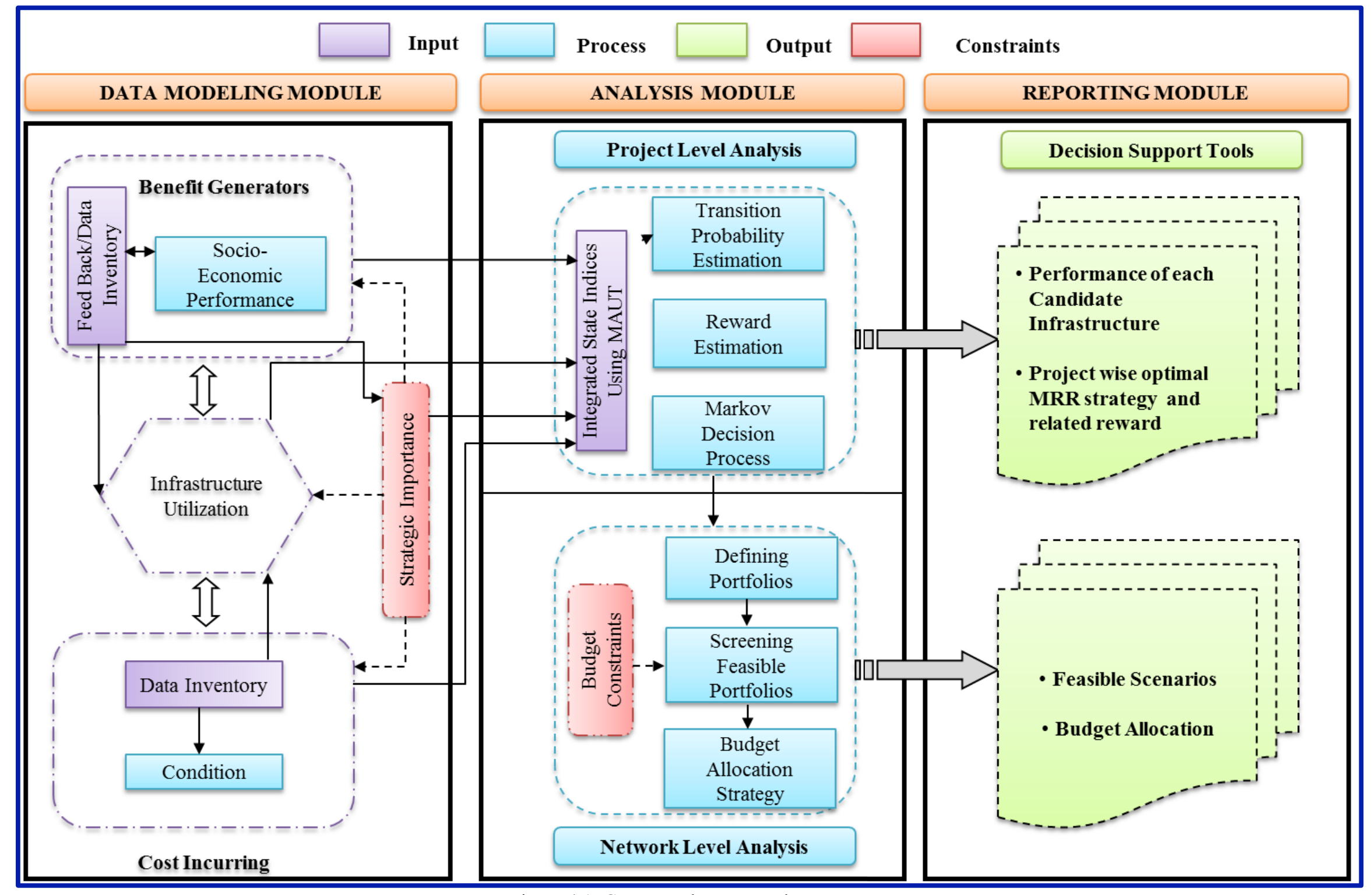

Figure 4.1: Conceptual Framework 
The data modeling module includes the identification of the influencing factors under each decision parameter. These parameters can be classified under three broad categories: (1) constraints, (2) benefit generators, and (3) cost-incurring parameters. The constraints will include the strategic importance, while the benefit generator will mainly include socioeconomic performance (contribution). Physical condition will fall under the cost-incurring category. Infrastructure utilization is the only variable that can have factors related to both the benefit generators and cost-incurring category. The factors within each parameter will be measured mostly utilizing the available published data from DOTs, counties, local town planning agencies, maps, etc. Once the parameters have been measured, those can be integrated to form a dimensionless index called an "Integrated State Rating (ISR)" using the Multi-attribute Utility Theory (MAUT). The purpose of using the MAUT is to establish the interrelationships among parameters considering the risk-taking ability of the decision-making entity. This exercise will also be conducted to measure the historical performance of the candidate infrastructure. Thus, the main outcome of the data modeling module will be the integrated state rating of the infrastructure considering the interrelationship of the decision parameters.

The analysis module has two levels. These include (1) Project (Candidate)-Level Analysis, and (2) Network-Level Analysis. The project-level perspective will evaluate how a candidate infrastructure's maintenance is influenced by the decision parameters as well as different decisions over the planning horizon. The measurements obtained from the data modeling module will be utilized for performing project-level analysis using the Markov Decision Process (MDP). The measurements will be utilized to develop transition probability matrices, and then a reward maximization function will be used to 
identify the optimal solution. The optimal solution will provide the most suitable maintenance strategy for a particular candidate infrastructure from a set of strategies (including maintenance, repair and rehabilitation) for each planning year based on maximized rewards out of that strategy.

The network-level perspective addresses how a particular candidate infrastructure stands in a network. The project-level analysis provided assessment of each candidate infrastructure based on its multiple decision parameters' performance, benefits and investment required without consideration of budget constraints. The network-level analysis will utilize the outcomes of the project-level analysis. It will consider different scenarios that can occur in the network due to the varying individual state of each candidate infrastructure. From an investment perspective, each of these scenarios-i.e., the different combinations of investments into candidate infrastructures - can be termed as portfolios. Hence, a portfolio investment for competing candidate infrastructures will be a combined investment in various infrastructure maintenance projects considering each unique scenario. Once the scenarios are generated, the budget constraint will be applied to screen out the feasible portfolios. However, on many occasions, the decision maker cannot reject a particular candidate project if it underperforms at any of the performance levels. This is because the current condition of the infrastructure may not allow it to be totally ignored. Another case would be that a scenario does not come out to be feasible but it may still happen in future. Such uncertainties will always be present while we are planning budget allocation for physical infrastructure. Also, there is a possibility that there will be no feasible scenarios or more than one feasible scenario. Therefore, a strategy will be devised and proposed to allocate budget to all candidate 
infrastructures included in the network to provide most beneficial use of the available funds.

\subsection{PROOF OF CONCEPT}

The purpose of taking proof of concept was to determine whether the proposed framework has the potential and usefulness to for real-world application. The proof of concept was taken at two different stages of the research i.e., (1) agreement to (preliminary) concept by DOT professionals (during state-of-the practice survey), and (2) agreement by infrastructure management experts (during and after development of conceptual framework). The following subsections provide further details.

\subsubsection{AGREEMENT BY DOT PROFESSIONALS}

The DOT professionals were provided with the preliminary concept of the framework through the abstract of the research. As mentioned in chapter 3, abstract was sent alongside the request to participate in the survey. The respondents were asked a single question in the survey about whether they think that framework will be useful for their district. Sixty (60) out of total sixty-three (63) professionals responded to the question. The pie chart in Figure 4.2 represents the distribution of the responses in terms

of percentage of agreement (Yes) or disagreement (No). The results were encouraging, since $77 \%$ of the DOT professionals agreed to the basic concept of the framework. 


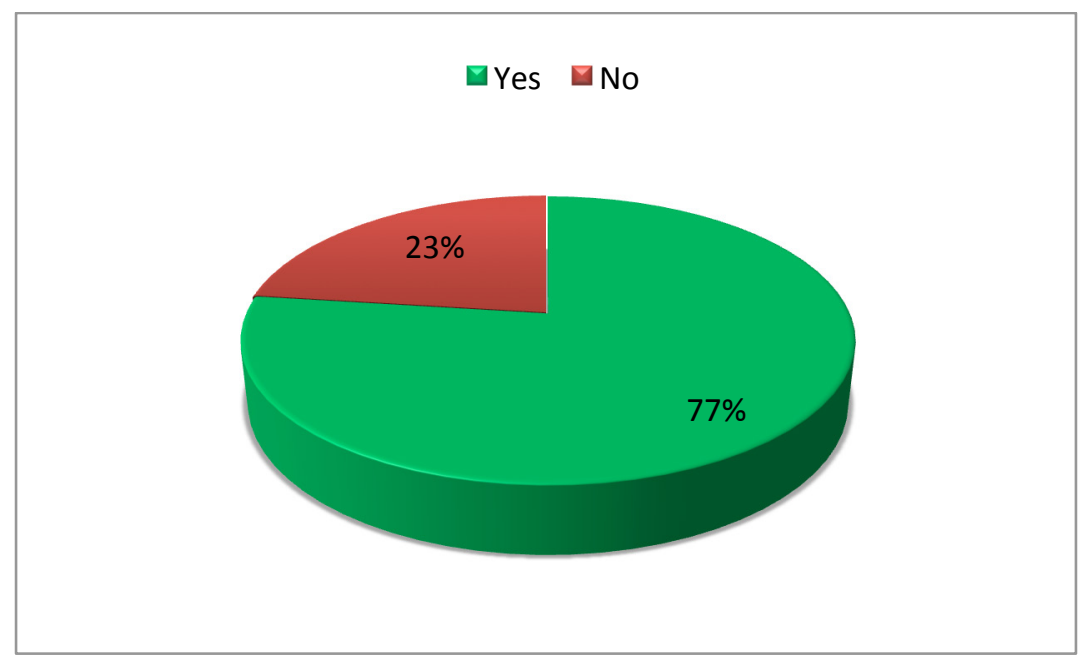

Figure 4.2: Agreement to Conceptual Framework by DOT Professionals

Furthermore, the respondents of the survey were also asked to share their point of view or the reasons for their agreement to the concept of the framework. The reasons for agreement with the concept of research, as stated by some of the DOT professionals, are listed below.

1. We tend to treat low-ADT roads as equal to higher-volume roads. With decreasing funds, we need to be able to forecast where we get the biggest value for the dollars ("bang for the dollars") we do have.

2. Anything that will help in the process of allocating funds to the proper place where they can do the most good would be beneficial. It would then have to be evaluated in relation to other factors used to see if it can be used in your situation.

3. Anything that can help us budget more effectively is welcome.

4. It will help with the prioritization of rehabilitation projects.

5. Lack of resources is constantly a challenge to produce projects with the limited funding. Additionally, many of the requirements for safety and environmental 
laws have put the maintenance personal in a bind. There are not enough people out in the field to take care of the current inventory and respond to emergencies such as traffic accidents.

6. Currently we have little formal guidance [for such decision making].

7. Most decisions are made trying to take into account at least most of these factors. Having something that helps better describe the impacts of each and their interactivity would help evaluate each project. Adding the relative importance of each factor would greatly enhance the system.

8. Due to budget constraints and the deterioration of our infrastructure, it is often difficult to prioritize because the need greatly exceeds the budget. Any options that will provide additional analysis' tools will be helpful.

9. Any tool that allows smarter allocation of limited resources is good.

10. Any assistance in cost-effective planning for maintenance would be helpful.

11. [It] will help to define and quantify maintenance/rehab investment decisions.

12. We currently are more reactive in our spending, and this would help us be more proactive and possibly request funds well in advance for this type of work.

13. [It would] be nice to end up with a computer-type program where we could enter data and factors and have a report come out giving a list. [It] may have to be adjusted, but it would be a very helpful tool.

14. [It will] help define long-range needs and projections.

15. Any tool which leads to improved decision making is an asset.

16. As long something positive comes out of the study that we can implement.

17. [It is an] improved method of prioritizing projects and planning. 
Therefore, it can be concluded that most of the respondent DOT professionals involved in the infrastructure maintenance decision-making overwhelmingly agreed to the presented concept. There comments showing agreement also indicate their willingness to implement the framework. They concur with the concept mainly due to the fact that they want to have a decision support framework that can provide them with the best value for dollars spent while maintaining level of service to their users within budget constraints. Considering the decision parameters defined in this research, DOT professionals also accept that they make decisions in a less informed and less integrated manner. This decision support framework also intends to overcome this limitation.

\subsubsection{AGREEMENT BY INFRASTRUCTURE MANAGEMENT EXPERTS}

The researcher presented the framework and findings of the survey at different forums, mainly research conferences through poster presentations (Arif and Bayraktar 2012a; Arif and Bayraktar 2012b). A number of participants at the conferences showed their interest in the research and the proposed conceptual framework. Using this opportunity, certain interviews were also conducted by the researcher from the experts. Eight major infrastructure management experts were interviewed; whose characteristics are presented in the following Table 4.1. These interviews helped in improving and updating the conceptual framework, and also to assess the opinion of experts regarding the concept of framework. In general, all the experts appreciated the overall concept of the research and the conceptual framework. 
Table 4.1: Infrastructure Management Experts' Characteristics

\begin{tabular}{|c|l|c|}
\hline Expert No & \multicolumn{1}{|c|}{ Expertise } & Experience \\
\hline Expert 1 & Benchmarking Advisor & 29 years \\
\hline Expert 2 & Sustainable Infrastructure Academician & 30 years \\
\hline Expert 3 & $\begin{array}{l}\text { Engineering-Procurement-Construction (EPC) Projects, } \\
\text { Infrastructure, Institutional, Oil and Gas, Power and Process } \\
\text { Industries }\end{array}$ & 41 years \\
\hline Expert 4 & $\begin{array}{l}\text { Infrastructure Technologies, Innovation in Building and } \\
\text { Construction, Infrastructure Systems, Engineering } \\
\text { Innovation Leadership }\end{array}$ & 27 years \\
\hline Expert 5 & Engineering Public Policy Expert & 24 years \\
\hline Expert 6 & Infrastructure Management, Socioeconomic Analysis & 20 years \\
\hline Expert 7 & Infrastructure Portfolio Analysis & 15 years \\
\hline Expert 8 & Public Projects Contract Management & 20 years \\
\hline
\end{tabular}

The experts acknowledged the consideration of multiple decision parameters specifically subjective factors, since those have traditionally been more on the philosophical side. One of the experts termed this approach similar to that of front-end planning. They also appreciated the flexibility of the framework to integrate decision parameters' performance (through MAUT) based on the preference of particular decision-making agency. Another expert appreciated the multi-objectivity addressed by the research. One of the experts showed interest in the reward estimation at the project level and its necessity. The expert was explained that the reward estimation in the form of reward matrix for each particular maintenance strategy will be necessary to be incorporated in the Markov Decision Process (MDP). Since the MDP will mainly be conducted using the integrated state rating, and the model proposes to provide budget allocation in dollar amount at the network level, it was important to include the reward estimation at the project level with each scenario so that a mix of investment allocation under portfolio assessment could be defined at a later stage. The experts, in general, 
acknowledged the idea of adapting portfolio management approach for budget allocation at the network level. However, one of the experts was of the opinion that it may sometimes be of lesser significance for particular decision-making group. The expert was of the opinion that decision makers will usually try to access such investments on the basis of how much improvement could be made to a particular infrastructure by spending the money on its maintenance. Experts also agreed that such a framework can help in reducing the current pressure due to budgetary constraints on the public infrastructure system.

The experts also gave suggestions for future additions to the framework. One of the experts suggested that the framework should have capability to do multi-class infrastructure comparison and assessment, such as providing an optimal portfolio for a mixture of a road and bridge network under a decision group's jurisdiction. Another suggestion was that in future, the framework may be made capable to provide decision support for contracting strategies for such projects based on feasibility analysis as one of the decision support outcomes.

\subsection{CHAPTER SUMMARY}

This chapter defined the conceptual framework. It also discussed proof of concept by DOT professionals and infrastructure management experts. The next chapter will present the mathematical and modeling details of the final framework developed based on the conceptual framework. 


\section{CHAPTER-5: INFRASTRUCTURE MAINTENANCE INVESTMENT DECISION}

\section{SUPPORT FRAMEWORK}

\subsection{INTRODUCTION}

The conceptual framework was discussed in chapter four and shown in Figure 4.1. Based on the framework and conclusions drawn from survey analysis, expert opinion, this chapter describes details of final framework for maintenance investment decisionmaking. The framework consists of three major modules i.e. data modeling module, analysis module and reporting module. Following sections explain in detail the objectives and steps involved in each module.

\subsection{DATA MODELING MODULE}

The purpose of this module is to measure performance of multiple decision parameters through measuring the factors that constitute those parameters. Furthermore, decision parameters' performances will be integrated to determine Integrated State Rating (ISR) for candidate projects under consideration for maintenance investment decision. Furthermore, it also includes inputting and defining costs and benefits data. Therefore, data modeling module comprises of three major steps i.e. (1) Performance measurement, (2) Determination of Integrated State Rating (ISR), and (2) Cost and Benefit data.

\subsubsection{PERFORMANCE MEASUREMENT}

The first step of the data modeling module will be the performance measurement, also referred as performance level (PL) in the dissertation, of candidate infrastructure, 
based on the decision parameters defined for the research. As mentioned earlier, the four decision parameters defined for this study are (1) Strategic Importance (ST) (2) Socioeconomic Contribution (SE), (3) Infrastructure Utilization (UT), and (4) Physical Condition (PC). Therefore, infrastructure performance (IP) is a function of its strategic importance criticality and performance of rest of the decision parameters. Mathematically, it can be stated as follows.

$$
\mathrm{IP}=f(\mathrm{ST}, \mathrm{SE}, \mathrm{UT}, \mathrm{PC})
$$

There can be multiple factors within each of the decision parameters, which can indicator of performance of that particular decision parameter for an infrastructure. The number, type, and measurement mechanism for those factors will vary depending upon the type, service provided and purpose of the infrastructure under consideration alongside the preference of the decision-making entity. Considering the aforementioned argument and scope for implementation of the proposed framework in this research, performance measurement mechanism has been developed for bridges.

A comprehensive list of factors that can be used for performance measurement of strategic importance, socioeconomic contribution, and infrastructure utilization was developed based on the literature review and responses of state-of-the-practice survey from the districts departments of transportation (see table 3.2). The list was screened and filter with the decision-making group formed for case study implementation (detailed explanation in next chapter) to identify the preferred factors for performance measurement. A total number of 17 factors (see Table 5.1 through 5.4) were selected to be included under the four decision parameters. The selected factors are interrelated among themselves from various aspects. For instance, Organization for Economic Co- 
Operation and Development conducted an international working group study highlighting the impact of transport infrastructure investment on regional development. It emphasized that there is a direct link between the accessibility and investment. This is because the purpose of infrastructure investments is to reduce the travel time and cost of travel. It further underlined that the improvement in travel conditions as an outcome to transport infrastructure investment leads towards promoting inter-modal and cross-cross demands and improving the quality of network through enhanced reliability (OECD 2002). Another important perspective is that deteriorating condition and performance of existing transportation infrastructure can result in reducing and/or diminishing productivity benefits of that infrastructure. For instance; if the speeds and service levels of the interstate deteriorates to the point where it becomes no better than other arterials will result in reducing the benefits of being faster and safer system. "Lack of system investments to maintain performance will thus be equivalent to disinvestments" (NCHRP 2006). The reliability of the system is also related to age of infrastructure. Frangopol et. al. (2001) state that service life of a bridge is a progression of reliability states. This progression has been represented using reliability index, generally a measure of bridge safety and age through a hypothetical linear approximation of the actually nonlinear reliability degradation. On the other hand, condition deterioration is related to age of infrastructure. Hence, deterioration in physical condition is also related to reliability of the system. Deteriorating physical condition of a bridge can also result in load restrictions on a bridge. Load carrying capacity deficiencies can also cause percentages of the traffic stream to be detoured incurring more users and operating cost (Small and Swisher 1999). It may also result in impact economic activity of an area by influencing 
freight's access to market. Infrastructure utilization is another aspect that conceptually means the effectiveness of the system being used. The usual performance measures related to utilization is congestion. Congestion is a condition in which traffic demand is sufficient to cause the LOS to be at or below DOT's LOS standards (FDOT 2012). Traffic congestion means that the roadway is not performing up to its designed capacity. It generally causes increase in travel delay and operating costs caused due to interactions among vehicles, as traffic volumes approach roadway capacity (Litman 2009). Alternate routes can also be an important strategic consideration for bridge managers while planning for rehabilitation and replacement plans. Non-availability of alternative routes or longer alternative routes can cause an increase in the user cost (Cheng and $\mathrm{Wu} 2007$ ). Moreover, condition damage to a bridge that is only connection between two distant geographical locations may also result in cutting down the supply chain and result in more emergencies in case of natural calamities. Even nominal physical deterioration to such an infrastructure may have relatively bigger impact as compared to other bridges. Thus it is important to incorporate both the detour length and criticality of geographical areas connected through bridge while taking maintenance decisions. Likewise, if a bridge is part of emergency response route, it becomes strategically more critical to look after its deteriorating condition.

Furthermore, performance measurement matrix was developed providing the definition and measurement mechanism and its explanations for each of the factors based on the published literature and standards etc. The performance measurement matrix was conformed and validated with the decision-making group formed for the case study implementation. Tables 5.1 through 5.4 provide the performance measurement matrices. 
Table 5.1: Strategic Importance Measurement Matrix

\begin{tabular}{|c|c|c|c|c|}
\hline Factor & Definition & Measurement & Measurement Explanation & Reference \\
\hline ST-1 Alternative Routes & $\begin{array}{l}\text { Availability and length of alternate route in case } \\
\text { bridge is not able to serve at full capacity or bridge } \\
\text { closure. }\end{array}$ & $\%$ Criticality = Detour Length in $\%$ & $\begin{array}{l}\text { - Based on NBI Item: N-19 Detour Length. } \\
\text { - The actual length to the nearest kilometer of the detour length. It is the total additional } \\
\text { travel for a vehicle which would result from closing of the bridge. } \\
\text { - Considering that maximum length of detour could be } 100 \text { miles. Higher the detour } \\
\text { length, more critical will be the bridge. }\end{array}$ & NBI (2013b) \\
\hline $\begin{array}{l}\text { ST-2 Emergency Reponses } \\
\text { Route }\end{array}$ & $\begin{array}{l}\text { Whether the bridge is on the designated evacuation } \\
\text { or response route in case of emergency. }\end{array}$ & Yes $(100 \%$ Critical $)$ or No $(0 \%$ Critical $)$ & & \\
\hline ST-3 Defense Considerations & $\begin{array}{l}\text { Whether the bridge is on a Strategic Highway } \\
\text { Network (STRAHNET) route. This is a network of } \\
\text { highways which are important to the United States' } \\
\text { strategic defense policy and which provide defense } \\
\text { access, continuity and emergency capabilities for } \\
\text { defense purposes. }\end{array}$ & $\begin{array}{l}\cdot 1=20 \% \text { Critical } \\
\cdot 2=50 \% \text { Critical } \\
\cdot 3=75 \% \text { Critical } \\
\cdot 4=100 \% \text { Critical }\end{array}$ & $\begin{array}{l}\text { - Based on NBI Item: N-100 STRAHNET Highway Designation (description) } \\
\text { 1. The inventory route is not a STRAHNET route. } \\
\text { 2. The inventory route is on an Interstate STRAHNET route. } \\
\text { 3. The inventory route is on a Non-Interstate STRAHNET route. } \\
\text { 4. The inventory route is on a STRAHNET connector route. }\end{array}$ & $\begin{array}{c}\text { USDOT (2013) } \\
\text { NBI (2013b) }\end{array}$ \\
\hline ST-4 Age of Infrastructure & $\begin{array}{l}\text { Design or service life of the bridge that has already } \\
\text { passed. }\end{array}$ & $\begin{array}{l}\text { The more the original service life has passed more } \\
\text { critical it will be. Therefore, } \\
\text { Criticality }=\% \text { of bridge's original life that has passed. }\end{array}$ & $\begin{array}{l}\text { - More the bridge has passed its design or service life; more critical will be the bridge. } \\
\text { - NBI Item: N-27 Year Built } \\
\text { - Initial design or service Life (assuming } 50 \text { years) }\end{array}$ & NBI (2013b) \\
\hline
\end{tabular}


Table 5.2: Socioeconomic Performance Measurement Matrix

\begin{tabular}{|c|c|c|c|c|}
\hline Factor & Definition & Measurement & Measurement Explanation & Reference \\
\hline SE-1 Accessibility & $\begin{array}{l}\text { - Ability to reach desired goods, services, } \\
\text { activities and destinations (collectively called } \\
\text { opportunities). } \\
\text { - Conceptually the ease in engaging in activities. }\end{array}$ & $\begin{array}{l}\cdot 1=20 \% \text { Performance } \\
\cdot 2=33 \% \text { Performance } \\
\cdot 3=50 \% \text { Performance } \\
\cdot 4=66 \% \text { Performance } \\
\cdot 5=83 \% \text { Performance } \\
\cdot 6\end{array}$ & $\begin{array}{l}\text { - Expert opinion based relationship between connectivity and time to reach destination. } \\
1 \text { = Low Connectivity + More Time to Reach Destination } \\
2 \text { = Low Connectivity + Less Time to Reach Destination } \\
3=\text { Medium Connectivity + More Time to Reach Destination } \\
4=\text { High Connectivity + More Time to Reach Destination } \\
5 \text { = Medium Connectivity + Less Time to Reach Destination } \\
6=\text { High Connectivity + Less Time to Reach Destination }\end{array}$ & $\begin{array}{c}\text { Litman T.A. } \\
\text { (2011) } \\
\text { Litman T.A. } \\
(2012) \\
\text { FDOT (2012) }\end{array}$ \\
\hline SE-2 Affordability & $\begin{array}{l}\text { Transportation affordability means that users' } \\
\text { financial costs of transport are not excessive, } \\
\text { particularly for basic access (travel with high } \\
\text { social value). }\end{array}$ & 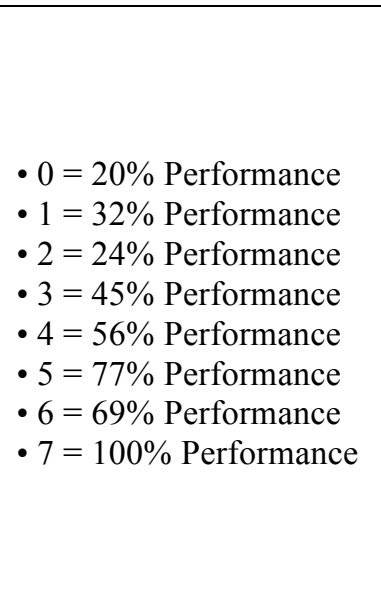 & $\begin{array}{l}\text { - Affordability can be improved by reducing user costs (vehicle purchase costs, fuel prices, transit fares, etc.), by improving more } \\
\text { affordable modes (such as walking, cycling and public transit), and by increasing land use accessibilitit. } \\
\text { - Therefore, affordability performances percentages for modes other than driving (considering driving as a constant service } \\
\text { provided by all bridges) have been calculated for different combinations of affordable modes. The percentages have been } \\
\text { calculated based on affordability improvement strategies, and importance and support for different transportation modes for } \\
\text { different groups of society as explained by Litman T.A. (2012). } \\
\text {. No mode is supported ( } 20 \%) \\
\text { 1. Walking }(32 \%) \\
\text { 2. Cycling }(24 \%) \\
\text { 3. Public Transit }(45 \%) \\
\text { 4. Walking + Cycling }(56 \%) \\
\text { 5. Walking + Public Transit }(77 \%) \\
\text { 6. Cycling + Public Transit }(69 \%) \\
\text { 7. Walking + Cycling + Public Transit }(100 \%) \\
\text { (NBI Item N-42 was used for finding out service types) }\end{array}$ & $\begin{array}{l}\text { Litman T.A. } \\
\quad(2012)\end{array}$ \\
\hline SE-3 Traffic Safety & $\begin{array}{l}\text { Traffic safety has been linked to acceptability of } \\
\text { traffic safety features of the bridge. }\end{array}$ & 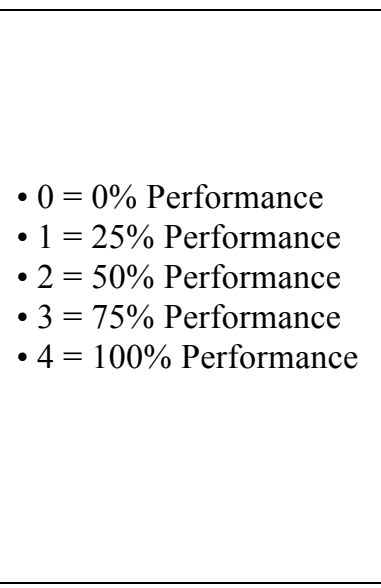 & $\begin{array}{l}\text { NBI Item: N-36 Traffic Safety Features have following four features. } \\
\text { Bridge railings } \\
\text { Transitions } \\
\text { Approach guardrail } \\
\text { Approach guardrail ends } \\
1=\text { None of the traffic safety features meet currently acceptable standards. } \\
2=\text { Only one of the traffic safety features meet currently acceptable standards } \\
3=\text { Only tho of the traffic safety features meet currently acceptable standards } \\
4=\text { All four of traffic saffety features meet currently acceptable standards } \\
\text { The more the safety features are acceptable, lesser will be the chances of crashes or accidents thus, more performance contribution } \\
\text { towards traffic safety. }\end{array}$ & NBI (2013b) \\
\hline SE-4 Quality of Travel & $\begin{array}{l}\text { Quality of Travel was measured in terms of } \\
\text { Travel Time Performance (TTP). Travel time } \\
\text { performance is defined on the basis of } \\
\text { percentage contribution of time delay (person- } \\
\text { hours) in the total network delay. The higher } \\
\text { percentage contribution of delay of a particular } \\
\text { bridge, lower the travel time performance } \\
\text { percentage. }\end{array}$ & $\begin{array}{l}\% \mathrm{TTP}=\% \text { Travel Time } \\
\text { Performance }\end{array}$ & $\begin{array}{l}\text { It is calculated as below: } \\
\qquad \text { TTP }=\left(1-\frac{P H D}{T N D}\right) \times 100 \\
\text { Where, } \\
\text { TTP }=\text { Travel time Performance } \\
\text { PHD }=\text { Total Annual Peak Hour Delay for a particular bridge (Person-Hours) } \\
\text { TND }=\text { Total Network Peak Hour Delay (Person-Hours) (i.e. sum of PHD for all the bridges in the network being considered for } \\
\text { analysis) }\end{array}$ & \\
\hline
\end{tabular}


Table 5.3: Infrastructure Utilization Performance Measurement Matrix

\begin{tabular}{|c|c|c|c|c|c|}
\hline Factor & Definition & Measurement & \multicolumn{2}{|c|}{ Measurement Explanation } & Reference \\
\hline UT-1 Quantity of Travel & $\begin{array}{l}\text { Daily mileage traveled by passengers using the } \\
\text { bridge. }\end{array}$ & $\begin{array}{l}- \text { Indictor used: Daily Vehicle Miles Traveled }= \\
\text { ADT X length of structure. } \\
\cdot \% \text { Performance }=\% \text { of the bridge DVMT in } \\
\text { the total DVMT of network under } \\
\text { consideration. }\end{array}$ & \multicolumn{2}{|c|}{$\begin{array}{l}\text { - Daily vehicle miles traveled has been utilized as a measurement indicator for quantity of } \\
\text { travel. It can be calculated using NBI Items: N-29 Average Daily Traffic, N-49 Length of } \\
\text { Structure. } \\
\text { AASHTO Guidelines for Traffic Data Programs (2009) defines ADT and DVMT as follows. } \\
\text { - Average Daily Traffic (ADT): The total traffic volume during a given time period (more than } \\
\text { a day and less than a year) divided by the number of days in that time period. Also used } \\
\text { generically to mean values of ADT or AADT. } \\
\text { - Daily Vehicle--Miles Traveled (DVMT): A Average daily vehicle-miles traveled on a road } \\
\text { segment or set of segments. DVMT for a segment is obtained by multiplying AADT on the } \\
\text { segment by the length of the segment. DVMT for any set of segments is obtained as the sum of } \\
\text { the values for the individual segments. }\end{array}$} & $\begin{array}{l}\text { AASHTO } \\
(2009)\end{array}$ \\
\hline \multirow{6}{*}{ UT-2 Congestion (congested conditions) } & \multirow{6}{*}{$\begin{array}{l}\text { Congestion is defined as a condition in which } \\
\text { traffic demand is sufficient to cause the level of } \\
\text { service (LOS) to be at or below defined LOS } \\
\text { standards. }\end{array}$} & \multirow{6}{*}{$\begin{array}{l}- \text { Severe }=25 \% \text { performance } \\
\text { - Heavy }=50 \% \text { performance } \\
\text { - Moderate }=75 \% \text { performance } \\
\text { - Low }=100 \% \text { performance }\end{array}$} & \multicolumn{2}{|c|}{$\begin{array}{l}\mathrm{V} / \mathrm{C} \text { is a standard way of categorizing congestion. Congestion levels are categorized into four } \\
\text { levels of severity based on different range of volume to capacity ratio }(\mathrm{V} / \mathrm{C}) \text {. } \\
\text { The congestion adjectives alongside respective } \mathrm{V} / \mathrm{C} \text { ratio ranges as defined for this research } \\
\text { are as follows: }\end{array}$} & \multirow[t]{6}{*}{$\begin{array}{l}\text { PAG } \\
(2013)\end{array}$} \\
\hline & & & \begin{tabular}{|r|} 
Congestion Levels \\
\end{tabular} & V/C Range & \\
\hline & & & Severe & $1.01-2.00$ & \\
\hline & & & Heavy & $0.76-1.00$ & \\
\hline & & & Moderate & $0.51-0.75$ & \\
\hline & & & Low & $0.00-0.50$ & \\
\hline UT-3 Commercial Traffic & $\begin{array}{l}\text { Percentage of truck traffic traveled over a bridge } \\
\text { in the network under consideration. }\end{array}$ & $\begin{array}{l}\text { NBI Item: } 109 \text { Percentage of average daily } \\
\text { truck traffic } \\
\% \text { performance }=\% \text { of number of trucks } \\
\text { traveled each year of a bridge to total truck } \\
\text { traffic in the considered network. }\end{array}$ & \multicolumn{2}{|c|}{ Based on NBI Item 109 - Average Daily Truck Traffic } & $\begin{array}{c}\text { NBI } \\
(2013 b)\end{array}$ \\
\hline UT-4 Freight Load Capacity & $\begin{array}{l}\text { Freight load capacity has been defined } \\
\text { synonymous to the bridge postings on the bridge. } \\
\text { Thus it means the reduction in the load carrying } \\
\text { capacity of the bridge affecting the freight load } \\
\text { carrying capacity and/or movement in case the } \\
\text { bridge has been posted due to some structural } \\
\text { safety reasons. }\end{array}$ & 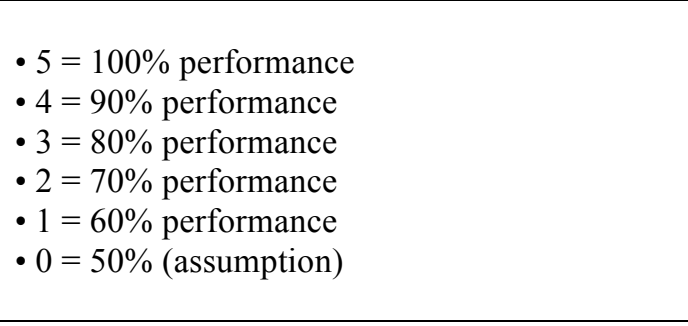 & \multicolumn{2}{|c|}{$\begin{array}{l}\text { Based on NBI Item: } N-70 \text { Bridge Posting (descriptions). Higher the posting percentage, lower } \\
\text { will be the bridge performance. } \\
\text { 5. Equal to or above legal loads } \\
\text { 4. } 00.1-09.9 \% \text { below } \\
\text { 3. } 0.0-19.9 \% \text { below } \\
\text { 2. } 0.0-29.9 \% \text { below } \\
\text { 1. } 30.0-39.9 \% \text { below } \\
0 .>39.9 \% \text { below }\end{array}$} & $\begin{array}{c}\text { NBI } \\
(2013 b)\end{array}$ \\
\hline
\end{tabular}




\begin{tabular}{|c|c|c|c|}
\hline Factor & Definition/Measurement & Measurement Explanation & Reference \\
\hline $\begin{array}{l}\text { PC-1 Deck Condition } \\
\text { PC-2 Super Structure } \\
\text { Condition } \\
\text { PC-3 Sub-Structure } \\
\text { Condition }\end{array}$ & $\begin{array}{l}\text { Bridge deck condition } \\
\text { Bridge super structure } \\
\text { condition } \\
\begin{array}{l}\text { Bridge sub-structure } \\
\text { condition } \\
0 \text { to } 9 \text { rating }=0 \% \text { to } 90 \% \\
\text { performance }\end{array}\end{array}$ & $\begin{array}{l}\text { - Based on NBI Item: N-58 Deck condition ratings } \\
\text { - Based on NBI Item: } \mathrm{N}-59 \text { Super structure condition ratings } \\
\text { - Based on NBI Item: N-60 Sub-structure condition ratings } \\
\text { N. NOT APPLICABLE } \\
\text { 0. FAILED CONDITION - out of service; beyond corrective action. } \\
\text { 1. "IMMINANT" FAILURE CONDITION - major deterioration or section loss present in critical structural components or obvious vertical or horizontal movement affecting structure } \\
\text { stability. Bridge is closed to traffic but corrective action may put it back in light service. } \\
\text { 2. CRITICAL CONDITION - advanced deterioration of primary structural elements. Fatigue cracks in steel or shear cracks in concrete may be present or scour may have removed } \\
\text { substructure support. Unless closely monitored it may be necessary to close the bridge until corrective action is taken. } \\
\text { 3. SERIOUS CONDDTION - loss of section, deterioration of primary structural elements. Fatigue cracks in steel or shear cracks in concrete may be present. } \\
\text { 4. POOR CONDITION - advanced section loss, deterioration, spalling or scour. } \\
\text { 5. FAIR CONDITION - all primary structural elements are sound but may have minor section loss, cracking, spalling or scour. } \\
\text { 6. SATISFACTORY CONDITION - structural elements show some minor deterioration. } \\
\text { 7. GOOD CONDITION - some minor problems. } \\
\text { 8. VERY GOOD CONDITION - no problems noted. } \\
\text { 9. EXCELLENT CONDITION }\end{array}$ & \multirow{3}{*}{$\begin{array}{c}\text { NBI } \\
(2013 \mathrm{~b})\end{array}$} \\
\hline $\begin{array}{l}\text { PC-4 Channel } \\
\text { Condition }\end{array}$ & $\begin{array}{l}\text { Bridge channel condition } \\
0 \text { to } 9 \text { rating }=0 \% \text { to } 90 \% \\
\text { performance }\end{array}$ & $\begin{array}{l}\text { - Based on NBI Item: N-61 Channel and channel protection } \\
\text { N. Not applicable. } \\
\text { 0. Bridge closed because of channel failure. Replacement necessary. } \\
\text { 1. Bridge closed because of channel failure. Corrective action may put back in light service. } \\
\text { 2. The channel has changed to the extent the bridge is near a state of collapse. } \\
\text { 3. Bank protection has failed. River control devices have been destroyed. Stream bed aggradation, degradation or lateral movement has changed the channel to now threaten the bridge } \\
\text { and/or approach roadway. } \\
\text { 4. Bank and embankment protection is severely undermined. River control devices have severe damage. Large deposits of debris are in the channel. } \\
\text { 5. Bank protection is being eroded. River control devices and/or embankment have major damage. Trees and brush restrict the channel. } \\
\text { 6. Bank is beginning to slump. River control devices and embankment protection have widespread minor damage. There is minor stream bed movement evident. Debris is restricting the } \\
\text { channel slightly. } \\
\text { 7. Bank protection is in need of minor repairs. River control devices and embankment protection have a little minor damage. Banks and/or channel have minor amounts of drift. } \\
\text { 8. Banks are protected or well vegetated. River control devices such as spur dikes and embankment protection are not required or are in a stable condition. } \\
\text { 9. There are no noticeable or noteworthy deficiencies which affect the condition of the channel. }\end{array}$ & \\
\hline $\begin{array}{l}\text { PC- } 5 \text { Culvert Condition } \\
\text { (if applicable) }\end{array}$ & $\begin{array}{l}\text { Bridge culvert condition } \\
-0 \text { to } 9 \text { rating }=0 \% \text { to } \\
90 \% \text { performance }\end{array}$ & 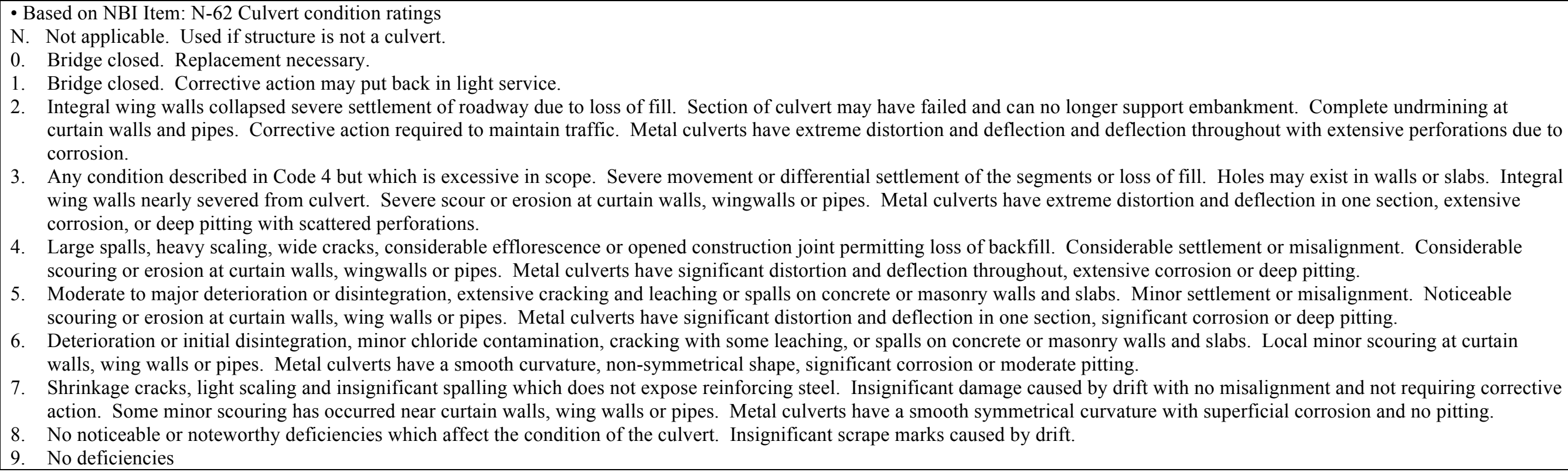 & \\
\hline
\end{tabular}


The performance measurement will always be in terms of percentage. The factors performance will be aggregated into decision parameter performance. It can be done either by assigning weightages to factors within each parameter or simply by taking average of factor performances considering that all factors within a parameter has an equal importance in defining that parameter. The later approach has been adopted in this research while implementing framework through case study. The performance measurement will not only be required for current year but would also be required for certain number of past years. The purpose is to enumerate historical transitions of candidate infrastructure's (bridge) integrated state assuming that only preventive maintenance was performed. Further explanation on this has been provided in section 5.2.2.

\subsubsection{DETERMINATION OF INTEGRATED STATE RATING (ISR)}

The individual decision parameter performances measured in the previous step will be combined into an integrated state rating (ISR) of the candidate infrastructure. Every infrastructure management entity can have its own perception and preference for each of the decision parameters. This preference can also be termed as the "risk attitude" of that entity. Therefore, it was deemed necessary that the integration of decision parameter's performances must align with this risk attitude of a particular decisionmaking entity. For this purpose, multi-attribute utility theory (MAUT) will be utilized. The purpose of selecting MAUT in this research is to incorporate decision maker's risk attribute towards the decision parameters. The outcome of the MAUT is a Multi Attribute Utility Function (MAUF). The MAUF is a mathematical equation that relates the 
parameters under consideration on a dimensionless index that usually varies from 0 to 1 knows as multi-attribute utility. 0 represents the least preference and represents the highest preference. The development of MAUF consists of three main steps (Gharaibeh et al. 2006; Keeney and Raiffa 1976), while an additional step will be required to convert multi-attribute utility value (MAU) to integrated state rating (ISR). These four steps are as follows.

1. Developing Single Attribute Utility Function (SAUF) for each parameter.

2. Determining the Scaling Factor.

3. Development of Multi-Attribute Utility Function (MAUF).

4. Conversion of Multi-Attribute Utility (MAU) to Integrated State Rating (ISR).

\subsubsection{DEVELOPING SINGLE ATTRIBUTE UTILITY (SAU) FUNCTION}

Single attribute utility functions for each of the decision parameters are developed through decision maker's preference. Single attribute function is developed in the form of utility curve that relates the parameter's performance level (in terms of percentage) with the preference of decision maker in terms of utility values (i.e. dimensionless index from 0 to 1). The SAU function will define the risk attitude of the decision maker towards infrastructure's performance level for a particular decision parameter under consideration. Therefore, a SAU function will be developed for each parameter in the scope of this research, i.e. socioeconomic performance, strategic importance, infrastructure utilization and physical condition. Normally, five pairs of (performance level, utility) are enough to plot a SAU curve (Gharaibeh et al. 2006). The lower and upper limit pairs can said to be known as the least preferable performance level $\left(\mathrm{PL}_{0}\right)$ has 
a zero utility while the most preferable performance level $\left(\mathrm{PL}_{1}\right)$ has utility set equal to 1 . The lower performance level can be set equal to the threshold performance level percentage already set by the decision maker or decision-making entity. While, the upper performance level will usually be equal to $100 \%$. Thus, if three more (performance level, utility) pairs can be evaluated using decision makers/decision-making entity's input, a SAU curve can be developed.

Direct assessment method has been adopted for establishing a SAU function. This method follows "Certainty-Lottery" approach in which decision makers are presented with a series of $50 \%-50 \%$ lotteries against certain equivalent outcomes to provide an equivalent performance level that is "sure" to happen having a 100\% possibility (Keeney and Raiffa 1976). Decision maker or decision-making entity will be presented with a set of three lotteries per each decision parameters to evaluate the three intermediate (performance level, utility) pairs. These three pairs include $\left(\mathrm{PL}_{0.25}, 0.25\right),\left(\mathrm{PL}_{0.5}, 0.5\right)$ and $\left(\mathrm{PL}_{0.75}, 0.75\right)$. Once the five pairs are known, SAU function curve can be developed by simple curve-fitting to the (performance level, utility) pairs. The equations of those curves will represent the SAU functions and will be utilized in step 3 to develop a MAU function.

Considering the aforementioned procedure, a performa titled "Tool for Evaluating Single Attribute Utility (SAU) functions" was developed as a part of application of the mode (Appendix B). 


\subsubsection{DETERMINING THE SCALING FACTOR}

After this scaling factor $\left(k_{i}\right)$ needs to be evaluated for each decision parameter. Scaling factor relates different attributes (parameters). The scaling factor can be determined through certainty-lottery approach (Gharaibeh et al. 2006). In this method, the decision maker or the decision-making entity is presented with a certain strategy and a lottery strategy. The certain strategy has a 100\% possibility of occurrence. For instance; the certain strategy is that the decision parameter is set to have the most preferred performance level $(100 \%)$, and rest of the decision parameters will perform at the least preferred performance level (20\%). On the other hand, the lottery strategy is a binary lottery having two possible outcomes. One possibility is that all decision parameters are set to have the most preferred performance level (100\%) having probability (p), and other possibility is that all decision parameters are set to have the least preferred performance level (20\%) having probability (1-p). The decision maker is asked to pick one out of certain or lottery strategy with increasing value of $p$. The probability value at which the decision maker or the decision-making entity switches from picking one strategy to the other (i.e. lottery strategy to the certain strategy or vice versa) is termed as probability of strategy shift (p'). Hence the scaling factor $\left(k_{i}\right)$ for each of the decision parameters will be calculated as follows.

$$
\text { Scaling factor }\left(k_{i}\right)=\mathrm{p}^{\prime} / 100
$$

The sum of scaling factors will also be utilized to determine whether multiattribute function can be determined through additive form (if sum of scaling factor $=1$ ) or multiplicative form (if sum of scaling factors $\neq 1$ ). 


\subsubsection{DEVELOPMENT OF MULTI ATTRIBUTE UTILITY FUNCTION (MAUF)}

An overall multi-attribute utility function (MAUF) can then be developed, using single attribute utility functions and scaling factors. First, normalizing factor $(K)$ will be computed to ensure that the outcome of the MAUF i.e. the multi-attribute utility value remains between 0 and 1 . If the sum of scaling factors of all the decision parameters evaluated in the previous step comes out any value other than 1 , (i.e. $\Sigma k_{i} \neq 1$ ), then normalizing factor $(K)$ is determined using the following equation.

$$
K+1=\prod_{i=1}^{n}\left(K k_{i}+1\right)
$$

Where $K=$ normalizing factor; $k_{i}=$ individual scaling factor for decision parameter $i$; and $i=$ decision parameter number $(\mathrm{i}=1-\mathrm{n})$.

Hence, the multi attribute utility function (MAUF) will be determined through multiplicative form as defined by Keeney and Raiffa (1976).

$$
K U(P L)+1=\prod_{i=1}^{n}\left[K k_{i} u_{i}\left(P L_{i}\right)+1\right.
$$

Where $U(P L)=$ multi attribute utility function; $K=$ normalizing factor, $u_{i}\left(P L_{i}\right)=\mathrm{SAU}$ function for the decision parameter $i$; $k_{i}=$ individual scaling factor for decision parameter $i$; and $n=$ number of decision parameter $(i=1-\mathrm{n})$.

However, if sum of scaling factors of all the decision parameter comes out to be 1 (i.e. $\Sigma k i=1), K$ will be equal to zero $(K=0)$. The multi attribute utility function (MAUF) will then be determined through additive form as defined by Keeney and Raiffa (1976).

$$
U(P L)=\sum_{i=1}^{n} k_{i} u_{i}\left(P L_{i}\right)
$$


Where $U(P L)=$ multi attribute utility function; $u_{i}\left(P L_{i}\right)=$ SAU function for the decision parameter $i ; k_{l}=$ individual scaling factor for decision parameter $i$; and $n=$ number of decision parameter $(i=1-n)$.

\subsubsection{CONVERSION OF MULTI ATTRIBUTE UTILITY (MAU) TO INTEGRATED} STATE RATING (ISR)

The developed MAUF will basically represent the interrelationship of decision parameters as per decision maker's preference. The performance for each decision parameter for each candidate infrastructure obtained in measurement step can then be input in the MAUF to find out the multi-attribute utility (MAU) value for that infrastructure. However, the objective is to find out the integrated state rating (ISR). Therefore, the five point MAU conversion scale (Table 5.5) developed and conformed through expert opinion will be utilized for determining the ISR. The procedure will be repeated to determine the integrated state rating of the infrastructure for past years performances. The integrated state ratings (ISR) for each infrastructure will be used in the analysis module to directly develop the transition probability matrix for maintenance action while performance curves will also be plotted which can be utilized by decision makers to provide expert input for determining transition probability matrices under repair and rehabilitation action.

Table 5.5: Five Point MAU Conversion Scale

\begin{tabular}{|c|c|}
\hline MAU Range & ISR \\
\hline 0.8 to 1.0 & Excellent (1) \\
\hline 0.6 to 0.8 & Good (2) \\
\hline 0.4 to 0.6 & Fair (3) \\
\hline 0.2 to 0.4 & Poor (4) \\
\hline 0 to 0.2 & Severe (5) \\
\hline
\end{tabular}




\subsubsection{COST AND BENEFIT DATA}

It was earlier discussed as well that the decision parameters have been characterized into three broad categories for data modeling module. The categories include: (1) constraint, (2) benefit generators, and (3) cost-incurring parameters. The constraint includes strategic importance. The benefit generator includes socioeconomic contribution and infrastructure utilization while physical condition mainly falls under the cost-incurring category. Thus, another input in the data modeling module is to have the cost and benefit data estimates for each probable maintenance action i.e. Maintenance (MAIN), repair (RPR) and rehabilitation (REH) described later in detail in section 5.3.1.2. The cost and benefit data will be utilized for generating reward matrix explained later in section 5.3.1.4.

\subsubsection{COST DATA}

The scope of this framework does not include the cost estimation. Therefore, cost data will be a direct input from the already prepared estimates. The different maintenance actions (i.e. MAIN, RPR, REH) has been characterized with spending ranges. The details of this will be provided later (see Table 5.7).

\subsubsection{BENEFIT DATA}

Benefit data will also be input in the framework based on the estimation of the decision-making agency's considerations. However, benefits were required to be identified and validated. The initial list of benefits was identified through DOT district's survey as explained in section 3.5.2.5. The benefits included in the identified lists were 
allocated to the maintenance actions (MAIN, RPR, REH), and their relationship with different decision parameters' factors was identified to develop benefit matrix. This matrix was then validated and updated based on the expert opinion and with the decisionmaking group formed for the case study implementation. For the case study, decisionmaking agency had no standard procedure for estimating benefits. Therefore, agency identified the benefits and the researcher developed procedures to estimate those based on suggestions and consultations with the decision-making group explained later in chapter 6. The benefit matrix adapted is shown in Table 5.6.

Table 5.6: Benefit Matrix

\begin{tabular}{|c|l|l|}
\hline Maintenance Action & \multicolumn{1}{|c|}{ Benefits } & \multicolumn{1}{|c|}{$\begin{array}{c}\text { Associated Decision } \\
\text { Parameter (Factors) }\end{array}$} \\
\hline Maintenance (MAIN) & Reduced future maintenance cost. & PC, SE-2 \\
\hline \multirow{4}{*}{ Repair (RPR) } & Benefit of improved rideability & SE-4 \\
\cline { 2 - 3 } & $\begin{array}{l}\text { Benefit of delaying deterioration of } \\
\text { structural components }\end{array}$ & ST-4, SE-2 \\
\cline { 2 - 3 } & Reduced Accident risk & UT-3, SE-2 \\
\hline \multirow{5}{*}{ Rehabilitation (REH) } & Benefits of Reduction in Congestion & PC, SE-2, UT-1 \\
\cline { 2 - 3 } & $\begin{array}{l}\text { Benefits of Raising the Bridge/Vertical } \\
\text { Clearance }\end{array}$ & SE-2, UT-3, PC \\
\cline { 2 - 3 } & $\begin{array}{l}\text { Benefits of Strengthening/Partial } \\
\text { Replacement (Delaying Full } \\
\text { Replacement) }\end{array}$ & UT-4, PC \\
\cline { 2 - 3 } & Reduced Accident risk & UT-3, SE-2, UT-2 \\
\cline { 2 - 3 } & Reduction in Detour Cost & ST-1, ST-2, SE-1, SE-2 \\
\hline
\end{tabular}

Once the data modeling module has been applied to enumerate integrated state ratings, cost and benefit data, all of the processed data will be transferred to the analysis module. The details of the analysis module are described in the following sections. 


\subsection{ANALYSIS MODULE}

Once the ISR has been obtained from the data modeling module, those will be utilized as inputs in the analysis module. The analysis module has two levels. The first level (Level-1), named "Project Level Analysis," and the second level (Level-2), named "Network Level Analysis."

\subsubsection{LEVEL 1: PROJECT LEVEL ANALYSIS}

As explained in the Chapter 4, while describing conceptual framework, the project level analysis will be conducted through Markov Decision Process. A six step procedure has been devised in order to perform project level analysis. These steps include;

1. Defining states

2. Defining set of probable actions

3. Calculating transition probabilities

4. Estimating rewards

5. Markov Decision Process (MDP)

6. Development of Decision Login Maps (DLM)

These steps are explained in detail in the following subsections. 


\subsubsection{DEFINING STATES}

The detailed explanation regarding the sequence of states had already been provided Chapter 2, and decision parameters measurement step. The possible states for the purpose of this research are Excellent (1), Good (2), Fair (3), Poor (4) and Severe (5).

\subsubsection{DEFINING SET OF PROBABLE ACTIONS (A)}

Figure 5.1 shows the bridge action categories as defined in the bridge preservation guidelines. There are two major domains (1) Bridge Preservation (2) Bridge Replacement. Bridge preservation includes preventive maintenance of two types that is cyclic and non-cyclic or Condition based maintenance (Ahmad 2011).

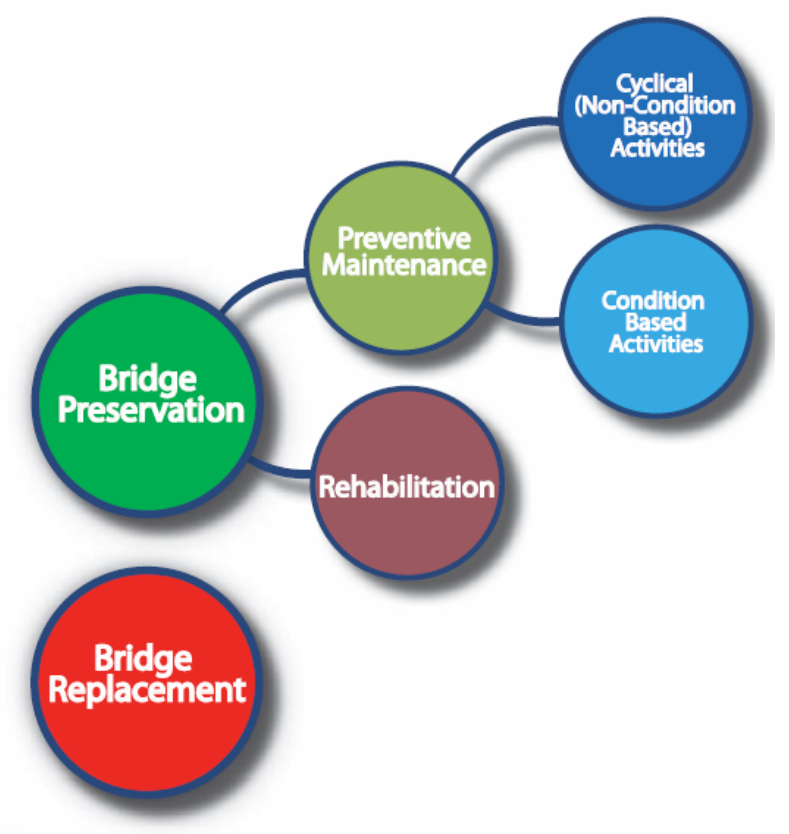

Figure 5.1: Bridge Management Action Categories (Ahmad 2011)

The same guidelines define that replacement is not a preservation action. Therefore, replacement is not considered as an action for the purpose of this research. The set of 
actions defined for this research consist of three distinct actions that are Maintenance (MAIN), Repair (RPR) and Rehabilitation (REH). The definitions of these actions as adapted from Klaiber W.F. and Wipf T.J. (2003) are as follows:

Maintenance: The technical aspect of the upkeep of the bridges; it is preventative in nature. Maintenance is the work required to keep a bridge in its present condition and to control potential future deterioration.

Repair: The technical aspect of rehabilitation; action taken to correct damage or deterioration on a structure or element to restore it to its original condition (assumed as fair to good state for this research).

Rehabilitation: The process of restoring the bridge to its original service level (assumed to bring bridge into good to excellent state for this research).

\subsubsection{CALCULATING TRANSITION PROBABILITIES (T)}

It is required to develop three transition matrices under each action i.e., "Maintenance", "Repair", and "Rehabilitation". The procedure for developing each of the transition probability matrices has been explained in the following text. 


\subsection{TRANSITION PROBABILITY MATRIX FOR "MAINTENANCE"}

\section{(MAIN) ACTION}

The transition probabilities can be calculated using simple approach. The data modeling module already yielded ISR for each candidate project for prior years based on the infrastructure performance measurements which will be utilized to enumerate transition probabilities for maintenance scenario. Two years has been used as a transition period. This is because, generally, for bridges (scope of this research), inspection exercise takes place every other year. A change of ISR from year 1 to year 3, then year 3 to year 5 and so on shows individual transitions i.e. if a bridge inspection record or data is available from 1990, the transitions will be from 1990 to 1992,1992 to 1994,1994 to 1996 and so on. Ideally, more data is available more the better would be for generation of transition probabilities. For the Maintenance action, it is assumed that infrastructure (bridge) was not subjected to major repair or rehabilitation in the years for which data is being taken into account for generating transition probabilities.

There can be a total of 25 transitions in a 5 state system considered in this research for a bridge that has been historically subjected to Maintenance action only. If physical condition performance is the only criteria for decision-making, it is logical to assume that the infrastructure will deteriorate homogeneously over the passage of time while subjected to only preventive maintenance. It means that no transition can take place by more than one stage. Assuming homogeneity in infrastructure deterioration transition is a common practice among researchers (Reale1 and Connor 2012; Jiang et al. 1988; Cesare et al. 1992; Morcous et al. 2003; Baik et al. 2006). However, it is not necessary that other decision parameters for instance socioeconomic contribution and infrastructure 
utilization may upgrade or downgrade (equivalent to deteriorate) each year with deteriorating condition. Thus, combination of all the four parameters may cause integrated state rating (ISR) to either go up or down depending upon decision parameters' performance each year. Considering the above, for simplicity, it can safely be assumed for the purpose of this research that integrated state of an infrastructure may either stay unchanged, upgrade or downgrade (deteriorate) with respect to previous year's integrated state homogeneously. It means that no transition can take place by more than one stage such as excellent to fair or fair to excellent. Hence, transition probabilities for all such cases can be assumed negligible i.e. equal to zero (Reale1 and Connor 2012). Furthermore, transition probabilities have been assumed to be same for each stage of planning horizon (i.e. 5 to 6 years for this research) using zoning concept (Patidar et. al 2007, Baik 2006). A zone is time period within which the transition process is stationary. Five year term has been utilized for a zone in line with the five year investment planning horizon requirement elicited through DOT survey and period of a single transition (two years) as explained earlier. This assumption was necessary to make sure that values of transition probabilities do not change for at least 6 years in order to run one complete cycle of the decision process.

Considering the assumptions, the transition scenario is depicted through Figure 5.2. Once the number of possible transitions have been enumerated, these can then be converted into a $\mathrm{n} \times \mathrm{n}$ matrix ( $5 \times 5$ matrix for this research) called "transition matrix" in which rows show the "starting state" (From State) and column shows "ending state" (To State). The transition matrix can then be converted into "transition probability matrix" by dividing the each matrix element with the sum of transition in its respective 
row. Since, it is assumed that no action was applied in the previous years to the candidate projects other than preventive maintenance, the transition probability matrix resulted from this step will be termed as "Maintenance" transition probability matrix. Typical transition probability matrix for maintenance $\operatorname{action}\left(\boldsymbol{p}_{i j}^{M A I N}\right)$ is shown by table 5.7. Transition probability matrix for all the candidate bridges can be developed with similar approach.

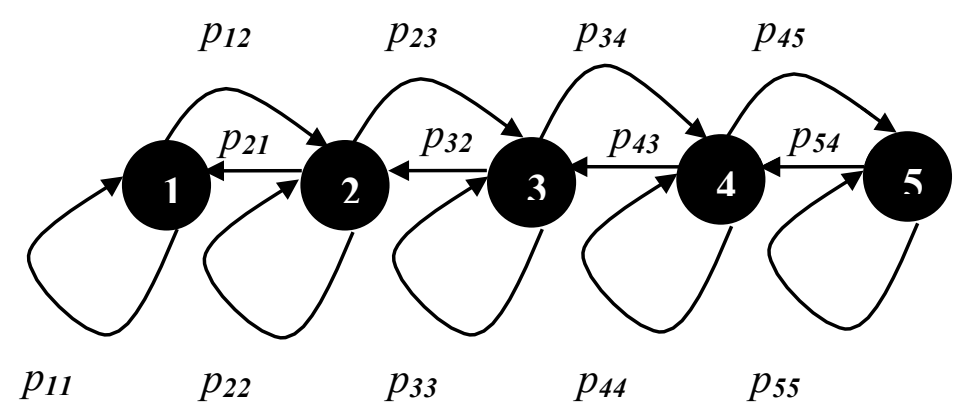

Figure 5.2: Transition Scenario for Maintenance Action

Table 5.7: Typical Transition Probability Matrix for Maintenance Action

$$
\boldsymbol{p}_{\boldsymbol{i j}}^{\boldsymbol{M A I N}}=\begin{array}{c|ccccc}
1 & 2 & 3 & 4 & 5 \\
1 & p_{11} & p_{12} & 0 & 0 & 0 \\
2 & p_{21} & p_{22} & p_{23} & 0 & 0 \\
3 & 0 & p_{32} & p_{33} & p_{34} & 0 \\
4 & 0 & 0 & p_{43} & p_{44} & p_{45} \\
5 & 0 & 0 & 0 & p_{54} & p_{55}
\end{array} \mid
$$

There can be different transitions i.e. from good to fair, fair to poor, poor to severe etc. for all the prior years. Therefore, number of all such transition happened can be calculated.

\subsection{TRANSITION PROBABILITY MATRIX FOR “REPAIR" (RPR) ACTION}

The action of repair (RPR) is only applied to bring the bridge to fair (3) to good state (2); from either poor (4) or severe state (5). Therefore, it is safe to assume that 
decision horizon will be only covering states from good to fair. This means that whenever "RPR" decision is applied, it will result in maintaining the bridge's state at current level or upgrade to good (3) state if it is currently in fair (3) state. However, if the RPR is applied when the state of bridge is either poor (4) or severe (5), it is assumed that the state will be upgraded either to fair (3) or to good (2) state. This assumption is aligned with past researches (Madanat and Akiva 1994; Carnahan 1987). It is logical to assume that a degradation of condition after RPR is highly unlikely within the decision horizon. For instance, a bridge is in fair (3) state and have been applied by RPR action, can't degrade to poor (4) state otherwise, there will be no use of RPR action. The probability for all such transitions will be equal to zero. Furthermore, there will be no transitions from states of excellent (1) or good (2) because they are above the RPR horizon. Hence, six transitions are possible in this case. These include, fair (3) to good (2) and fair (3) to fair (3) (i.e. no change), poor (4) to fair (3), poor (4) to good (2), severe (5) to fair (3), severe (5) to good (2). This transition scenario is depicted through Figure 5.3 while typical transition probability matrix under RPR action $\left(\boldsymbol{p}_{i j}^{\boldsymbol{R P R}}\right)$ is shown by Table 5.8.

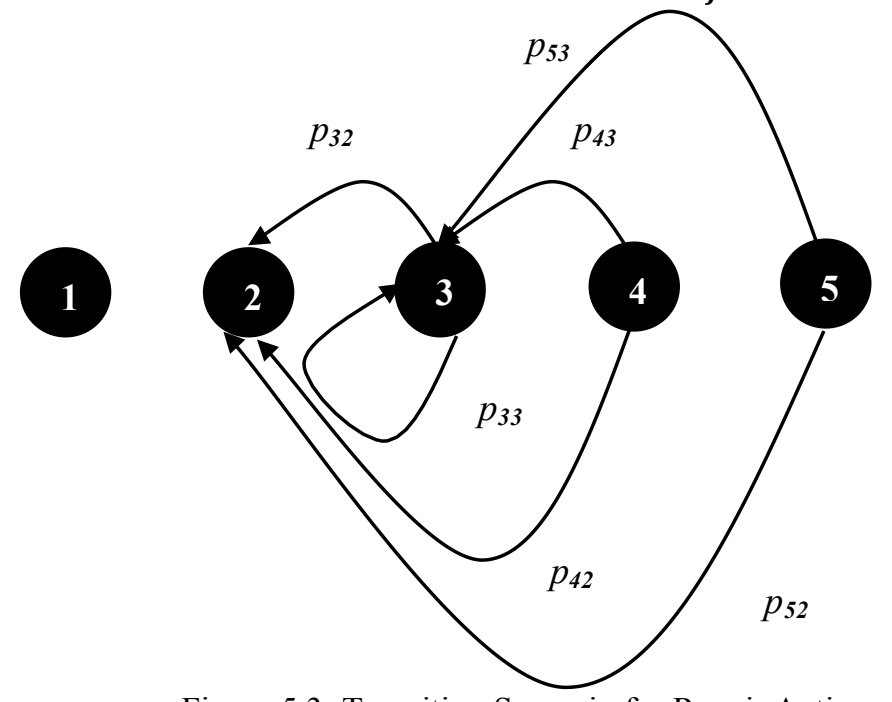

Figure 5.3: Transition Scenario for Repair Action 


$$
\boldsymbol{p}_{\boldsymbol{i} \boldsymbol{j}}^{\boldsymbol{R P R}}=\begin{array}{c|ccccc}
1 & 2 & 3 & 4 & 5 \\
1 & 0 & 0 & 0 & 0 & 0 \\
2 & 0 & 0 & 0 & 0 & 0 \\
3 & 0 & p_{32} & p_{33} & 0 & 0 \\
4 & 0 & p_{42} & p_{43} & 0 & 0 \\
5 & 0 & p_{52} & p_{53} & 0 & 0
\end{array}
$$

\subsection{TRANSITION PROBABILITY MATRIX FOR “REHABILITATION” (REH)}

\section{ACTION}

As discussed previously, rehabilitation is action taken to correct damage or deterioration on a structure or element to restore it to its original condition (assumed as excellent to good state for this research). This means that the bridge has a requirement of major restoration due to its current state. Therefore, the action of rehabilitation is generally applied to upgrade the state of the bridge to almost new. Whenever REH action will be applied to a particular candidate bridge, no matter what its current state is, it should result in bringing bridge's state to either excellent or good. Mandat and Akiva (1994), Carnahan et. al (1987) adopted a similar approach for enumerating transition probabilities under reconstruction action for pavement management. However, they included all the states within the decision horizon for reconstruction action. This research adopts modified approach to make it more realistic. Hence, REH action decision horizon is considered to cover only from severe (5) to fair (3) states. Considering this, six transitions are possible in this case. These include, severe (5) to excellent (1), severe (5) to good (2), poor (4) to excellent (1), poor (4) to good (2), fair (3) to excellent (1), and fair (3) to good (2). This transition scenario is depicted through Figure 5.4 while typical transition probability matrix under REH action $\left(\boldsymbol{p}_{\boldsymbol{i} \boldsymbol{j}}^{\boldsymbol{R} \boldsymbol{H}}\right)$ is shown by Table 5.9. It is 
worth mentioning here that homogeneity assumption for transitions can't be valid when applying rehabilitation action because purpose is to uplift the state of bridge to the best possible state that can also means up gradation by more than one state. The values of transition probabilities under rehabilitation action will be elicited through decision makers' expert opinion based on their past experience of rehabilitation projects.

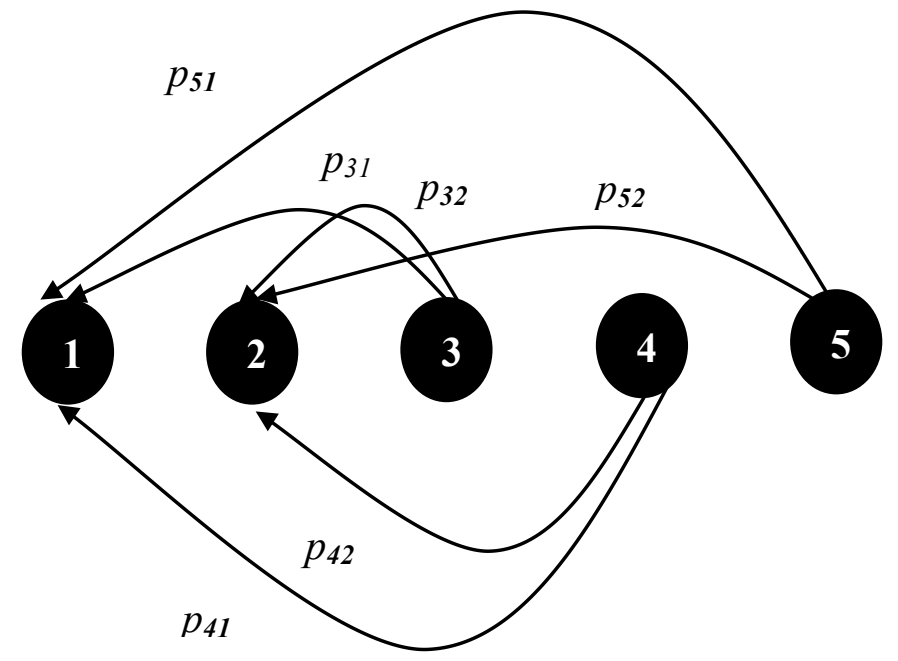

Figure 5.4: Transition Scenario for Rehabilitation Action

Table 5.9: Typical Transition Probability Matrix for Rehabilitation Action

$$
\boldsymbol{p}_{\boldsymbol{i j}}^{\boldsymbol{R E \boldsymbol { H }} \boldsymbol{H}=} \begin{array}{c|ccccc}
1 & 0 & 0 & 0 & 0 & 0 \\
2 & 0 & 0 & 0 & 0 & 0 \\
3 & p_{31} & p_{32} & 0 & 0 & 0 \\
4 & p_{41} & p_{42} & 0 & 0 & 0 \\
5 & p_{51} & p_{52} & 0 & 0 & 0
\end{array} \mid
$$




\subsubsection{ESTIMATING REWARDS}

The rewards matrix will be generated using cost and benefit data as described in section 5.2.3. A reward matrix will be generated considering the possible transitions only for each of the probable actions for all the candidate projects. Typical reward matrices under three probable decisions (i.e. MAIN, RPR, REH) are shown in Tables 5.10 through 5.12.

Table 5.10: Typical Reward Matrix for Maintenance Action

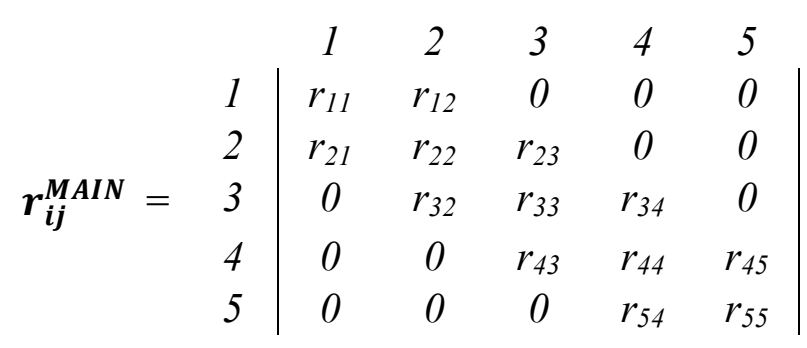

Table 5.11: Typical Reward Matrix for Repair Action

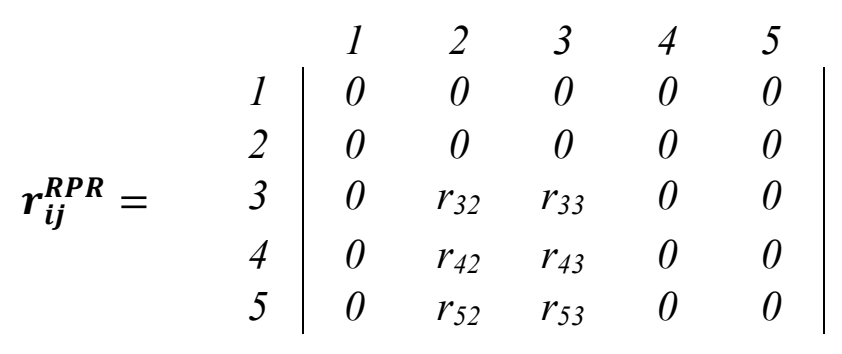

Table 5.12: Typical Reward Matrix for Rehabilitation Action

$$
\boldsymbol{r}_{\boldsymbol{i} \boldsymbol{j}}^{\boldsymbol{R} \boldsymbol{H} \boldsymbol{H}}=\begin{array}{c|ccccc}
1 & 2 & 3 & 4 & 5 \\
1 & 0 & 0 & 0 & 0 & 0 \\
2 & 0 & 0 & 0 & 0 & 0 \\
3 & r_{31} & r_{32} & 0 & 0 & 0 \\
4 & r_{41} & r_{42} & 0 & 0 & 0 \\
5 & r_{51} & r_{52} & 0 & 0 & 0
\end{array}
$$




\subsubsection{MARKOV DECISION PROCESS (MDP)}

Transition probabilities and reward matrices generated under each action in the set of probable actions will be utilized as input to the Markov Decision Process (MDP) model. It was explained in the text earlier that the planning horizon of investment decision-making has been kept to five years based on the outcomes of the DOT survey. Based on this, zoning concept was also utilized in order to keep the transition probabilities constant for the similar period i.e. 6 years (because of 2 years of transition). This makes the decision process as a finite horizon problem. Therefore, the decision scenario for this research from the project level analysis perspective is aligned with Finite Stage Dynamic Programming (DP) Model of the MDP. In such modeling, decision maker is interested in determining the optimal course of action from the set of probable actions for each year of the planning horizon. Optimality, in this case, means accumulating the highest expected reward at the end of $\mathrm{N}$ years, i.e., end of planning horizon. The decision scenario expressed as a finite-stage dynamic programming model (DP) adopted from Taha (1997) is described as follows.

Let $f_{n}(\mathrm{i})$ be the optimal expected revenue of stages (years) $\mathrm{n}, \mathrm{n}+1, \ldots ., \mathrm{N}$, given that the state of the system (ISR) at the beginning of year $n$ is $i$. The problem is modeled using backward recursion in order to reduce computational complexity. It means that a problem will be solved by first for the final stage (year 5 in this research) and then proceeding backwards to the first stage (year 1). Since, the bridge inspection is usually conducted every other year; performance measurement can only be done according to the inspection schedule. Hence, there will be only one intermediate stage i.e. year 3. It is important to mention here that year 1 means the very next year to the planning year (let's 
say year 0). Therefore, if this investment decision-making exercise is conducted in year 2013, it will provide decisions for year 2018, 2016 and 2014 in backward recursive form. The backward recursive equation relating $f_{\mathrm{n}}$ and $f_{\mathrm{n}+1}$ is represented below.

$$
f_{n}(i)=\max _{k}\left\{\sum_{j=1}^{m} p_{i j}^{k}\left[r_{i j}^{k}+f_{n+1}(j)\right]\right\}, \quad n=1,2,3, \ldots, N
$$

Where, $m=$ number of states for each stage (year), i.e. $=5$

$k=$ action or strategy (let's say; $1=$ MAIN, $2=\mathrm{RPR}, 3=\mathrm{REH}$ )

$p_{i j}^{k}=$ transition probability due to state change (i.e. change in ISR) from $i$ to $j$ due to action $k$.

$r_{i j}^{k}=$ reward (revenue) due to state change (i.e. change in ISR) from $i$ to $j$ due to action $k$. Also, $f_{N+1}(j) \equiv 0$ for all $j$.

A justification for the equation is that cumulative revenue, $r_{i j}^{k}+f_{n+1}(j)$, resulting from reaching state $j$ at stage $n+1$ from state $i$ at stage $n$ occurs with probability $p_{i j}^{k}$. Letting

$$
v_{i}^{k}=\sum_{j=1}^{m} p_{i j}^{k} r_{i j}^{k}
$$

Therefore, the DP recursive equation can be written as

$$
\begin{gathered}
f_{n}(i)=\max _{k}\left\{v_{i}^{k}\right\} \\
f_{n}(i)=\max _{k}\left\{v_{i}^{k}+\sum_{j=1}^{m} p_{i j}^{k} f_{n+1}(j)\right\}, \quad n=1,2,3, \ldots, N-1
\end{gathered}
$$

\subsubsection{DEVELOPMENT OF DECISION LOGIC MAP (DLM)}

The application of MDP will result in providing the best solution based on reward maximization for each probable integrated state that an infrastructure may attain in future (i.e. in year 1, year 3, year 5 in within this research's scope). However, one assumption stated earlier was to keep transition probabilities matrix constant using the zoning 
concept for the decision analysis period (or the investment planning period). Therefore, in order to show continuity and impact of suggested maintenance actions at each stage of investment planning period, decision logic maps will be developed. DLM can be defined as "combined graphical representation of project level analysis outcomes (i.e. the suggested maintenance actions) and the logic with which possible transitions were defined under each maintenance action." A typical decision map is shown in Figure 5.5. Three columns are banded with different colors to signify future time stages, i.e. light blue for year 1, olive green for year 3, and red accent for year 5. For first year, the possible integrated state for any infrastructure (bridge) will correspond to its state level at current stage (or state of the latest performance evaluation year). The decision outcome from the MDP will be applied with respect to corresponding state (shown in the rectangles in the Figure 5.5). The arrow depicts that if a particular decision is applied based on the MDP, the outcomes will be transmitted to the next stage (year 3) and will create a chance node that can result in maximum of three possible outcomes. For example, if we look on the typical DLM, if the ISR of the bridge was 4 and a RPR is applied, this RPR action can result in either ISR of 2 or 3 based on the concept of which was utilized in the development of transition probability matrix for RPR action as explained in section 5.3.1.3.2. In year 3, if RPR action results in ISR of 2, MAIN action will be applied while if infrastructure attains state 3, RPR action will be required. Following the same procedure, rest of the possibilities are identified and decision logics are plotted for whole of the planning horizon. Each of the decision logic develops a 3stage decision path for the bridge based on its current state (i.e. planning year state or the latest available state). Based on the model set-up, any infrastructure (bridge) can have a 
maximum of 9 decision paths. The DLM provides a plan of action for future years (i.e. years $1,3,5$ ) considering the best suitable actions that can be made without consideration of the budgetary constraints. The decision makers can utilize DLM to assess the individual needs of a particular infrastructure for future. Thus, DLM will act as a decision support tool for the decision makers.

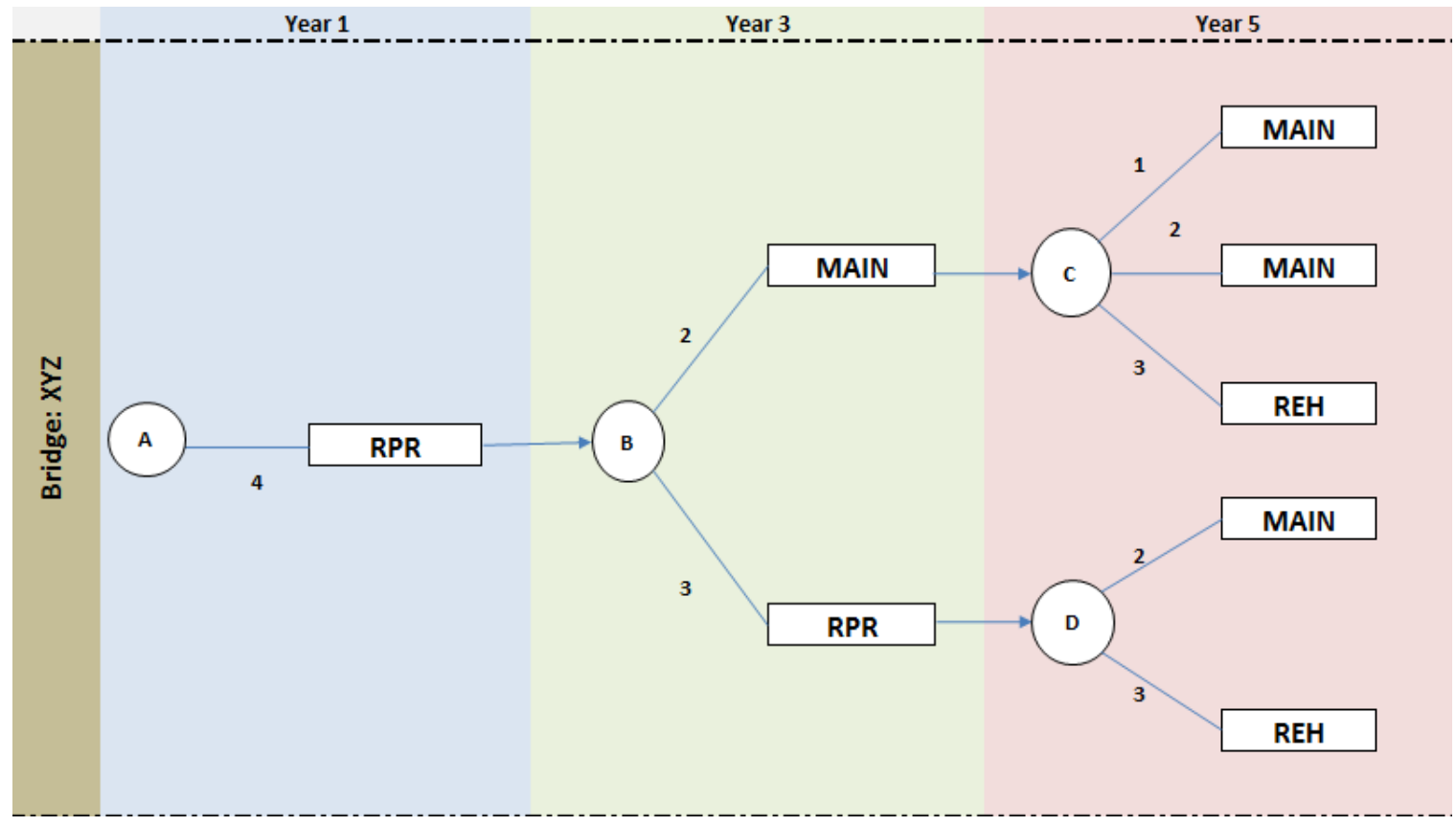

Figure 5.5: Decision Logic Map Example

\subsubsection{LEVEL 2: NETWORK LEVEL ANALYSIS}

For the purpose of this research, a network of infrastructure is defined as "set of infrastructure having a maintenance investment trade-off, and are present in same geographical region, under same decision-making entity that is responsible for their maintenance and preservation operations." The objective of network level analysis is to optimize the use of available budget taking portfolio investment approach to find out feasible portfolios. The feasible portfolio will be the one that will provide maximum 
benefits against its cost. The project level analysis has already resulted in providing a plan of action for future years considering the performance of multiple decision parameters, costs, benefits and probable state transitions that an infrastructure may go through in future. The outcomes of the project level analysis will be utilized as an input to the network level analysis and applied with a budgetary constraint. Network level analysis has four steps.

1. Assigning the cost and benefits to decision logic maps

2. Defining portfolios

3. Screening of portfolios to define feasible portfolios based on budgetary constraint

4. Eliciting the most feasible portfolio based on $\mathrm{B} / \mathrm{C}$ ratio and budget allocation to candidate infrastructure.

\subsubsection{ASSIGNING THE COST AND BENEFITS TO DECISION LOGIC MAPS}

The project level analysis provided decision logic maps (DLM). DLMs of the entire candidate infrastructure can be utilized to perform network level analysis. Each candidate infrastructure (bridge) has a maximum of 9 possible paths as mentioned earlier. The cost information will be assigned to each of the decision outcome nodes considering stage (year) of decision and certain interest rate (i) for future years (\$ amount at top of the decision outcome node in Figure 5.6). Similarly, benefits calculated for each of the each of the decision outcome nodes will be assigned considering stage (year) of decision and certain interest rate ( $i$ ) for future years (\$ amount at bottom of the decision outcomes node in Figure 5.6). Once cost and benefit information has been assigned, total cost and 
benefits of each decision path for planning period will be calculated by adding cost and benefits of individual outcome nodes. The same procedure for each decision logic path will be repeated for the decision logic maps of the entire candidate infrastructure included in the network. A typical representation (adapted from Chapter 6) is shown in figure 5.6.

\subsubsection{DEFINING PORTFOLIOS}

Once the DLM for individual infrastructure has been assigned with the cost and benefit information, possible portfolios will be defined. In this research portfolios will be termed as "all possible unique combinations of decision paths of candidate infrastructures included in the network considering each infrastructure will follow only one decision path at a time for a particular combination." This means that the number of unique possible portfolios will depend on the number of possible decision paths for each candidate and number of candidate infrastructure included in the network for analysis.

Mathematically, maximum number of possible paths can be represented as follows.

$$
n_{p}=S^{x}
$$

Where; $n_{p}=$ maximum number of possible portfolios

$$
S=\text { Number of possible decision paths }=9
$$

$x=$ Number of candidate infrastructure in a network 


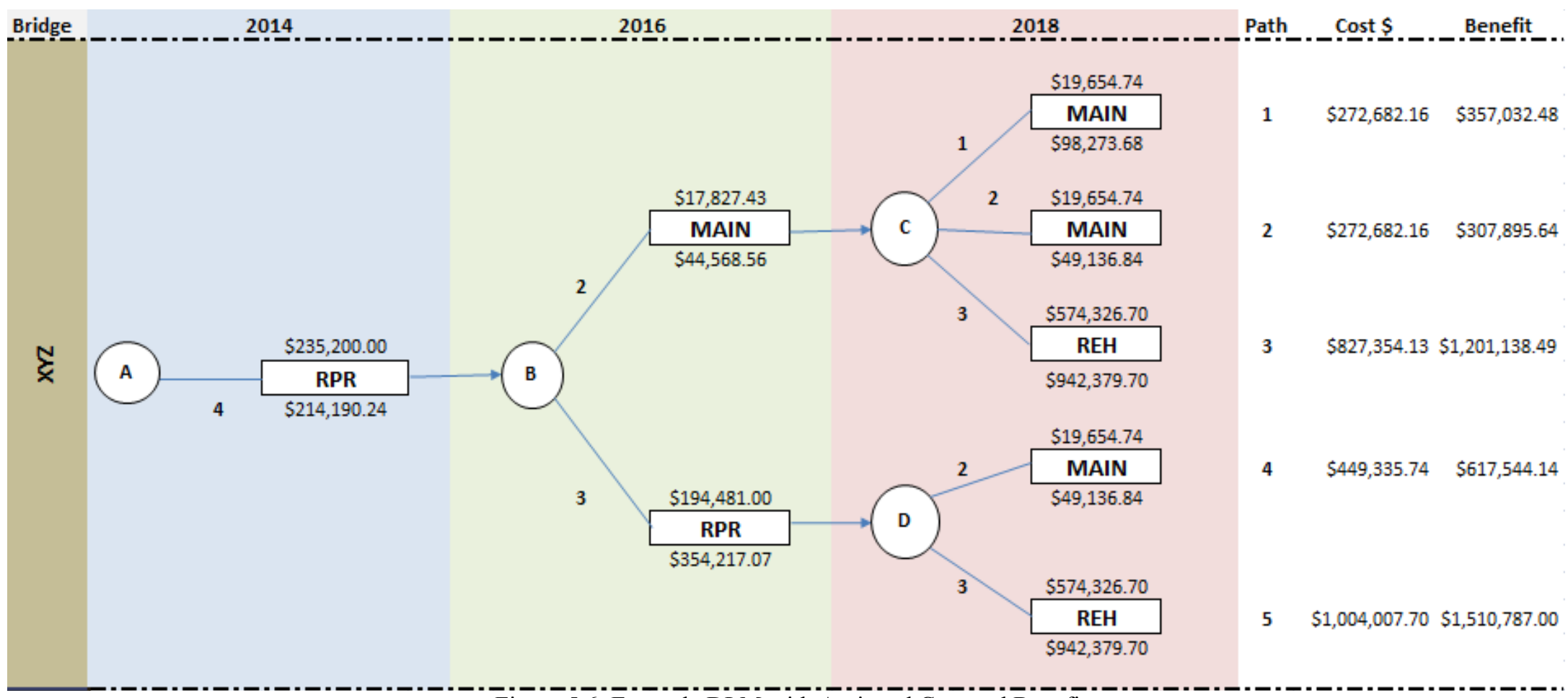

Figure 5.6: Example DLM with Assigned Cost and Benefits 
For example; if there are four candidate infrastructures, having nine decision paths each, the maximum number of possible portfolios based on state level combinations will be 6561. However, it is highly unlikely to get this high number of possible combinations. Therefore, the total number of possible portfolios will mostly be a customized (lesser) number depending upon possible decision paths for each of the candidate infrastructure.

\subsubsection{SCREENING OF PORTFOLIOS TO DETERMINE FEASIBLE PORTFOLIOS}

The cost of each portfolio will be found by adding cost of decision paths for individual candidate infrastructure included in portfolio. Afterwards, budget limit will be applied to screen out all feasible portfolios. The feasible portfolios will be the one which are within the available budget.

\subsubsection{FUNDING ALLOCATION TO CANDIDATE INFRASTRUCTURE}

The screening of feasible portfolio may result in identifying only one feasible portfolio, no feasible portfolio or more than one feasible portfolio. Therefore, a fund allocation strategy has been proposed to address different scenarios (Figure 5.7).

In case, one feasible portfolio is identified, it will automatically become the most feasible portfolio. Therefore, no further analysis will be required and funding will be allocated according to the decision paths that form feasible portfolio. 


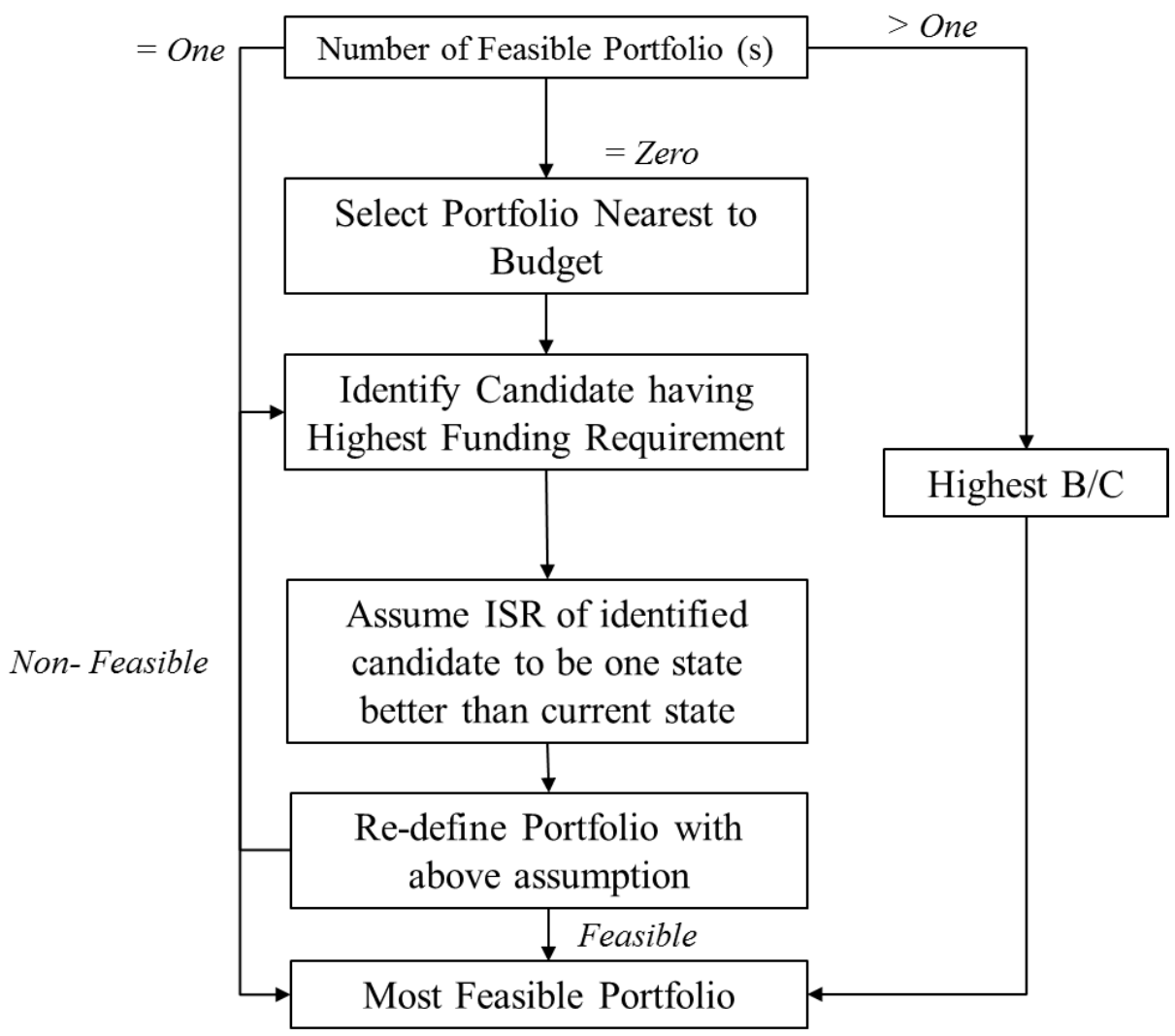

Figure 5.7: Funds Allocation Strategy

If no feasible portfolio have been identified, then portfolio that is nearest to budget limit can be selected and modified to make it within budgetary constraint and thus feasible. Following are proposed modification steps that can be applied.

1. Identify a candidate infrastructure included in the portfolio (i.e., portfolio having funding requirement nearest to budget limit) that has the highest funding requirement.

2. If the current state for that infrastructure is severe (5) or poor (4), assume it to be one state above its current state, i.e. poor (4) or fair (3) respectively, and re-define 
portfolio with this assumption (i.e. with modified costs for the identified candidate).

3. With the above assumption in step 3 , if the portfolio becomes feasible, funding will be allocated according to the decision paths that form that portfolio.

4. If still, modified portfolio comes out to be non-feasible, second modification will be applied. Identify candidate infrastructure with second highest funding requirement in the first modified portfolio. Apply steps 2 and 3 in order to make second modified portfolio feasible.

If screening for feasible portfolios results in more than one feasible portfolio, benefit-to cost ratio $(\mathrm{b} / \mathrm{c})$ will be calculated for all feasible portfolios and the one with highest $\mathrm{b} / \mathrm{c}$ ratio will be selected as the most feasible portfolio.

\subsection{REPORTING MODULE}

The reporting module consists of all useful decision support tools that have been obtained through, data modeling and analysis modules (i.e. both project and network level analysis). Following table 5.13 provides the useful decision support outcomes and their probable use by the decision-making entity. 
Table 5.13: Decision Support Outcomes and their Usefulness

\begin{tabular}{|c|c|c|}
\hline $\begin{array}{c}\text { Decision } \\
\text { Support Tools }\end{array}$ & Nature & Usefulness \\
\hline $\begin{array}{l}\text { Performance } \\
\text { Trend Curves }\end{array}$ & $\begin{array}{l}\text { Curves showing } \\
\text { different decision } \\
\text { parameters' } \\
\text { performance } \\
\text { trends. }\end{array}$ & $\begin{array}{l}\text { The decision makers can assess the } \\
\text { performance and usefulness of each of the } \\
\text { candidate infrastructures specially the extent to } \\
\text { which each individual infrastructure is } \\
\text { providing service to the public. This will } \\
\text { further help them while taking decisions to } \\
\text { spending funds on their maintenance. }\end{array}$ \\
\hline $\begin{array}{l}\text { Decision Logic } \\
\text { Maps (DLM) for } \\
\text { Candidate } \\
\text { Infrastructures }\end{array}$ & $\begin{array}{c}\text { Individual } \\
\text { decision tree style } \\
\text { networks }\end{array}$ & $\begin{array}{l}\text { Decision logic maps provide a plan of action } \\
\text { for the candidate infrastructures based on MDP } \\
\text { for the future stages (years) considering the } \\
\text { benefits provided by the infrastructure and } \\
\text { without considering any budgetary constraints. } \\
\text { This will provide real need assessment of each } \\
\text { individual candidate infrastructure. }\end{array}$ \\
\hline $\begin{array}{l}\text { Network Level } \\
\text { Maintenance } \\
\text { Investment Plan }\end{array}$ & Tabular & $\begin{array}{l}\text { The feasible portfolio considering the } \\
\text { budgetary constraints will be helpful for } \\
\text { budget allocation to each individual } \\
\text { infrastructure which is the part of the network. } \\
\text { It may also help as a rationale for procuring } \\
\text { budget from the higher organizational level (let } \\
\text { us say for district level to procure funds from } \\
\text { the States). }\end{array}$ \\
\hline
\end{tabular}

\subsection{CHAPTER SUMMARY}

This chapter discussed details of the framework for infrastructure maintenance investment decisions. It provided extensive step-by-step details in data modeling, project level analysis, and network level analysis modules. It analytically explained procedures, mathematics, and assumptions involved within each of the modules. Furthermore, it discussed the decision support outcomes as part of the reporting module. The next chapter will present implementation of the framework through case study. 


\section{CHAPTER-6: FRAMEWORK IMPLEMENTATION THROUGH CASE STUDY}

\subsection{INTRODUCTION}

This chapter presents implementation of the framework. The case study is conducted on a set of bridges for maintenance investment for next five years. The bridges are located in Pima County, Az. Pima County Department of Transportation (PCDOT) showed interest in the application of the proposed proto-type framework as described in the previous chapter. This provided excellent opportunity for the application of proposed decision support framework as PCDOT faces same sort of budgetary constraints as explained in the need for the proposed framework, and is willing to test some innovative way of managing its available funds for maintenance investment. The following sections describe the characteristics of geographical area for Pima County, decision-making group for the case study and detailed implementation of proposed framework and results. Finally, it presents feedback of decision-making group regarding various aspects of proto-type framework and its usefulness based on case study implementation.

\subsection{CHARACTERISTICS OF GEOGRAPHICAL AREA FOR CASE STUDY (PIMA COUNTY)}

Pima County is located in the south central region of Arizona, USA (Figure 6.1). 


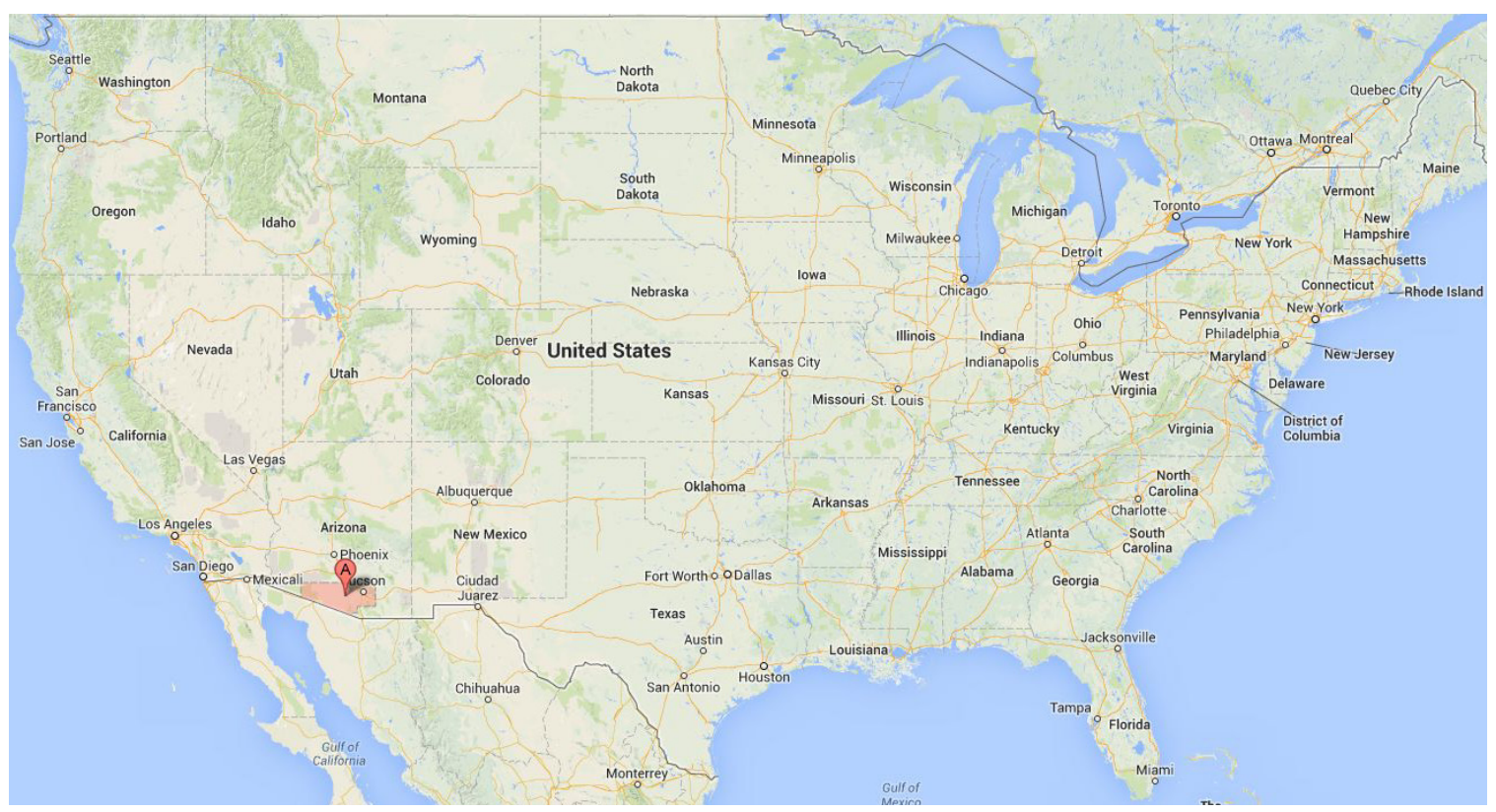

Figure 6.1: Pima County, AZ location.

The county has a total area of 9,188.83 square miles $(23,799.0 \mathrm{~km} 2)$, of which 9,186.27 square miles $(23,792.3 \mathrm{~km} 2)$ (or $99.97 \%)$ is land and 2.57 square miles (6.7 $\mathrm{km} 2$ ) (or $0.03 \%$ ) is water (Census 2000). The county has a population of more than 980,000 (Census 2010). Majority of county's population lives around city of Tuscon. Tuscon is second largest city in Arizona and is commercial and academic hub of the Pima County. Thus, the eastern part of the county has much of urbanized development. Some other urban areas include suburbs of Oro Valley, Marana, Sahuarita and south Tuscon. Pima County also contains Indian reservations such as parts of Tohono O'odham Nation, all of the San Xavier Indian Reservation, the Pascua Yaqui Indian Reservation (Figure $6.2)$. 


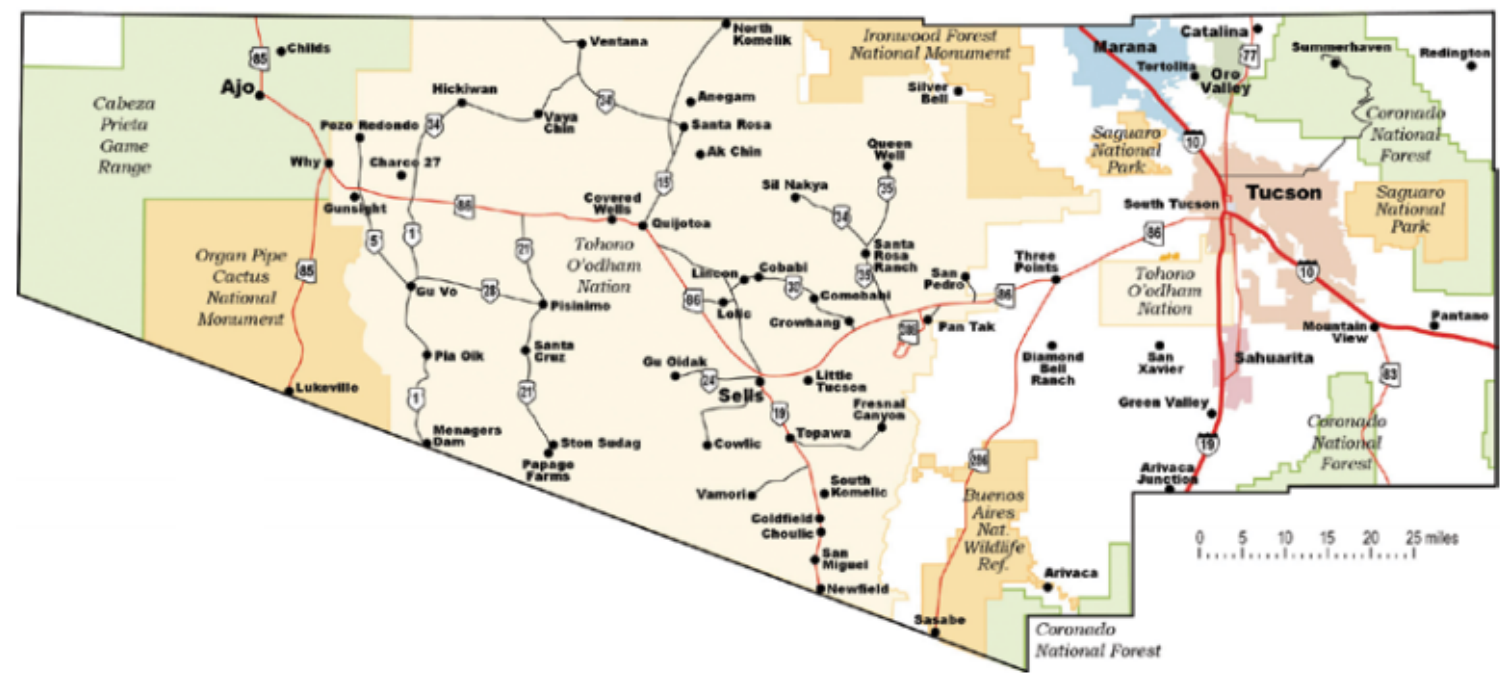

Figure 6.2: Pima County Map

\subsection{DECISION-MAKING GROUP FOR CASE STUDY}

One of the conclusions from state-of-the-practice survey was that the probable users of the proposed framework can be a decision-making committee. Therefore, for case study implementation, a decision-making group was formed comprising of four Pima County Department of Transportation Professionals (PCDOT) professionals. These professionals, in one way or the other, are involved in infrastructure maintenance/preservation investment decision-making from an overall perspective. The brief characteristics of the decision-making group members are as follows (Table 6.1).

Table 6.1: PCDOT Decision-Making Group for Case Study

\begin{tabular}{|l|c|c|}
\hline Role at PCDOT & $\begin{array}{c}\text { Overall } \\
\text { Professional } \\
\text { Experience }\end{array}$ & $\begin{array}{c}\text { Experience } \\
\text { with } \\
\text { PCDOT }\end{array}$ \\
\hline Deputy Director, Transportation Infrastructure & 23 Years & 7 Years \\
\hline Engineering Division Manager & 22 Years & 10 Years \\
\hline Civil Engineering Manager & 14 Years & 8 Years \\
\hline Bridge Engineer & 30 Years & 28 Years \\
\hline
\end{tabular}


The researcher coordinated with the decision-making group for various aspects of case study implementation. The main tasks included; inputs to the development of utility functions, identification of candidate infrastructure, data collection for performance assessment, cost and benefits input for candidate infrastructure, defining budget constraints, expert opinion for missing data, conformation and validation of different aspects of case study implementation.

\subsection{CHARACTERISTICS OF CANDIDATE INFRASTRUCTURE FOR CASE STUDY}

The case study focused on bridge infrastructure. It was necessary to have an agreed definition of candidate infrastructure in order to identify the candidate bridges for implementation of maintenance investment decision framework through case study. Therefore, following definition was developed and furthermore, shared with the decisionmaking group of PCDOT for their better understanding.

Such infrastructure (bridges) that have been under routine maintenance and neither had major condition based maintenance program or significant improvements through major rehabilitation or reconstruction in past years. However, those are now candidates for either of the decisions included in the set of actions defined for this research, i.e. preventive maintenance (MAIN), repair (RPR), rehabilitation (REH) and that an investment plan has to be developed for the next $4-5$ years within the budgetary constraint. The candidate should be from same network, i.e. under same decision-making entity related to preservation operations and investments related and geographical area. The projects may not be suffering from major structural safety issues. 
Based on the definition, four bridges were identified. The general characteristics of bridges are Table 6.2 while Figure 6.3 shows location map of bridges.

Table 6.2: General Characteristics of Candidate Bridges

\begin{tabular}{|l|l|l|l|l|l|}
\hline $\begin{array}{c}\text { Structure } \\
\text { Number/Name }\end{array}$ & $\begin{array}{c}\text { Year } \\
\text { Built }\end{array}$ & \multicolumn{1}{|c|}{ Road Name } & \multicolumn{1}{|c|}{ Feature Under } & \multicolumn{1}{c|}{$\begin{array}{c}\text { Structure } \\
\text { Type }\end{array}$} & $\begin{array}{c}\text { Dimensions } \\
\text { (Length/ } \\
\text { Width) }\end{array}$ \\
\hline $\begin{array}{l}\text { 9552-Santa Cruz } \\
\text { River Bridge }\end{array}$ & 1959 & $\begin{array}{l}\text { Trico-Marana } \\
\text { Road }\end{array}$ & Santa Cruz River & $\begin{array}{l}\text { Concrete/Tee } \\
\text { Beam }\end{array}$ & $\begin{array}{l}358 \mathrm{ft} . \\
/ 30 \mathrm{ft} .\end{array}$ \\
\hline $\begin{array}{l}\text { 8724-TV Pantano } \\
\text { Wash Bridge }\end{array}$ & 1982 & Craycroft Road & $\begin{array}{l}\text { Tanque Verde and } \\
\text { Pantano Wash } \\
\text { concrete } \\
\text { continuous/ } \\
\text { Box beam or } \\
\text { girders - } \\
\text { Multiple }\end{array}$ & $\begin{array}{l}841 \mathrm{ft} . \\
/ 72 \mathrm{ft} .\end{array}$ \\
\hline $\begin{array}{l}7760 \text { Tanque Verde } \\
\text { CR Bridge }\end{array}$ & 1989 & Houghton Road & $\begin{array}{l}\text { Tanque Verde } \\
\text { Creek }\end{array}$ & $\begin{array}{l}\text { Prestressed } \\
\text { concrete/ Box } \\
\text { beam or } \\
\text { girders - } \\
\text { Multiple }\end{array}$ & $\begin{array}{l}1100 \mathrm{ft} . \\
/ 42 \mathrm{ft} .\end{array}$ \\
\hline $\begin{array}{l}\text { 8318-Mission Road } \\
\text { OP }\end{array}$ & 1973 & $\begin{array}{l}\text { IRR Mission } \\
\text { Road }\end{array}$ & Mine Haul Road & $\begin{array}{l}\text { Prestressed } \\
\text { concrete/ } \\
\text { Stringer/Mult } \\
\text { i-beam or } \\
\text { girder }\end{array}$ & $\begin{array}{l}240 \mathrm{ft} . \\
/ 41.5 \mathrm{ft} .\end{array}$ \\
\hline
\end{tabular}




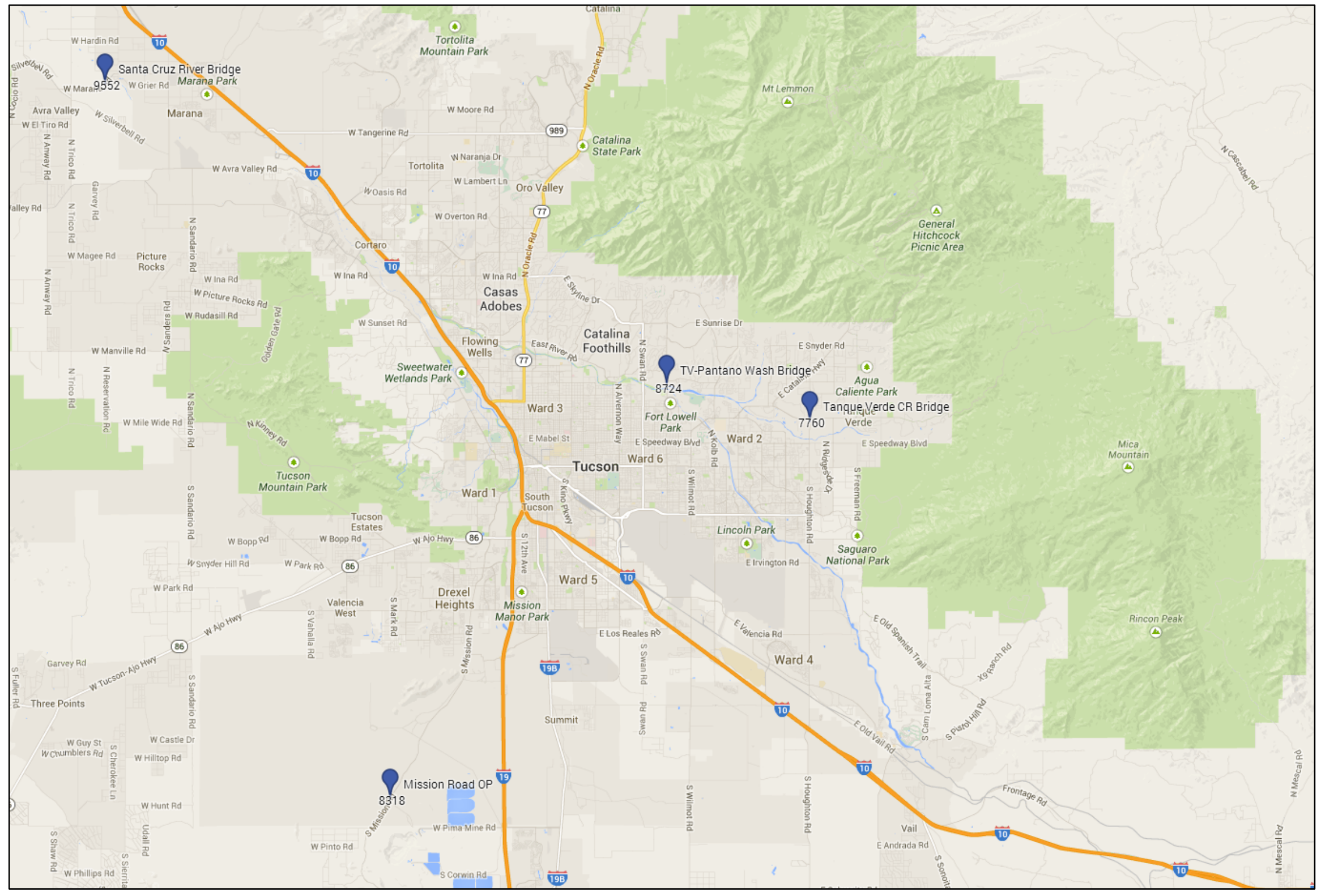

Figure 6.3: Location Map of Candidate Bridges 


\subsection{DEVELOPMENT OF MULTI-ATTRIBUTE UTILITY FUNCTION}

As it was explained earlier in chapter 5, determination of Integrated State Rating (ISR) has four steps as follows.

1. Developing Single Attribute Utility Function (SAUF) for each parameter.

2. Determining the Scaling Factor.

3. Development of Multi Attribute Utility Function (MAUF).

4. Conversion of Multi Attribute Utility (MAU) to Integrated State Rating (ISR).

The above steps were implemented with Pima County decision-making group formed for the case study. For the development of single attribute utility function, each of the four decision-making group members was provided with "Tool for Evaluating Single Attribute Utility Curve" (Appendix B). The tool was basically a set of worksheets that provided with the instructions, purpose technique utilized and how to use the tool. Then, it provided the list of factors included in each of the decision parameters.

Afterwards, three lotteries were presented for each of the decision parameter to evaluate corresponding acceptable performance level for utility values of 0.5 , 0.25 and 0.75. First, the lottery for evaluating performance level (PL) for a utility of 0.5 was presented, i.e. to find out acceptable or desired performance level between $20 \%$ and $100 \%$ against a $50: 50$ chance of it certainly being $20 \%$ or $100 \%$. Then, the identified performance level for utility of 0.5 was used to present the second lottery for evaluation of acceptable or desired performance 
level for a utility of 0.25 between $20 \%$ and $\mathrm{PL}_{0.5}$ against a 50:50 chance of it certainly being $20 \%$ or $\mathrm{PL}_{0.5}$. In a similar way, third lottery was presented for evaluating performance level for a utility of 0.75 presented, i.e. to find out acceptable or desired performance level (PL) between $20 \%$ and $100 \%$ against a 50:50 chance of it certainly being $\mathrm{PL}_{0.5}$ or $100 \%$.

The provided responses for performance levels by the four members of the decision-making group was averaged out to find out the final performance level that can represent the desired or acceptable performance levels for the Pima County. Thus, five pairs (performance level, utility) i.e. $(20 \%, 0),\left(\mathrm{PL}_{0.25}, 0.25\right)$, $\left(\mathrm{PL}_{0.5}, 0.5\right),\left(\mathrm{PL}_{0.75}, 0.75\right)$ and $(100 \%, 1)$. The identified pair for each of the decision parameters were plotted individually (using MS Excel), and curve fitting was applied using the trend line option to develop single attribute utility curves and define SAU functions for each of the decision parameters. The four Single Attribute Utility (SAU) curves of the four decision parameter are presented in Figures 6.4 through 6.7. The SAU function (rounded up to two decimal places for representation) for each decision parameters are as follows.

$$
\begin{aligned}
& U\left(P L_{S T}\right)=\left[1.26 \times 10^{-7}\left(P L_{S T}\right)^{4}-3.62 \times 10^{-5}\left(P L_{S T}\right)^{3}+3.53 \times 10^{-3}\left(P L_{S T}\right)^{2}\right. \\
& \left.-0.12\left(P L_{S T}\right)+1.23\right] \\
& U\left(P L_{S E}\right)=\left[-1.19 \times 10^{-7}\left(P L_{S E}\right)^{4}+2.69 X 10^{-5}\left(P L_{S E}\right)^{3}-1.95 X 10^{-3}\left(P L_{S E}\right)^{2}\right. \\
& \left.+0.06\left(P L_{S E}\right)-0.67\right] \\
& U\left(P L_{U T}\right)=\left[1.01 \times 10^{-4}\left(P L_{U T}\right)^{2}+6.91 \times 10^{-4}\left(P L_{U T}\right)-0.06\right] \\
& U\left(P L_{P C}\right)=\left[1.22 \times 10^{-4}\left(P L_{P C}\right)^{2}-1.89 \times 10^{-3}\left(P L_{P C}\right)-0.01\right]
\end{aligned}
$$




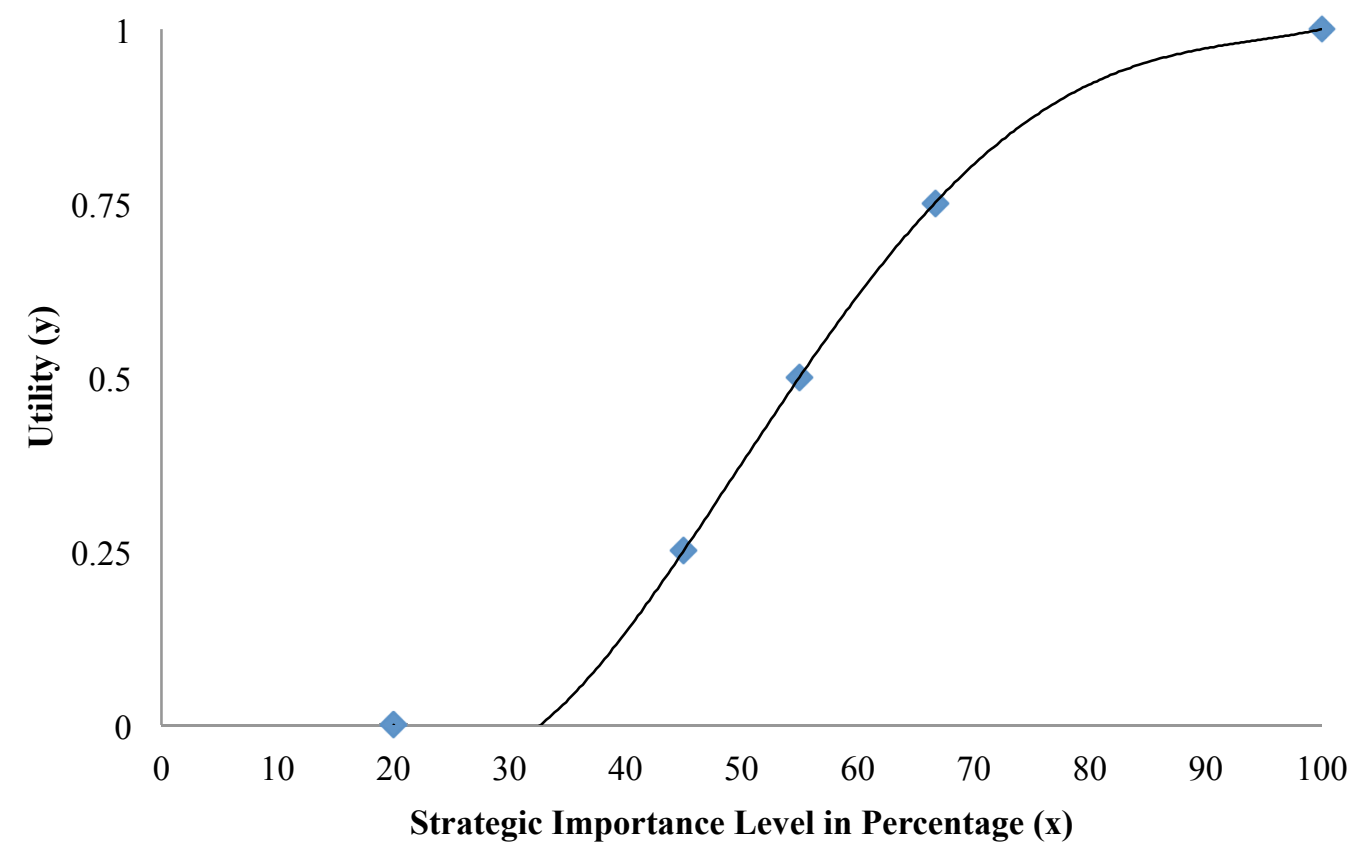

Figure 6.4: SAU Curve for Strategic Importance

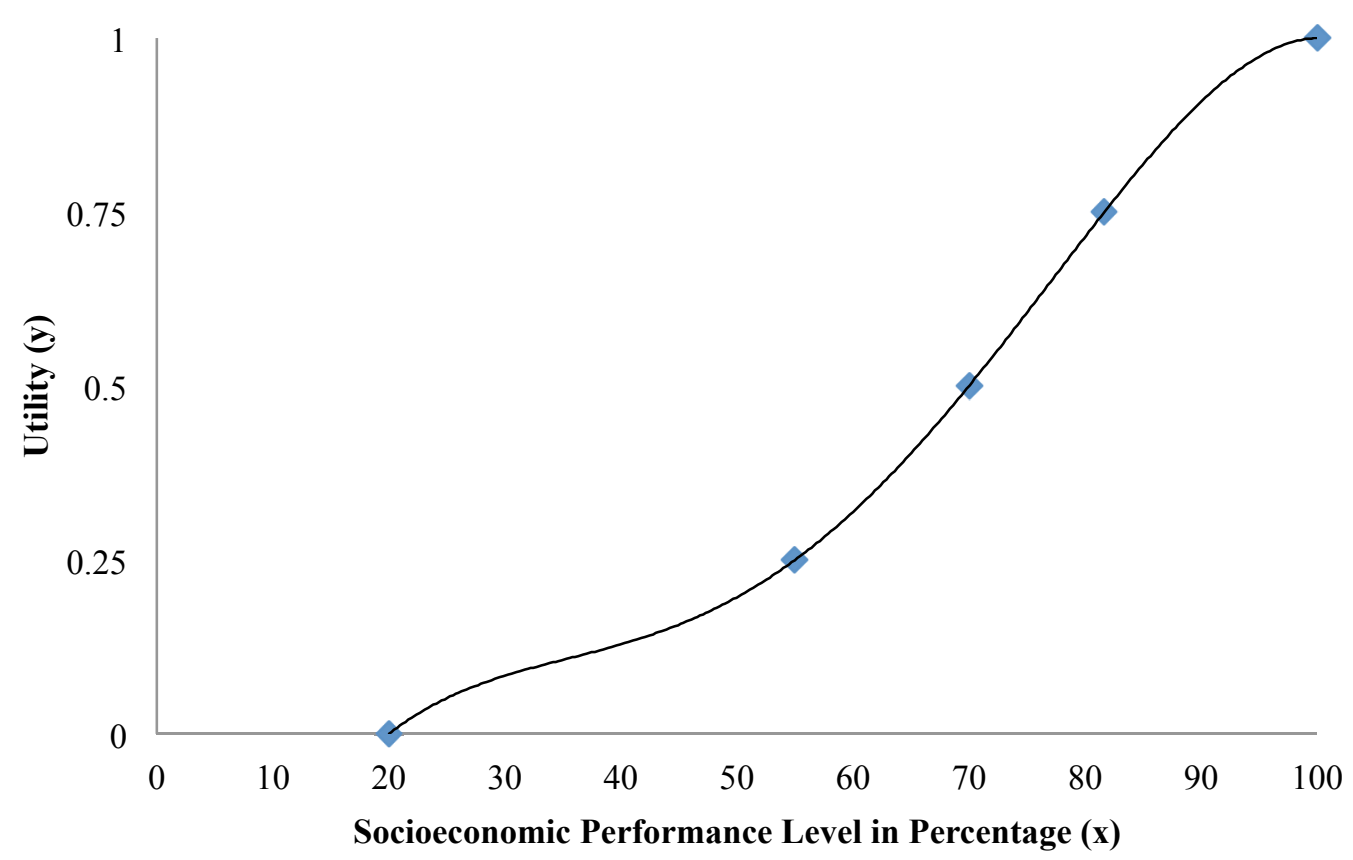

Figure 6.5: SAU Curve for Socioeconomic Contribution 


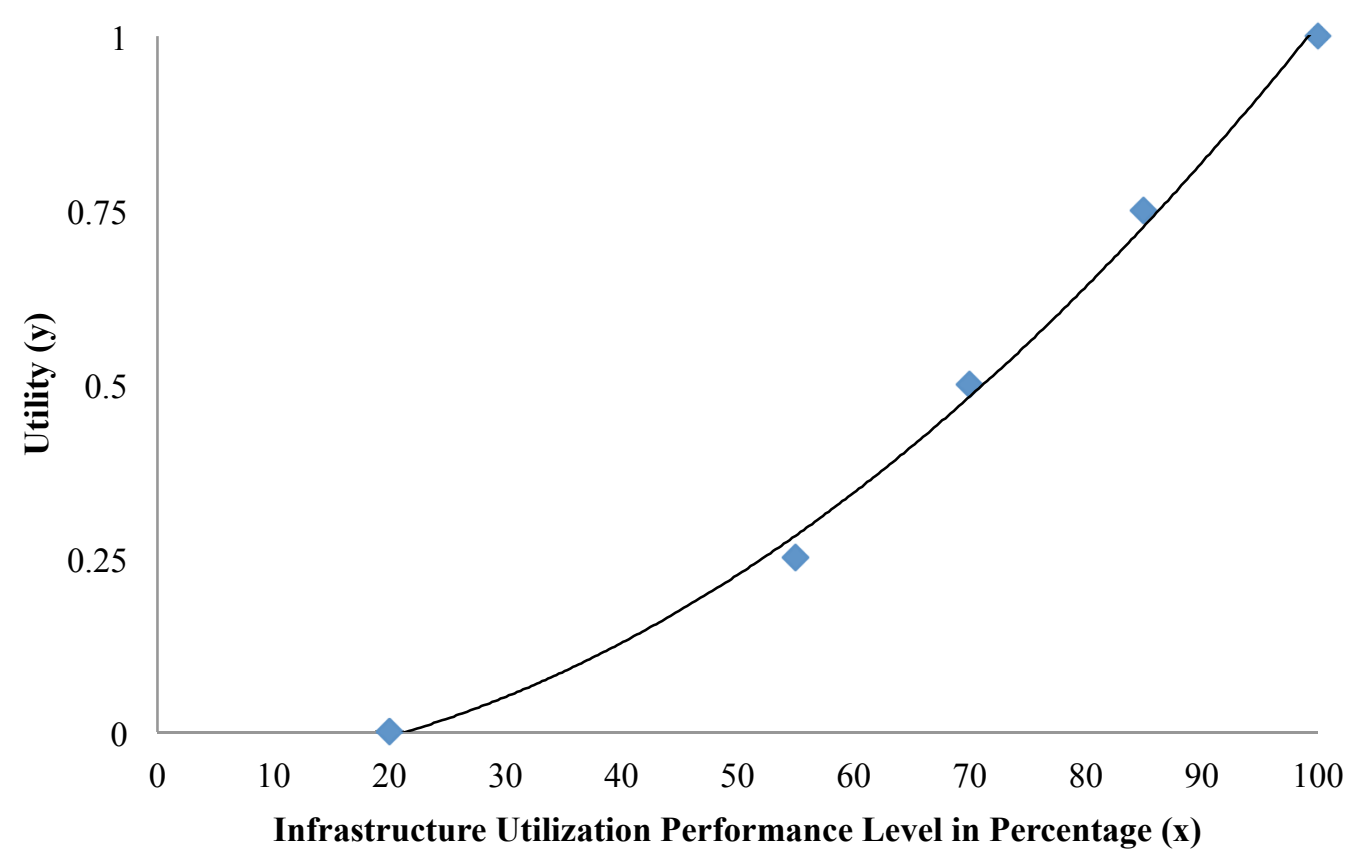

Figure 6.6: SAU Curve for Infrastructure Utilization

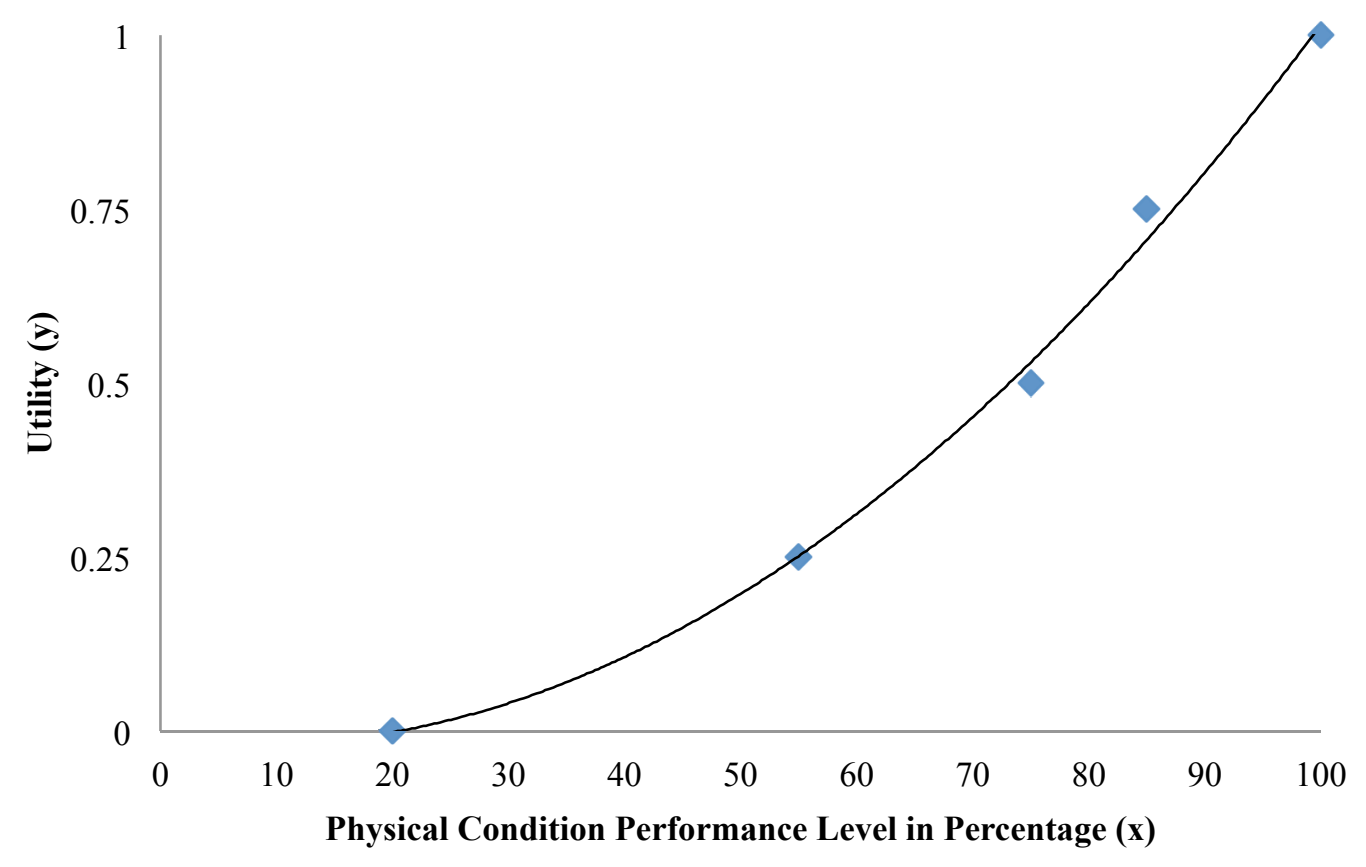

Figure 6.7: SAU Curve for Physical Condition 
Once the SAU functions were developed, scaling factors were determined for each decision parameter. As already mentioned in section 5.2.2.2, certainty-lottery approach was used for determination of scaling factors. The evaluation of the scaling factor was also made part of the "Tool for Evaluating Single Attribute Utility Curve." However, for scaling factor, decision-making group was asked to respond with one agreed value of probability of strategy shift ( $\left.\mathrm{p}^{\prime}\right)$ (i.e. shift from lottery strategy to the certain strategy or vice versa) for each decision parameter. The reason was to simplify process of determining scaling factors as well as the fact that scaling factor basically reflects the decision-making agency's preference of the attributes (i.e. decision parameters) as a whole. One of the members from the decision-making group of the PCDOT was explained process of evaluating the scaling factor who acted as facilitator to evaluate the scaling factors by discussing it further with the rest of the group members. Based on the response from the decision-making group, Table 6.3 shows the values of $\mathrm{p}^{\prime}$ and calculation of scaling factors.

Table 6.3: Scaling Factors for Decision Parameters

\begin{tabular}{|l|c|c|}
\hline \multicolumn{1}{|c|}{ Decision Parameter } & $\begin{array}{c}\text { Probability of Strategy shift } \\
\mathbf{p}^{\prime}\end{array}$ & $\begin{array}{c}\text { Scaling Factors } \\
\left(\boldsymbol{k}_{\boldsymbol{i}}=\mathbf{p}^{\prime} / \mathbf{1 0 0}\right)\end{array}$ \\
\hline Strategic Importance & $15 \%$ & 0.15 \\
\hline Socioeconomic & $25 \%$ & 0.25 \\
\hline Infrastructure Utilization & $25 \%$ & 0.25 \\
\hline Physical Condition & $35 \%$ & 0.35 \\
\hline \multicolumn{2}{|r|}{} & 1 \\
\hline
\end{tabular}


After evaluation of scaling factors, normalizing factor $(K)$ is required to be computed. Since, the sum of scaling factors of all decision parameters comes out to be 1 ; normalizing factor $(K)$ will be equal to zero. Therefore, multi attribute utility function (MAUF) will be determined through additive form as already explained in section 5.2.2.3. Additive form of function will be as follows.

$$
U(P L)=k_{S T}\left[U_{S T}\right]+k_{S E}\left[U_{S E}\right]+k_{U T}\left[U_{U T}\right]+k_{P C}\left[U_{P C}\right]
$$

Considering SAU functions, scaling factors and additive form, following is the equation (rounded up to two decimal places for representation) for MAUF developed for the case study.

$$
\begin{array}{rl}
\mathbf{U}(\mathbf{P L})=\mathbf{0 . 1 5} & X\left[1.26 \times 10^{-7}\left(P L_{S T}\right)^{4}-3.62 \times 10^{-5}\left(P L_{S T}\right)^{3}+3.53 \times 10^{-3}\left(P L_{S T}\right)^{2}\right. \\
& \left.-0.12\left(P L_{S T}\right)+1.23\right] \\
& +\mathbf{0 . 2 5} X\left[-1.19 \times 10^{-7}\left(P L_{S E}\right)^{4}+2.69 \times 10^{-5}\left(P L_{S E}\right)^{3}\right. \\
& \left.-1.95 \times 10^{-3}\left(P L_{S E}\right)^{2}+0.06\left(P L_{S E}\right)-0.67\right] \\
& +\mathbf{0 . 2 5} \times\left[1.01 \times 10^{-4}\left(P L_{U T}\right)^{2}+6.91 \times 10^{-4}\left(P L_{U T}\right)-0.06\right] \\
& +\mathbf{0 . 3 5} \times\left[1.22 \times 10^{-4}\left(P L_{P C}\right)^{2}-1.89 \times 10^{-3}\left(P L_{P C}\right)-0.01\right]
\end{array}
$$

\subsection{PERFORMANCE MEASUREMENT AND INTEGRATED STATE} RATING (ISR)

Performance for four decision parameters was measured through assessment of performance for various factors included within each parameter as explained in section 5.2.1. The performance were measured considering two 
years transitions for the candidate bridges included in the case study based on the availability of data provided by for the periods shown in table 6.4 .

Table 6.4: Data Availability Period for Candidate Bridges

\begin{tabular}{|c|c|}
\hline Bridge Number & Period for Performance Measurement \\
\hline 7760 & 1990 to 2012 \\
\hline 8318 & 1980 to 2012 \\
\hline 8724 & 1984 to 2012 \\
\hline 9552 & 1988 to 2012 \\
\hline
\end{tabular}

The data for performance measurement was mainly elicited from the National Bridge Inventory (NBI) reports. However, the factors for which no direct information was available in the NBI reports, or for which updated data was not available, multiple sources included but not limited to other agency's publications, data bases, annual reports, maps, and expert opinion (provided by decision-making group) etc. The detail of data sources is provided in Table 6.5.

Once, performances have been measured, the MAU function developed was then used to find out multi attribute utility of each candidate bridge for past years using the performance measurement of decision parameters. Afterwards, calculated multi attribute utilities were converted to Integrated State Ratings (ISR) for candidate bridges using conversion scale discussed in section 5.2.2.4 and provided in table 5.5. Tables 6.6 through 6.9 provides details of performance and MAU calculated alongside corresponding ISR for each of the candidate bridges. 
Table 6.5: Data Sources Details for Performance Measurement

\begin{tabular}{|c|c|c|}
\hline Factor & Data Source & Comments \\
\hline \multicolumn{3}{|c|}{ Strategic Importance } \\
\hline ST-1 Alternative Routes & NBI Reports & \\
\hline ST-2 Emergency Reponses Route & $\begin{array}{c}\text { Emergency route map } \\
\text { developed with } \\
\text { information provided by } \\
\text { Pima Association of } \\
\text { Government (PAG) }\end{array}$ & See Appendix C \\
\hline ST-3 Defense Considerations & NBI Reports & \\
\hline ST-4 Age of Infrastructure & NBI Reports & \\
\hline \multicolumn{3}{|c|}{ Socioeconomic Contribution } \\
\hline SE-1 Accessibility & & $\begin{array}{c}\text { Expert opinion by } \\
\text { decision-making group }\end{array}$ \\
\hline SE-2 Affordability & NBI Reports & $\begin{array}{l}\text { Elicitation using NBI } \\
\text { Item N-42 Service Type }\end{array}$ \\
\hline SE-3 Traffic Safety & NBI Reports & \\
\hline SE-4 Quality of Travel & $\begin{array}{l}\text { Texas Transportation } \\
\text { Institute Mobility Data }\end{array}$ & See Appendix C \\
\hline \multicolumn{3}{|c|}{ Infrastructure Utilization } \\
\hline UT-1 Quantity of Travel & $\begin{array}{l}\text { NBI Reports, PAG } \\
\text { Maps }\end{array}$ & \\
\hline $\begin{array}{l}\text { UT-2 Congestion (congested } \\
\text { conditions) }\end{array}$ & $\begin{array}{c}\text { Congestion Maps by } \\
\text { PAG }\end{array}$ & See Appendix C \\
\hline UT-3 Commercial Traffic & NBI Reports & \\
\hline UT-4 Freight Load Capacity & NBI Reports & \\
\hline \multicolumn{3}{|c|}{ Physical Condition } \\
\hline PC-1 Deck Condition & NBI Reports & \\
\hline PC-2 Super Structure Condition & NBI Reports & \\
\hline PC-3 Sub-Structure Condition & NBI Reports & \\
\hline PC-4 Channel Condition & NBI Reports & \\
\hline
\end{tabular}


Table 6.6: Performance Measurement Results for Bridge 7760

\begin{tabular}{|c|c|c|c|c|c|c|c|c|c|c|}
\hline $\begin{array}{c}\text { Bridge } \\
7760\end{array}$ & \multicolumn{2}{|c|}{ Strategic } & \multicolumn{2}{|c|}{ Socioeconomic } & \multicolumn{2}{|c|}{$\begin{array}{c}\text { Infrastructure } \\
\text { Utilization }\end{array}$} & \multicolumn{2}{|c|}{$\begin{array}{l}\text { Physical } \\
\text { Condition }\end{array}$} & \multirow{2}{*}{ MAU } & \multirow{2}{*}{ ISR } \\
\hline Year & $\begin{array}{c}\text { PL }_{\text {ST }} \\
(\%)\end{array}$ & SAU & $\begin{array}{l}\text { PL }_{\text {SE }} \\
(\%)\end{array}$ & SAU & $\begin{array}{l}\text { PL }_{\text {UT }} \\
(\%)\end{array}$ & SAU & $\begin{array}{c}\text { PL }_{\mathbf{P C}} \\
(\%)\end{array}$ & SAU & & \\
\hline 1990 & 6.50 & 0.60 & 72.76 & 0.56 & 63.70 & 0.39 & 90.00 & 0.80 & 0.61 & 2 \\
\hline 1992 & 7.50 & 0.53 & 70.77 & 0.52 & 66.45 & 0.43 & 80.00 & 0.61 & 0.53 & 3 \\
\hline 1994 & 8.50 & 0.46 & 71.65 & 0.53 & 65.83 & 0.42 & 77.50 & 0.57 & 0.51 & 3 \\
\hline 1996 & 9.50 & 0.39 & 71.10 & 0.52 & 66.35 & 0.43 & 77.50 & 0.57 & 0.50 & 3 \\
\hline 1998 & 10.50 & 0.33 & 70.01 & 0.50 & 61.45 & 0.36 & 77.50 & 0.57 & 0.47 & 3 \\
\hline 2000 & 11.50 & 0.28 & 69.69 & 0.49 & 61.75 & 0.37 & 77.50 & 0.57 & 0.46 & 3 \\
\hline 2002 & 12.50 & 0.23 & 69.52 & 0.49 & 61.93 & 0.37 & 75.00 & 0.53 & 0.43 & 3 \\
\hline 2004 & 13.50 & 0.19 & 60.67 & 0.33 & 62.45 & 0.38 & 75.00 & 0.53 & 0.39 & 3 \\
\hline 2006 & 14.50 & 0.15 & 60.38 & 0.32 & 62.83 & 0.38 & 77.50 & 0.57 & 0.40 & 3 \\
\hline 2008 & 15.50 & 0.11 & 53.36 & 0.23 & 63.35 & 0.39 & 70.00 & 0.45 & 0.33 & 4 \\
\hline 2010 & 16.50 & 0.08 & 53.80 & 0.24 & 62.90 & 0.38 & 75.00 & 0.53 & 0.35 & 3 \\
\hline 2012 & 17.50 & 0.05 & 52.33 & 0.22 & 62.55 & 0.38 & 72.50 & 0.49 & 0.33 & 4 \\
\hline
\end{tabular}

Table 6.7: Performance Measurement Results for Bridge 8318

\begin{tabular}{|c|c|c|c|c|c|c|c|c|c|c|}
\hline $\begin{array}{c}\text { Bridge } \\
8318 \\
\end{array}$ & Stra & gic & Socioe & nomic & $\begin{array}{r}\text { Infrast } \\
\text { Utiliz }\end{array}$ & $\begin{array}{l}\text { cture } \\
\text { tion }\end{array}$ & $\begin{array}{l}\text { Phy } \\
\text { Con }\end{array}$ & & MAU & ISP \\
\hline Year & $\begin{array}{l}\text { PL }_{S T} \\
(\%)\end{array}$ & SAU & $\begin{array}{l}\text { PL } \\
(\%)\end{array}$ & SAU & $\begin{array}{l}\text { PL }_{\mathrm{UT}} \\
(\%)\end{array}$ & SAU & $\begin{array}{l}\text { PLPC } \\
(\%)\end{array}$ & SAU & INAOU & ISK \\
\hline 1980 & 17.25 & 0.06 & 35.00 & 0.11 & 75.00 & 0.56 & 75.00 & 0.53 & 0.36 & 4 \\
\hline 1982 & 18.25 & 0.03 & 62.98 & 0.37 & 50.28 & 0.23 & 75.00 & 0.53 & 0.34 & 4 \\
\hline 1984 & 18.00 & 0.04 & 64.80 & 0.40 & 50.20 & 0.23 & 80.00 & 0.61 & 0.38 & 4 \\
\hline 1986 & 19.00 & 0.02 & 64.85 & 0.40 & 50.15 & 0.23 & 73.33 & 0.50 & 0.34 & 4 \\
\hline 1988 & 20.00 & 0.00 & 64.88 & 0.40 & 50.13 & 0.23 & 73.33 & 0.50 & 0.33 & 4 \\
\hline 1990 & 21.00 & 0.02 & 64.58 & 0.40 & 44.20 & 0.17 & 73.33 & 0.50 & 0.31 & 4 \\
\hline 1992 & 22.00 & 0.03 & 64.75 & 0.40 & 50.35 & 0.23 & 56.67 & 0.27 & 0.25 & 4 \\
\hline 1994 & 23.00 & 0.04 & 58.53 & 0.30 & 50.73 & 0.23 & 63.33 & 0.36 & 0.25 & 4 \\
\hline 1996 & 24.00 & 0.04 & 58.47 & 0.30 & 50.80 & 0.23 & 63.33 & 0.36 & 0.25 & 4 \\
\hline 1998 & 25.00 & 0.05 & 58.48 & 0.30 & 50.78 & 0.23 & 63.33 & 0.36 & 0.25 & 4 \\
\hline 2000 & 26.00 & 0.05 & 58.49 & 0.30 & 50.78 & 0.23 & 63.33 & 0.36 & 0.25 & 4 \\
\hline 2002 & 27.00 & 0.05 & 58.48 & 0.30 & 50.75 & 0.23 & 63.33 & 0.36 & 0.25 & 4 \\
\hline 2004 & 28.00 & 0.04 & 64.76 & 0.40 & 50.75 & 0.23 & 56.67 & 0.27 & 0.25 & 4 \\
\hline 2006 & 29.00 & 0.04 & 58.54 & 0.30 & 50.73 & 0.23 & 50.00 & 0.20 & 0.20 & 5 \\
\hline 2008 & 30.00 & 0.03 & 64.82 & 0.40 & 50.70 & 0.23 & 53.33 & 0.23 & 0.24 & 4 \\
\hline 2010 & 31.00 & 0.02 & 64.75 & 0.40 & 50.65 & 0.23 & 53.33 & 0.23 & 0.24 & 4 \\
\hline 2012 & 32.00 & 0.01 & 58.54 & 0.30 & 50.98 & 0.24 & 50.00 & 0.20 & 0.20 & 5 \\
\hline
\end{tabular}


Table 6.8: Performance Measurement Results for Bridge 8724

\begin{tabular}{|c|c|c|c|c|c|c|c|c|c|c|}
\hline \multirow{2}{*}{$\begin{array}{c}\begin{array}{c}\text { Bridge } \\
8724\end{array} \\
\text { Year }\end{array}$} & \multicolumn{2}{|c|}{ Strategic } & \multicolumn{2}{|c|}{ Socioeconomic } & \multicolumn{2}{|c|}{$\begin{array}{c}\text { Infrastructure } \\
\text { Utilization }\end{array}$} & \multicolumn{2}{|c|}{$\begin{array}{c}\text { Physical } \\
\text { Condition }\end{array}$} & \multirow{2}{*}{ MAU } & \multirow{2}{*}{ ISR } \\
\hline & $\begin{array}{c}\text { PLsT } \\
(\%)\end{array}$ & SAU & $\begin{array}{l}\text { PLsE } \\
(\%)\end{array}$ & SAU & $\begin{array}{c}\mathbf{P L}_{\mathrm{UT}} \\
(\%)\end{array}$ & SAU & $\begin{array}{c}\mathbf{P L}_{\mathbf{P C}} \\
(\%)\end{array}$ & SAU & & \\
\hline 1984 & 7.25 & 0.54 & 43.45 & 0.15 & 93.55 & 0.89 & 80.00 & 0.61 & 0.56 & 3 \\
\hline 1986 & 8.25 & 0.47 & 43.39 & 0.15 & 87.35 & 0.77 & 75.00 & 0.53 & 0.49 & 3 \\
\hline 1988 & 9.25 & 0.41 & 43.58 & 0.15 & 80.65 & 0.65 & 72.50 & 0.49 & 0.43 & 3 \\
\hline 1990 & 10.25 & 0.35 & 50.40 & 0.20 & 71.80 & 0.51 & 80.00 & 0.61 & 0.44 & 3 \\
\hline 1992 & 11.25 & 0.29 & 60.33 & 0.32 & 63.15 & 0.38 & 75.00 & 0.53 & 0.41 & 3 \\
\hline 1994 & 12.25 & 0.24 & 51.07 & 0.21 & 63.65 & 0.39 & 77.50 & 0.57 & 0.39 & 4 \\
\hline 1996 & 13.25 & 0.20 & 60.30 & 0.32 & 62.90 & 0.38 & 72.50 & 0.49 & 0.38 & 4 \\
\hline 1998 & 14.25 & 0.16 & 61.35 & 0.34 & 61.60 & 0.36 & 72.50 & 0.49 & 0.37 & 4 \\
\hline 2000 & 15.25 & 0.12 & 61.69 & 0.35 & 61.28 & 0.36 & 70.00 & 0.45 & 0.35 & 4 \\
\hline 2002 & 16.25 & 0.09 & 61.77 & 0.35 & 61.20 & 0.36 & 70.00 & 0.45 & 0.35 & 4 \\
\hline 2004 & 17.25 & 0.06 & 68.54 & 0.47 & 60.70 & 0.35 & 70.00 & 0.45 & 0.37 & 4 \\
\hline 2006 & 18.25 & 0.03 & 68.96 & 0.48 & 60.28 & 0.35 & 70.00 & 0.45 & 0.37 & 4 \\
\hline 2008 & 19.25 & 0.01 & 69.65 & 0.49 & 72.33 & 0.52 & 67.50 & 0.41 & 0.40 & 4 \\
\hline 2010 & 20.25 & 0.00 & 69.16 & 0.48 & 72.83 & 0.52 & 67.50 & 0.41 & 0.40 & 4 \\
\hline 2012 & 21.25 & 0.02 & 69.16 & 0.48 & 72.58 & 0.52 & 67.50 & 0.41 & 0.39 & 4 \\
\hline
\end{tabular}

Table 6.9: Performance Measurement Results for Bridge 9552

\begin{tabular}{|c|c|c|c|c|c|c|c|c|c|c|}
\hline $\begin{array}{c}\text { Bridge } \\
9552\end{array}$ & \multicolumn{2}{|c|}{ Strategic } & \multicolumn{2}{|c|}{ Socioeconomic } & \multicolumn{2}{|c|}{$\begin{array}{c}\text { Infrastructure } \\
\text { Utilization }\end{array}$} & \multicolumn{2}{|c|}{$\begin{array}{l}\text { Physical } \\
\text { Condition }\end{array}$} & \multirow{2}{*}{ MAU } & \multirow{2}{*}{ ISR } \\
\hline Year & $\begin{array}{l}\text { PL }_{S T} \\
(\%)\end{array}$ & SAU & $\begin{array}{l}\text { PL } \\
(\%)\end{array}$ & $\mathbf{S A U}$ & $\begin{array}{l}\text { PL }_{\text {UT }} \\
(\%)\end{array}$ & $\mathbf{S A U}$ & $\begin{array}{l}\text { PLPC } \\
(\%)\end{array}$ & SAU & & \\
\hline 1988 & 21.00 & 0.02 & 39.29 & 0.13 & 50.50 & 0.23 & 76.67 & 0.56 & 0.28 & 4 \\
\hline 1990 & 22.00 & 0.03 & 38.76 & 0.12 & 51.33 & 0.24 & 70.00 & 0.45 & 0.24 & 4 \\
\hline 1992 & 23.00 & 0.04 & 38.99 & 0.12 & 51.08 & 0.24 & 63.33 & 0.36 & 0.21 & 4 \\
\hline 1994 & 24.00 & 0.04 & 39.00 & 0.12 & 51.05 & 0.24 & 63.33 & 0.36 & 0.21 & 4 \\
\hline 1996 & 25.00 & 0.05 & 38.88 & 0.12 & 51.20 & 0.24 & 60.00 & 0.31 & 0.19 & 5 \\
\hline 1998 & 26.00 & 0.05 & 38.89 & 0.12 & 41.18 & 0.14 & 36.67 & 0.08 & 0.09 & 5 \\
\hline 2000 & 27.00 & 0.05 & 38.88 & 0.12 & 41.20 & 0.14 & 36.67 & 0.08 & 0.09 & 5 \\
\hline 2002 & 28.00 & 0.04 & 32.71 & 0.10 & 41.10 & 0.14 & 43.33 & 0.13 & 0.10 & 5 \\
\hline 2004 & 29.00 & 0.04 & 32.71 & 0.10 & 41.10 & 0.14 & 43.33 & 0.13 & 0.10 & 5 \\
\hline 2006 & 30.00 & 0.03 & 32.63 & 0.10 & 41.20 & 0.14 & 43.33 & 0.13 & 0.10 & 5 \\
\hline 2008 & 31.00 & 0.02 & 32.68 & 0.10 & 41.40 & 0.14 & 43.33 & 0.13 & 0.10 & 5 \\
\hline 2010 & 32.00 & 0.01 & 32.69 & 0.10 & 41.38 & 0.14 & 40.00 & 0.11 & 0.10 & 5 \\
\hline 2012 & 33.00 & 0.00 & 32.64 & 0.10 & 41.43 & 0.14 & 40.00 & 0.11 & 0.10 & 5 \\
\hline
\end{tabular}




\subsection{DECISION SUPPORT OUTCOMES FROM PERFROMANCE MEASUREMENT}

The ISR obtained from performance measurement step will be utilized as input in the project level analysis. However, in addition to that, performance measurements for individual parameters (excluding strategic importance because it is considered as a constraint parameter) and their utility for the candidate bridges have been used to plot two types of performance curves that can be useful decision support tool for decision makers (or decision-making group) as explained earlier in section 5.4. These performance curves include; (1) Performance Trend Curves (Figure 6.8), and (2) Performance Utility Trend Curves (Figure 6.9). The former represents the trend of actual performance, while the latter represents corresponding utility trends for the decision parameters, throughout the measurement period for each of the candidate bridges.

The general trend represented by the performance curves show that physical condition of all four candidate bridges has deteriorated over the years while subjected to preventive maintenance only. The other parameters i.e. socioeconomic and infrastructure utilization have generally varied (increased or decreased both) over the years for all the candidate bridges. This also shows to somehow satisfy the assumption made earlier that an infrastructure may still be able to attain a better integrated state while under preventive maintenance only. Decision makers can also use these to provide expert opinion for defining transition probability matrices for repair and rehabilitation action. 


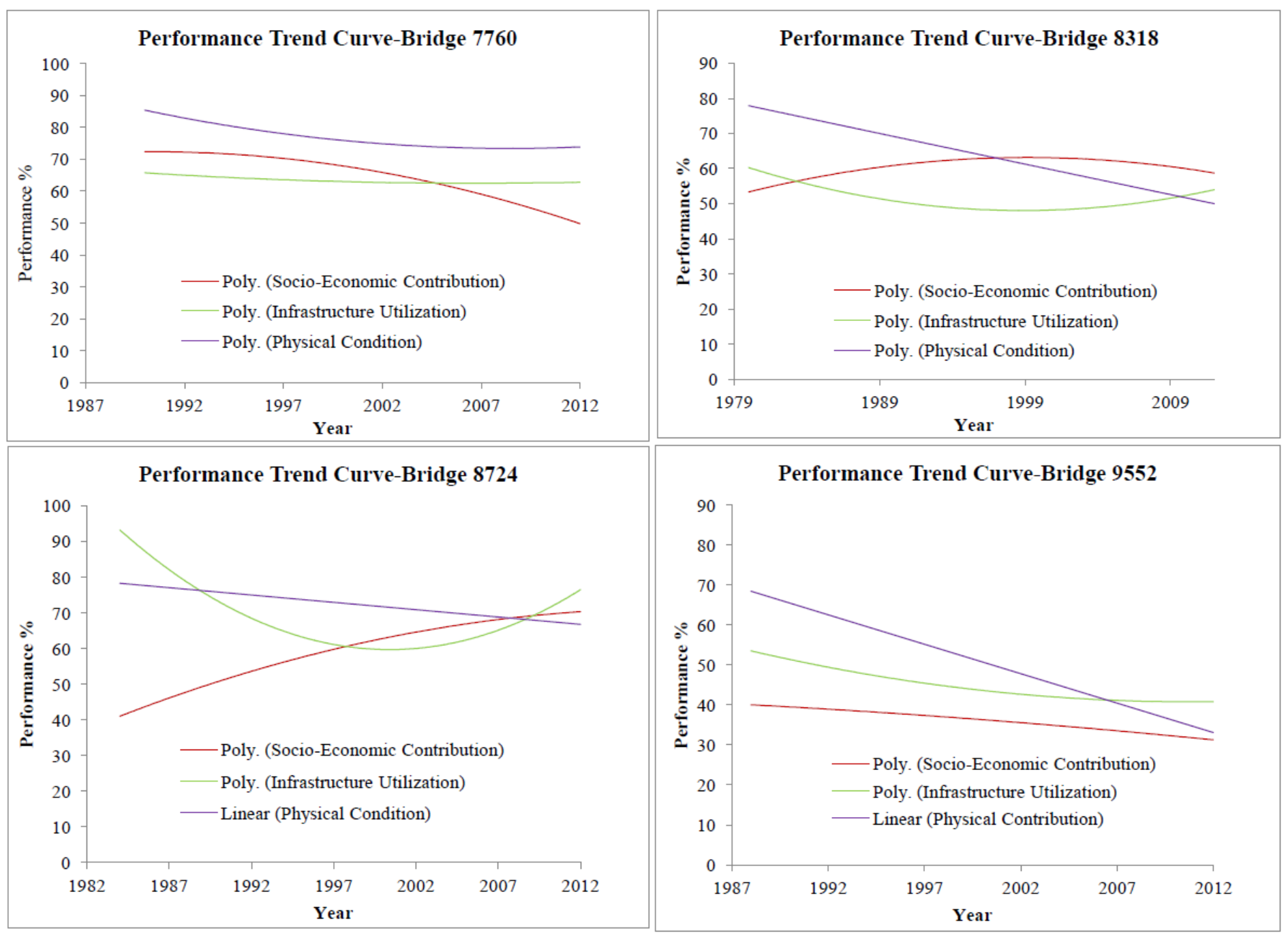

Figure 6.8: Performance Trend Curves 


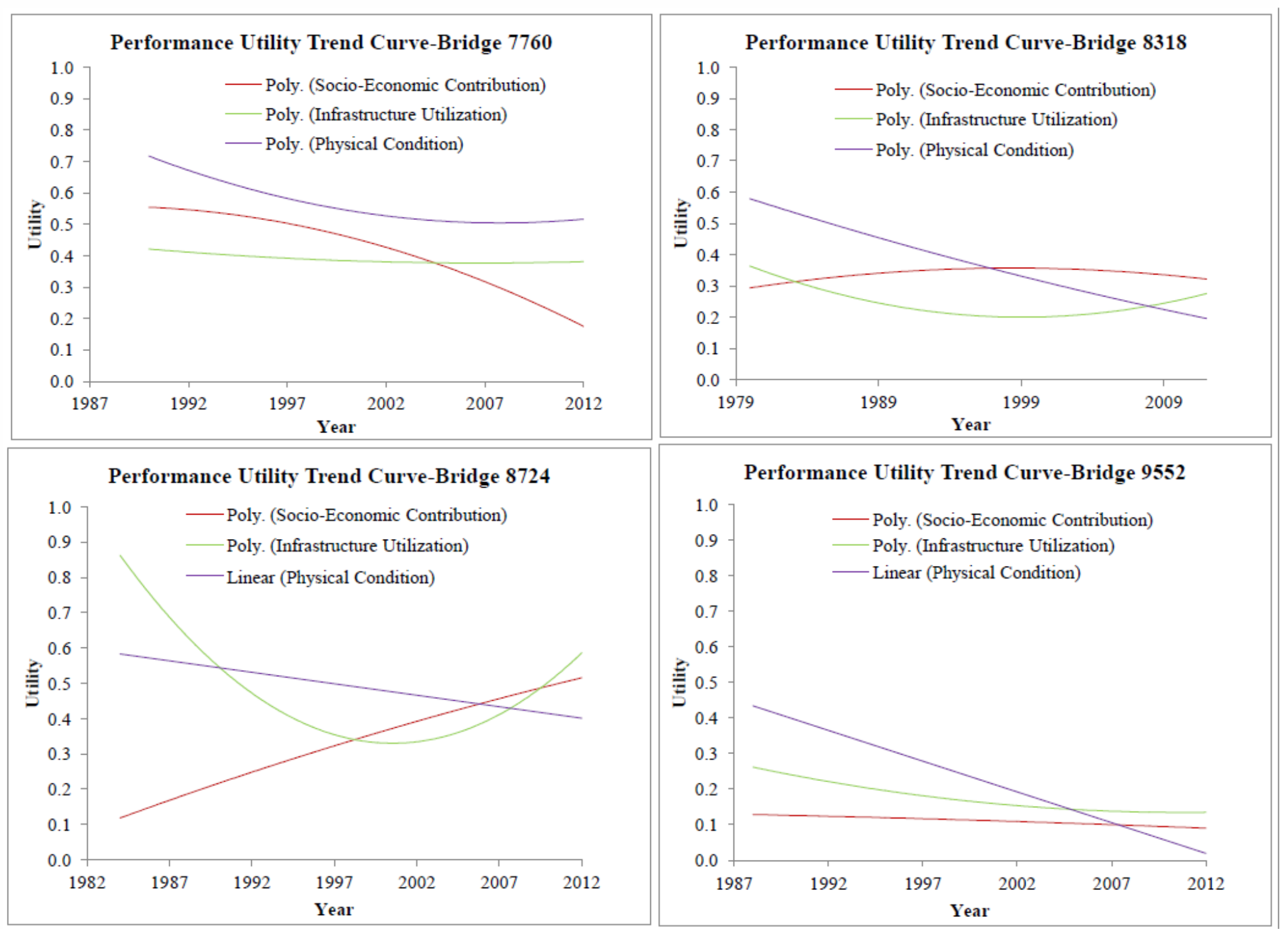

Figure 6.9: Performance Utility Trend Curves 


\subsection{PROJECT LEVEL ANALYSIS}

The integrated state ratings (ISR) for each bridge obtained from performance measurement were utilized to enumerate transitions and find out probability matrix for MAIN action as explained in section 5.3.1.3.1. The matrices developed for all four candidate bridges are shown in Table 6.10.

Table 6.10: Transition Probability Matrices for "MAIN" Action

Transitions Probability Matrix (7760)-MAIN

\begin{tabular}{|c|c|c|c|c|c|c|}
\hline \multirow{7}{*}{ 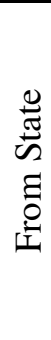 } & \multicolumn{6}{|c|}{ To state } \\
\hline & & 1 & 2 & 3 & 4 & 5 \\
\hline & 1 & 0 & 0 & 0 & 0 & 0 \\
\hline & 2 & 0 & 0.5 & 0.5 & $\overline{0}$ & $\overline{0}$ \\
\hline & 3 & 0 & $\overline{0}$ & 0.78 & 0.22 & 0 \\
\hline & 4 & 0 & 0 & 1 & 0 & 0 \\
\hline & 5 & 0 & 0 & 0 & 0 & $\overline{0}$ \\
\hline
\end{tabular}

Transitions Probability Matrix (8318)-MAIN

\begin{tabular}{|c|c|c|c|c|c|c|}
\hline \multirow{7}{*}{ 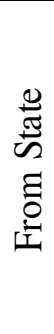 } & \multicolumn{6}{|c|}{ To state } \\
\hline & & 1 & 2 & 3 & 4 & 5 \\
\hline & 1 & 0 & 0 & 0 & 0 & 0 \\
\hline & 2 & 0 & 0 & 0 & 0 & 0 \\
\hline & 3 & $\overline{0}$ & $\overline{0}$ & $\overline{0}$ & 0 & $\overline{0}$ \\
\hline & 4 & 0 & 0 & 0 & 0.87 & 0.13 \\
\hline & 5 & 0 & 0 & $\overline{0}$ & 1 & 0 \\
\hline
\end{tabular}

Transitions Probability Matrix (8724)-MAIN

\begin{tabular}{|c|c|c|c|c|c|c|}
\hline \multirow{7}{*}{ 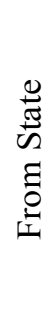 } & & \multicolumn{5}{|c|}{ To state } \\
\hline & & 1 & 2 & 3 & 4 & 5 \\
\hline & 1 & 0 & 0 & 0 & 0 & 0 \\
\hline & 2 & 0 & 0 & 0 & 0 & 0 \\
\hline & 3 & 0 & 0 & 0.83 & 0.17 & 0 \\
\hline & 4 & 0 & 0 & 0 & 1 & 0 \\
\hline & 5 & 0 & 0 & 0 & 0 & 0 \\
\hline
\end{tabular}

Transitions Probability Matrix (9552)-MAIN

\begin{tabular}{|c|c|c|c|c|c|c|}
\hline & & \multicolumn{5}{|c|}{ To state } \\
\cline { 2 - 7 } & & 1 & 2 & 3 & 4 & 5 \\
\cline { 2 - 7 } & 1 & 0 & 0 & 0 & 0 & 0 \\
\cline { 2 - 7 } \\
\cline { 2 - 7 } & 2 & 0 & 0 & 0 & 0 & 0 \\
\cline { 2 - 7 } & 3 & 0 & 0 & 0 & 0 & 0 \\
\cline { 2 - 7 } & 4 & 0 & 0 & 0 & 0 & 1 \\
\hline
\end{tabular}


The transition probabilites for RPR and REH actions were elicited through opinion of the decision-making group based on their experience with the similar projects for possible transitions as explained in section 5.3.1.3.2 and 5.3.1.3.3 respectively. The transition probabilty matrix for RPR action is shown in Table 6.11 while transition probability matrix for REH action is shown in Table 6.12

Table 6.11: Transition Probability Matrix for "RPR" Action

\begin{tabular}{|c|c|c|c|c|c|c|}
\hline \multirow{7}{*}{ 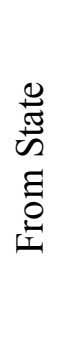 } & \multicolumn{6}{|c|}{ To State } \\
\hline & & 1 & 2 & 3 & 4 & 5 \\
\hline & 1 & 0 & 0 & 0 & 0 & 0 \\
\hline & 2 & 0 & 0 & 0 & 0 & 0 \\
\hline & 3 & 0 & 0.25 & 0.75 & 0 & 0 \\
\hline & 4 & 0 & 0.25 & 0.75 & 0 & 0 \\
\hline & 5 & 0 & 0.25 & 0.75 & 0 & 0 \\
\hline
\end{tabular}

Table 6.12: Transition Probability Matrix for "REH" Action

\begin{tabular}{|c|c|c|c|c|c|c|}
\hline \multirow{4}{*}{$\underset{\varpi}{*}$} & \multicolumn{7}{|c|}{ To State } \\
\cline { 2 - 7 } & & 1 & 2 & 3 & 4 & 5 \\
\cline { 2 - 7 } & 1 & 0 & 0 & 0 & 0 & 0 \\
\cline { 2 - 7 } & 2 & 0 & 0 & 0 & 0 & 0 \\
\cline { 2 - 7 } & 3 & 0.85 & 0.15 & 0 & 0 & 0 \\
\cline { 2 - 7 } & 4 & 0.85 & 0.15 & 0 & 0 & 0 \\
\cline { 2 - 7 } & 5 & 0.85 & 0.15 & 0 & 0 & 0 \\
\hline
\end{tabular}

After development of transition probability matrices, it was required to develop reward matrices based on costs and benefits of each action in different state. The cost of each maintenance action for all candidate projects as provided by the decision-making group from their current year estimates are as shown in following table 6.13. 
Table 6.13: Cost Estimates for Maintenance Actions

\begin{tabular}{|c|c|c|c|}
\hline Bridge No. & $\begin{array}{c}\text { Maintenance } \\
\text { (MAIN) Action } \\
\text { Cost (\$) }\end{array}$ & $\begin{array}{c}\text { Repair (RPR) } \\
\text { Action Cost (\$) }\end{array}$ & $\begin{array}{c}\text { Rehabilitation } \\
\text { (REH) Action Cost } \\
\text { (\$) }\end{array}$ \\
\hline 7760 & 15,400 & 280,000 & 750,000 \\
\hline 8318 & 4,000 & 485,000 & 632,500 \\
\hline 8724 & 20,184 & 300,000 & 700,000 \\
\hline 9552 & 4,058 & 350,000 & 585,000 \\
\hline
\end{tabular}

The decision-making group stated that there was no standard mechanism developed in PCDOT for quantifying the benefits of each of the maintenance actions. Therefore, benefits were identified as per benefit matrix shown in section 5.2.3.2 in consultation with decision-making group, and procedures were developed for quantifying those for the purpose of this study. The total benefits for each maintenance action corresponding to every bridge are shown in table 6.14 , while the details of quantification are provided in Appendix D.

Table 6.14: Benefits Estimates for Maintenance Actions

\begin{tabular}{|c|c|c|c|}
\hline Bridge No. & $\begin{array}{c}\text { Maintenance } \\
\text { (MAIN) Action } \\
\text { Benefit (\$) }\end{array}$ & $\begin{array}{c}\text { Repair (RPR) } \\
\text { Action Benefit (\$) }\end{array}$ & $\begin{array}{c}\text { Rehabilitation } \\
\text { (REH) Action } \\
\text { Benefit (\$) }\end{array}$ \\
\hline 7760 & 77,000 & $509,976.7$ & $1,230,631.92$ \\
\hline 8318 & 20,000 & $148,364.68$ & $1,097,364.68$ \\
\hline 8724 & 100,920 & $453,728.02$ & $841,842.85$ \\
\hline 9552 & 20,290 & $61,360.04$ & $1,267,610.04$ \\
\hline
\end{tabular}


The above costs and benefits provided by the decision-making group were maximum costs and maximum benefits. Realistically, costs and benefits should vary with respect to the possible integrated state that an infrastructure may attain. Since there was no standard mechanism to define cost and benefits for each state, a percentage of maximum cost and maximum benefits were assigned to calculate costs and benefits for each state. In doing so, certain assumptions were defined in consultation with decision-making group for the specific purpose of this case study. These are as follows.

1. Preventive Maintenance will cost same at all stages in its own capacity, however, at later stages, it will cost more because it will generate the need to at least repair the infrastructure., thus it will also not have benefits at later stages.

2. An early stage repair will cost less but will be more meaningful in avoiding further deterioration, thus will provide comparatively more benefits.

3. Rehabilitation at an early stage will cost less but will also provide fewer benefits as rehabilitating at that stage is less meaningful.

Considering aforementioned assumptions, costs and benefits for each state for all candidate bridges under different actions were defined based state wise distribution factors (Also See Appendix D. Table 6.15 provides state wise costs and benefits. 
Table 6.15: State wise Costs and Benefits for Candidate Bridges

\begin{tabular}{|c|c|c|c|c|c|c|c|c|c|}
\hline \multirow{2}{*}{\multicolumn{2}{|c|}{$\begin{array}{c}\text { Action } \\
\text { and } \\
\text { State }\end{array}$}} & \multicolumn{2}{|c|}{7760} & \multicolumn{2}{|c|}{8318} & \multicolumn{2}{|c|}{8724} & \multicolumn{2}{|c|}{9552} \\
\hline & & Cost & Benefit & Cost & Benefit & Cost & Benefit & Cost & Benefit \\
\hline \multirow{5}{*}{ 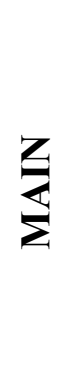 } & 1 & $15,400.00$ & $77,000.00$ & $4,000.00$ & $20,000.00$ & $20,184.00$ & $100,920.00$ & $4,058.00$ & $20,290.00$ \\
\hline & 2 & $15,400.00$ & $38,500.00$ & $4,000.00$ & $10,000.00$ & $20,184.00$ & $50,460.00$ & $4,058.00$ & $10,145.00$ \\
\hline & 3 & $15,400.00$ & $15,400.00$ & $4,000.00$ & $4,000.00$ & $20,184.00$ & $20,184.00$ & $4,058.00$ & $4,058.00$ \\
\hline & 4 & $239,400.00$ & 0.00 & $392,000.00$ & 0.00 & $260,184.00$ & 0.00 & $284,058.00$ & 0.00 \\
\hline & 5 & $295,400.00$ & 0.00 & $489,000.00$ & 0.00 & $320,184.00$ & 0.00 & $354,058.00$ & 0.00 \\
\hline \multirow{5}{*}{$\underline{\underline{\alpha}}$} & 1 & $56,000.00$ & $509,976.70$ & $97,000.00$ & $148,364.68$ & $60,000.00$ & $453,728.02$ & $70,000.00$ & $61,360.04$ \\
\hline & 2 & $112,000.00$ & $407,981.36$ & $194,000.00$ & $118,691.74$ & $120,000.00$ & $362,982.41$ & $140,000.00$ & $49,088.03$ \\
\hline & 3 & $168,000.00$ & $305,986.02$ & $291,000.00$ & $89,018.81$ & $180,000.00$ & $272,236.81$ & $210,000.00$ & $36,816.02$ \\
\hline & 4 & $224,000.00$ & $203,990.68$ & $388,000.00$ & $59,345.87$ & $240,000.00$ & $181,491.21$ & $280,000.00$ & $24,544.02$ \\
\hline & 5 & $280,000.00$ & $101,995.34$ & $485,000.00$ & $29,672.94$ & $300,000.00$ & $90,745.60$ & $350,000.00$ & $12,272.01$ \\
\hline \multirow{5}{*}{$\frac{\theta}{\underline{\alpha}}$} & 1 & $150,000.00$ & $246,126.38$ & $126,500.00$ & $219,472.94$ & $140,000.00$ & $168,368.57$ & $117,000.00$ & $253,522.01$ \\
\hline & 2 & $300,000.00$ & $492,252.77$ & $253,000.00$ & $438,945.87$ & $280,000.00$ & $336,737.14$ & $234,000.00$ & $507,044.02$ \\
\hline & 3 & $450,000.00$ & $738,379.15$ & $379,500.00$ & $658,418.81$ & $420,000.00$ & $505,105.71$ & $351,000.00$ & $760,566.02$ \\
\hline & 4 & $600,000.00$ & $984,505.54$ & $506,000.00$ & $877,891.74$ & $560,000.00$ & $673,474.28$ & $468,000.00$ & $1,014,088.03$ \\
\hline & 5 & $750,000.00$ & $1,230,631.92$ & $632,500.00$ & $1,097,364.68$ & $700,000.00$ & $841,842.85$ & $585,000.00$ & $1,267,610.04$ \\
\hline
\end{tabular}


Using the cost and benefits, reward matrices were developed for each candidate bridge for each action at different integrated states. Reward for a transition will be the benefit of the "state to" where transition has been made minus cost of "state from" where transition was made. Tables 6.16 through 6.19 represents reward matrices for the four candidate bridges.

Table 6.16: Reward Matrix for Bridge 7760

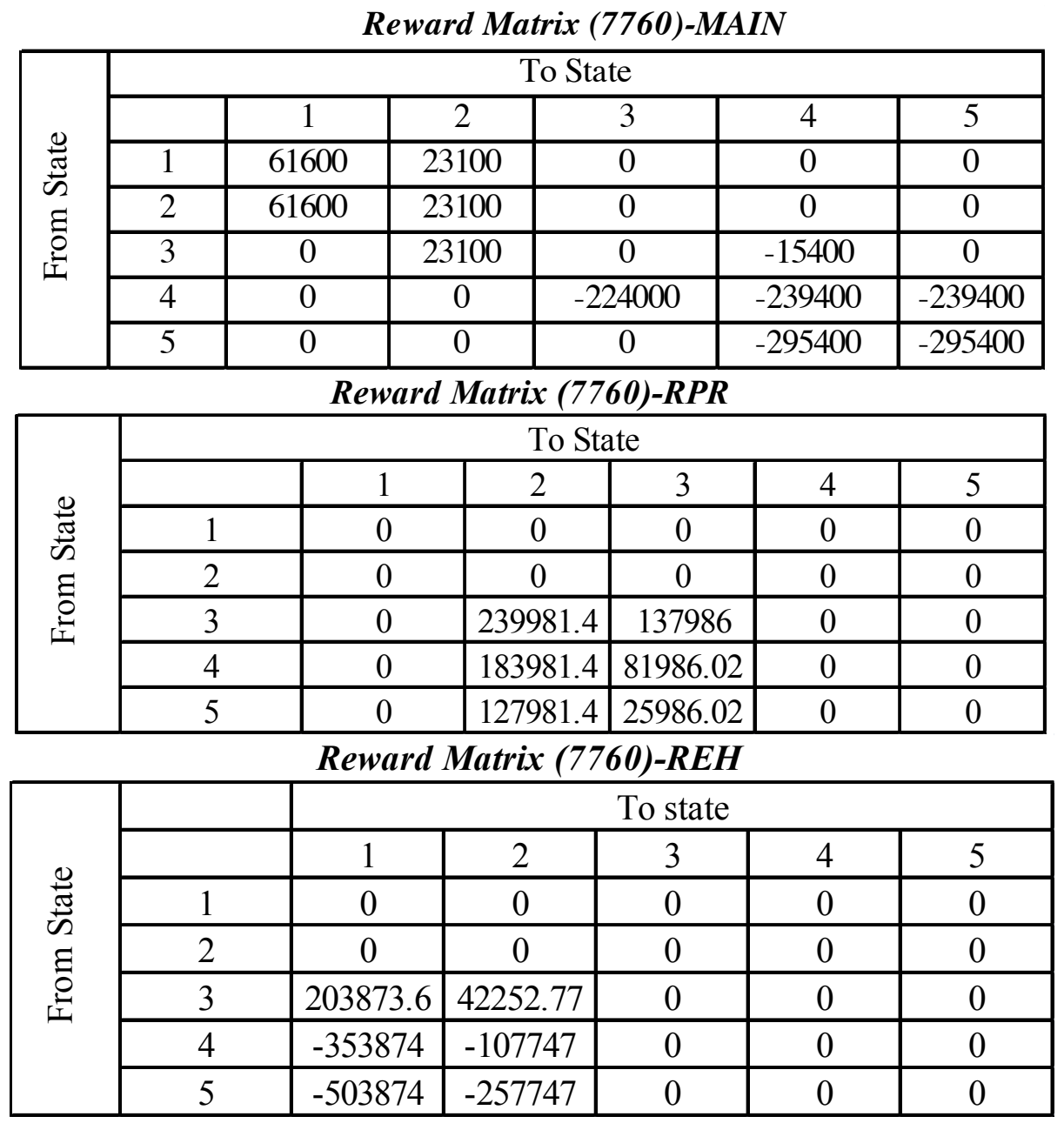


Table 6.17: Reward Matrices for Bridge 8318

Reward Matrix (8318)-MAIN

\begin{tabular}{|c|c|c|c|c|c|c|}
\hline \multicolumn{7}{|c|}{ To State } \\
\hline \multirow{6}{*}{ 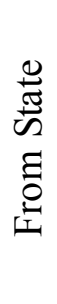 } & & 1 & 2 & 3 & 4 & 5 \\
\hline & 1 & 16000 & 6000 & 0 & 0 & 0 \\
\hline & 2 & 16000 & 6000 & 0 & 0 & 0 \\
\hline & 3 & 0 & 6000 & 0 & -4000 & 0 \\
\hline & 4 & 0 & 0 & -388000 & -392000 & -392000 \\
\hline & 5 & 0 & 0 & 0 & -489000 & -489000 \\
\hline
\end{tabular}

Reward Matrix (8318)-RPR

\begin{tabular}{|c|c|c|c|c|c|c|}
\hline \multirow{4}{*}{ 营 } & \multicolumn{7}{|c|}{ To State } \\
\cline { 2 - 7 } & & 1 & 2 & 3 & 4 & 5 \\
\cline { 2 - 7 } & 1 & 0 & 0 & 0 & 0 & 0 \\
\cline { 2 - 7 } & 2 & 0 & 0 & 0 & 0 & 0 \\
\cline { 2 - 7 } & 3 & 0 & -172308 & -201981 & 0 & 0 \\
\cline { 2 - 7 } & 4 & 0 & -269308 & -298981 & 0 & 0 \\
\cline { 2 - 7 } & 5 & 0 & -366308 & -395981 & 0 & 0 \\
\hline
\end{tabular}

Reward Matrix (8318)-REH

\begin{tabular}{|c|c|c|c|c|c|c|}
\hline \multirow{7}{*}{ 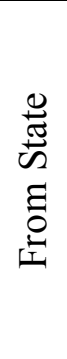 } & \multicolumn{6}{|c|}{ To State } \\
\hline & & 1 & 2 & 3 & 4 & 5 \\
\hline & 1 & 0 & 0 & 0 & 0 & 0 \\
\hline & 2 & 0 & 0 & 0 & 0 & 0 \\
\hline & 3 & -160027 & 59445.87 & 0 & 0 & 0 \\
\hline & 4 & -286527 & -67054.1 & 0 & 0 & 0 \\
\hline & 5 & -413027 & -193554 & 0 & 0 & 0 \\
\hline
\end{tabular}


Table 6.18: Reward Matrices for Bridge 8724

Reward Matrix (8724)-MAIN

\begin{tabular}{|c|c|c|c|c|c|c|}
\hline \multirow{7}{*}{ 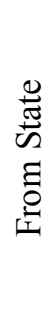 } & \multicolumn{6}{|c|}{ To State } \\
\hline & & 1 & 2 & 3 & 4 & 5 \\
\hline & 1 & 80736 & 30276 & 0 & 0 & 0 \\
\hline & 2 & 80736 & 30276 & 0 & 0 & 0 \\
\hline & 3 & 0 & 30276 & 0 & -20184 & 0 \\
\hline & 4 & 0 & 0 & -240000 & -260184 & -260184 \\
\hline & 5 & 0 & 0 & 0 & -320184 & -320184 \\
\hline
\end{tabular}

Reward Matrix (8724)-RPR

\begin{tabular}{|c|c|c|c|c|c|c|}
\hline \multirow{4}{*}{} & \multicolumn{7}{|c|}{ To State } \\
\cline { 2 - 7 } & & 1 & 2 & 3 & 4 & 5 \\
\cline { 2 - 7 } & 1 & 0 & 0 & 0 & 0 & 0 \\
\cline { 2 - 7 } & 2 & 0 & 0 & 0 & 0 & 0 \\
\cline { 2 - 7 } & 3 & 0 & 182982.4 & 92236.81 & 0 & 0 \\
\cline { 2 - 7 } & 4 & 0 & 122982.4 & 32236.81 & 0 & 0 \\
\cline { 2 - 7 } & 5 & 0 & 62982.41 & -27763.2 & 0 & 0 \\
\hline \multirow{2}{*}{} & 5 & 0 &
\end{tabular}

Reward Matrix (8724)-REH

\begin{tabular}{|c|c|c|c|c|c|c|}
\hline \multirow{7}{*}{ 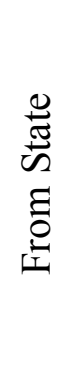 } & \multicolumn{6}{|c|}{ To State } \\
\hline & & 1 & 2 & 3 & 4 & 5 \\
\hline & 1 & 0 & 0 & 0 & 0 & 0 \\
\hline & 2 & 0 & 0 & 0 & 0 & 0 \\
\hline & 3 & -251631 & -83262.9 & 0 & 0 & 0 \\
\hline & 4 & -391631 & -223263 & 0 & 0 & 0 \\
\hline & 5 & -531631 & -363263 & 0 & 0 & 0 \\
\hline
\end{tabular}


Table 6.19: Reward Matrices for Bridge 9552

Reward Matrix (9552)-MAIN

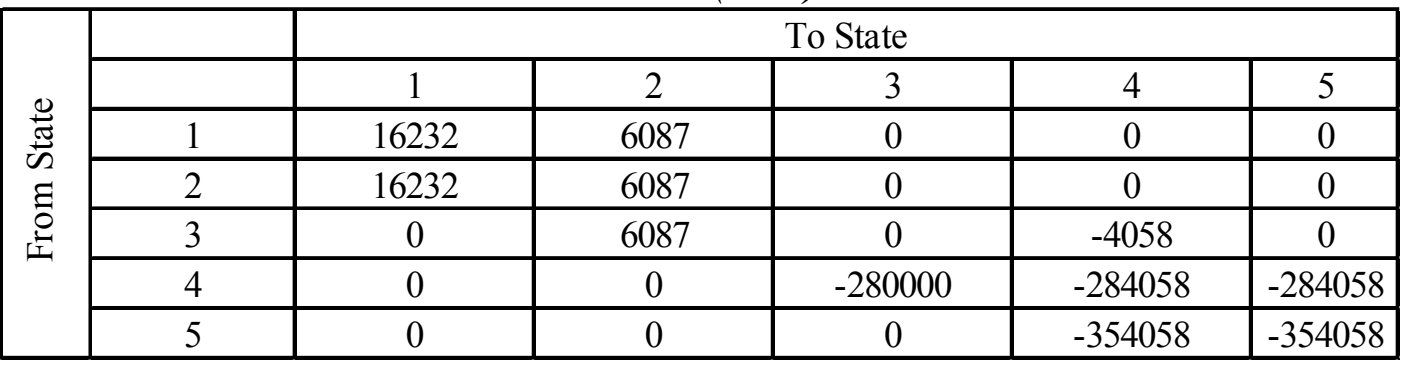

Reward Matrix (9552)-RPR

\begin{tabular}{|c|c|c|c|c|c|c|}
\hline \multirow{4}{*}{$\underset{\varpi}{*}$} & \multicolumn{7}{|c|}{ To state } \\
\cline { 2 - 7 } & & 1 & 2 & 3 & 4 & 5 \\
\cline { 2 - 7 } & 1 & 0 & 0 & 0 & 0 & 0 \\
\cline { 2 - 7 } & 2 & 0 & 0 & 0 & 0 & 0 \\
\cline { 2 - 7 } & 3 & 0 & -160912 & -173184 & 0 & 0 \\
\cline { 2 - 7 } & 4 & 0 & -230912 & -243184 & 0 & 0 \\
\cline { 2 - 7 } & 5 & 0 & -300912 & -313184 & 0 & 0 \\
\hline
\end{tabular}

Reward Matrix (9552)-REH

\begin{tabular}{|c|c|c|c|c|c|c|}
\hline \multirow{4}{*}{ 营 } & \multicolumn{7}{|c|}{ To State } \\
\cline { 2 - 7 } & & 1 & 2 & 3 & 4 & 5 \\
\cline { 2 - 7 } & 1 & 0 & 0 & 0 & 0 & 0 \\
\cline { 2 - 7 } & 2 & 0 & 0 & 0 & 0 & 0 \\
\cline { 2 - 7 } & 3 & -97478 & 156044 & 0 & 0 & 0 \\
\cline { 2 - 7 } & 4 & -214478 & 39044.02 & 0 & 0 & 0 \\
\cline { 2 - 7 } & 5 & -331478 & -77956 & 0 & 0 & 0 \\
\hline
\end{tabular}

Once, both transition and reward matrices has been developed, MDP was applied to determine the optimal course of action from the set of probable actions for each year of the planning horizon. As explained earlier as well, optimality, in this case, means accumulating the highest expected reward (revenue). Tables 6.20 through 6.23 show the summary of results from Markov Decision Process providing optimal actions for the four candidate bridges for years 2018, 2016 and 2014 at different ISR. 
Table 6.20: Markov Decision Process Results for Bridge 7760

\begin{tabular}{|c|c|c|c|c|c|c|}
\hline \multirow{4}{*}{2018} & ISR (i) & $\mathbf{k}=$ MAIN & $\mathbf{k}=\mathbf{R P R}$ & $\mathbf{k}=\mathbf{R E H}$ & $\mathbf{f}_{\mathbf{3}}(\mathbf{i})$ & $\begin{array}{c}\text { K } \\
\text { (Optimal Action) }\end{array}$ \\
\cline { 2 - 7 } & 1 & 0 & 0 & 0 & 0 & MAIN \\
\cline { 2 - 7 } & 2 & 11550 & 0 & 0 & 11550 & MAIN \\
\cline { 2 - 7 } & 3 & -3422.222 & 163484.9 & 179630.489 & 179630.5 & REH \\
\cline { 2 - 7 } & 4 & -224000 & 107484.9 & -316954.66 & 107484.9 & RPR \\
\cline { 2 - 7 } & 5 & 0 & 51484.86 & -466954.66 & 51484.86 & RPR \\
\hline
\end{tabular}

\begin{tabular}{|c|c|c|c|c|c|c|}
\hline \multirow{7}{*}{2016} & ISR (i) & $\mathbf{k}=$ MAIN & $\mathbf{k}=\mathbf{R P R}$ & $\mathbf{k}=\mathbf{R E H}$ & $\mathbf{f}_{\mathbf{3}}(\mathbf{i})$ & $\begin{array}{c}\text { K } \\
\text { (Optimal Action) }\end{array}$ \\
\cline { 2 - 7 } & 1 & 0 & 0 & 0 & 0 & MAIN \\
\cline { 2 - 7 } & 2 & 107140.24 & 0 & 0 & 107140.2 & MAIN \\
\cline { 2 - 7 } & 3 & 160175.9 & 301095.2 & 181362.989 & 301095.2 & RPR \\
\cline { 2 - 7 } & 4 & -44369.51 & 245095.2 & -315222.16 & 245095.2 & RPR \\
\cline { 2 - 7 } & 5 & 0 & 189095.2 & -465222.16 & 189095.2 & RPR \\
\hline
\end{tabular}

\begin{tabular}{|c|c|c|c|c|c|c|}
\hline \multirow{6}{*}{2014} & ISR (i) & $\mathbf{k}=$ MAIN & $\mathrm{k}=\mathbf{R P R}$ & $\mathbf{k}=\mathbf{R E H}$ & $\mathbf{f}_{3}(\mathbf{i})$ & $\begin{array}{c}\text { K } \\
\text { (Optimal Action) }\end{array}$ \\
\hline & 1 & 0 & 0 & 0 & 0 & MAIN \\
\hline & 2 & 215667.73 & 0 & 0 & 215667.7 & MAIN \\
\hline & 3 & 285228.56 & 416091.3 & 195701.525 & 416091.3 & RPR \\
\hline & 4 & 77095.222 & 360091.3 & -300883.62 & 360091.3 & RPR \\
\hline & 5 & 0 & 304091.3 & -450883.62 & 304091.3 & RPR \\
\hline
\end{tabular}


Table 6.21: Markov Decision Process Results for Bridge 8318

\begin{tabular}{|c|c|c|c|c|c|c|}
\hline \multirow{6}{*}{2018} & ISR (i) & $\mathbf{k}=$ MAIN & $\mathbf{k}=\mathbf{R P R}$ & $\mathbf{k}=\mathbf{R E H}$ & $\mathbf{f}_{\mathbf{3}}(\mathbf{i})$ & $\begin{array}{c}\mathbf{K} \\
\text { (Optimal } \\
\text { Action) }\end{array}$ \\
\cline { 2 - 7 } & 1 & 0 & 0 & 0 & 0 & MAIN \\
\cline { 2 - 7 } & 2 & 0 & 0 & 0 & 0 & MAIN \\
\cline { 2 - 7 } & 3 & 0 & -194563 & -127106.12 & 0 & MAIN \\
\cline { 2 - 7 } & 4 & -392000 & -291563 & -253606.12 & -253606 & REH \\
\cline { 2 - 7 } & 5 & -489000 & -388563 & -380106.12 & -380106 & REH \\
\hline
\end{tabular}

\begin{tabular}{|c|c|c|c|c|c|c|}
\hline \multirow{7}{*}{2016} & ISR (i) & $\mathbf{k}=$ MAIN & $\mathbf{k}=\mathbf{R P R}$ & $\mathbf{k}=\mathbf{R E H}$ & $\mathbf{f}_{3}(\mathbf{i})$ & $\begin{array}{c}\mathbf{K} \\
\text { (Optimal } \\
\text { Action) }\end{array}$ \\
\cline { 2 - 7 } & 1 & 0 & 0 & 0 & 0 & MAIN \\
\cline { 2 - 7 } & 2 & 0 & 0 & 0 & 0 & MAIN \\
\cline { 2 - 7 } & 3 & 0 & -194563 & -127106.12 & 0 & MAIN \\
\cline { 2 - 7 } & 4 & -662472.8 & -291563 & -253606.12 & -253606 & REH \\
\cline { 2 - 7 } & 5 & -742606.1 & -388563 & -380106.12 & -380106 & REH \\
\hline
\end{tabular}

\begin{tabular}{|c|c|c|c|c|c|c|}
\hline \multirow{7}{*}{} & ISR (i) & $\mathbf{k}=$ MAIN & $\mathbf{k}=\mathbf{R P R}$ & $\mathbf{k}=\mathbf{R E H}$ & $\mathbf{f}_{3}(\mathbf{i})$ & $\begin{array}{c}\text { K } \\
\text { (Optimal } \\
\text { Action) }\end{array}$ \\
\cline { 2 - 7 } & 1 & 0 & 0 & 0 & 0 & MAIN \\
\cline { 2 - 7 } & 2 & 0 & 0 & 0 & 0 & MAIN \\
\cline { 2 - 7 } & 3 & 0 & -194563 & -127106.12 & 0 & MAIN \\
\cline { 2 - 7 } & 4 & -662472.8 & -291563 & -253606.12 & -253606 & REH \\
\cline { 2 - 7 } & 5 & -742606.1 & -388563 & -380106.12 & -380106 & REH \\
\hline
\end{tabular}


Table 6.22: Markov Decision Process Results for Bridge 8724

\begin{tabular}{|c|c|c|c|c|c|c|}
\hline \multirow{7}{*}{2018} & ISR (i) & $\mathbf{k}=\mathbf{M A I N}$ & $\mathbf{k}=\mathbf{R P R}$ & $\mathbf{k}=\mathbf{R E H}$ & $\mathbf{f}_{3}(\mathbf{i})$ & $\begin{array}{c}\mathbf{K} \\
\text { (Optimal } \\
\text { Action) }\end{array}$ \\
\cline { 2 - 7 } & 1 & 0 & 0 & 0 & 0 & MAIN \\
\cline { 2 - 7 } & 2 & 0 & 0 & 0 & 0 & MAIN \\
\cline { 2 - 7 } & 3 & -3364 & 114923.2 & -226376.14 & 114923.2 & RPR \\
\cline { 2 - 7 } & 4 & -260184 & 54923.21 & -366376.14 & 54923.21 & RPR \\
\cline { 2 - 7 } & 5 & -320184 & -5076.79 & -506376.14 & -5076.79 & RPR \\
\hline
\end{tabular}

\begin{tabular}{|c|c|c|c|c|c|c|}
\hline \multirow{7}{*}{} & ISR (i) & $\mathbf{k}=$ MAIN & $\mathbf{k}=\mathbf{R P R}$ & $\mathbf{k}=\mathbf{R E H}$ & $\mathbf{f}_{3}(\mathbf{i})$ & $\begin{array}{c}\mathbf{K} \\
\text { (Optimal } \\
\text { Action) }\end{array}$ \\
\cline { 2 - 8 } & 1 & 0 & 0 & 0 & 0 & MAIN \\
\cline { 2 - 7 } & 2 & 0 & 0 & 0 & 0 & MAIN \\
\cline { 2 - 7 } & 3 & 101559.21 & 201115.6 & -226376.14 & 201115.6 & RPR \\
\cline { 2 - 7 } & 4 & -205260.8 & 141115.6 & -366376.14 & 141115.6 & RPR \\
\cline { 2 - 7 } & 5 & -325260.8 & 81115.62 & -506376.14 & 81115.62 & RPR \\
\hline
\end{tabular}

\begin{tabular}{|c|c|c|c|c|c|c|}
\hline \multirow{7}{*}{2014} & ISR (i) & $\mathbf{k}=\mathbf{M A I N}$ & $\mathbf{k}=\mathbf{R P R}$ & $\mathbf{k}=\mathbf{R E H}$ & $\mathbf{f}_{\mathbf{3}}(\mathbf{i})$ & $\begin{array}{c}\mathbf{K} \\
\text { (Optimal } \\
\text { Action) }\end{array}$ \\
\cline { 2 - 7 } & 1 & 0 & 0 & 0 & 0 & MAIN \\
\cline { 2 - 7 } & 2 & 0 & 0 & 0 & 0 & MAIN \\
\cline { 2 - 7 } & 3 & 187751.62 & 265759.9 & -226376.14 & 265759.9 & RPR \\
\cline { 2 - 7 } & 4 & -119068.4 & 205759.9 & -366376.14 & 205759.9 & RPR \\
\cline { 2 - 7 } & 5 & -239068.4 & 145759.9 & -506376.14 & 145759.9 & RPR \\
\hline
\end{tabular}


Table 6.23: Markov Decision Process Results for Bridge 9552

\begin{tabular}{|c|c|c|c|c|c|c|}
\hline \multirow{6}{*}{2018} & ISR (i) & $\mathbf{k}=$ MAIN & $\mathbf{k}=\mathbf{R P R}$ & $\mathbf{k}=\mathbf{R E H}$ & $\mathbf{f}_{\mathbf{3}}(\mathbf{i})$ & $\begin{array}{c}\mathbf{K} \\
\text { (Optimal } \\
\text { Action) }\end{array}$ \\
\cline { 2 - 7 } & 1 & 0 & 0 & 0 & 0 & MAIN \\
\cline { 2 - 7 } & 2 & 0 & 0 & 0 & 0 & MAIN \\
\cline { 2 - 7 } & 3 & 0 & -170116 & -59449.691 & 0 & MAIN \\
\cline { 2 - 7 } & 4 & -284058 & -240116 & -176449.69 & -176450 & REH \\
\cline { 2 - 7 } & 5 & -354058 & -310116 & -293449.69 & -293450 & REH \\
\hline
\end{tabular}

\begin{tabular}{|c|c|c|c|c|c|c|}
\hline \multirow{7}{*}{2016} & ISR (i) & $\mathbf{k}=$ MAIN & $\mathbf{k}=\mathbf{R P R}$ & $\mathbf{k}=\mathbf{R E H}$ & $\mathbf{f}_{\mathbf{3}}(\mathbf{i})$ & $\begin{array}{c}\mathbf{K} \\
\text { (Optimal } \\
\text { Action) }\end{array}$ \\
\cline { 2 - 7 } & 1 & 0 & 0 & 0 & 0 & MAIN \\
\cline { 2 - 7 } & 2 & 0 & 0 & 0 & 0 & MAIN \\
\cline { 2 - 7 } & 3 & 0 & -170116 & -59449.691 & 0 & MAIN \\
\cline { 2 - 7 } & 4 & -483907.7 & -240116 & -176449.69 & -176450 & REH \\
\cline { 2 - 7 } & 5 & -647507.7 & -310116 & -293449.69 & -293450 & REH \\
\hline
\end{tabular}

\begin{tabular}{|c|c|c|c|c|c|c|}
\hline \multirow{7}{*}{2014} & ISR (i) & $\mathbf{k}=$ MAIN & $\mathbf{k}=\mathbf{R P R}$ & $\mathbf{k}=\mathbf{R E H}$ & $\mathbf{f}_{3}(\mathbf{i})$ & $\begin{array}{c}\text { K } \\
\text { (Optimal } \\
\text { Action) }\end{array}$ \\
\cline { 2 - 7 } & 1 & 0 & 0 & 0 & 0 & MAIN \\
\cline { 2 - 7 } & 2 & 0 & 0 & 0 & 0 & MAIN \\
\cline { 2 - 7 } & 3 & 0 & -170116 & -59449.691 & 0 & MAIN \\
\cline { 2 - 7 } & 4 & -483907.7 & -240116 & -176449.69 & -176450 & REH \\
\cline { 2 - 7 } & 5 & -647507.7 & -310116 & -293449.69 & -293450 & REH \\
\hline
\end{tabular}

\subsection{DECISION SUPPORT OUTCOME FROM PROJECT LEVEL ANALYSIS}

Based on the results of MDP, and considering the current state of candidate bridges, decision logic maps (DLMs) have been developed, providing plan of action for future maintenance decisions for individual candidate bridges. DLMs for four candidate bridges are shown in figures 6.10 through 6.13 . 


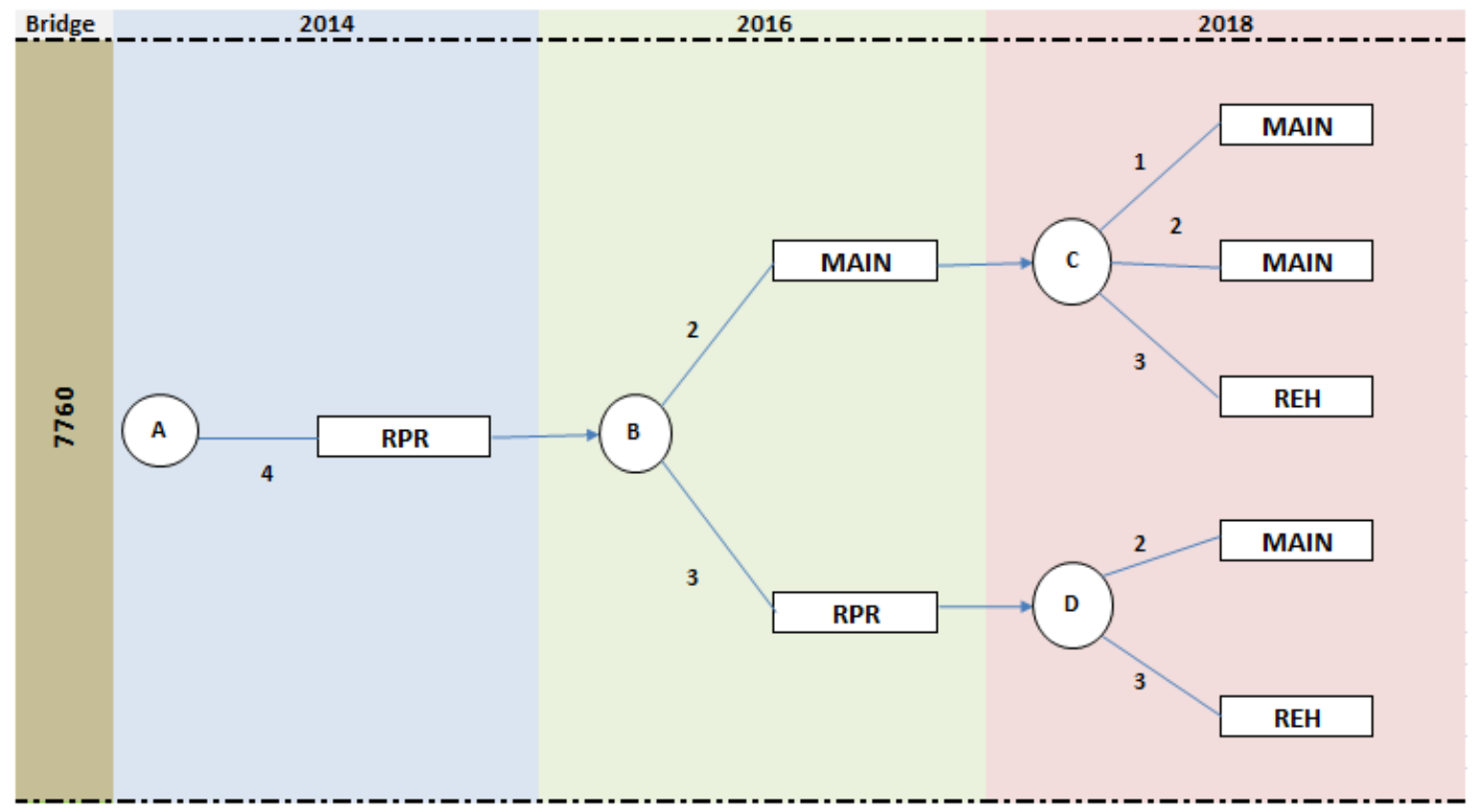

Figure 6.10: DLM for Bridge 7760

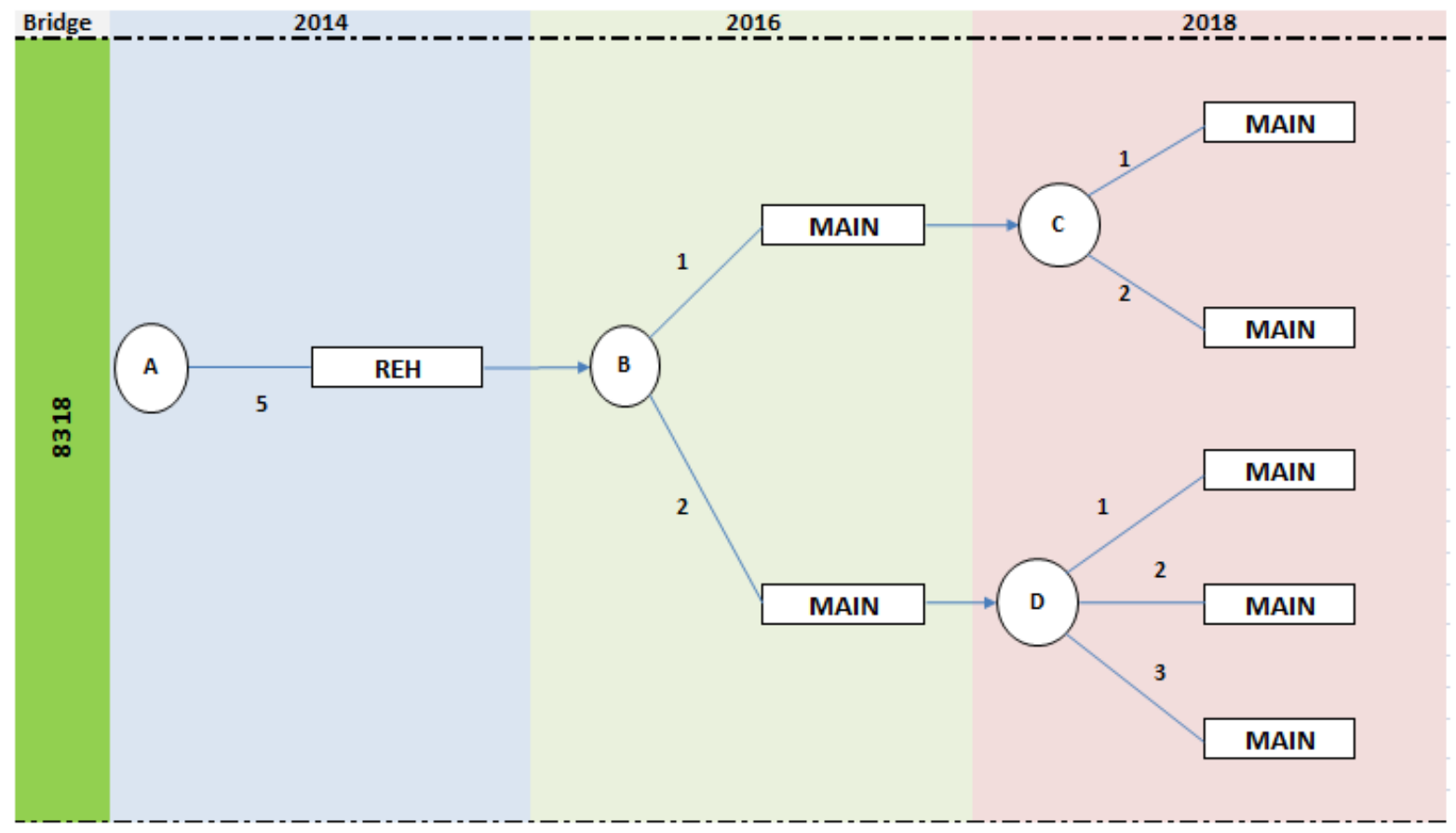

Figure 6.11: DLM for Bridge 8318 


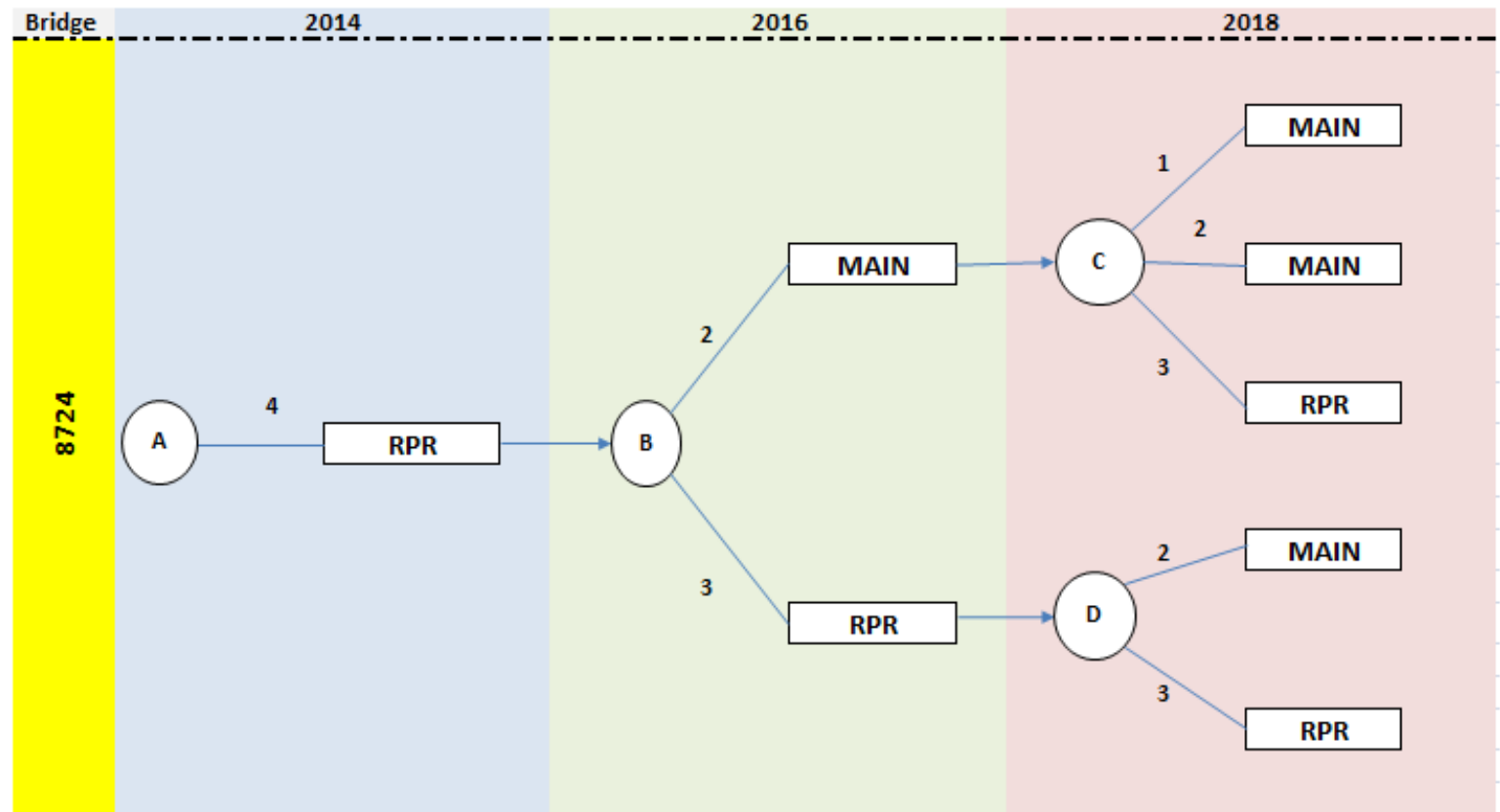

Figure 6.12: DLM for Bridge 8724

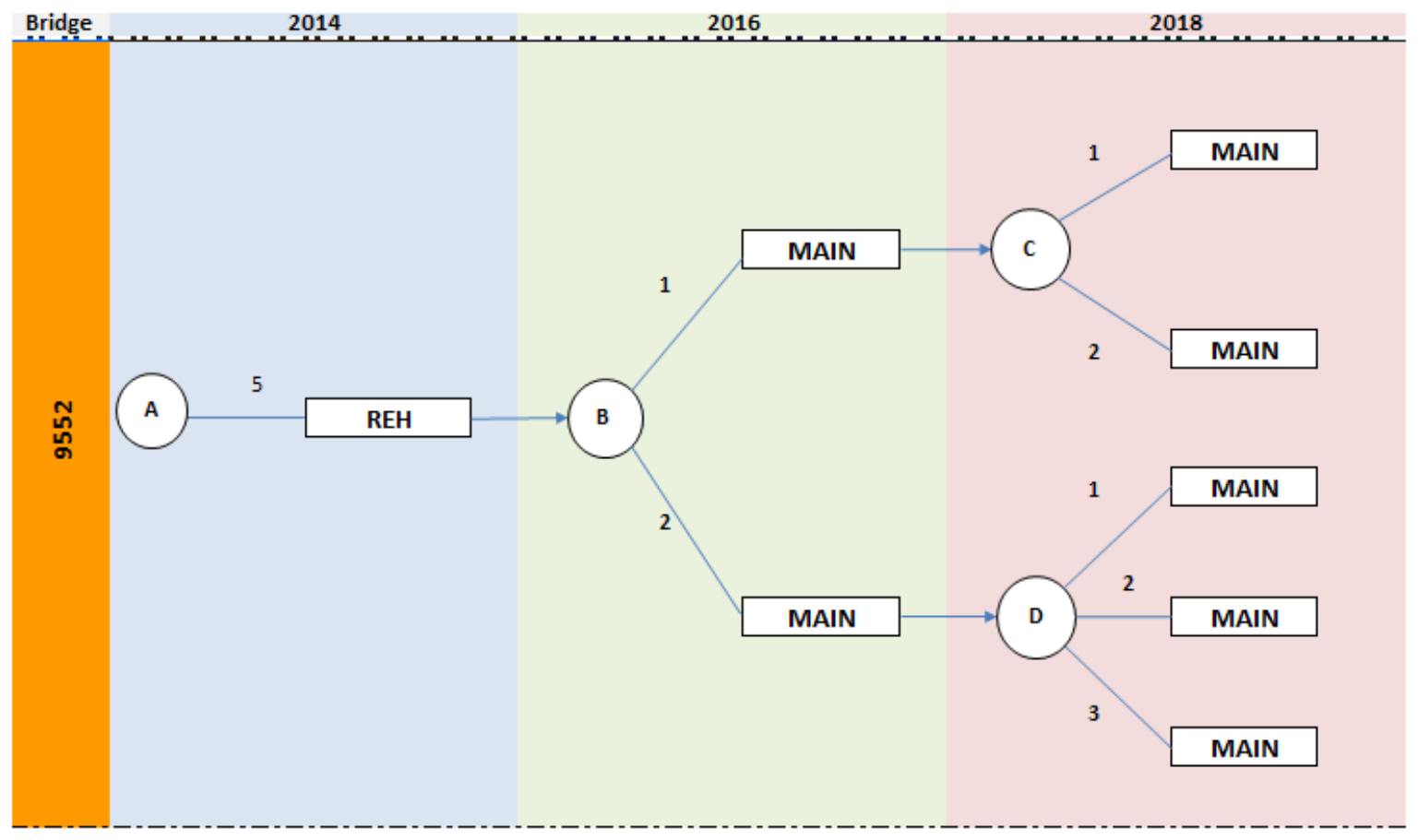

Figure 6.13: DLM for Bridge 9552 


\subsection{NETWORK LEVEL ANALYSIS}

The DLMs developed as an outcome to project level analysis were then assigned with cost and benefits considering an interest rate of 5\% (assumed by decision-making group for this case study). Furthermore, the total cost of decision logic paths was calculated (see figure 6.14). The values at the top of the decision outcome nodes show costs while bottom values show benefits.

Since, decision logic maps show that each candidate bridge have 5 possible decision logic paths, therefore, total number of possible portfolios for this case study were 625 . As a next step, budgetary constraint of $\$ 2$ million (budget available for next 5 years for 4 candidate bridges) was applied. This resulted in 100 feasible portfolios. Benefit/cost ratio for the feasible portfolios was calculated to determine the most feasible portfolio. As a result, portfolio $1111(\mathrm{~B} / \mathrm{C}=1.7716140)$ came out to be the most feasible portfolio.

\subsection{DECISION SUPPORT OUTCOME FROM NETWROK LEVEL ANALYSIS}

Based on feasible portfolio 1111, the proposed network level maintenance investment plan for next five years for the candidate bridges is shown by Table 6.24. 


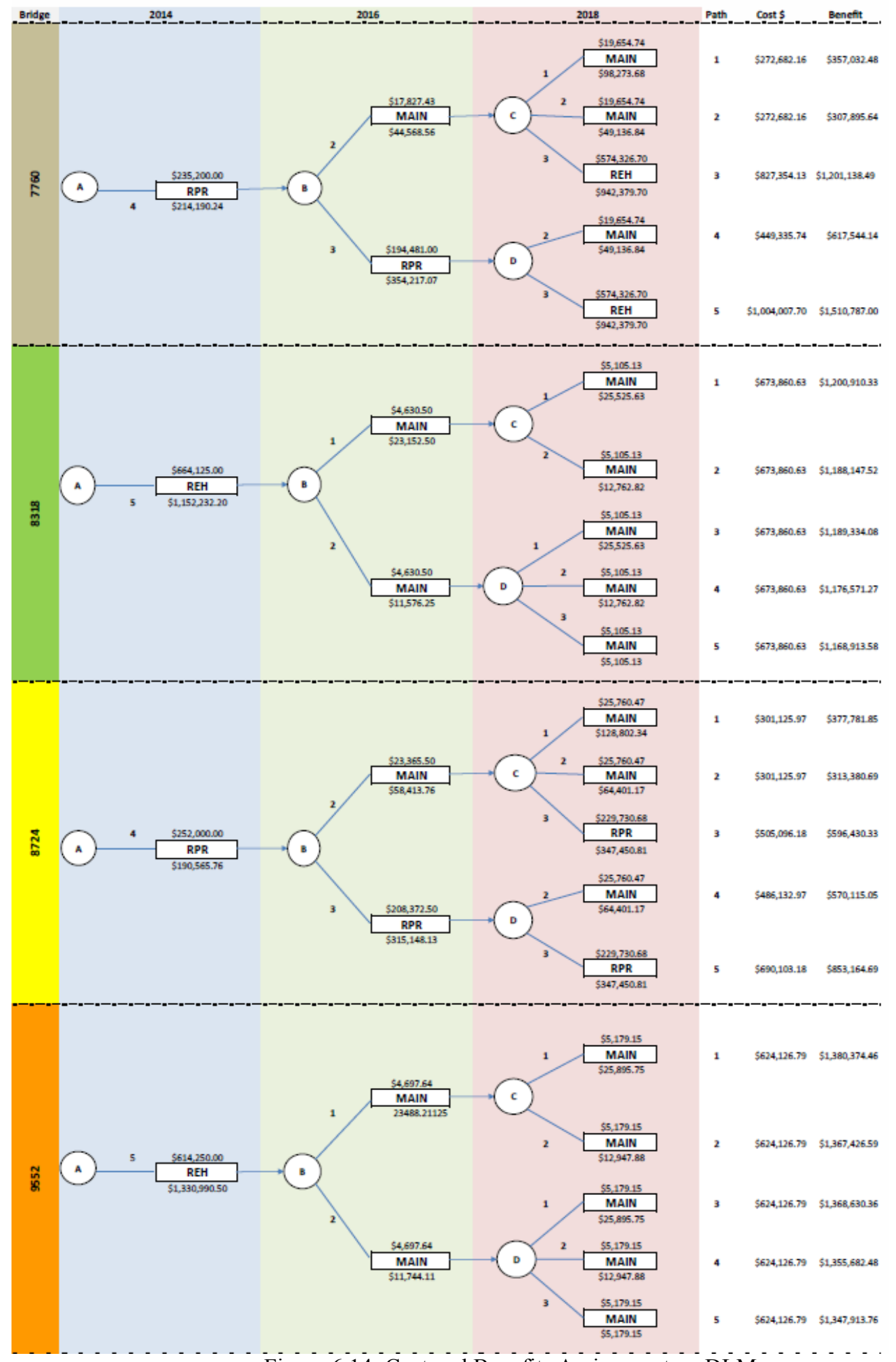

Figure 6.14: Cost and Benefits Assignment on DLMS 
Table 6.24: Network Level Maintenance Investment Plan for Five Years

\begin{tabular}{|c|c|c|c|}
\hline Bridge & Year 2014 & Year 2016 & Year 2018 \\
\hline \multirow{2}{*}{7760} & Action: RPR & Action: MAIN & Action: MAIN \\
\cline { 2 - 4 } & Cost: \$235,200 & Cost: \$17,827.43 & Cost: \$19,654.74 \\
\hline \multirow{2}{*}{8318} & Action: REH & Action: MAIN & Action: MAIN \\
\cline { 2 - 4 } & Cost: \$664,125.00 & Cost: \$4,630.50 & Cost: \$5,105.13 \\
\hline \multirow{2}{*}{8724} & Action: RPR & Action: MAIN & Action: MAIN \\
\cline { 2 - 4 } & Cost: \$252,000.00 & Cost: \$23,365.50 & Cost: \$25,760.47 \\
\hline \multirow{2}{*}{9552} & Action: REH & Action: MAIN & Action: MAIN \\
\cline { 2 - 4 } & Cost: \$614,250.00 & Cost: \$4,697.64 & Cost: \$5,179.15 \\
\hline
\end{tabular}

\subsection{FEEDBACK FROM THE DECISION-MAKING GROUP}

The members of the decision-making group were asked to share their level of agreement and opinions regarding different aspects of the framework at different stages of case study implementation. Total eleven questions were asked regarding different aspects of data modeling, project (candidate) level analysis and network level analysis. Following Tables $6.25,6.26$ and 6.27 provide summary of their agreement level and comments. 
Table 6.25: Feedback on Data Modeling and its Outcomes

\begin{tabular}{|c|c|c|}
\hline Questions & \begin{tabular}{|c|}
$\begin{array}{c}\text { Agreement } \\
\text { Level }\end{array}$ \\
\end{tabular} & Comments/Feedback \\
\hline $\begin{array}{l}\text { Do the main performance } \\
\text { categories (Strategic, } \\
\text { Socioeconomic, Utilization, and } \\
\text { Condition) capture the main } \\
\text { criteria in deciding infrastructure } \\
\text { re-investment? }\end{array}$ & $\begin{array}{c}\text { Strong } \\
\text { Agreement }\end{array}$ & $\begin{array}{l}\text { "These } 4 \text { main categories cover the important } \\
\text { aspects of evaluating infrastructure, however, in } \\
\text { reality; the condition is the driving factor for } \\
\text { decisions in Pima County." } \\
\text { "The diversity of these four categories was good." }\end{array}$ \\
\hline $\begin{array}{l}\text { Do the factors capture the main } \\
\text { components of each category? }\end{array}$ & $\begin{array}{c}\text { Strong } \\
\text { Agreement }\end{array}$ & $\begin{array}{l}\text { "Interrelatedness of performance measures is } \\
\text { good." }\end{array}$ \\
\hline $\begin{array}{l}\text { Are the definitions of each factor } \\
\text { clear and do they thoroughly } \\
\text { describe the factor? }\end{array}$ & $\begin{array}{c}\text { Strong } \\
\text { Agreement }\end{array}$ & "The definitions were clear and comprehensive." \\
\hline $\begin{array}{l}\text { Do the measurement methods } \\
\text { accurately reflect the factor? }\end{array}$ & $\begin{array}{c}\text { Strong } \\
\text { Agreement }\end{array}$ & $\begin{array}{l}\text { "Methods were good but may not always be easily } \\
\text { quantifiable as there may be a high degree of } \\
\text { subjectivity that often comes into play. But this } \\
\text { tool went a long ways in trying to reduce that, as } \\
\text { well as the subjective trade off element." }\end{array}$ \\
\hline $\begin{array}{l}\text { Do you think that performance } \\
\text { curves will be useful for you as a } \\
\text { decision tool? }\end{array}$ & $\begin{array}{c}\text { Strong } \\
\text { Agreement }\end{array}$ & $\begin{array}{l}\text { "Curves and graphs are very helpful when trying } \\
\text { to explain to others what is needed." } \\
\text { "Curves will be useful to show trends and help } \\
\text { extrapolate projections as much as possible. It will } \\
\text { certainly be a good aid in the decision making." }\end{array}$ \\
\hline
\end{tabular}


Table 6.26: Feedback on Project (Candidate) Level Analysis and its Outcomes

\begin{tabular}{|c|c|c|}
\hline Questions & Agreement Level & Comments/Feedback \\
\hline $\begin{array}{l}\text { Are the objectives of the } \\
\text { project (candidate) level } \\
\text { analysis clear? }\end{array}$ & Strong Agreement & $\begin{array}{l}\text { "The objectives and goals of this effort have been } \\
\text { well explained." }\end{array}$ \\
\hline $\begin{array}{l}\text { Do you think that the } \\
\text { implemented framework } \\
\text { appropriately addresses the } \\
\text { requirements and } \\
\text { considerations of project } \\
\text { (candidate) level analysis for } \\
\text { maintenance investment } \\
\text { decision making? }\end{array}$ & $\begin{array}{l}\text { Moderate to Strong } \\
\text { Agreement }\end{array}$ & $\begin{array}{l}\text { "Tool has great potential to help guide the } \\
\text { development and implementation on specific project } \\
\text { actions." } \\
\text { "The two year period for transition is reasonable } \\
\text { and fits the inspection cycle." } \\
\text { "Transitioning to adjacent stages and not skipping } \\
\text { stages seems reasonable, unless some "event" } \\
\text { caused damage to the structure, such as a big storm } \\
\text { or an accident." } \\
\text { "The recommended action and correlated costs are } \\
\text { helpful and useful." } \\
\text { "A limitation is that analysis does not seem to } \\
\text { indicate the life extension of a particular intervention } \\
\text { action." }\end{array}$ \\
\hline $\begin{array}{l}\text { Do you think that "decision } \\
\text { logic maps" (i.e., outcome of } \\
\text { project level analysis) can be } \\
\text { a helpful decision tool for } \\
\text { your agency while evaluating } \\
\text { infrastructure maintenance } \\
\text { investment decisions? }\end{array}$ & Strong Agreement & $\begin{array}{l}\text { "The tool is a good aid in simplifying the } \\
\text { representation of analysis outcomes." }\end{array}$ \\
\hline
\end{tabular}


Table 6.27: Feedback on Network Level Analysis and its Outcomes

\begin{tabular}{|c|c|c|}
\hline Questions & Agreement Level & Comments/Feedback \\
\hline $\begin{array}{l}\text { Are the objectives of the } \\
\text { network level analysis clear? }\end{array}$ & Strong Agreement & $\begin{array}{c}\text { The network analysis concept matches with an } \\
\text { agencies "inventory" of bridges. }\end{array}$ \\
\hline $\begin{array}{l}\text { Do you think that the } \\
\text { implemented framework } \\
\text { appropriately addresses the } \\
\text { requirements and } \\
\text { considerations of network level } \\
\text { analysis for maintenance } \\
\text { investment decision making } \\
\text { and as stated by concept of this } \\
\text { research? }\end{array}$ & $\begin{array}{l}\text { Moderate to } \\
\text { Strong Agreement }\end{array}$ & $\begin{array}{l}\text { "This tool has great potential to help guide the } \\
\text { development and implementation of dedicated } \\
\text { investment across many candidate projects." } \\
\text { "It does not include political trade-offs.", }\end{array}$ \\
\hline $\begin{array}{l}\text { Do you think that "network } \\
\text { level investment maintenance } \\
\text { plan" (i.e., outcome of network } \\
\text { level analysis) can be a helpful } \\
\text { decision tool for your agency } \\
\text { while evaluating infrastructure } \\
\text { maintenance investment } \\
\text { decisions? }\end{array}$ & Strong Agreement & $\begin{array}{c}\text { "The investment plan can provide useful } \\
\text { information." } \\
\text { "This approach could be a great tool in } \\
\text { helping to establish not only the specific target } \\
\text { areas needed, but also how a maintenance } \\
\text { program could be established based on } \\
\text { potential benefits." }\end{array}$ \\
\hline
\end{tabular}

\subsection{CHAPTER SUMMARY}

The chapter presented case study implementation of the framework to real infrastructures having a maintenance investment trade-off. User of the framework was a decision-making group, having responsibility to provide plan of action for future years related to maintenance actions and investments for the candidate bridges. The framework provided decision makers an innovative option to spend available funds in more beneficial way by making budget allocations based on performance of multiple decision parameters, and adapting portfolio management approach. Feedback shows that decisionmaking group generally finds the framework to be useful. 


\section{CHAPTER-7: CONCLUSIONS}

\subsection{RESEARCH SUMMARY}

Infrastructure management agencies are facing multiple challenges. The challenges include aging infrastructure, reduction in capacity and capability of existing infrastructure to provide optimum utilization, and availability of limited funds to preserve and maintain infrastructure. These challenges have resulted in reduced global competitiveness of the U.S. infrastructure. The two extreme solutions to these challenges either provide unlimited funding resources or leave infrastructure at its current trend, i.e., continuing to work with a "worst first" approach. However, both are less feasible because limited funds are available, while the "worst first" approach may result in ignoring an infrastructure that provides more utility to the public. Thus, infrastructure management and maintenance agencies are faced with the challenging task of maintaining and preserving the infrastructure with limited budgets.

This requires maintenance investment decision makers to adopt innovate methods of decision-making and to try to develop ingenious ways of using available funds. Traditionally, investment decisions have mostly been made based on physical condition. However, spending money on public infrastructure is synonymous with spending money on people themselves. Therefore, decision parameters other than physical condition should also be taken into account when making infrastructure maintenance and management decisions. Such parameters include the strategic importance, socioeconomic contribution and utilization of infrastructure. 
Considering the context of maintenance investment decision making and its challenges, this dissertation described a decision support tool to evaluate the trade-offs among competing infrastructures that are candidate for infrastructure maintenance, repair and rehabilitation investments. The purpose is to assist investment decision makers in better usage of money so that the overall infrastructure can be made sustainable from the user's point of view. The decision parameters and factors included in those parameters that have the potential to influence the overall integrated performance of an infrastructure were identified through literature review and series of consultations with infrastructure management experts. A conceptual framework was created and validated through expert opinion (through discussions and interviews) and was used to develop a working framework that can incorporate the utility of each of the four decision parameters for a particular decision-making agency while measuring their performance. It then optimizes maintenance actions based on maximizing reward maintenance actions to provide project-level perspective while providing for the needs of each candidate's infrastructure. Furthermore, the framework adapts a portfolio management approach to select the most feasible of the investment combinations within the budgetary constraints. The result is a future investment plan of action for the entire candidate's infrastructure having a tradeoff within the considered network.

Furthermore, the developed framework was implemented on set of bridges treated as a network located in Pima County, Arizona, and is maintained by the Pima County Department of Transportation to show the decision support capabilities of the developed framework. 


\subsection{SUMMARY OF RESULTS}

The context and background of the research presented in this research was explained in Chapter 1 to identify the research thesis, objectives and scope.

Chapter 2 provided a detailed review of publications related to infrastructure management, infrastructure decision making, and in particular, infrastructure maintenance investment decision making.

Building on the findings from the literature review and considering the objectives of the research, Chapter 3 discussed a comprehensive survey exercise that was conducted to assess the current state-of-the-practice of district departments of transportation throughout the U.S. Major findings of the exercise revealed that the main decision parameter considered for such a decision is physical condition, while a majority of the districts are currently working under budgetary constraints. They have an average budget deficit of $30 \%$. These findings provided justification for the research thesis. In addition, further elicitation of state-of-practice provided valuable information that helped to identify the needs for, and expectations of, a decision support mechanism to deal with the maintenance investment challenges.

These findings, alongside the literature review, helped in the development of a conceptual framework. The conceptual framework presented in Chapter 4 and proof of concept was presented through expert interviews and DOT professionals' agreement so that it can finally be converted into a working framework. 
Chapter 5 described the final framework in detail alongside the assumptions and the decision support potential of three modules that constitute the framework. These include performance assessment, project-level analysis and network-level analysis.

Chapter 6 focused on the implementation of the framework with the help of the Pima County Department of Transportation. It resulted in providing three main decision support tools. These include performance curves for individual candidate bridges that provide the trend of the historical performance of each infrastructure in terms of socioeconomic contribution, infrastructure utilization, and physical condition. It confirmed the main assumption of the framework that while the physical condition of an infrastructure may continue to deteriorate over a period of time when subjected to preventive maintenance, the other parameters' performance may increase or decrease, meaning that integrated utility or stare ratings may increase or decrease, as well. Projectlevel analysis resulted in decision logic maps providing a snapshot of maintenance requirements, cost and benefits associated with each requirement for individual candidate's infrastructure without considering budget constraints. Network-level analysis resulted in providing a five-year future plan of action for the entire candidate's infrastructure taking a portfolio management approach. The case study was conducted on a set of four bridges (considered as network) with the help of the Pima County DOT. Feedback from decision-making group shows that they generally agree to the usefulness and outcomes of the framework implementation. 


\subsection{RESEARCH CONTRIBUTIONS}

1. A framework that provides value addition to the infrastructure's performance assessment by considering nontraditional parameters for maintenance investments and the utility of each decision parameter for a particular decision-making agency.

2. A framework for identifying the most suitable maintenance actions considering the integrated performance-based state of an infrastructure by optimizing (maximizing) rewards rather taking a minimal cost approach.

3. A framework that adapts a portfolio management approach to allocate budgets to entire candidates included in the network rather than spending everything on single candidate and neglecting others due to limited budget.

4. Assessment of the current state-of-the-practice regarding infrastructure maintenance investment decision-making.

5. A nontraditional and innovative perspective on dealing with infrastructure maintenance investment decision making that may help as a conceptual foundation in changing the means with which infrastructure maintenance investments are managed.

The decision support tool presented in this research provides the user with five main outputs with respect to candidate infrastructure:

1. Performance trend curves for each infrastructure that provides an insight into the historical performance of the infrastructure for the decision parameters.

2. Transition probabilities of each infrastructure based on its performance that can provide insight into the probable state it may attain in future. 
3. Results of the Markov Decision Process provide optimal maintenance actions or strategies considering maximized reward for each possible integrated state rating.

4. Decision Logic Maps for each candidate infrastructure that provide a snapshot of the requirements for a planning horizon of five years for the candidate's infrastructure without considering budgetary constraints.

5. A Network-Level Maintenance Investment Plan for five years considering budgetary constraints and a portfolio management approach.

\subsection{LIMITATIONS AND FUTURE RESEARCH POTENTIAL}

The decision support framework presented in this dissertation has been applied only to maintenance projects of bridges due to the type and level of detail of factors included in the framework. Future research could include other infrastructures such as highways, utilities, etc.

The mechanism developed has been implemented on a network of similar type infrastructure. As a future research, it will be helpful to further develop it for considering an investment trade-off among multiple types of infrastructure.

Finally some other parameters such as, financial feasibility, life cycle cost and political considerations may also be considered in further development of framework. 


\section{REFERENCES}

AASHTO (2002), Transportation Asset Management Guide, AASHTO Publication RPTAMG-1, Washington, DC, prepared for the National Cooperative Highway Research Program (NCHRP), November.

Ahmad A.S. (2011). "Bridge Preservation Guide: Maintaining a State of Good Repair Using Cost Effective Investment Strategies.” U.S. Department of Transportation, Federal Highway Administration, FHWA-HIF-11-042.

$<$ http://www.fhwa.dot.gov/bridge/preservation/guide/guide.pdf $>$ (March 2013)

Amekudzi, A. and S. McNeil, (2000). "Capturing data and model uncertainties in highway performance estimation.” J. Transp. Eng., ASCE 126(6), 455-463.

Arif F. and Bayraktar M.E. (2012a). "A Decision Support System for Infrastructure Maintenance/Rehabilitation/Replacement Investments." Construction Research Congress (CRC 2012) PhD Student Poster Session Proceedings, West Lafayette, IN, USA, May 21st, $2012 \mathrm{pp}$

53. $<$ http://rebar.ecn.purdue.edu/crc2012/docu/CRC_Poster\%20Abstract.pdf $>$ (2012)

Arif F. and Bayraktar M.E. (2012b). "A Decision Support System for Infrastructure Maintenance, Rehabilitation, Replacement Investments" at 2012 CII Annual Conference Baltimore, MD on July 23 25.." Construction Research Congress PhD Student Poster Session Proceedings.

$<$ http://rebar.ecn.purdue.edu/crc2012/docu/CRC_Poster\%20Abstract.pdf $>$ (2012)

ASCE (2011) "Failure to Act: The economic impact of current Investment Trends in surface Transportation Infrastructure.” American Society of Civil Engineers, Reston, VA, USA. <http://www.asce.org/uploadedfiles/infrastructure/report_card/ascefailuretoactfinal.pdf $>$ (March 2011).

ASCE. (2013). "Report Card for America's Infrastructure." American Society of Civil Engineers, Reston, VA, USA. < http://www.infrastructurereportcard.org/a/\#p/home> (March 2013).

ASME (2009) "Optimizing infrastructure investments for the $21^{\text {st }}$ Century." Report of the research conducted for ASME Innovative Technologies Institute, LLC 1828 L Street, NW Suite 906 Washington, DC 20036.

Baik, H. S., Jeong, H. S., and Abraham, D. M. (2006). "Estimating transition probabilities in Markov chain-based deterioration models for management of wastewater systems." J. Water Resour. Plann. Manage., 132(1), 15-24. 
Camahan, J., Davis, W., Shahin, M., Keane, P., and Wu, M. (1987). "Optimal Maintenance Decisions for Pavement Management." J. Transp. Eng., 113(5), 554572.

Cambridge Systematics. (2007). U.S. domestic scan program: Best practices in transportation asset management, Washington, DC.

Chan, W. T., T. F. Fwa, and J. Y. Tan. (2003). "Optimal fund-allocation analysis for multidistrict highway agencies." Journal of Infrastructure Systems, ASCE 9(4), 167175.

Chang, S. E. and M. Shinozuka. (1996). "Life-cycle cost analysis with natural hazard risk." Journal of Infrastructure Systems, ASCE 2(3), 118-126.

Chin, K. H., Chae, M. J., Lee, G., and Lee, K. S. (2009). "Infrastructure asset management policy and strategy development." Journal of KICEM, 10(6).

Cheng M.Y. and Wu Y.W. (2007). "Economic Evaluation Model for Post-Earthquake Repair/Rehabilitation of Bridge" Proceedings of 24th International Symposium on automation and Robotics in construction (ISARC 2007), Kochi, India, September 1921, 2007 pp. 389-395.

Clemen, R.T., Making Hard Decisions: An Introduction to Decision Analysis, Second Edition, Duxbury Press, Belmont, California, 1996

Cohen P.L.D. and Tadepalli N. (2006) "Using Advanced Inspection Technologies to Support Investments in Maintenance and Repair of Transportation Infrastructure Facilities." Journal of Transportation Engineering, ASCE Vol. 132, No. 1, January 1, 2006.

Donaghy, K. P. and L. A. Schintler (1998). "Managing congestion, pollution, and pavement conditions in a dynamic transportation network model." Transportation Research.D, 3(2), 59-80.

Dornan, D. L. (2000). Asset management and innovative finance." Transportation Research Board Second National Conference on Transportation Finance. Washington, DC: National Academy Press.

Easa, S. M., A. Shalaby, and A. O. A. E. Halim. (1996). "Reliability-based model for predicting pavement thermal cracking.” J. Transp. Eng., ASCE 122(5), 374-380.

Fwa, T. F., W. T. Chan, and K. Z. Hoque. (2000). "Multi-objective optimization for pavement maintenance programming." Journal of Transportation Engineering, ASCE 126(5), 367-374. 
Florida Department of Transportation (2012) "Mobility Performance Measures Definitions."

$<$ http://www.dot.state.fl.us/planning/statistics/mobilitymeasures/mpmdfns4.pdf $>$ (March 2013)

Frangopol, D., Kong, J., and Gharaibeh, E. (2001). ”Reliability-Based Life-Cycle Management of Highway Bridges." J. Comput. Civ. Eng. 15, special issue: information technology for life-cycle infrastructure management, 27-34.

Gharaibeh, N. G., Chiu, Y. C., and Gurian, P. L. (2006). "Decision methodology for allocating funds across transportation infrastructure assets." J. Infrastruct. Syst., 12(1), 1-9.

Gharaibeh, N. G., M. I. Darter, and D. R. Uzarski. (1999). Development of Prototype Highway Asset Management System. J. Infrastruct. Syst., ASCE 5(2), 61-68.

Gokhale, S. and Hastak, M. (2000). "Decision Aids for the Selection of Installation Technology for Underground Municipal Infrastructure Systems.” Journal: Trenchless Technology Research, Elsevier Science Publishers, Oxford, England, Vol. 15, No. 1, pp 1-11.

Goodman A.S. and Hastak M. (2006). "Infrastructure Planning Handbook: Planning Engineering and Economics" ASCE Press, McGraw-Hill Construction, Alexander Bell Drive, Reston, Virginia, 2006.

Graves, L. (2013). "U.S. Infrastructure Down in World Rankings Since 2008." The Huff Post Politics. http://www.huffingtonpost.com/2013/05/24/us-infrastructure-downin n $3332732 . h t m l$ (May 2013).

Halfawy, M., Newton, L., Vanier, D., (2006). "Review of commercial municipal infrastructure asset management systems," J. ITCON, 11, 211-224.

Hanis H., Trigunarsyah B. and Susilawati C. (2011) "The application of public asset management in Indonesian local government: A case study in South Sulawesi province." Journal of Corporate Real Estate Vol. 13 No. 1, 2011 pp. 36-47.

Hastak, M. (1994). "Decision Support System for Project Cost Control Strategy and Planning." Thesis in partial fulfillment of the requirements for the degree of Doctor of Philosophy, at Purdue University, West Lafayette, Indiana.

Hastak, M. and Abu-Mallouh, M. (2000). "A Decision Support System for Subway Station Rehabilitation and Planning." In: refereed proceedings of the Second International Conference on Decision Making in Urban and Civil Engineering, November 20-22, Lyon, France, pp. 273-284. 
Hastak, M. and Vanegas, J. A. (1993). "Decision Support Systems in Construction Management." In: Refereed Proceedings of the Fifth International Conference on Computing in Civil and Building Engineering. Anaheim, CA. June 7-9. pp. 15551562.

Hastak, M., Cui, Q., Safi, B., and Gokhale, S. (2005). “A Decision Support System for Infrastructure Rehabilitation Planning" In the Proceedings of ASCE International Conference on Computing in Civil Engineering, www.iccc2005.org, Cancun, Mexico, July 12-15, 2005.

Hsieh, T. Y. and H. L. Liu. (1997). Multistage heuristic approach for solving infrastructure investment decision problems. J. Infrastruct. Syst., ASCE 3(4), 134142.

Humphrey, B. (2003), “Asset management, in theory and practice”, Energy Pulse: Insight, Analysis and Commentary on the Global Power Industry, <www.energypulse. Net>

Infraguide (2011) "Decision Making and Investment Planning." Retrieved from $<$ http://gmf.fcm.ca/Infraguide/Best_Practice_Reports.asp $>$ on October 1, 2011).

Kaganova, O. and Nayyar-Stone, R. (2000), "Municipal real property asset management: an overview of world experience, trends and financial", Journal of Real Estate Portfolio Management, Vol. 6 No. 4, p. 307.

Kamalesh,P. "A Methodological Framework for Modeling Pavement Maintenance Costs for Projects with Performance-based Contracts" (2009).FIU Electronic Theses and Dissertations. Paper $120 .<$ http://digitalcommons.fiu.edu/etd $/ 120>$

Keeney, R. L., and Raiffa, H. (1976). Decision with multiple objectives_-Preferences and value tradeoffs, Wiley, New York.

Kroenke, D., and Hatch, R. (1993). Business information systems. Mitchell McGraw-Hill, Watsonville, Calif., 409-414.

Lange, J. (2011). "U.S. infrastructure woes: A roadblock to growth." Reuters, $<$ http://www.reuters.com/article/2011/08/16/uk-usa-economy-infrastructureidUSLNE77E04E20110816> (August 2011).

Lemer, A. (1999), "Building public works infrastructure management systems for achieving high return on public assets", Public Works Management \& Policy, Vol. 3 No. 3, p. 255.

LGV (2004), “Asset management policy, strategy and plan”, Department of Victorian Communities, Local Government Victoria, Melbourne, August. 
Litman T. (2009), Transportation Cost and Benefit Analysis Guidebook, VTPI (www.vtpi.org/tca).

Litman (2011) "Measuring Transportation Traffic, Mobility and Accessibility." Victoria Transport Policy Institute, Victoria, BC, Canada. <http://www.vtpi.org/measure.pdf $>$ (October 2012).

Litman (2012) "Evaluating Accessibility for transportation planning." Victoria Transport Policy Institute, Victoria, BC, Canada. <http://www.vtpi.org/access.pdf $>$ (October 2012)

Loughlin, D. H., Neal, K., Ranjithan, S., Downey Brill, E., and Baugh, J. W. (1995). "Decision support system for air quality management. "ASCE Conf., Proc., 2nd Congress on Computing in Civil Engineering., ASCE, Reston, Va., 1367-1374

Mandat S. and Akiva M.B. (1994). "Optimal Inspection and Repair Policies for Infrsatructure Facilities.” Transportation Science, Operations Research society of America., 28(1), 55-62.

Matthews, H. S., L. Lave, and H. MacLean. (2002). "Life cycle impact assessment: a challenge for risk analysts.” Risk Analysis, 22(5), 853-860

McIntyre, C., Parfitt, M. K. (1998). "Decision Support System for Residential Development Site Selection Process." Jourbal of Architecture Engineering., Volume 4, Issue 4, pp. 125-131.

Mihai, F., Binning, N., and Dowling, L. (2000). "Road Network Asset Management as A Business Process." REAAA Conference, Japan, 1-10.

MIIP (2011) "Municipal Infrastructure Investment Planning” retrieved from $<$ http://www.nrccnrc.gc.ca/eng/projects/irc/municipal-infrastructure.html $>$ (October 2011).

Mohan, S. and Bushnak, A. (1985). 'Multi-Attribute Utility in Pavement Rehabilitation Decisions." J. Transp. Eng., 111(4), 426-440.

Molenaar, K. R., and Songer, A. D. (2001). "Web-based decision support systems: case study in project delivery." J. Comput. Civ. Eng., 15(4), 259-267.

Morcous, G., Lounis, Z., and Mirza, M. S. (2003). "Identification of environmental categories for Markovian deterioration models of bridge decks.” J. Bridge Eng., 8(6), 353-361. 
NBI (2013a). "National Bridge Inventory-Bridges by Posting Status." U.S. department of Transportation, Federal Highway Administration.

$<$ http://www.fhwa.dot.gov/bridge/nbi/posting.cfm > (March 2013).

NBI (2013b). "National Bridge Inventory [NBI] - Data Dictionary"

$<$ http://nationalbridges.com/nbiDesc.html $>$ (March 2013).

NCHRP (2003) "Synthesis 311: Performance Measures of Operational Effectiveness for Highway Segments and Systems -A Synthesis of Highway Practice." Transportation Research Board Washington, D.C., USA, 2003.

NCHRP (2005) "Report 545: Analytical Tools for Asset Management" Transportation Research Board, Washington, D.C., USA, 2005.

NCHRP (2006) "Report 551: Performance Measures and Targets for Transportation Asset Management" Transportation Research Board Washington, D.C., USA, 2006.

NCHRP (2007) "REPORT 590: Multi-Objective Optimization for Bridge Management Systems" Transportation Research Board Washington, D.C., USA, 2007

NCHRP (2009) "Report 632: An Asset-Management Framework for the Interstate Highway System" Transportation Research Board, Washington, D.C., USA, 2007.

Park, J. (2004). "Development and application of probabilistic decision support framework for seismic rehabilitation of structural systems." Ph.D. thesis, Georgia Institute of Technology, Atlanta.

Paté-Cornell, E. (2002a). "Finding and fixing systems weaknesses: probabilistic methods and applications of engineering risk analysis." Risk Analysis, 22(2), 319-334.

Paté-Cornell, E. (2002b). "Risk and uncertainty analysis in government safety decisions." Risk Analysis, 22(3), 633-646.

PAG (2013). "2005-2010 Regional Transportation System Performance Assessment." $<$ http://www.pagnet.org/documents/regtranssystperfassessspreadsfin.pdf $>$ (August 2013)

Piyatrapoomi N., Kumar A., Robertson N. and Weligamage J. (2003a) "Strategy for the development of investment decision making framework for road asset management for Queensland department of main roads. Project Report 2001-010-C June 2003.

Piyatrapoomi, N., \& Kumar, A., (2003b). "Investment Decision-Making under Risk (Reliability) and Uncertainty for Infrastructure Asset Management" CRC CI Report No. 2001-010-C/006, The Cooperative Research Centre for Construction Innovation, Queensland University of Technology, Brisbane, Queensland, Australia. 
Piyatrapoomi, N., Kumar, A., \& Setunge, S. (2004), Framework for Investment DecisionMaking under Risk and Uncertainty for Infrastructure Asset Management, in: Bekiaris, E. \& Nakanishi, Y.J. Economic Impacts of Intelligent Transportation Systems: Innovation and Case Studies, Research in Transportation and Economics, Volume 8, 193-209, Elsevier Ltd.

Rahman, S.; Vanier, D.J (2004) "Life cycle cost analysis as a decision support tool for managing municipal infrastructure" Proceedings of CIB 2004 Triennial Congress, Toronto, Ontario, May 2-9, 2004, pp. 1-12

Ravirala, V. and D. A. Grivas. (1995). "Goal-programming methodology for integrating pavement and bridge programs." J. Transp. Eng., ASCE 121(4), 345351.

Reale1 T. and Connor A. O, "Cross-Entropy as an Optimization Method for Bridge Condition Transition Probability Determination.” J. Transp. Eng., Vol. 138, No. 6, June 1, 2012

Rogers P.D. and Grigg N.S. (2006) "Failure Assessment Model to Prioritize Pipe Replacement in Water Utility Asset Management." Water Distribution Systems Analysis Symposium 2006 Proceedings of the 8th Annual Water Distribution Systems Analysis Symposium.

Sadek, A. W., A. Kvasnak, and J. Segale. (2003). "Integrated infrastructure management systems: small urban areas experience.” J. Infrastruct. Syst, ASCE 9(3), 98-106.

Salem, O., Abourizk, S., and S. Ariaratnam. "Risk-Based Life-Cycle Costing of Infrastructure Rehabilitation and Construction Alternatives," J. Infrastruct. Syst., ASCE Volume 9, Number 1, 2003.

Small E.P. and Swisher M. (1999) "Integration of Bridge and Pavement Management Systems: A Proposed Strategy for Asset." Transportation Research Circular 498 (June 2000)-8th International Bridge Management Conference, Denver, Colorado, April 26-28, 1999, pp. J-1 / 1- J-1 / 16.

Snavely,L. (2011) “Infrastructure” Published on Reference for Business Encyclopedia of Business $2^{\text {nd }}$ Edition. Retrieved from $<$ http://www.referenceforbusiness.com/encyclopedia/Inc- Int/Infrastructure.html $>$ (January 2011).

Sobanjo J.O. and Tompson P.D. (2011) “Enhancement of the FDOT's Project level and Network level bridge management analysis tool." Project report prepared for State Maintenance Office, Florida Department of Transportation, Tallahassee, Florida, USA February , 2011

$<$ http://www.dot.state.fl.us/researchcenter/Completed_Proj/Summary_MNT/FDOT_ BDK83_977-01_rpt..pdf $>$ 
Sobanjo, J. O. (2000). "Cost estimation under uncertainty: issues in bridge management." Transportation Research Circular 498. Washington, DC. Transportation Research Board.

Taha H.A. (1997). “Operations Research: An Introduction.” Prentice-Hall, Inc. Upper Saddle River, NJ, 07458, USA.

Too, E., Betts, M. and Kumar, A. (2006), “A strategic approach to infrastructure asset management", paper presented at BEE Postgraduate Research Conference, Infrastructure 2006: Sustainability and Innovation, Queensland University of Technology, Brisbane, 26 September.

TRB (2006) "Maintenance and Operations of Transportation Facilities-2005 Strategic Vision." Transportation Research Board 500 Fifth Street, NW Washington, DC 20001 .

USDOT (2013) " National Highway System-Office of Planning, Environment, \& Realty (HEP)" <http://www.fhwa.dot.gov/planning/national_highway_system/> (June 2013)

Vanier, D. J. (2001). "Why industry needs asset management tools", J. Comput. Civ. Eng, ASCE 15(1), 35-43.

Wang, K. and F. Liu. (1997). "Fuzzy set-based and performance-oriented pavement network optimization system.” J. Infrastruct. Syst, ASCE 3(4), 154-159.

Woodside, A.G. (2010). "Case Study Research: Theory, Methods and Practice.” Emerald Group Publishing Limited, Bingley, UK.

Worm, J. M., and A. Van Harten. (1996). "Model-based decision support for planning of road maintenance." Reliability Engineering and Systems Safety, 51, 305-316.

Wu, Z., Flintsch, G., Ferreira, A., and Picado-Santos, L. (2012). "Framework for Multiobjective Optimization of Physical Highway Assets Investments." J. Transp. Eng., 138(12), 1411-1421. 
APPENDIX A

SURVEY INVITATION EMAIL AND QUESTIONNAIRE 
July 17, 2012

\section{Invitation Email}

\section{Dear Mr. XXX \\ Director of XXX \\ XXX DOT}

I am a Ph.D. Candidate (Major: Civil Engineering, Minor: Construction Management) in the College of Engineering \& Computing at Florida International University. I am also a Graduate Research Assistant at the OHL School of Construction. I am currently working on my Ph.D. research under the supervision of M. Emre Bayraktar, Ph.D., an Assistant Professor at the OHL School of Construction at Florida International University. My research is titled " $\boldsymbol{A}$ Decision Support Framework for Infrastructure Maintenance Investment Decision-Making." This research intends to provide an investment decision support model for public highway agencies to be used in making maintenance investment decisions. For your convenience and better understanding of the research objectives, I have also included abstract of my research at the bottom of this email.

One of the key tasks included in my research approach is to survey the Department of Transportation personnel who are involved in making maintenance investment decisions at the district level. This is required to assess the current state-of-the-practice and identify potential needs to be addressed in my research. In this regard, I would like to request your participation in my survey. The survey is in an online user-friendly format, has been pre-tested for time and will not take more than 15-20 minutes for completion.

Your response will remain strictly confidential and the results of the survey will be reported only as a summary in an aggregated form, without links to individual responses.

Following is the link to the survey (either click or copy and paste in the web browser):

\section{XXXXXXXXXXXXXXXXXXXXXXXXXXXXXXXXX}

If you think that someone else in your organization will be interested in the survey, you are welcome to forward this invitation to him/her.

Thank you in advance for your participation in this survey. If you have any questions about the survey, please contact me by e-mail at farif001@fiu.edu

I appreciate your time and effort.

Best regards,

Farrukh Arif

Ph.D. Candidate (Civil Engineering) 


\title{
Under Supervision of:
}

M.Emre Bayraktar, Ph.D.

Assistant Professor

OHL School of Construction

College of Engineering and Computing

Florida International University

10555 West Flagler Street

Miami, Florida 33174

Email: bayrakm@fiu.edu

\section{A Decision Support System for Infrastructure Maintenance Investment Decision-Making}

\begin{abstract}
Public infrastructure in the United States faces many challenges including aging and inadequate funding. The available infrastructure-related funding is spent on a mixture of system expansion and preservation projects. Although these allocations have often been sufficient to avoid the imminent failure of key facilities, the continued deterioration leaves a significant and mounting burden on the U.S. economy. Infrastructure maintenance \& rehabilitation investment decisionmaking is a challenging and unique task due to the involvement of various objective and subjective variables. The existing decision-making frameworks generally focus on existing conditions and the cost to improve them. This ignores the importance of certain other multiple decision parameters, which may be important to have more beneficial use of available limited funding. Such parameters include strategic importance, socioeconomic contribution, infrastructure utilization, other and physical condition of infrastructure.
\end{abstract}

The objective of this research is to develop an integrated decision support framework. The framework would allow the user to evaluate aforementioned decision parameters at candidate level analysis. It will also take into account the available options and constraints. Furthermore, the framework will be treating the investment decision by adopting a portfolio management approach at a network level. Once developed, the decision support system will be applied to real world cases through case study. 
DOT's District Survey Questionnaire

Research Title

\section{A Decision Support Framework for Infrastructure Maintenance Investment Decision-Making}

\section{DISTRICT QUESTIONNAIRE}

\section{State-of-the Practice of Investment Decision Making \\ Contact Information:}

Farrukh Arif

Ph.D. Candidate

$\mathrm{OHL}$ School of Construction

Florida International University

10555 West Flagler Street - EC2953

Miami, FL 33174

Phone: (305) 348-3172

Email:farif001@fiu.edu

The research is being conducted under supervision of :

Mehmet Emre Bayraktar, Ph.D.

Assistant Professor

$\mathrm{OHL}$ School of Construction

Florida International University

10555 West Flagler Street - EC2953

Miami, FL 33174

Phone: (305) 348-3174

Email: bayrakm@fiu.edu

\section{Confidentiality Statement}

All the information gathered here will be kept strictly confidential and will be used solely for research and analysis without mentioning the person or company names. 


\section{Kindly Specify District Name:}

2. What is the range of annual infrastructure maintenance/rehabilitation spending of your district (on average)?

口 $<\$ 1$ million

- $\$ 1$ million to less than $\$ 10$ million

口 $\$ 10$ million to less than $\$ 50$ million

- $\$ 50$ million to less than $\$ 100$ million

口 $\$ 100$ million to less than $\$ 500$ million

口 $>\$ 500$ million

3. What percentage of the annual infrastructure maintenance/rehabilitation spending is used for bridges by your district (on average)?

less than $25 \%$

口 $25 \%$ to $50 \%$

ㄷ $50 \%$ to $75 \%$

口 $75 \%$ to $100 \%$

4. What is typical number of bridge maintenance/rehabilitation projects undertaken by your district annually?

口 1 to 5

口 6 to 10

口 11 to 25

口 26 to 50

․ More than 50

5. How much average funding deficit (gap) exists for infrastructure/maintenance rehabilitation projects in your district annually as a percentage (\%) of amount required?
口 $0 \%$ to $10 \%$
ㅁ $10 \%$ to $20 \%$
ㄱ $20 \%$ to $30 \%$
口 30 to $40 \%$
口 40 to $50 \%$
ㄱ $50 \%$ to $75 \%$

․ More than $75 \%$

6. What is the frequency of the investment decision making exercise?

$\square$ Quarterly

Semi-annually

- Annually / Fiscal Year

Other (Please Specify): 
7. For how many years, are the investment decisions made for a particular infrastructure at the time of decision making?

$\square$ Fiscal Year

$\square>1$ year to 3 years

$\square>3$ Years to 5 Years

Other (Please Specify):

8. Which of the following constraints are considered for infrastructure management (maintenance, repair $\&$ rehabilitation) investment decision making by your district?

$\square$ For Known budget

ㄱor Known Threshold Condition

- Pre-defined priority of infrastructure

$\square$ Other (Please Specify):

9. Who defines the budget limit for each candidate project in case of "known budget" constraint?

D District Maintenance Engineer

$\square$ DOT Maintenance Engineer

口 DOT based committee

$\square$ District based committee

$\square$ Other (Please Specify):

10. Who defines the threshold condition for each candidate project in case of "known threshold condition" constraint?

口 District Maintenance Engineer

FDOT Maintenance Engineer

口 FDOT based committee

口 District based committee

$\square$ Other (Please Specify):

11. How are the performance measures reported? (like condition, infrastructure utilization, socioeconomic contribution etc.) 
12. Which of the following parameters (condition, socioeconomic contribution, infrastructure utilization.) are considered for the particular maintenance strategies listed below?

\begin{tabular}{|c|c|c|c|c|}
\hline Preventive & Condition & $\begin{array}{c}\text { Socio- } \\
\text { Economic }\end{array}$ & Utilization & Strategic Importance \\
Maintenance & $\square$ & $\square$ & $\square$ & $\square$ \\
Corrective & $\square$ & $\square$ & $\square$ & $\square$ \\
Maintenance & $\square$ & $\square$ & $\square$ & $\square$ \\
Rehabilitation & $\square$ & $\square$ & $\square$ & $\square$ \\
Replacement & $\square$ & $\square$ & $\square$ \\
\hline
\end{tabular}

13. How does your department currently account for the strategic importance of a particular infrastructure in the network while making investment decisions for maintenance and rehabilitation?

14. Which of the following benefits are considered during investment decision-making for maintenance/rehabilitation? (Choose all that are applicable)
ㄱenefit of Widening
- Reduced Accident Risk
ㅁ Benefit of Strengthening
a Benefit of Replacement
口 Reduction in Detour Cost
O Other-1 (Please Specify):
口 Other-2 (Please Specify):
口 Other-3 (Please Specify):

- Benefit of Raising the Bridge/Vertical Clearance 
15. Do you think that the proposed study as defined by the abstract is useful for your district?

$\square$ Yes (Please Provide Reasons)

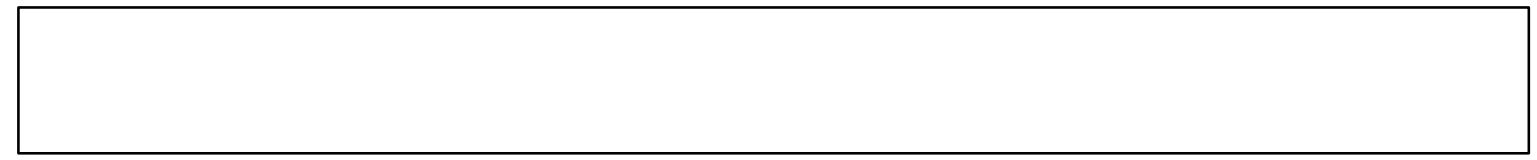

口 No (Please Provide Reasons)

\section{Contact Information (Optional)}

\section{Your Name:}

Title/Designation:

Email Address:

Your Office Phone:

Thank you for your time spent in responding this survey 


\section{APPENDIX B}

TOOL FOR EVALUATING SINGLE ATTRIBUTE UTILITY (SAU) FUNCTION 


\section{INSTRUCTIONS}

\section{Purpose:}

The purpose of developing the single attribute utility (SAU) curves/functions is to find out the Multi-attribute utility function (MAUF). A MAU function is a mathematical model that relates the attributes under consideration to a 0 -to-1 index known as (MAU), with 0 representing the multi-attribute value least preferred by the decision maker. In this research, those attributes are the four decision parameters i.e., Socio-Economic Performance, Strategic Importance, Utilization, and Physical condition. Once the MAU function is developed, it will be utilized to calculate the overall utility of a particular candidate project. The calculated overall utility will then be utilized on a score band that will provide the Integrated State Index (ISI) of the candidate project (bridge).

\section{Technique Utilized for establishing SAU Curves/Functions:}

Direct Assessment Procedure has been selected for establishing a SAU Function. This method follows "Certainty-Lottery" approach in which decision makers are presented with a series of $50 \%-50 \%$ lotteries against certain equivalent outcomes to provide an equivalent performance level that is "sure" to happen.

\section{How to Use it?}

The first chart describes missing data in red question marks that is required from your side. The lottery chart presents the lotteries presented to the decision maker(s). The Lottery questions basically provide narration of the lottery chart for better understanding. Decision makers have to answer these questions in order to find out missing data.

The minimum utility i.e. 0 is already set to $20 \%$ (worst possible performance assumed), as no infrastructure is assumed to be working at $0 \%$ performance level (i.e. failure). Maximum utility value i.e. 1 is set to $100 \%$ performance level (i.e. best possible performance level).

We need to find the performance levels in-between $20 \%$ and $100 \%$ that are considered to be equivalent to utility values of $0.25,0.5$, and 0.75 . Only three utilities are assumed in-between because in general, 5 points are acceptable to plot a graph. For ease of understanding the next page provides a probable list of factors to be considered under each decision parameter. This will give you an idea for setting your risk preference for each parameter while defining performance level for a particular utility through each lottery.

Kindly, think as a decision maker who is part of a decision making committee or group that has the full responsibility of bridge infrastructure preservation. Such responsibility includes making decisions on budget procurement, planning to physical condition and providing value to the users

of the infrastructure. Kindly, answer the lotteries individually. 


\section{List of Probable Factors under each decision Parameter}

\section{Decision Parameter: Strategic Importance}

ST-1 Alternative Routes

ST-3 Emergency Reponses Route

ST-4 Defense Considerations

ST-5 Age of Infrastructure

\section{Decision Parameter: Socioeconomic Contribution}

SE-1 Accessibility

SE-2 Affordability

SE-3 Traffic Safety

SE-4 Quality of Travel

\section{Decision Parameter: Infrastructure Utilization}

UT-1 Quantity of Travel

UT-2 Congestion

UT-3 Commercial Traffic

UT-4 Load Restriction

\section{Decision Parameter: Physical Condition (one of the following)}

PC-1 NBI Ratings for Deck

PC-2 NBI Ratings for Super Structure

PC-3 NBI Ratings for Sub-Structure

PC-04 NBI Ratings for Channel

PC-05 NBI Ratings for Culvert (if applicable)

$\mathrm{NBI}=$ National Bridge Inventory

Respondent's Name: Provide your answer here 


\section{ASSESSMENT FOR SOCIO-ECONOMIC PERFORMANCE}

\section{Data Required}

\begin{tabular}{|c|c|}
\hline Utility of Performance Level & Performance Level (\%) \\
\hline 0 & $20 \%\left(\mathrm{PL}_{0}\right)$ \\
\hline 0.25 & $? \%\left(\mathrm{PL}_{0.25}\right)$ \\
\hline 0.5 & $? \%\left(\mathrm{PL}_{0.5}\right)$ \\
\hline 0.75 & $? \%\left(\mathrm{PL}_{0.75}\right)$ \\
\hline 1 & $100 \%\left(\mathrm{PL}_{1}\right)$ \\
\hline
\end{tabular}

\section{Lottery Chart}

\begin{tabular}{|c|c|c|c|}
\hline \multicolumn{2}{|c|}{ Lottery } & \multicolumn{2}{c|}{ Certainty Equivalent } \\
\hline Chance (Gamble) & Performance Level (\%) & Chance & Performance Level (\%) \\
\hline $50: 50$ & $20 \%-100 \%$ & $100 \%$ & $\mathrm{PL}_{0.5}$ \\
\hline $50: 50$ & $20 \%-\mathrm{PL}_{0.5}$ & $100 \%$ & $\mathrm{PL}_{0.25}$ \\
\hline $50: 50$ & $\mathrm{PL}_{0.5^{-}} 100 \% ?$ & $100 \%$ & $\mathrm{PL}_{0.75}$ \\
\hline
\end{tabular}

\section{Lottery Questions}

Lottery \#1: The chance of Socio-Economic Performance level being 20\% or $100 \%$ is 50:50. What Socio-Economic Performance level will be acceptable (between $20 \%$ and $100 \%$ ) as certain equivalent (i.e. having $100 \%$ possibility) instead of taking this chance?

Answer: Provide your answer here $=\mathrm{PL}_{0.5}$

Lottery \#2: The chance of Socio-Economic Performance level being $20 \%$ or $\mathrm{PL}_{0.5}$ is $50: 50$. What Socio-Economic Performance level will be acceptable (between $20 \%$ and $\mathrm{PL}_{0.5}$ ) as certain equivalent (i.e. having $100 \%$ possibility) instead of taking this chance?

$\left(P L_{0.5}=\right.$ Performance level provided as answer to the lottery \# 1 by respondent $)$

Answer: Provide your answer here $=\mathrm{PL}_{0.25}$

Lottery \#3: The chance of Socio-Economic Performance level being $\mathrm{PL}_{0.5}$ or $100 \%$ is 50:50. What Socio-Economic Performance level will be acceptable (between $\mathrm{PL}_{0.5}$ and $100 \%$ ) as certain equivalent (i.e. having $100 \%$ possibility) instead of taking this chance?

$\left(P L_{0.5}=\right.$ Performance level provided as answer to the lottery \# 1 by respondent $)$

Answer: Provide your answer here $=\mathrm{PL}_{0.75}$ 


\section{ASSESSMENT FOR STRATEGIC IMPORTANCE}

\section{Data Required}

\begin{tabular}{|c|c|c|}
\cline { 2 - 3 } & Utility of Performance Level & Performance Level (\%) \\
\cline { 2 - 3 } & 0 & $20 \%\left(\mathrm{PL}_{0}\right)$ \\
\cline { 2 - 3 } Lottery Chart & 0.25 & $? \%\left(\mathrm{PL}_{0.25}\right)$ \\
\cline { 2 - 3 } & 0.5 & $? \%\left(\mathrm{PL}_{0.5}\right)$ \\
\cline { 2 - 3 } & 0.75 & $? \%\left(\mathrm{PL}_{0.75}\right)$ \\
\cline { 2 - 3 } & 1 & $100 \%\left(\mathrm{PL}_{1}\right)$ \\
\hline
\end{tabular}

\begin{tabular}{|c|c|c|c|}
\hline \multicolumn{2}{|c|}{ Lottery } & \multicolumn{2}{c|}{ Certainty Equivalent } \\
\hline Chance (Gamble) & Performance Level (\%) & Chance & Performance Level (\%) \\
\hline $50: 50$ & $20 \%-100 \%$ & $100 \%$ & $\mathrm{PL}_{0.5}$ \\
\hline $50: 50$ & $20 \%-\mathrm{PL}_{0.5}$ & $100 \%$ & $\mathrm{PL}_{0.25}$ \\
\hline $50: 50$ & $\mathrm{PL}_{0.5^{-}} 100 \% ?$ & $100 \%$ & $\mathrm{PL}_{0.75}$ \\
\hline
\end{tabular}

\section{Lottery Questions}

Lottery \#1: The chance of Strategic Importance level being $20 \%$ or $100 \%$ is $50: 50$. What Strategic Importance level will be acceptable (between $20 \%$ and $100 \%$ ) as certain equivalent (i.e. having $100 \%$ possibility) instead of taking this chance?

Answer: Provide your answer here $\quad=\mathrm{PL}_{0.5}$

Lottery \#2: The chance of Strategic Importance level being $20 \%$ or $\mathrm{PL}_{0.5}$ is $50: 50$. What Strategic Importance level will be acceptable (between $20 \%$ and $\mathrm{PL}_{0.5}$ ) as certain equivalent (i.e. having $100 \%$ possibility) instead of taking this chance?

$\left(P L_{0.5}=\right.$ Performance level provided as answer to the lottery \# 1 by respondent $)$

Answer: Provide your answer here $\quad=\mathrm{PL}_{0.25}$

Lottery \#3: The chance of Strategic Importance level being $\mathrm{PL}_{0.5}$ or $100 \%$ is $50: 50$. What Strategic Importance level will be acceptable (between $\mathrm{PL}_{0.5}$ and $100 \%$ ) as certain equivalent (i.e. having $100 \%$ possibility) instead of taking this chance?

$\left(P L_{0.5}=\right.$ Performance level provided as answer to the lottery \# 1 by respondent $)$

Answer: Provide your answer here $=\mathrm{PL}_{0.75}$ 


\section{ASSESSMENT FOR INFRASTRUCTURE UTILIZATION}

\section{Data Required}

\begin{tabular}{|c|c|}
\hline Utility of Performance Level & Performance Level (\%) \\
\hline 0 & $20 \%\left(\mathrm{PL}_{0}\right)$ \\
\hline 0.25 & $? \%\left(\mathrm{PL}_{0.25}\right)$ \\
\hline 0.5 & $? \%\left(\mathrm{PL}_{0.5}\right)$ \\
\hline 0.75 & $? \%\left(\mathrm{PL}_{0.75}\right)$ \\
\hline 1 & $100 \%\left(\mathrm{PL}_{1}\right)$ \\
\hline
\end{tabular}

\section{Lottery Chart}

\begin{tabular}{|c|c|c|c|}
\hline \multicolumn{2}{|c|}{ Lottery } & \multicolumn{2}{c|}{ Certainty Equivalent } \\
\hline Chance (Gamble) & Performance Level (\%) & Chance & Performance Level (\%) \\
\hline $50: 50$ & $20 \%-100 \%$ & $100 \%$ & $\mathrm{PL}_{0.5}$ \\
\hline $50: 50$ & $20 \%-\mathrm{PL}_{0.5}$ & $100 \%$ & $\mathrm{PL}_{0.25}$ \\
\hline $50: 50$ & $\mathrm{PL}_{0.5^{-}} 100 \% ?$ & $100 \%$ & $\mathrm{PL}_{0.75}$ \\
\hline
\end{tabular}

\section{Lottery Questions}

Lottery \#1: The chance of Infrastructure Utilization level being $20 \%$ or $100 \%$ is $50: 50$. What Infrastructure Utilization level will be acceptable (between $20 \%$ and $100 \%$ ) as certain equivalent (i.e. having $100 \%$ possibility) instead of taking this chance?

Answer: Provide your answer here $=\mathrm{PL}_{0.5}$

Lottery \#2: The chance of Infrastructure Utilization level being $20 \%$ or $\mathrm{PL}_{0.5}$ is $50: 50$. What Infrastructure Utilization level will be acceptable (between $20 \%$ and $\mathrm{PL}_{0.5}$ ) as certain equivalent (i.e. having $100 \%$ possibility) instead of taking this chance?

$\left(P L_{0.5}=\right.$ Performance level provided as answer to the lottery \# 1 by respondent $)$

Answer: Provide your answer here $=\mathrm{PL}_{0.25}$

Lottery \#3: The chance of Infrastructure Utilization level being $\mathrm{PL}_{0.5}$ or $100 \%$ is $50: 50$. What Infrastructure Utilization level will be acceptable (between $\mathrm{PL}_{0.5}$ and $100 \%$ ) as certain equivalent (i.e. having $100 \%$ possibility) instead of taking this chance?

$\left(P L_{0.5}=\right.$ Performance level provided as answer to the lottery \# 1 by respondent $)$

Answer: Provide your answer here $=\mathrm{PL}_{0.75}$ 


\section{ASSESSMENT FOR PHYSICAL CONDITION}

\section{Data Required}

\begin{tabular}{|c|c|}
\hline Utility of Performance Level & Performance Level (\%) \\
\hline 0 & $20 \%\left(\mathrm{PL}_{0}\right)$ \\
\hline 0.25 & $? \%\left(\mathrm{PL}_{0.25}\right)$ \\
\hline 0.5 & $? \%\left(\mathrm{PL}_{0.5}\right)$ \\
\hline 0.75 & $? \%\left(\mathrm{PL}_{0.75}\right)$ \\
\hline 1 & $100 \%\left(\mathrm{PL}_{1}\right)$ \\
\hline
\end{tabular}

\section{Lottery Chart}

\begin{tabular}{|c|c|c|c|}
\hline \multicolumn{2}{|c|}{ Lottery } & \multicolumn{2}{c|}{ Certainty Equivalent } \\
\hline Chance (Gamble) & Performance Level (\%) & Chance & Performance Level (\%) \\
\hline $50: 50$ & $20 \%-100 \%$ & $100 \%$ & $\mathrm{PL}_{0.5}$ \\
\hline $50: 50$ & $20 \%-\mathrm{PL}_{0.5}$ & $100 \%$ & $\mathrm{PL}_{0.25}$ \\
\hline $50: 50$ & $\mathrm{PL}_{0.5^{-}} 100 \% ?$ & $100 \%$ & $\mathrm{PL}_{0.75}$ \\
\hline
\end{tabular}

\section{Lottery Questions}

Lottery \#1: The chance of Physical Condition level being $20 \%$ or $100 \%$ is $50: 50$. What Physical Condition level will be acceptable (between 20\% and 100\%) as certain equivalent (i.e. having $100 \%$ possibility) instead of taking this chance?

Answer: Provide your answer here $=\mathrm{PL}_{0.5}$

Lottery \#2: The chance of Physical Condition level being $20 \%$ or $\mathrm{PL}_{0.5}$ is $50: 50$. What Physical Condition level will be acceptable (between $20 \%$ and $\mathrm{PL}_{0.5}$ ) as certain equivalent (i.e. having $100 \%$ possibility) instead of taking this chance?

$\left(P L_{0.5}=\right.$ Performance level provided as answer to the lottery \# 1 by respondent $)$

Answer: Provide your answer here $\quad=\mathrm{PL}_{0.25}$

Lottery \#3: The chance of Physical Condition level being $\mathrm{PL}_{0.5}$ or $100 \%$ is $50: 50$. What Physical Condition level will be acceptable (between $\mathrm{PL}_{0.5}$ and 100\%) as certain equivalent (i.e. having $100 \%$ possibility) instead of taking this chance?

$\left(P L_{0.5}=\right.$ Performance level provided as answer to the lottery \# 1 by respondent $)$

Answer: Provide your answer here $=\mathrm{PL}_{0.75}$ 


\section{SCALING FACTOR}

\section{Scaling Factor Evaluation Procedure}

The purpose of evaluating scaling factor is to make sure that the outcomes from the multi attribute utility function results remain within 0 and 1 utility. The evaluation is performed through Certainty-Lottery approach as discussed below.

- Certainty-Lottery Approach

Certain: A particular decision parameter is set to have the most preferred performance level (100\%), and rest of the decision parameters will perform at the least preferred performance level $(20 \%)$

Lottery: One possibility is that all decision parameters are set to have most preferred performance level $(100 \%)$ having probability $\mathrm{p}$, and other possibility is that all decision parameters are set to have the least preferred performance level (20\%) having probability $1-p$

- Scaling factor (ki ) = p'/100; where $\mathrm{p}$ is the probability at which the decision maker switches from the lottery strategy to the certain strategy or vice versa

\section{Response}

\begin{tabular}{|c|c|}
\hline Decision Parameter & $\begin{array}{c}\text { Probability of Strategy shift } \mathbf{p}^{\prime} \\
(\mathbf{\%})\end{array}$ \\
\hline Socio-Economic & \\
\hline Strategic & \\
\hline Utilization & \\
\hline Physical Condition & \\
\hline
\end{tabular}


APPENDIX C

DATA SOURCES FOR PERFORMANCE MEASUREMENT 


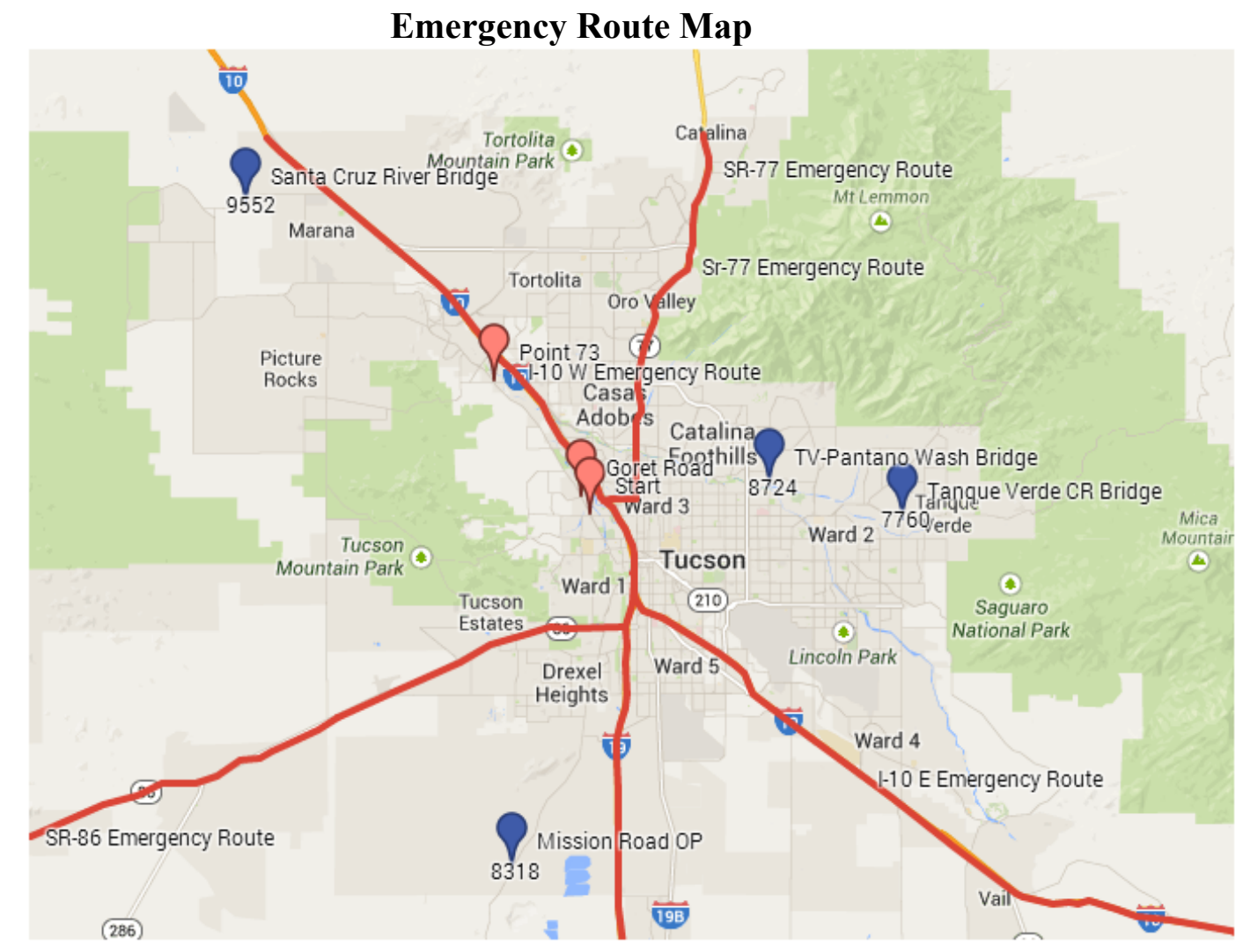




\section{Quality of Travel}

Quality of Travel was measured in terms of Travel Time Performance (TTP). Travel time performance is defined on the basis of percentage contribution of time delay (person-hours) in the total network delay. The higher percentage contribution of delay of a particular bridge, lower the travel time performance percentage. It is calculated as below:

Where,

$$
T T P=\left(1-\frac{P H D}{T N D}\right) X 100
$$

TTP $=$ Travel time Performance

PHD $=$ Total Annual Peak Hour Delay for a particular bridge (Person-Hours)

TND $=$ Total Network Peak Hour Delay (Person-Hours) (i.e. sum of PHD for all the bridges in the network being considered for analysis)

Where, for this study the PHD for each bridge was calculated as follows:

PHD = Delay per Peak Auto Commuter (person-hrs) $x$ Number of Peak hour commuters in an year

Delay per Peak Auto Commuter (person-hrs) for a particular bridge for each of the years was calculated as follows.

Delay per Peak Auto Commuter (person - hrs)for a particular bridge

$$
=\left(\frac{\text { delay per peak auto commuter (person }- \text { hrs) }}{\text { Total Mileage of roads (i. e. in Pima County) }}\right) X(\text { Length of Bridge })
$$

While, the value of delay per peak auto commuter (person-hrs) for different years was elicited from Annual "Urban Mobility Report Data" for Tuscon, Arizona (City of Pima County) from Texas Transportation Institute (TTI ).

While, number of peak hour commuters in a particular year was calculated using following formula.

Number of Peak hour commuters in an year $=K$-factor X ADT X 365 (days) X 1.25

(Passengers/Vehicle)

The 1.25 Passenger/Vehicles is based on National Congestion Constants for 2012 Urban Mobility Report as explained in Methodology for the 2012 Urban Mobility Report.

\section{Sources:}

- http://d2dt15nnlpfr0r.cloudfront.net/tti.tamu.edu/documents/ums/congestion-data/tucso.pdf

- http://d2dt15nnlpfr0r.cloudfront.net/tti.tamu.edu/documents/mobility-report-2012-appx-a.pdf 


\section{Congestion Maps (Year 2008)}

\section{AM Peak Hours, 6:30AM - 8:30AM}

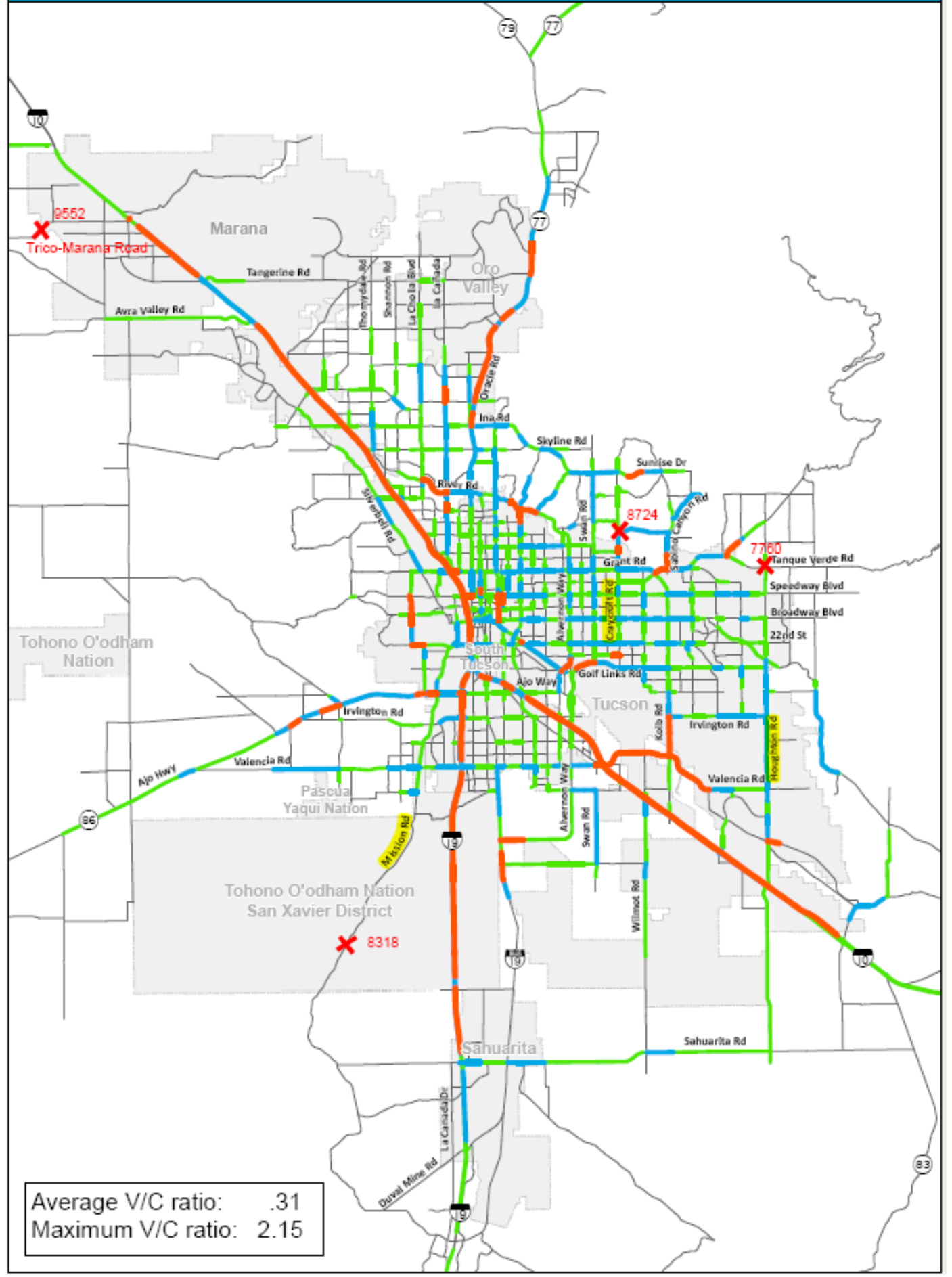




\section{PM Peak Hours, 4:00PM - 6:00 PM}

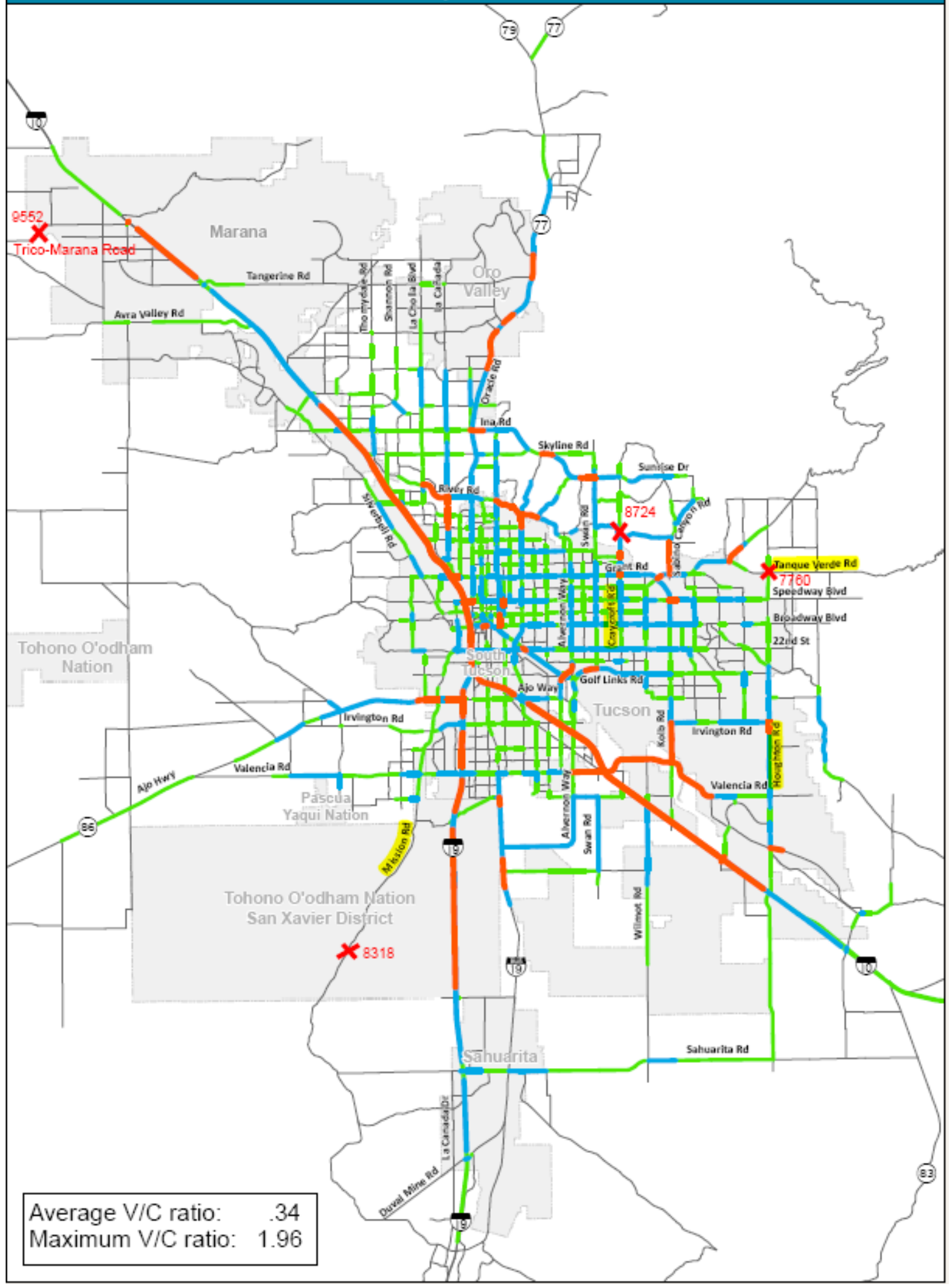




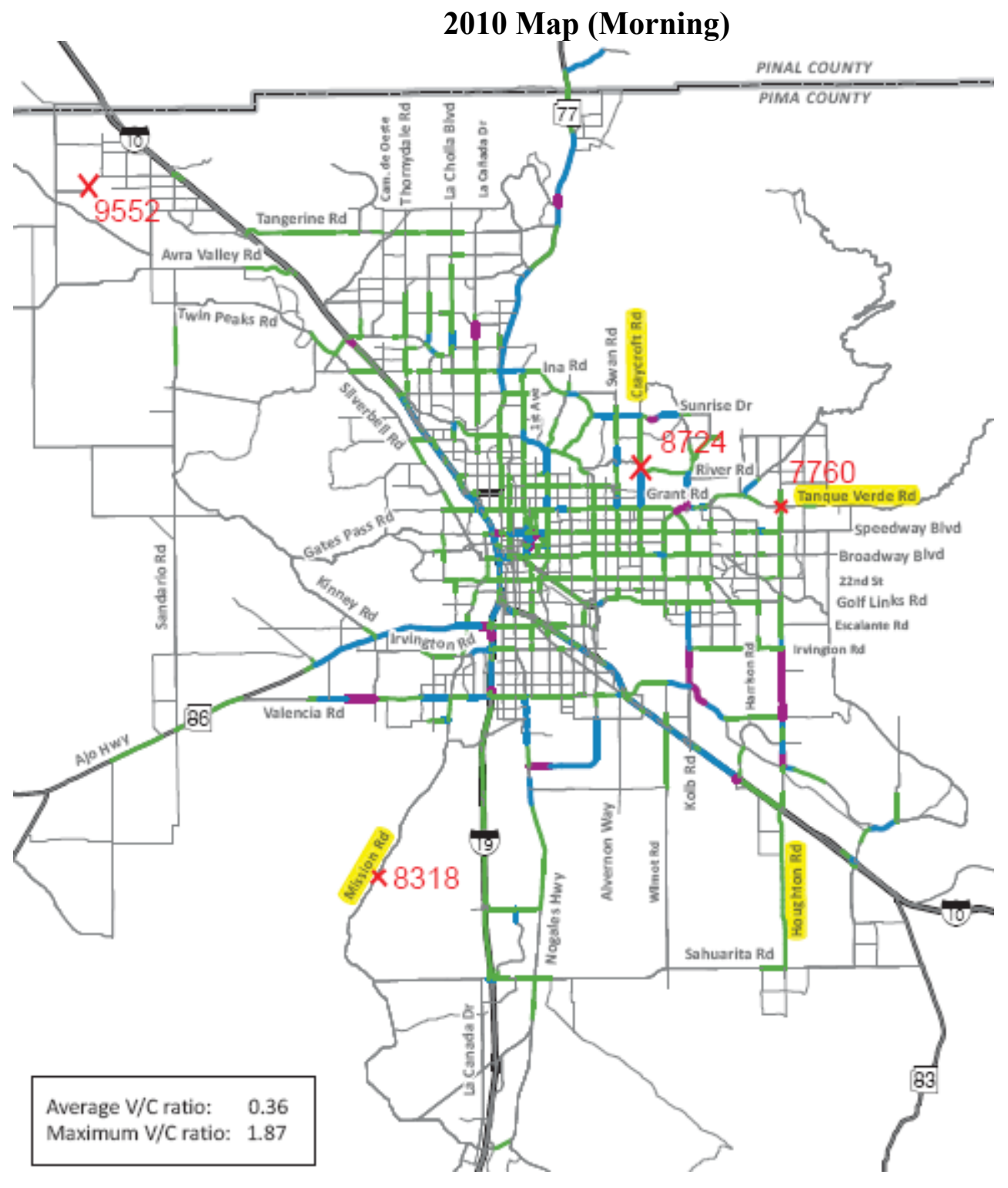


2010 Map (Afternoon)
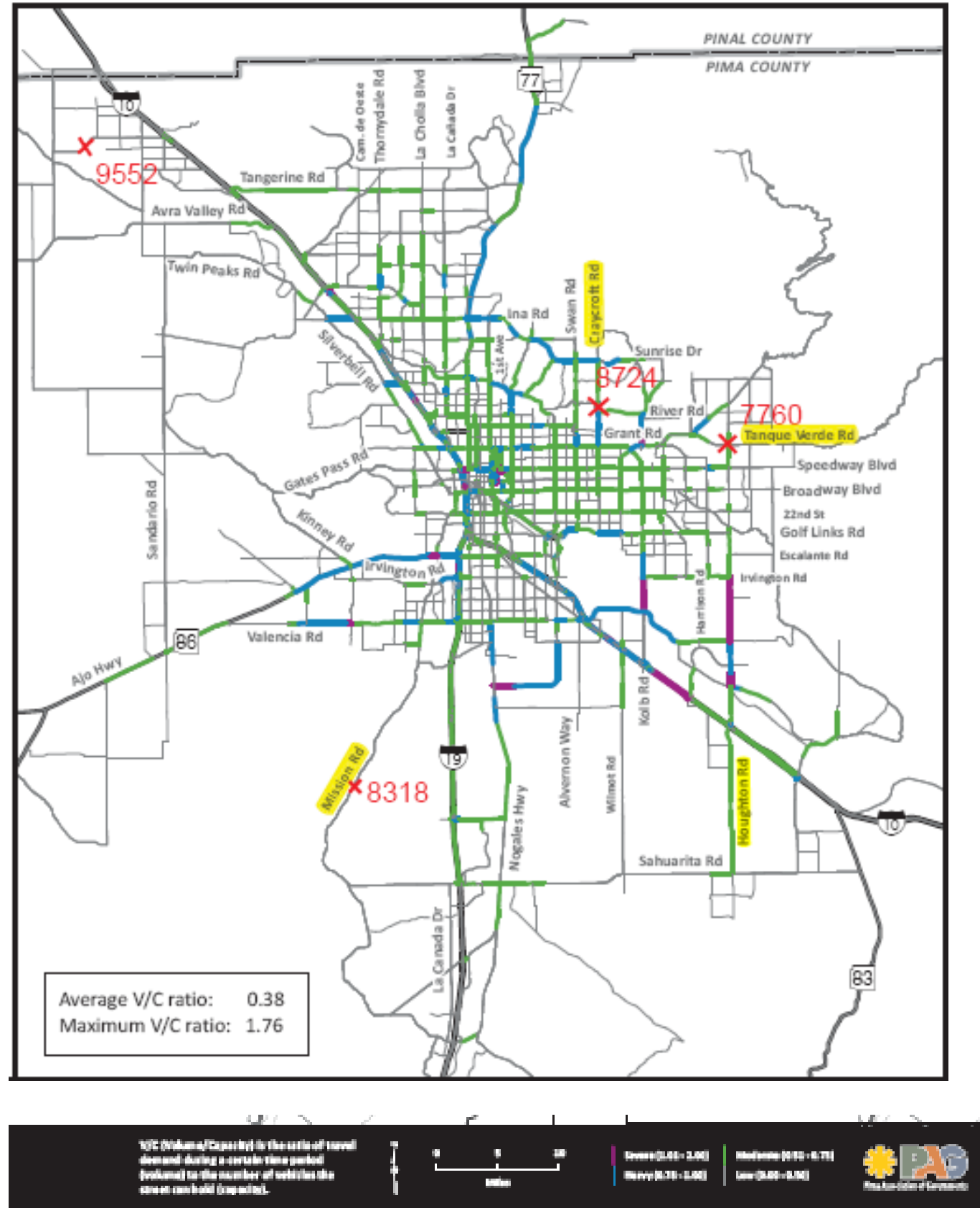

Source: http://www.pagnet.org/documents/regtranssystperfassessspreadsfin.pdf 
APPENDIX D

DETAILS OF BENEFIT QUANTIFICATION

DETAILS OF COST \& BENEFIT STATE WISE DISTRIBUTION FACTORS 


\section{Benefit of Improved Rideability}

A study from VDOT (2006) calculated approximate savings of \$1,295 in terms of owner/agency savings for every lane-mile of highway that is resurfaced under for improved rideability provision (McGhee and Gillespie 2006). The value was adjusted to year 2013 considering a National Highway construction cost index (NHCCI) of 127 for 2006 and 110 for 2013 (NHCCI 2013). Afterwards, it was re-adjusted for location, based on construction cost indices provided by Bureau of Labor Statistics (2013) i.e. 122.7 for Arizona and 175.4 for Virginia based on national average of 100 . This provides an equivalent savings of $\$ 785 /$ lane-mile of highway that is resurfaced for improved rideability in Arizona in 2013.

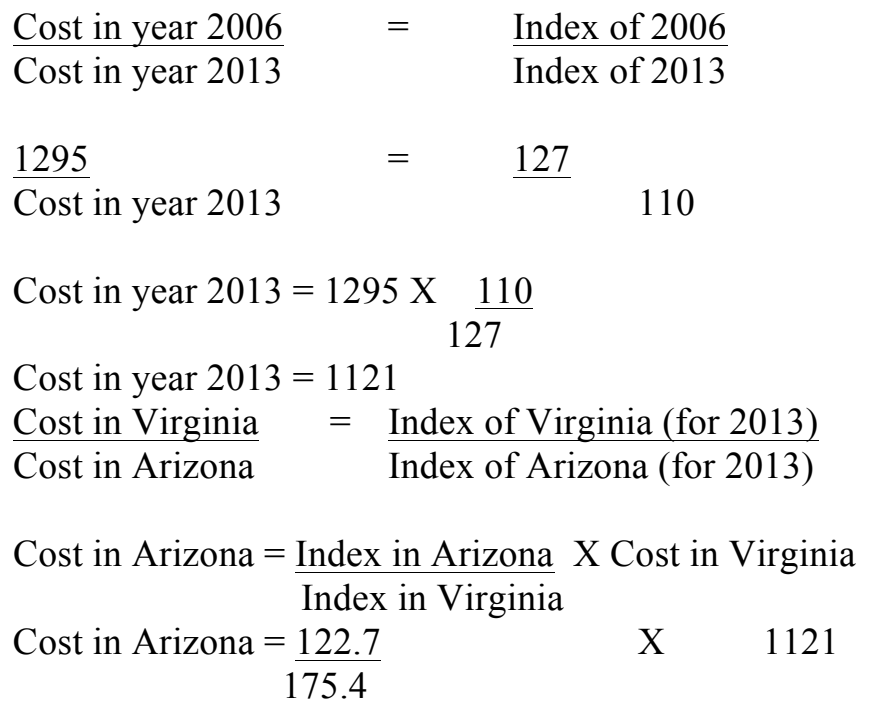

Cost in Arizona $=\$ 785 /$ lane-mile of highway that is resurfaced for improved riddebaility in Arizona

\section{Sources:}

- http://www.bls.gov/eag/eag.va.htm

- http://www.bls.gov/eag/eag.az.htm

- http://www.fhwa.dot.gov/policyinformation/nhcci/pt1.pdf

- McGhee K. K. and Gillespie J.S. (2006) "Impact of a Smoothness Incentive/Disincentive on Hot-Mix Asphalt Maintenance Resurfacing Costs." Virginia Department of Transportation, Richmond, VA < http://www.virginiadot.org/vtrc/main/online_reports/pdf/06-r28.pdf> 


\section{Reduced Future Cost of Maintenance (MAIN Action)}

Preventive maintenance (PM) is defined by AASHTO as the "planned strategy of cost-effective treatments to an existing roadway system and its appurtenances that preserves the system, retards future deterioration, and maintains or improves the functional condition of the system (without increasing the structural capacity)." (Huang and Dong 2009). Therefore, spending money now on preventive maintenance can delay further deterioration and hence provide savings on future maintenance. Baladi et al. (2000) visited six state highway agencies including Arizona, California, Georgia, Michigan, Montana, and Pennsylvania. One of the objectives was to obtain Pavement Management System performance data from several completed projects, tour the projects, and verify the performance data. They concluded that every dollar spent on preventive maintenance is equivalent to $\$ 4$ to $\$ 10$ spent on corrective maintenance in future. Jahren et. al (2007) also indicated that many highway agencies tend to save $\$ 6$ to $\$ 10$ as a benefit to every dollar spent on preventive maintenance as it delays further deterioration. Therefore, for the purpose of this research, benefit of reduced future maintenance in case of No-Action (i.e. preventive maintenance only) can safely be assumed as $\$ 5$ of every dollar spent on preventive maintenance.

\section{Sources:}

- Baladi, G. Y., T. Svasdisant, T. Van, N. Buch, and K. Chatti, (2000) "Cost-Effective Preventive Maintenance Case Studies.” Transportation Research Record, n 1795, 2002, p 17 26.

- Huang B. and Dong Q (2009). “Optimizing Pavement Preventive Maintenance Treatment Applications in Tennessee (Phase I).” Tennessee Department of Transportation, Nashville, $\mathrm{TN}<$ http://www.tdot.state.tn.us/longrange/reports/RES13070PP\%20Final_report_Phase_I. df $>$

\section{Benefits of Reduction in Congestion}

Cost per Peak Auto commuter $=\$ 921$ (based on TTI data from 2011 mobility report)

Total miles of road network $=2378$ miles

Cost per Peak Auto commuter per mile $=921 / 2378=\$ 0.387$

Congestion savings $=$ number of commuters in peak hours in an year $\mathrm{X}$ cost per Peak Auto commuter per mile (in 2012) X length of bridge (miles)

7760

Congestion Savings $=(433693$ X 4) X 0.387 X $0.21=\$ 140,984.92$

$\underline{8724}$

Congestion Savings $=(761536$ X 4 $) \times 0.387 X 0.16=\$ 188,617.236$

\section{Benefit of delaying deterioration of structural components (RPR Action)}

= Maximum Rehabilitation Cost - Maximum Repair Cost

Concept is that by doing repair, rehabilitation is delayed.

\section{Benefit of delaying deterioration of structural components (REH Action)}

= Maximum Replacement Cost - Maximum Rehabilitation Cost

Concept is that by doing rehabilitation, replacement is delayed. 


\section{Benefits of Reduced Accidents}

\begin{tabular}{|c|c|c|c|c|c|}
\hline & & & & & \\
\hline & Total & Fatal & Injury & PDO & \\
\hline Pima & 10401 & 104 & 4200 & 6097 & \\
\hline Total VMT & 8346820000 & 8346820000 & 8346820000 & 8346820000 & \\
\hline Crashes/VMT & 0.00000124610 & 0.00000001246 & 0.00000050319 & 0.00000073046 & \\
\hline $\mathbf{7 7 6 0}$ & 1.126153402 & 0.011260451 & 0.454748994 & 0.660143957 & \\
\hline $\mathbf{8 7 2 4}$ & 1.511847298 & 0.015117019 & 0.610495015 & 0.886235263 & \\
\hline $\mathbf{8 3 1 8}$ & 0.024560696 & 0.000245583 & 0.009917789 & 0.014397324 & \\
\hline $\mathbf{9 5 5 2}$ & 0.074136916 & 0.000741298 & 0.02993703 & 0.043458588 & \\
\hline Cost/incident & & $\$ 1,448,400$ & 47532 & 9282 & \\
\hline & & & & & Grand \\
Total Cost & & $\$ 16,309.64$ & $\$ 21,615.13$ & $\$ 6,127.46$ & Total \\
\hline $\mathbf{7 7 6 0}$ & & $\$ 21,895.49$ & $\$ 29,018.05$ & $\$ 8,226.04$ & $\$ 59,139.58$ \\
\hline $\mathbf{8 7 2 4}$ & & $\$ 355.70$ & $\$ 471.41$ & $\$ 133.64$ & $\$ 960.75$ \\
\hline $\mathbf{8 3 1 8}$ & & $\$ 1,073.70$ & $\$ 1,422.97$ & $\$ 403.38$ & $\$ 2,900.05$ \\
\hline $\mathbf{9 5 5 2}$ & & & & & \\
\hline
\end{tabular}

\section{Road Related Accidents Cost}

\begin{tabular}{|r|r|}
\hline $\mathbf{7 7 6 0}$ & $\$ 39,647.00$ \\
\hline $\mathbf{8 7 2 4}$ & $\$ 53,225.62$ \\
\hline $\mathbf{8 3 1 8}$ & $\$ 864.68$ \\
\hline $\mathbf{9 5 5 2}$ & $\$ 2,610.04$ \\
\hline
\end{tabular}

\section{DETAILS OF COST \& BENEFIT STATE WISE DISTRIBUTION FACTORS}

\begin{tabular}{|c|c|c|c|c|c|c|}
\hline ISR & \multicolumn{2}{|c|}{ MAIN } & \multicolumn{2}{c|}{ RPR } & \multicolumn{2}{c|}{ REH } \\
\hline & $\begin{array}{c}\text { Cost } \\
\text { Factor }\end{array}$ & $\begin{array}{c}\text { Benefit } \\
\text { Factor }\end{array}$ & $\begin{array}{c}\text { Cost } \\
\text { Factor }\end{array}$ & $\begin{array}{c}\text { Benefit } \\
\text { Factor }\end{array}$ & $\begin{array}{c}\text { Cost } \\
\text { Factor }\end{array}$ & $\begin{array}{c}\text { Benefit } \\
\text { Factor }\end{array}$ \\
\hline 1 & 1.0 & 1.0 & 0.2 & 1.0 & 0.2 & 0.2 \\
\hline 2 & 1.0 & 0.5 & 0.4 & 0.8 & 0.4 & 0.4 \\
\hline 3 & $1.0+$ RPR Cost & 0.2 & 0.6 & 0.6 & 0.6 & 0.6 \\
\hline 4 & $1.0+$ RPR Cost & 0 & 0.8 & 0.4 & 0.8 & 0.8 \\
\hline 5 & $1.0+$ RPR Cost & 0 & 1.0 & 0.2 & 1.0 & 1.0 \\
\hline
\end{tabular}




\section{VITA}

\section{EDUCATION}

\section{FARRUKH ARIF}

\begin{tabular}{|c|c|c|}
\hline Degree & Year & Details \\
\hline Ph.D. & 2013 & $\begin{array}{l}\text { Florida International University, } \\
\text { Department of Civil \& Environmental Engineering } \\
\text { Major area: Civil Engineering } \\
\text { Minor area: Construction Management }\end{array}$ \\
\hline M.E.M. & 2008 & $\begin{array}{l}\text { NED University of Engineering \& Technology, } \\
\text { Department of Civil Engineering } \\
\text { Major area: Engineering Management (Specialization } \\
\text { Construction Management) }\end{array}$ \\
\hline B.E. & 2007 & $\begin{array}{l}\text { NED University of Engineering \& Technology, } \\
\text { Department of Civil Engineering } \\
\text { Major area: Civil Engineering }\end{array}$ \\
\hline
\end{tabular}

\section{APPOINTMENTS}

Year

2010-2013

\section{Position/Institution}

Graduate Research Assistant, Florida International University

2007-Present (On study Leave) Lecturer, Department of Civil Engineering, NED University

\section{PROFESSIONAL AFFILIATIONS (Selected)}

1. American Society of Civil Engineers- A.M.ASCE

2. ASCE Global Center for Excellence in Computing-Member

3. American Association for Advancement of Cost Engineering-AACE (Member)

\section{RESEARCH PUBLICATIONS (24)}

\section{Publication Types}

Peer-Reviewed Journal Publications

Peer-Reviewed Conference Proceedings Publications

Government University or Industrial Project Reports

\section{Numbers}

Five

Sixteen

Three 


\section{RESEARCH PROJECTS (7)}

\section{Funding Agencies}

Florida Department of Transportation (FDOT)

Construction Industry Institute

Florida International University

Others

\section{Numbers}

Two

One

Two

Three

\section{HONORS AND AWARDS (7)}

\section{Award Types}

Fellowship/Scholarships Awards

Society/Industry Awards

Research/Scholarly Awards

\section{Details}

Dissertation Year Fellowship (UGS FIU) 2013 AACE International Scholarship Award 2012-13 Graduate Student of the Year Award by ASCE Miami-Dade Section

Four

\section{TEACHING}

\section{Undergraduate Courses}

Construction Cost Estimating

Economic Planning for Construction

Financial Management of Construction

Organizations

Engineering Drawing

Engineering Mechanics

Introduction to Computing

Engineering Construction

\section{Graduate Courses}

Fundamentals of Construction Estimating Construction Cost Analysis and Control Decision and Risk Analysis in Construction Developments in Construction Technology

\section{SERVICES (Selected)}

- Reviewer: Journal of Management in Engineering, American Society of Civil Engineers (ASCE).

- Reviewer: Construction Management and Economics, Routledge Taylor and Francis.

- Reviewer: Sixth International conference on Construction in 21st Century (CITC VI), Kuala Lumpur, Malaysia, July 5-7 2011.

- Reviewer \& Editorial Team Member: International Journal of Sustainable Construction Engineering and Technology, Concrete Society of Malaysia and Universiti Tun Hussein Onn Malaysia (UTHM). 